\author{
UNIVERSIDADE DE SÃO PAULO \\ INSTITUTO DE FÍSICA DE SÃO CARLOS
}

RENATA NOBREGA FLORINDO

Estudo da reação álcali-sílica em concretos através de ressonância magnética nuclear de alta resolução

São Carlos

2009 



\section{Estudo da reação álcali-sílica em concretos através de ressonância magnética nuclear de alta resolução}

Dissertação apresentada ao Programa de PósGraduação em Física do Instituto de Física de São Carlos da Universidade de São Paulo para obtenção do título de Mestre em Ciências

Área de concentração: Física Básica

Orientador: Prof. Dr. José Fabian Schneider

São Carlos

2009 


\section{Autorizo a reprodução e divulgação total ou parcial deste trabalho, por qualquer meio convencional ou eletrônico, para fins de estudo e pesquisa, desde que citada a}

fonte.

Florindo, Renata Nobrega.

Estudo da reação álcali-sílica em concretos através de ressonância magnética nuclear de alta resolução / Renata Nobrega Florindo; orientador José Fabian Schneider. - São Carlos, 2009.

$146 \mathrm{p}$.

Dissertação (Mestrado em Ciências - Área de concentração: Física Básica) - Instituto de Física de São Carlos da Universidade de São Paulo.

1. Reação álcali-sílica. 2. Gel. 3. Quartzito. 4. Estrutura. 5 Ressonância Magnética Nuclear. $6 .{ }^{29} \mathrm{Si}$. I. Título. 


\section{FOLHA DE APROVAÇÃO}

Renata Nóbrega Florindo

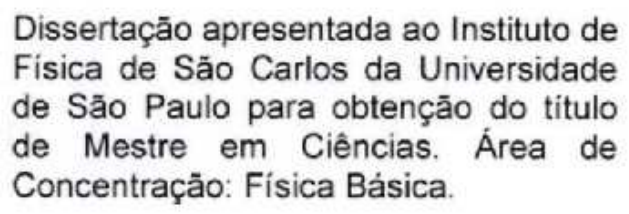

Aprovada em: 13/11/2009

\section{Comissão Julgadora}

Prof. Dr. Rogério Junqueira do Prado

Instituição: UFMT

Assinatura

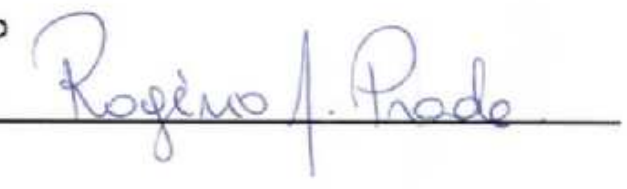

Prof. Dr. Eduardo Ribeiro de Azevêdo Instituição: IFSC/USP

Assinatura

Prof. Dr. Jose Fabian Schneider

Instituiçãa: IFSC/USP

Assinatura

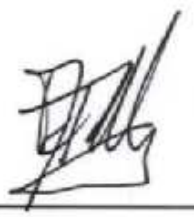



Dedico este trabalho à minha mãe, meu pai, meus irmãos e meu futuro marido. 



\section{Agradecimentos}

Ao meu orientador, José Fabian Schneider, por toda a sua dedicação nestes quatro anos juntos e a quem eu devo uma boa parte da minha formação em Física, especialmente todo meu conhecimento em RMN. Por quem eu tenho carinho, admiração e orgulho em trabalhar junto.

Aos integrantes deste projeto de pesquisa: Paulo Monteiro, Nicole Hasparyk, Vladimir Antonio Paulon, Helena Carasek, Márcia Gomes, Luiz Eiger, Francieli Tiecher, Paulo Henrique Rolin e Danilo Gonçalves Batista, pelas reuniões agradáveis em Furnas e pela ajuda nos diversos e-mails trocados.

Ao professor Eduardo Azevedo e ao técnico de laboratório Edson Vidoto, pelas horas em que me socorreram no laboratório.

Aos amigos de laboratório Jefferson e Marcos por todas as risadas, conversas e principalmente cooperação no laboratório.

As colegas responsáveis pela limpeza, principalmente Maria pelas suas palavras de carinho diárias.

Ao pessoal da biblioteca, especialmente Mara e Neuza

A minha mãe Maria Rosa, por toda a sua força e ajuda nas minhas decisões quando eu não conseguia fazê-las, por sua compreensão na minha total ausência e por coisas que se eu fosse escrever aqui não caberia. Mas o mais importante por acreditar em mim

Ao meu pai, Jorge Luiz, o qual aqui me deixa sem palavras, por toda a sua dedicação, orgulho e apoio. Por segurar minha barra sempre, por sua compreensão na minha ausência e o mais importante por acreditar em mim

A minha irmã Mônica pelo orgulho que sente de mim e pelo total apoio não deixando que eu desistisse nas horas de fraqueza.

Ao meu irmão Felipe pelas horas em que eu estava triste e me fez rir ao telefone, pelo carinho, por me dar exemplo de força e superação e também pelo orgulho que sente de mim.

Ao meu cunhado Junião, por todo seu interesse no meu trabalho nas nossas conversas e pelo amor a mim dedicado

Ao Rafael, que tem me dado a honra de participar da sua vida, por toda a ajuda no meu curso de mestrado e graduação, e também pelo apoio.

Ao meu irmão Bond (Camila), sempre empolgado com minhas conquistas 
A minha sogra Ivelise por sempre torcer por mim e por suas palavras de carinho ao telefone Ao meu sogro Lourival pelo carinho

A minha família pelo carinho e amor, especialmente Graça e Thiury, por demonstrar felicidade com minhas conquistas

Aos meus amigos: Kelly, com sua riqueza de detalhes e que sempre agüentou meus desabafos, Moema e Vanessa pelas conversas e cafezinhos da tarde, Caboclo (Thiago) e Artur.

Aos amigos: Fernanda, Raquel, Carol e Cauê por serem muito mais do que companheiras de casa, irmãs.

A FUNAPE/UFG pelo apoio financeiro. 


\section{Resumo}

Florindo,R.N. Estudo da reação álcali-sílica em concretos através de ressonância magnética nuclear de alta resolução. Dissertação (Mestrado)-Instituto de Física de São Carlos, Universidade de São Paulo, 2009.

A reação álcali-silica (RAS) ocorre entre certas formas de sílica, estruturalmente distorcidas ou amorfas, e soluções de hidróxido alcalino, como $\mathrm{KOH}$ e $\mathrm{NaOH}$. O produto da RAS é um gel de silicato e álcalis, susceptível de expansão pela absorção de água. Quando a RAS ocorre nos agregados minerais utilizados no concreto, o processo de reação e expansão do gel compromete a resistência mecânica da estrutura. Neste trabalho, foram estudados os efeitos sobre o gel de dois processos propostos respectivamente para mitigar a expansão e prevenir a ocorrência da RAS: 0 tratamento do gel com $\mathrm{LiNO}_{3}$ e a aplicação de metiltrimetoxisilano (MTMS, $\mathrm{Si}\left(\mathrm{OCH}_{3}\right)_{3} \mathrm{CH}_{3}$ ). Também foi analisada a reatividade de minerais utilizados como agregados (basalto, granito e quartzito), simulando a RAS em condições de laboratório. Utilizando técnicas de ressonância Magnética Nuclear (RMN) de ${ }^{29} \mathrm{Si},{ }^{7} \mathrm{Li},{ }^{23} \mathrm{Na},{ }^{13} \mathrm{C}$ e ${ }^{1} \mathrm{H}$, foi analisada a estrutura do gel, dos minerais e dos produtos resultantes dos tratamentos e de ataques com soluções alcalinas. Os resultados mostram que a estrutura de silicatos no gel é lamelar formada principalmente por silicatos do tipo $\mathrm{Q}^{3}$ e a aplicação de soluções de $\mathrm{LiNO}_{3}$ provoca uma transformação para um silicato de tipo linear. Esta alteração, eliminado os espaços interlamelares capazes de absorver água e causar expansão coletiva da estrutura, explica o efeito observado de redução da expansão pelos tratamentos com Li. Por outro lado, após exposição ao MTMS não foi detectada interação dos silicatos pertencentes ao gel com os grupos $\mathrm{SiCH}_{3}$, indicando autocondensaçao dos silanos. Com relação ao ataque dos minerais reativos, foram detectadas mudanças na distribuição de espécie de silicatos $\mathrm{Q}^{\mathrm{n}}$ nas três rochas. No basalto e no granito existe um aumento da fração de espécies $\mathrm{Q}^{1}$ e $\mathrm{Q}^{4}$ com relação ao mineral original. No quartzito as diferenças são maiores em magnitude e dependem dos parâmetros do ataque: temperatura e tempo de ataque. O aumento da temperatura dissolve os silicatos amorfos de conectividade baixa e média $\left(\mathrm{Q}^{0}, \mathrm{Q}^{1}\right.$ e $\left.\mathrm{Q}^{2}\right)$ e produz um silicato altamente conexo formado por espécies $\mathrm{Q}^{3}$ e $\mathrm{Q}^{4}$. O aumento do tempo de ataque à 
temperatura ambiente não produz transformações apreciáveis na parte amorfa, mas sim dissolução de silicatos $\mathrm{Q}^{4}$ pertencentes a grãos de quartzo de maior tamanho.

Palavras-chave: Reação álcali-sílica. Gel. Quartzito. Estrutura Ressonância Magnética Nuclear. ${ }^{29} \mathrm{Si}$. 


\section{Abstract}

Florindo,R.N. Study of alkali-silica reaction gel in concrete by high-resolution nuclear magnetic resonance. Dissertação (Mestrado)-Instituto de Física de São Carlos, Universidade de São Paulo, 2009.

The alkali-silica reaction (ASR) occurs between structurally distorted or disordered silica and aqueous solutions of alkaline hydroxides, as $\mathrm{KOH}$ or $\mathrm{NaOH}$. The product of the ASR is an alkalisilicate gel, which may expand upon water absorption. When the ASR occurs in mineral aggregate used in concrete, the process of reaction and expansion cause the decrease in the mechanical resistance of the structure. In this work, a structural study was carried out to analyze the effect on the gel of two processes proposed respectively to mitigate the expansion and prevent the ASR: the treatment with $\mathrm{LiNO}_{3}$ and the application of methyltrimethoxysilane (MTSM, $\left.\mathrm{Si}\left(\mathrm{OCH}_{3}\right)_{3} \mathrm{CH}_{3}\right)$. Also, the reactivity of three minerals (basalt, granite and quartzite) commonly used as aggregates was analyzed, simulating the ASR in laboratory conditions. Nuclear Magnetic Resonance (NMR) techniques of ${ }^{29} \mathrm{Si},{ }^{7} \mathrm{Li},{ }^{23} \mathrm{Na},{ }^{13} \mathrm{C}$ e ${ }^{1} \mathrm{H}$ in the solid state were applied to analyze the structure of the gel, the minerals and the products resulting from treatments and the attack with alkaline solutions $(\mathrm{KOH})$. The results show that the silicate network in the gel is a lamellar structure, composed mainly by $\mathrm{Q}^{3}$ silicates, which is transformed into a linear structure upon the treatment with $\mathrm{LiNO}_{3}$ solutions. This modification, eliminating the inter-lamellar spaces capable to host water and cause the collective expansion of the structure, explain the reduction in the expansion observed in mortar or concrete structures treated with Li. On the other hand, after exposing gel samples to MTMS aqueous solutions, no interaction of the silicate groups in the gel with $\mathrm{SiCH}_{3}$ groups were detected, indicating auto-condensation of silane in these samples. With respect to the attack of the reactive minerals, some changes were detected in the distribution of $\mathrm{Q}^{\mathrm{n}}$ silicate species in the three rocks. In attacked basalt and granite there is an increase in the fraction of $\mathrm{Q}^{1}$ and $\mathrm{Q}^{4}$ with respect to the original minerals. In attacked quartzite the differences are mores strong and depend on the reaction parameters: temperature and time of attack. The increment in temperature dissolve the amorphous silicates of low and medium connectivity $\left(\mathrm{Q}^{0}\right.$, $\mathrm{Q}^{1}$ and $\mathrm{Q}^{2}$ ) resulting in a highly connected silicate with $\mathrm{Q}^{3}$ and $\mathrm{Q}^{4}$. Conversely, no appreciable transformation in the amorphous silicates were observed during longer attack times at room 
temperature, but the dissolution of bigger silica particles with well defined $\mathrm{Q}^{4}$ species was observed.

Keywords: alkali-silica reaction. Gel. Nuclear Magnetic Resonance. 29Si. 


\section{Lista de Figuras}

Figura 2.1- Estrutura da esquemática bidimensional da sílica. (a) Sílica não hidratada. (b) Sílica hidratada

Figura 2.2- Gel exsudado a partir de uma fissura na superfície do concreto

Figura 2.3- $\quad$ Esquema da molécula de metiltrimetoxisilano (MTMS)

Figura 3.1 Níveis de energia para o núcleo de spin $1 \frac{1}{2}$ num campo magnético externo $\mathrm{B}_{0}$

Figura 3.2- Soma vetorial dos momentos magnéticos $\mu_{\mathrm{i}}$ resultando no vetor de magnetização macroscópica $\mathrm{M}$

Figura 3.3- Campo magnético efetivo no sistema de campo rotante

Figura 3.4- Movimento do momento magnético $\mathrm{M}$ em torno do campo magnético efetivo no sistema de coordenadas rotante.

Figura 3.5- Efeito do pulso de $90^{\circ}$ na direção x da magnetização em equilíbrio no sistema de coordenadas rotantes

Figura 3.6- Evolução do vetor de magnetização M após um pulso de $90^{\circ}$.

Figura 3.7- Relaxação transversal: evolução da magnetização no eixo xy mediante um pulso de $90^{\circ}$ aplicado.

Figura 3.8- Relaxação Longitudinal: Evolução da magnetização no eixo z mediante um pulso de $90^{\circ}$ aplicado.

Figura 3.9- Definição dos ângulos polares $\theta$ e $\phi$ definidos pelo campo magnético $B_{0}$ com o SEP do tensor de blindagem.

Figura 3.10- Espectro correspondente a um tensor de desvio químico de simetria axial.

Figura 3.11- Orientação de I e $S$ pelos ângulos polares $\theta$ e $\phi$ em relação ao campo $B_{0}$ ao longo do eixo z no sistema do laboratório.

Figura 3.12- Espectro teórico de acoplamento dipolar. (a) um par de spins com orientação única. (b) um par de spins num policristal. (c) par de spins num policristal com outras interações de spin. (d) muitos spins com múltiplas 
interações.

Figura 3.13- Representação geométrica da distribuição volumétrica das cargas elétricas dos núcleos de spin=1/2, spin $>1 / 2$ e spin $<1 / 2$.

Figura 3.14- (a) Esquema de níveis de energia de um núcleo de spin-3/2 para uma orientação arbitrária do tensor gce, $\eta_{\mathrm{Q}}=0$ (b) Espectro de um monocristal. (c) Espectro de policristal.

Figura 3.15- Evolução da magnetização $M$ utilizando técnica de spin-eco. (a) Magnetização no tempo $\mathrm{t}=0$, antes da aplicação do primeiro pulso. (b) Magnetização no eixo -y, logo após a aplicação do pulso de $90^{\circ}$. (c) Evolução da magnetização $\delta \mathrm{M}$ durante um tempo $\tau$. (d) Aplicação do pulso de $180^{\circ}$. (e) Inversão e evolução da magnetização $\delta \mathrm{M}$ após o pulso de $180^{\circ}$. (f) Refocalização do $\delta \mathrm{M}$, recuperação da magnetização.

Figura 3.16- Experimento de ângulo mágico MAS. Rotação macroscópica da amostra segundo um ângulo $\beta=54.74^{\circ}$ com relação ao campo magnético aplicado.

Figura 3.17- Sequência de pulsos do experimento de Polarização Cruzada entre as espécies I e S. tp é o tempo de aplicação do pulso, tc é o tempo de contato e até o tempo de aquisição do FID da espécie S.

Figura 3.18- População de spins no experimento de Polarização Cruzada e $\beta$ ฐ̃o os estados de spin no sistema rotante relativo a cada espécie I e S.

Figura 3.19- Intensidade da magnetização da espécie $S$ em função do tempo de contato no experimento de polarização cruzada $\{$ I $\}$-S.

Figura 3.20- (a) Seqüência básica de 3Q-MAS excitação-reconversão $(0, \pm p,-1) . \quad t_{2}$ : intervalo de aquisição, $\mathrm{t}_{1}$ intervalo de evolução das coerências $|\mathrm{p}|>1$. $\mathrm{t}_{2}{ }^{(\mathrm{E})}$ : tempo ao eco de spin isotrópico. (b) 3Q-MAS com filtro Z, para simetrização da transferência de coerência: $(0, \pm p, 0,-1)$.

Figura 3.21- Seqüência de pulsos no experimento de HETCOR $\left\{{ }^{1} \mathrm{H}\right\}-{ }^{29} \mathrm{Si}$, $\mathrm{d}_{1}$ : tempo de espera. pw: duração do pulso de $90^{\circ}$ de ${ }^{1} \mathrm{H}$. $\mathrm{X}={ }^{13} \mathrm{C}$ ou ${ }^{29} \mathrm{Si}$. Tempo de contato: tempo em que as duas espécies são colocadas em contato da condição de Hartmann-Hahn.

Figura 3.22- Grupos silicatos $\mathrm{Q}^{\mathrm{n}}(\mathrm{n}=0,1,2,3,4)$. Classificação quanto a quantidade de ligacões entre O-Si-O.

Figura 3.23- $\quad$ Intervalo de desvios químicos das unidades de silicatos $\mathrm{Q}^{\mathrm{n}}$ 
Figura 3.24- Grupos silicatos $\mathrm{D}^{\mathrm{OH}}$ (ligações $\mathrm{Si}-\mathrm{O}, \mathrm{CH}_{3}$ e $\mathrm{OH}$ ) e $\mathrm{T}$ ( ligações Si-O e $\left.\mathrm{CH}_{3}\right)$.

Figura 4.1- Diagrama de blocos do espectrômetro de RMN de dupla ressonância Varian UNITY Inova.

Figura 4.2- Esquema da sequência de pulsos simples para o experimento de polarização direta. $\mathrm{d}_{1}$ : tempo e espera. pw: duração do pulso de rf correspondente ao pulso de $90^{\circ}$ para espécies com I=1/2.

Figura 4.3- Esquema do experimento de polarização cruzada $\left\{{ }^{1} \mathrm{H}\right\}-\mathrm{X}$. $\mathrm{d}_{1}$ : tempo de espera. pw: duração do pulso de $90^{\circ}$ de ${ }^{1} \mathrm{H}$. $\mathrm{X}={ }^{13} \mathrm{C}$ ou ${ }^{29} \mathrm{Si}$. Tempo de contato: tempo em que as duas espécies são colocadas em contato da condição de Hartmann-Hahn.

Figura 5.1- $\quad$ Aspecto dos quatro tipos de amostras de gel extraídas da barragem de Furnas (Minas Gerais). (A) Branca transparente. (B) Amarelo claro. (C) Branco. (D) Marrom.

Figura 6.1- $\quad$ Difratograma de Raio X de pó para a amostra de gel.

Figura 6.2- $\quad$ Espectros de Polarização Direta de ${ }^{29} \mathrm{Si}$. (a) gel. (b) gel $+\mathrm{LiNO}_{3}-\mathrm{NaOH}$. (c) gel + MTMS. (d) gel + KOH + MTMS. (e) gel + NaOH + MTMS. (f) gel + MTMS + KOH. (g) gel + MTMS + NaOH.

Figura 6.3- Espectros de polarização cruzada $\left\{{ }^{1} \mathrm{H}\right\}-{ }^{29} \mathrm{Si}$. (a) gel. (b) gel $+\mathrm{LiNO}_{3}-$ $\mathrm{NaOH}$. (c) gel + MTMS. (d) gel $+\mathrm{KOH}+$ MTMS. (e) gel $+\mathrm{NaOH}+$ MTMS. (f) gel + MTMS + KOH. (g) gel + MTMS + NaOH.

Figura 6.4- Curvas de magnetização de ${ }^{29} \mathrm{Si}$ em função do tempo de contato com ${ }^{1} \mathrm{H}$, em experimentos de polarização cruzada, para as espécies de silicato mais abundantes $\mathrm{Q}^{2}$ e $\mathrm{Q}^{3}$. (a) $\mathrm{Q}^{2}$ no gel. (b) $\mathrm{Q}^{2}$ no gel $+\mathrm{LiNO}_{3}-\mathrm{NaOH}$. (c) $\mathrm{Q}^{3}$ no gel. (d) $\mathrm{Q}^{3}$ no gel $+\mathrm{LiNO}_{3}-\mathrm{NaOH}$.

Figura 6.5- Espectro bidimensional de HETCOR $\left\{{ }^{1} \mathrm{H}\right\}-{ }^{29} \mathrm{Si}$ do gel. Eixo vertical: desvio químico e espectro projetado de ${ }^{29} \mathrm{Si}$. Eixo horizontal: desvio químico e espectro projetado do ${ }^{1} \mathrm{H}$. Subespectros mostrados do lado direito: seções do espectro bidimensional, correspondentes às posições dos sítios $\mathrm{Q}^{1}, \mathrm{Q}^{2}, \mathrm{Q}^{3}, \mathrm{Q}^{4}$. Espectro superior: espectro de ${ }^{1} \mathrm{H}$ em $1 \mathrm{D}$. Asteriscos (*): bandas laterais de rotação da amostra.

Figura 6.6- Difratograma de Raio $\mathrm{X}$ de pó para o material resultante do ataque do gel + $\mathrm{LiNO}_{3}-\mathrm{NaOH} . \square \mathrm{LiNaCO}_{3} . \mathrm{O} \mathrm{K}_{2} \mathrm{CO}_{3} . \Delta \mathrm{Li}_{2} \mathrm{SiO}_{3} . \square \mathrm{KNO}_{3} . \mathrm{O} \mathrm{NaNO}_{3}$. 
Figura 6.7- Espectro bidimensional de HETCOR $\left\{{ }^{1} \mathrm{H}\right\}-{ }^{29} \mathrm{Si}$ do gel $+\mathrm{LiNO}_{3}-\mathrm{NaOH}$. Eixo vertical: desvio químico e espectro projetado de ${ }^{29} \mathrm{Si}$. Eixo horizontal: desvio químico e espectro projetado do ${ }^{1} \mathrm{H}$. Sub-espectros mostrados do lado direito: seções do espectro bidimensional, correspondentes às posições dos sítios $\mathrm{Q}^{0}, \mathrm{Q}^{1}, \mathrm{Q}^{2}, \mathrm{Q}^{3}$. Espectro superior: espectro de ${ }^{1} \mathrm{H}$ em $1 \mathrm{D}$.

Figura 6.8- Espectro estático de ${ }^{7} \mathrm{Li}$ utilizando sequência de spin eco da amostra de gel $+\mathrm{LiNO}_{3}-\mathrm{NaOH}$.

Figura 6.9- $\quad$ Espectro de RMN de alta resolução (MAS) do núcleo de ${ }^{23} \mathrm{Na}$. (a) gel: Trona (1). (b) gel $+\mathrm{LiNO}_{3}-\mathrm{NaOH}$.

Figura 6.10- Espectro estático de $\mathrm{RMN}$ de ${ }^{23} \mathrm{Na}$ na amostra de gel $+\mathrm{LiNO}_{3}-\mathrm{NaOH}$, sequência de spin-eco. As linhas indicadas por asterisco correspondem aos máximos do padrão de policristal das transições satélites.

Figura 6.11- Experimento de 3Q-MAS de ${ }^{23} \mathrm{Na}$ na amostra de gel $+\mathrm{LiNO}_{3}-\mathrm{NaOH}$. No eixo vertical está o desvio anisotrópico e no horizontal o desvio isotrópico.

Figura 6.12- Difratograma de Raio X de pó para o material resultante do ataque do gel com solução de KOH e tratamento com MTMS.

Figura 6.13- Difratograma de Raio X de pó para o material resultante do ataque do gel com solução de $\mathrm{NaOH}$ e tratamento com MTMS. $\square \mathrm{K}_{2} \mathrm{Si}_{2} \mathrm{O}_{5}$.

Figura 6.14- Espectro bidimensional de HETCOR $\left\{{ }^{1} \mathrm{H}\right\}-{ }^{29} \mathrm{Si}$ do gel + MTMS. Eixo vertical: desvio químico e espectro projetado de ${ }^{29} \mathrm{Si}$. Eixo horizontal: desvio químico e espectro projetado do ${ }^{1} \mathrm{H}$. Subespectros mostrados do lado direito: seções do espectro bidimensional, correspondentes às posições dos sítios $\mathrm{D}, \mathrm{T}, \mathrm{Q}^{2}, \mathrm{Q}^{3}, \mathrm{Q}^{4}$. Traço superior: espectro de ${ }^{1} \mathrm{H}$ em polarização direta. Asteriscos $(*)$ : bandas laterais de rotação da amostra.

Figura 6.15- Espectros de ${ }^{13} \mathrm{C}$ em polarização direta e em polarização cruzada $\left\{{ }^{1} \mathrm{H}\right\}-{ }^{13} \mathrm{C}$. Amostra de gel + MTMS: (a) polarização direta, (b) polarização cruzada. Amostra de gel + KOH + MTMS: (c) polarização direta, (d) polarização cruzada.

Figura 6.16- Espectros de Polarização Direta de ${ }^{29} \mathrm{Si}$ das amostras de: (a) basalto puro. (b) basalto $+\mathrm{KOH} / \mathrm{T}_{\mathrm{A}}$. (c) basalto $+\mathrm{KOH} / 80^{\circ} \mathrm{C}$. (d) basalto $+\mathrm{LiNO}_{3}$ $\mathrm{KOH} / \mathrm{T}_{\mathrm{A}}$. (e) basalto $+\mathrm{LiNO}_{3}-\mathrm{KOH} / 80^{\circ} \mathrm{C}$. Asteriscos: bandas laterais. 
Figura 6.17- Espectros de Polarização Direta de ${ }^{29}$ Si. (a) Granito. (b) Granito + $\mathrm{KOH} / 80^{\circ} \mathrm{C}$. (c) Granito $+\mathrm{LiNO}_{3}-\mathrm{KOH} / 80^{\circ}$.

Figura 6.18- Espectros de polarização direta de ${ }^{29} \mathrm{Si}$. (a) Quartzito. (b) Quartzito + $\mathrm{KOH} / \mathrm{T}_{\mathrm{A}}$. (c) Quartzito $+\mathrm{KOH} / 45^{\circ} \mathrm{C}$. (d) Quartzito $+\mathrm{KOH} / 80^{\circ} \mathrm{C}$. (e) Quartzito $+\mathrm{KOH}+\mathrm{MTMS} / 80^{\circ} \mathrm{C}$. (f) Quartzito $+\mathrm{LiNO}_{3}-\mathrm{KOH} / \mathrm{T}_{\mathrm{A}}$. (g) Quartzito $+\mathrm{LiNO}_{3}-\mathrm{KOH} / 45^{\circ} \mathrm{C}$. (h) Quartzito $+\mathrm{LiNO}_{3}-\mathrm{KOH} / 80^{\circ} \mathrm{C}$.

Figura 7.1- Curva de Maekawa (57): desvio químico das espécies $\mathrm{Q}^{\mathrm{n}}$ em função da concentração em mol de $\mathrm{K}_{2} \mathrm{O}$. Linha pontilhada: valores de concentração de $\mathrm{K}_{2} \mathrm{O}$ no gel. 



\section{Lista de Tabelas}

Tabela 5.1- Composição química dos quatro tipos de gel em \% Mol

Tabela 5.2- Análise química das rochas de granito, quartzito e basalto (\% em fração molar)

Tabela 5.3- Procedimento utilizado no tratamento das amostras de gel

Tabela 5.4- Procedimento de ataque das amostras de basalto, granito e quartzito

Tabela 6.1- Desvio químico $\delta$ (ppm, módulo do valor negativo) e área relativa A (\%) das gaussianas dos espectros de ${ }^{29} \mathrm{Si}-\mathrm{RMN}$ de polarização direta e de polarização cruzada $\left\{{ }^{1} \mathrm{H}\right\}-{ }^{29} \mathrm{Si}$ para os sítios $\mathrm{Q}^{\mathrm{n}}$, T e D no gel, gel + $\mathrm{LiNO}_{3}-\mathrm{NaOH}$ e gel + MTMS. NBO= número médio de oxigênios não ponte. $\mathrm{PD}=$ Polarização Direta. $\mathrm{PC}=$ Polarização Cruzada.

$A_{P C} / A_{P D}=$ razão entre as áreas de polarização cruzada e polarização direta

Tabela 6.2- Tempos de contato $T_{\mathrm{H}-\mathrm{Si}}$ e relaxação spin-rede $\mathrm{T}_{1 \rho}$ das espécies de silicatos mais abundantes em cada gel $\left(\mathrm{Q}^{2}\right.$ e $\left.\mathrm{Q}^{3}\right)$, obtidos dos experimentos de polarização cruzada $\left\{{ }^{1} \mathrm{H}\right\}-{ }^{29} \mathrm{Si}$ das amostras de gel e gel $+\mathrm{LiNO}_{3}-\mathrm{NaOH}$

Tabela 6.3- Desvio químico $\delta\left({ }^{1} \mathrm{H}\right)$ das linhas centrais do subespectro com relação ao desvio químico $\delta\left(\mathrm{Q}^{\mathrm{n}}\right)$ do espectro de ${ }^{29} \mathrm{Si}$ dos experimentos de HETCOR $\left\{{ }^{1} \mathrm{H}\right\}-{ }^{29} \mathrm{Si}$

Tabela 6.4- Parâmetros obtidos do espectro 3Q-MAS do ${ }^{23} \mathrm{Na}$

Tabela 6.5- Desvio químico $\delta$ (ppm, módulo do valor negativo) e área relativa A (\%) das gaussianas dos espectros de ${ }^{29} \mathrm{Si}$-RMN de polarização direta e de polarização cruzada $\left\{{ }^{1} \mathrm{H}\right\}-{ }^{29} \mathrm{Si}$ para os sítios $\mathrm{Q}^{\mathrm{n}}, \mathrm{T}, \mathrm{D}$ e M no gel + $\mathrm{KOH}+\mathrm{MTMS}$, gel + MTMS + KOH, gel + $\mathrm{NaOH}+\mathrm{MTMS}$ e gel + $\mathrm{MTMS}+\mathrm{NaOH}$. $\mathrm{NBO}=$ número médio de oxigênio não ponte. $\mathrm{PD}=$ Polarização Direta. $\mathrm{PC}=$ Polarização Cruzada. $\mathrm{A}_{\mathrm{PC}} / \mathrm{A}_{\mathrm{PD}}=$ razão entre as áreas de polarização cruzada e polarização direta

Tabela 6.6- Desvio químico $\delta$ (ppm) das linhas observadas nos espectros de ${ }^{13} \mathrm{C}$ RMN de polarização direta e de polarização cruzada $\left\{{ }^{1} \mathrm{H}\right\}-{ }^{13} \mathrm{C}$ nas amostras de gel + MTMS e gel + KOH +MTMS 
Tabela 6.7- Quantidade em porcentagem, dos sítios de alta e baixa conectividade, das áreas relativas das curvas de ajuste dos espectros de polarização direta de ${ }^{29} \mathrm{Si}$ de basalto, basalto $+\mathrm{KOH} / 80^{\circ} \mathrm{C}$, basalto $+\mathrm{LiNO}_{3}-\mathrm{KOH} / 80^{\circ} \mathrm{C}$, basalto $+\mathrm{KOH} / \mathrm{T}_{\mathrm{A}}$ e basalto $+\mathrm{LiNO}_{3}-\mathrm{KOH} / \mathrm{T}_{\mathrm{A}}$

Tabela 6.8- Desvios químicos $\delta$ e áreas relativas das curvas de ajuste dos espectros de polarização direta de ${ }^{29} \mathrm{Si}-\mathrm{RMN}$ das amostras de granito, granito + $\mathrm{KOH} / 80^{\circ} \mathrm{C}$ e granito $+\mathrm{LiNO}_{3}-\mathrm{KOH} / 80^{\circ} \mathrm{C}$

Tabela 6.9- Quantidade em porcentagem, dos sítios de alta e baixa conectividade, das áreas relativas das curvas de ajuste dos espectros de polarização direta de ${ }^{29} \mathrm{Si}$ de quartzito, quartzito $+\mathrm{KOH} / \mathrm{T}_{\mathrm{A}}$, quartzito $+\mathrm{KOH} / 45^{\circ} \mathrm{C}$, quartzito $+\mathrm{KOH}+80^{\circ} \mathrm{C}$, quartzito $+\mathrm{KOH}+\mathrm{MTMS} / 80^{\circ} \mathrm{C}$, quartzito $+\mathrm{LiNO}_{3}-$ $\mathrm{KOH} / \mathrm{T}_{\mathrm{A}}$, quartzito $+\mathrm{LiNO}_{3}-\mathrm{KOH} / 45^{\circ} \mathrm{C}$ e quartzito $+\mathrm{LiNO}_{3}-\mathrm{KOH} / 80^{\circ} \mathrm{C}$. 


\section{Sumário}

$\begin{array}{ll}\text { Capítulo 1: Introdução } & 25\end{array}$

Capítulo 2: A Reação Álcali-Sílica $\quad 29$

$\begin{array}{ll}2.1 \text { Descrição da RAS } & 29\end{array}$

2.2 Fatores que influenciam a RAS $\quad 31$

2.3 O gel produzido pela RAS 32

2.4 Expansão do gel da RAS

2.5 Tratamentos aplicados ao gel $\quad 35$

Capítulo 3: Técnicas Experimentais $\quad 39$

3.1 Introdução a RMN

3.1.1 Princípios básicos de RMN 39

$\begin{array}{ll}\text { 3.1.2 RMN pulsada } & 43\end{array}$

3.1.3 Obtendo o sinal de RMN 48

3.1.4 Interações Nucleares $\quad 49$

3.1.4.1 Interação Zeeman $\quad 49$

3.1.4.2 Interação de Desvio Químico $\quad 50$

3.1.4.3 Interação Dipolo-Dipolo

3.1.4.4 Interação de Quadrupolo 56

3.2 Técnica de RMN de Baixa Resolução: Spin-eco de Hahn 59

3.3 Técnicas de RMN de Alta Resolução $\quad 61$

3.3.1 Rotação em Torno do Ângulo Mágico (MAS) 62 
3.3.3 Polarização Cruzada $\quad 64$

3.3.4 Triplo Quantum-MAS (3Q-MAS) 67

3.3.5 Experimentos de Correlação Heteronuclear (HETCOR) 71

3.4 Grupos Silicatos $\quad 72$

Capítulo 4: Montagem Experimental $\quad 75$

4.1 Espectrômetro de RMN

$\begin{array}{ll}\text { 4.1.1 Sondas de RMN } & 77\end{array}$

4.1.2 Parâmetros utilizados nos experimentos de RMN 77

4.1.3 Substâncias de referência das linhas dos espectros 80

Capítulo 5: Amostras e Tratamentos $\quad 81$

5.1 Amostras de gel da RAS $\quad 81$

5.2 Amostras de Rochas Reativas

$\begin{array}{ll}\text { 5.2.1 Basalto } & 82\end{array}$

5.2.2 Granito Gnaisse

5.2.3 Quartzito 83

5.3 Ataques e Tratamentos das Amostras $\quad 84$

5.3.1 Tratamentos nas amostras de gel $\quad 85$

$\begin{array}{ll}\text { 5.3.2 Ataques nas amostras das rochas } & 87\end{array}$

5.3.3 Preparo das soluções 89

Capítulo 6: Resultados $\quad 91$

$\begin{array}{ll}\text { 6.1. Gel } & 91\end{array}$ 
6.1.1. Difração de Raios-X 91

6.1.2. ${ }^{29} \mathrm{Si}-\mathrm{RMN} \quad 92$

6.1.3. Polarização Cruzada $\left\{{ }^{1} \mathrm{H}\right\}-{ }^{29} \mathrm{Si}$ com tempo de contato variável 96

6.1.4. HETCOR $\left\{{ }^{1} \mathrm{H}\right\}-{ }^{29} \mathrm{Si} \quad 97$

$\begin{array}{lr}\text { 6.2. Tratamentos } & 99\end{array}$

6.2.1. Tratamento com solução de Li 99

$\begin{array}{ll}\text { 6.2.1.1. Difração de raios-X } & 100\end{array}$

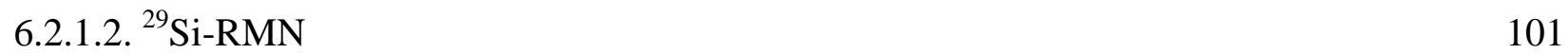

6.2.1.3. Polarização Cruzada $\left\{{ }^{1} \mathrm{H}\right\}-{ }^{29}$ Si com tempo de contato variável 102

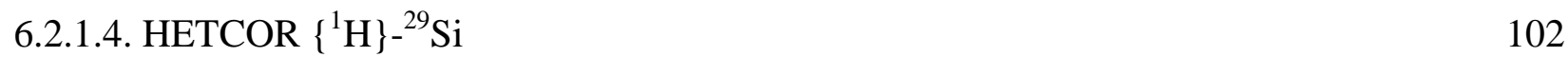

6.2.1.5. ${ }^{7} \mathrm{Li}-\mathrm{RMN} \quad 104$

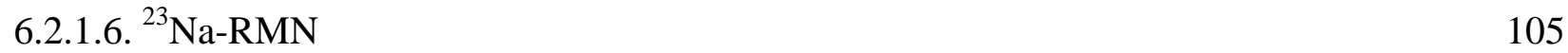

6.2.2. Tratamentos com solução de MTMS 108

$\begin{array}{ll}\text { 6.2.2.1. Difração de raios-X } & 108\end{array}$

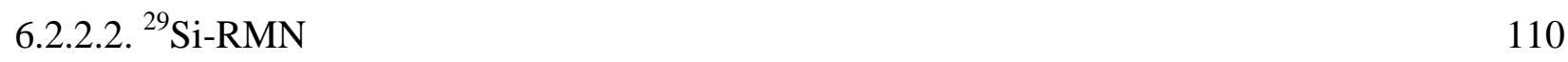

6.2.2.3. HETCOR $\left\{{ }^{1} \mathrm{H}\right\}-{ }^{29} \mathrm{Si} \quad 114$

6.2.2.4. ${ }^{13} \mathrm{C}-\mathrm{RMN}$ nas amostras de gel + MTMS e gel + KOH + MTMS 115

$\begin{array}{ll}\text { 6.3. Rochas } & 117\end{array}$

$\begin{array}{ll}\text { 6.3.1. Basalto } & 118\end{array}$

$\begin{array}{lr}\text { 6.3.2. Granito } & 120\end{array}$

6.3.3. Quartzito 122

$\begin{array}{ll}\text { Capítulo 7: Discussão } & 127\end{array}$ 
7.1. Estrutura do Gel

7.2. Tratamento do Gel com Li

7.3. Exposição do Gel ao MMS

7.4. Efeitos dos ataques e tratamentos nas Rochas

Capítulo 8: Conclusões

137

Referências

139 




\section{Capítulo 1}

\section{Introdução}

Alguns tipos de minerais contem formas de sílica, capazes de reagir na presença de soluções aquosas de espécies alcalinas. A reação álcali-sílica (RAS) é a reação química entre certas formas de sílicas, que estão presentes nos agregados minerais do concreto, e soluções aquosas de hidróxidos alcalinos, como $\mathrm{KOH}$ e $\mathrm{NaOH}$. Essas soluções alcalinas estão presentes nas pastas de cimento hidratadas que contem ainda grão de agregados minerais. Entre os processos indesejáveis que ocorrem internamente em estruturas de concreto e que comprometem mecanicamente a estrutura, a RAS é a que registra maior número de ocorrências e a que se desenvolve mais rapidamente em função das formas minerais de sílicas reativas envolvidas.

Algumas formas de sílica desordenadas ou metaestáveis presentes no agregado mineral do concreto (por exemplo: opala, tridimita, cristobalita, quartzo distorcido e sílica vítrea) reagem em presença da solução aquosa alcalina $\left(\mathrm{Na}^{+}, \mathrm{K}^{+}, \mathrm{Ca}^{+2}\right)$ ocluída nos poros do concreto (1). O produto principal da reação é um silicato no estado de gel, que apresenta a capacidade de absorver moléculas de água em cavidades dentro de sua rede amorfa de grupos silicatos. Este processo de absorção causa a expansão do gel, provocando tensões sobre os grãos de mineral e eventualmente criando fraturas. Estas fraturas dos agregados minerais incrementam a permeabilidade e diminuem a resistência mecânica da estrutura (2). Quando os grãos fraturados são reativos, aumenta a área exposta à solução alcalina, acelerando assim o processo de reação. As escalas de tempo da RAS em condições reais são lentas e os efeitos se manifestam após vários anos.

O problema da RAS afeta particularmente barragens, sendo contabilizadas 104 barragens com problemas decorrentes desta reação em todo o mundo (2). No Brasil existem 25 usinas hidrelétricas afetadas pela RAS, sendo a represa de Furnas (MG) um dos exemplos mais importantes desta patologia encontrados no país. Os custos de manutenção permanente das estruturas afetadas por este fenômeno motivam a busca de tratamentos de prevenção e controle da 
reação em estruturas afetadas. Neste contexto existem três situações a serem analisadas: em primeiro lugar, o tratamento de concretos já afetados pela RAS, desenvolvendo processos para reduzir a expansão do gel; em segundo lugar, tratamentos que reduzam a reatividade dos agregados minerais da estrutura do concreto, evitando o avanço RAS; e finalmente a identificação de agregados minerais potencialmente reativos para evitar o uso em obras futuras. No entanto, os mecanismos da reação, a estrutura e composição do gel resultante e a forma de interferir no processo são assuntos ainda pouco compreendidos do ponto de vista científico, sendo objetos de pesquisa ativa na atualidade na área de ciência dos materiais $(2,4,5)$.

Com relação aos concretos afetados pela RAS, tem sido verificado que é possível diminuir a expansão através do tratamento com soluções baseadas em $\mathrm{LiNO}_{3}$ e $\mathrm{NaOH}(6,7,8)$. Experimentos realizados no laboratório de RMN do IFSC-USP provaram que a exposição do gel à solução de $\mathrm{LiNO}_{3}-\mathrm{NaOH}$ transforma a estrutura amorfa da rede de silicatos essencialmente lamelar numa estrutura de cadeias lineares que dificulta a absorção de água e desfavorece a expansão do gel (9). Com relação à inibição da RAS nos agregados minerais, existem propostas para substituir os grupos OH presentes na superfície dos silicatos reativos, onde ocorre a reação com o álcali da solução que consistem na aplicação de soluções contendo polímeros com grupos silanos que reagem com os $\mathrm{OH}$ dos silicatos, criando ligações Si-C estáveis na superfície do grão de mineral. Estes resultados são promissores com relação ao desenvolvimento de tratamentos que impeçam o avanço da RAS ou que diminuam a expansão do gel já presente no concreto.

O objetivo da pesquisa desta dissertação é determinar através de Ressonância Magnética Nuclear (RMN) de estado sólido as características estruturais do gel original, as transformações estruturais do gel induzidas pelos tratamentos com complexos de Li e exposição à silanos, obtendo uma imagem precisa do efeito destes tratamentos sobre a estrutura dos silicatos alvos. Os resultados contribuem assim, para um maior entendimento da redução da expansão do gel nas estruturas já atacadas pela RAS, no caso do tratamento com Li e auxiliam na compreensão sobre a redução da reatividade dos agregados, no caso das exposições às soluções de silano. Este último ainda não tem sido estudado. Neste presente trabalho serão apresentados os primeiros resultados de aplicação de silanos, metiltrimetoxisilano (MTMS), em silicatos. Este trabalho tem ainda como objetivo estudar a reatividade de rochas, analisando a alteração na estrutura dos silicatos após ataques com soluções alcalinas de $\mathrm{KOH}$, identificando fases ou sítios reativos em minerais 
comumente usados como agregados dos concretos. As rochas analisadas aqui foram o granito, basalto e quartzito. Esta pesquisa faz parte de um projeto mais amplo (P\&D de FURNAS, ciclo 2004/2005 da ANEEL: "Identificação de agregados reativos e combate da reação álcali-agregado em concreto") desenvolvido em colaboração entre várias instituições: Furnas Centrais Elétricas S.A.- Departamento de Apoio e Controle Técnico (DCT.T.), Universidade Federal de GoiásEscola de Engenharia Civil e Universidade Federal do Rio Grande do Sul- Departamento de Mineralogia.

No trabalho desenvolvido, as amostras de gel e rochas foram analisadas através de técnicas $\mathrm{RMN}$ de ${ }^{29} \mathrm{Si},{ }^{7} \mathrm{Li},{ }^{13} \mathrm{C}$ e ${ }^{23} \mathrm{Na}$ para obter informações estruturais e químicas, especialmente para o caso dos grupos silicatos ao redor das espécies das espécies de silicatos. Uma importante contribuição para este trabalho foram os experimentos de correlação heteronuclear (HETCOR) entre os núcleos de ${ }^{29} \mathrm{Si} \mathrm{e}{ }^{1} \mathrm{H}$, que permitiu analisar os ambientes de hidrogênio ao redor dos silícios.

No capítulo 2 deste trabalho são apresentados alguns conceitos gerais sobre a formação da reação álcali-sílica, os fatores que influenciam a RAS, o método de expansão e os tratamentos aplicados. No capítulo 3 são discutidos os princípios básicos de RMN e as técnicas experimentais de RMN utilizadas, como rotação em torno do ângulo mágico (MAS), polarização cruzada, triplo quantum (3Q-MAS) e HETCOR. O capítulo 4 é apresentado a montagem experimental utilizada nas medidas de RMN. A descrição das amostras utilizadas de gel e rochas e o preparo das soluções de ataques e tratamentos são apresentados no capítulo 5. No capítulo 6 estão os resultados obtidos através do conjunto de técnicas de RMN e Raios-X aplicadas seguidos da discussão dos resultados no capítulo7 e conclusão no capítulo 8. 


\section{Capítulo 2}

\section{A Reação Álcali-Sílica}

O gel resultante da RAS é o responsável pelo comprometimento da resistência mecânica da estrutura do concreto. Neste capítulo serão apresentados os mecanismos de formação do gel, os estudos já realizados, os fatores que influenciam a formação e os tratamentos propostos para diminuir a expansão.

\subsection{Descrição da RAS}

A reação entre alguns constituintes mineralógicos do agregado de concreto e os hidróxidos alcalinos provenientes da hidratação do cimento que ocorrem internamente no concreto dá origem à RAS. Em outras palavras a reação ocorre entre as formas minerais de sílica reativa do agregado e o álcali do cimento.

Os álcalis provem de compostos silicosos presentes na matéria prima do cimento e se encontram na forma de sulfato ou incorporados nas fases de silicatos e aluminatos. A alcalinidade da solução dos poros do concreto é dominada principalmente por álcalis sódio e potássio. A sílica

é formada por unidades tetraédricas $\left(\mathrm{SiO}_{4}{ }^{4-}\right)$ formando uma estrutura tridimensional através de pontes Si-O-Si.

A estrutura da sílica pode ser representada esquematicamente de forma plana como mostra na figura 2.1. No interior da matéria, as cargas entre os íons de $\mathrm{Si}^{4+}$ e $\mathrm{O}^{2-}$ estão equilibradas, mas o mesmo não ocorre na superfície. Na superfície, o íon de oxigênio está ligado a um único íon de silício, como mostra a figura 2.1.a, ficando com uma carga negativa desequilibrada e o íon de silício é ligado a apenas três íons de oxigênio ficando com uma carga 
positiva. Quando ocorre a hidratação da superfície, os íons hidroxilas $\left(\mathrm{OH}^{-}\right)$, provenientes da água, fazem ligação com o íon positivo de silício e o íon positivo $\mathrm{H}^{+}$entra em contato com o íon negativo do oxigênio, como mostra a figura 2.1.b. Nas sílicas amorfas, a estrutura desordenada aumenta a quantidade de superfícies expostas sem equilíbrio de cargas aumentando a reatividade com a solução aquosa.

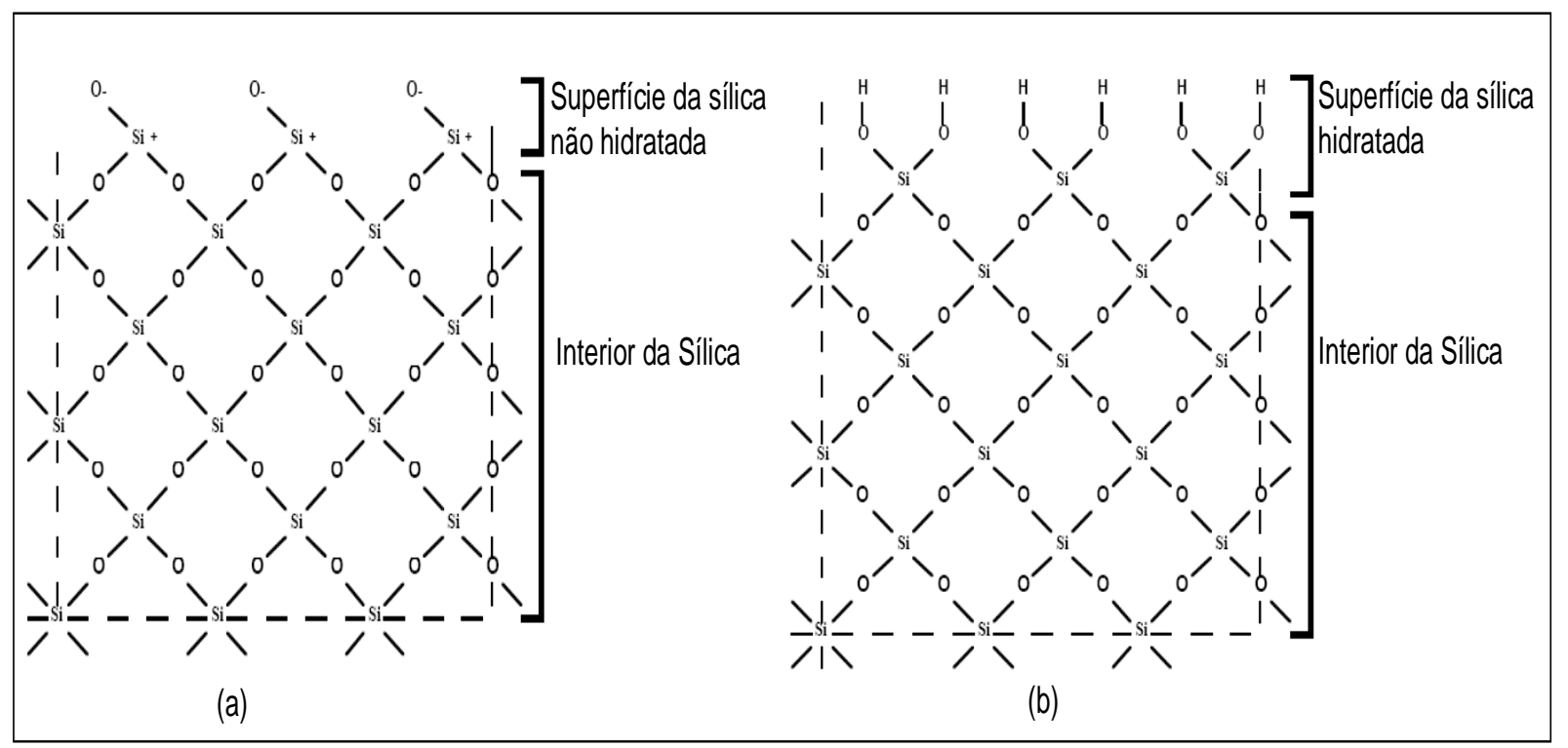

Figura 2.1- Estrutura da esquemática bidimensional da sílica. (a) Sílica não hidratada. (b) Sílica hidratada (10).

A despolimerização da sílica por hidratação é expressa na equação.

$$
-\mathrm{Si}-\mathrm{O}-\mathrm{Si}-+\mathrm{H}_{2} \mathrm{O}=-\mathrm{Si}-\mathrm{OH}+\mathrm{OH}-\mathrm{Si}-(2.1)
$$

Num meio alcalino onde o $\mathrm{NaOH}$, por exemplo, estiver presente, os íons $\mathrm{H}^{+}$da equação 2.1 são deslocados pelos íons $\mathrm{Na}^{+}$, resultando em uma solução de sílicas de cargas negativas e cátions formando uma camada difusa (11). O balanceamento da equação pelos íons alcalinos forma o gel sílico-alcalino descrita pela reação

$$
-\mathrm{Si}-\mathrm{OH}+\mathrm{Na}^{+}+\mathrm{OH}^{-}=-\mathrm{Si}-\mathrm{O}^{-} \mathrm{Na}^{+}+\mathrm{H}_{2} \mathrm{O}
$$

O gel é formado por partículas pequenas apresentando um comportamento semelhante a um sistema coloidal. Um colóide é um estado da matéria constituído de partículas finas com dimensões entre $0.2 \mu \mathrm{m}$ e $5 \mathrm{~nm}$. A interação de uma partícula coloidal com o líquido aumenta a 
viscosidade tornando-se uma massa com partículas organizadas no meio da dispersão. Quando se formam precipitados de hidróxidos volumosos, grandes quantidades de líquidos podem ser imobilizadas por retenção mecânica dentro de agregados de partículas assumindo um aspecto de sólido rígido que é o gel.

O excesso de $\mathrm{NaOH}$ ataca as ligações mais internas da sílica, grupos siloxano (Si-O-Si), de acordo com a reação expressada na equação

$$
-\mathrm{Si}-\mathrm{O}-\mathrm{Si}-+2 \mathrm{NaOH}=-\mathrm{Si}-\mathrm{O}^{-} \mathrm{Na}^{+}+\mathrm{Na}^{+} \mathrm{O}^{-}-\mathrm{Si}-+\mathrm{H}_{2} \mathrm{O}
$$

desintegrando a estrutura da sílica e deixando em solução monômeros de silicatos $\mathrm{Si}(\mathrm{OH})_{4}$, $\mathrm{H}_{3} \mathrm{SiO}_{4}{ }^{-}$e $\mathrm{H}_{2} \mathrm{SiO}_{4}{ }^{2-}$ solúveis, assim permitindo a absorção de água e dos íons alcalinos. A solubilidade da sílica depende do alto pH da solução alcalina. Os monômeros são liberados na solução e com o tempo formam partículas coloidais. Essas partículas coloidais são capazes de se condensar juntas constituindo uma estrutura aberta e contínua, se estendendo através do meio, obtendo assim, certo grau de rigidez. Em solução bastante diluída partículas coloidais maiores são mais susceptíveis de serem formadas ao passo que em soluções mais concentradas são formadas partículas coloidais menores por falta de espaço. Na secagem, o gel com partículas maiores terá uma estrutura ligada mais fracamente. A estrutura danificada é capaz de embeber água e expandir (11).

O gel sílico-alcalino é muito reativo na superfície e absorve água por osmose e expande. Essa água adsorvida que fica nos micro poros do gel permite a difusão das moléculas de água nos poros, mas não permite a difusão dos cátions hidratados (12).

\subsection{Fatores que influenciam a RAS}

Três fatores são decisivos para a formação da RAS: tipo de mineral agregado, teor de álcalis do cimento $(\mathrm{NaOH}, \mathrm{KOH})$ e umidade. Aqui será apresentado apenas um breve resumo sobre cada uma destas causas. 
- Agregados: A estrutura, o tamanho dos grãos, a porosidade, a permeabilidade e o tamanho dos grãos influenciam na velocidade da reação álcali-sílica. Quanto mais desorganizada e instável for a estrutura (sílicas amorfas), maior será a quantidade de superfícies expostas, mais reativa a sílica será. Como materiais mais reativos podem ser citados a opala e o vidro, entanto que fases metaestáveis e cristalinas são em geral menos reativas (13).

- Teor de Álcalis: A concentração dos álcalis na solução do poro do concreto é fundamental para que a RAS ocorra, pois aumenta o pH da solução aumentado a concentração dos grupos $\mathrm{OH}^{-}$formando $\mathrm{Si}-\mathrm{O}^{-}$, que são responsáveis pela RAS (13).

- Umidade: Este é um dos fatores mais importantes. A solubilidade da sílica e a migração dos íons alcalinos na solução dos poros do concreto são aumentadas com ciclos de secagem e molhagem da estrutura do concreto, o que favorece a reação.

\subsection{O gel produzido pela RAS}

Os estudos nas amostras de gel do concreto são poucos devido à dificuldade de se obter amostras de gel puro para análises em quantidades significativas. Devido a este problema existem muitos estudos feitos em gel sintético.

O gel em seu estado natural tem uma estrutura desordenada dominada por silicatos $Q^{3}$, Wiecker (14) observou, através de medidas de RMN de ${ }^{29} \mathrm{Si}$, que o gel da RAS tem uma estrutura semelhante a estrutura de camada de um silicato de $\mathrm{Na}$, a kanemite $\left(\mathrm{NaHSi}_{2} \mathrm{O}_{5} .3 \mathrm{H}_{2} \mathrm{O}\right)$. O gel sintético é obtido a partir da evaporação à vácuo de solução ou suspensão, uma mistura de sílica ácida com soluções de hidróxido alcalino (sódio ou potássio) ou suspensão. Experimentos de RMN de ${ }^{29} \mathrm{Si}$, difração de raios- $\mathrm{x}$ e análises químicas mostram que o gel puro e o gel sintético são bastante similares, ambos apresentam o mais abundante sítio de $\mathrm{Si}$ com polimerização $\mathrm{Q}^{3}$ e a difração de raios-x apresenta picos indicando espaçamento entre $8 \AA \AA$ até $12 \AA$, dependendo do grau de hidratação da amostra, indicando que a estrutura é dominada por unidades planas, o que 
condiz com a idéia da polimerização ser predominantemente $Q^{3}$ (15). Os resultados suportam fortemente os conceitos do modelo de kanemite para o gel RAS, entretanto a estrutura do gel é mais complexa e requer mais pesquisas.

Helmuth e Stark (16) concluíram que a composição do gel pode ser considerada como uma mistura de duas componentes contendo quantidades variadas de silicato de cálcio e silicatos de álcalis. Para investigar a estrutura do gel, Cong e Kirkpatrick (17) realizaram experimentos de espectroscopia por RMN de ${ }^{29} \mathrm{Si}$ em amostras que simulavam a composição a ser encontrada numa barra de argamassa atacada em solução alcalina, utilizando reações de misturas entre sílicas reativas (opala Nevada, opala Beltane e cristobalita) e hidróxido de cálcio com soluções de hidróxido de potássio. O principal resultado observado por RMN de ${ }^{29} \mathrm{Si}$ foi a mudança na polimerização dos silicatos em todos os tipos de amostras atacadas com solução alcalina. Na presença do cálcio (presente na solução de reação) observaram predominância de sítios $\mathrm{Q}^{4}$ diferente do material inicial, sem hidróxido de cálcio, onde há mais sítios $\mathrm{Q}^{3}$ e $\mathrm{Q}^{2}$ e os sítios $\mathrm{Q}^{1}$ em ambos aparecem em menor quantidade. Com o objetivo de conhecer melhor o ambiente químico e a vizinhança próxima dos átomos de silício, realizaram também experimentos de polarização cruzada em RMN (CPMAS) entre os núcleos de ${ }^{1} \mathrm{H}$ e ${ }^{29} \mathrm{Si}$ onde concluíram que muitos dos prótons presentes no produto da reação álcali-sílica-cálcio estão em rápido movimento à temperatura ambiente. Isso indica que os prótons mais próximos do átomo de Si são de ligações com moléculas de água e não dos íons $\mathrm{OH}^{-}$(17). Nas amostras de gel original, Tambelli (3) realizou experimentos de RMN de ${ }^{29} \mathrm{Si}$ e observou uma estrutura amorfa com predominância de sítios de $\mathrm{Si}$ com conectividade $\mathrm{Q}^{3}$ com alto índice de $\mathrm{Si}-\mathrm{OH}$ funcionais e clusters de silicatos $\mathrm{Q}^{4}$. Tambelli concluiu, também, por meio de $\mathrm{RMN}$ de ${ }^{23} \mathrm{Na}$ que há domínios cristalinos compatíveis com o $\mathrm{Na}_{2} \mathrm{CO}_{3} \cdot \mathrm{NaHCO}_{3} \cdot 2 \mathrm{H}_{2} \mathrm{O}$ (3).

\subsection{Expansão do gel da RAS}

O gel da RAS é formado na presença de solução alcalina como $\mathrm{KOH}$ ou $\mathrm{NaOH}$, como visto na seção 2.2. O ataque destas soluções alcalinas no concreto envolve a depolimerização da 
estrutura da sílica do agregado por $\mathrm{OH}^{-}$seguidos pela adsorção dos íons álcalis. O gel na presença de água embebe grandes quantidades por osmose e expande. A pressão exercida pela água pode ser suficiente para causar expansão se o grau de restrição do sistema é baixo. Como conseqüência pode ocorrer rachaduras nas partículas de agregado afetadas e também na matriz do cimento em torno do agregado. A figura 2.2 mostra um exemplo do gel exsudado na superfície do concreto, correspondendo a um estado avançado de deterioração da estrutura do concreto.

O grau de solubilidade do gel sílico-alcalino é responsável pela mobilidade do interior das partículas de agregado para as micro rachaduras. A quantidade de água contínua no concreto vai causando o alargamento e a extensão das micro rachaduras, causando a perda de resistência mecânica no concreto.

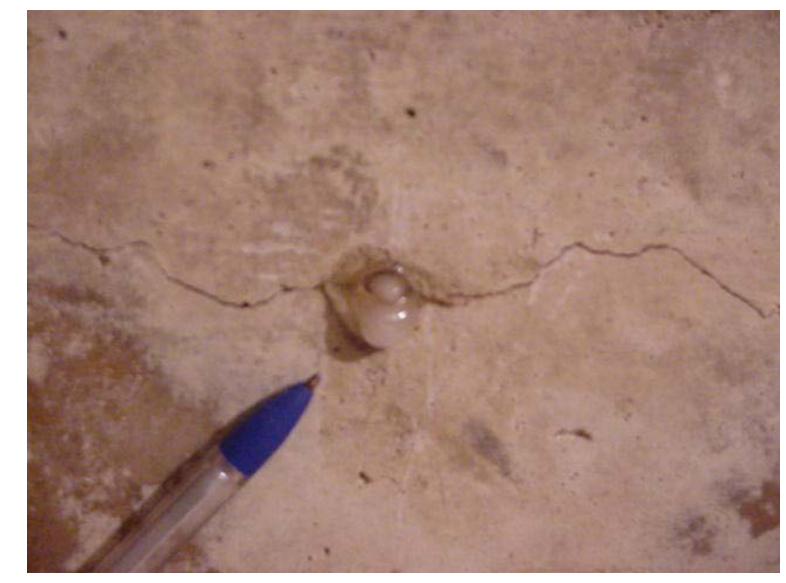

Figura 2.2- Gel exsudado a partir de uma fissura na superfície do concreto. (13)

A descrição em escala molecular do processo de expansão do gel é motivo de pesquisa na atualidade, existindo duas teorias são mais aceitas: a teoria da dupla camada elétrica (18) e teoria da adsorção (19). O primeiro modelo baseia-se na dupla camada elétrica de cátions que se desenvolve na superfície da sílica para contrabalancear sua carga negativa, e à medida que a reação vai ocorrendo, a estrutura dos poros se modifica em função da formação de um sistema de fissuras que permite o ingresso de água. O segundo modelo, a teoria da adsorção está atribuída às tensões produzidas pelo crescimento do gel quando tensionado, a expansão dependerá da concentração volumétrica do gel, da sua taxa de crescimento e propriedades físicas. Este modelo 
afirma que se a taxa de crescimento do gel for lenta, ele poderá migrar ao longo do concreto dissipando as tensões.

Vários estudos envolvendo produtos químicos têm sido realizados em barras de argamassa para entender a influencia das misturas químicas na expansão das barras. Os estudos feitos utilizando hidróxidos e sais clorídricos nas barras como $\mathrm{NaOH}, \mathrm{KOH}, \mathrm{LiOH}, \mathrm{NaCl}, \mathrm{KCl}$, $\mathrm{LiCl}, \mathrm{CaCl}_{2}, \mathrm{MgCl}_{2}$ e $\mathrm{AlCl}_{3}$ indicaram que os sais clorídricos com cátions monovalentes são os mais prejudiciais (20), favorecendo a formação dom gel.

\subsection{Tratamentos aplicados ao gel}

Duas estratégias diferentes têm sido propostas para tratar o problema das barragens afetadas pela RAS. A primeira é uma tentativa de reduzir a expansão do gel aplicando tratamentos com soluções de Li. A segunda é uma proposta bastante recente de expor o concreto parcialmente afetado pela RAS às soluções com silano, com o objetivo de impermeabilizar os grãos de agregados reativos e impedir o avanço da reação.

Pesquisas têm mostrado que é possível diminuir a expansividade dos concretos afetados pela RAS através do tratamento com sais de lítio, incluindo $\mathrm{LiF}, \mathrm{LiCl}, \mathrm{LiBr}, \mathrm{LiOH}, \mathrm{LiOH} . \mathrm{H}_{2} \mathrm{O}$, $\mathrm{LiNO}_{3}, \mathrm{LiNO}_{2}, \mathrm{Li}_{2} \mathrm{CO}_{3}, \mathrm{Li}_{2} \mathrm{SO}_{4}, \mathrm{Li}_{2} \mathrm{HPO}_{4}$, e $\mathrm{Li}_{2} \mathrm{SiO}_{3}$, mas os tratamentos com $\mathrm{LiNO}_{3}$ e $\mathrm{NaOH}$ são os mais promissores $(6,7)$. O conceito de usar sais de lítio na tentativa de inibir a expansão do gel foi proposto originalmente por McCoy e Caldwell em 1951 (21), que fizeram testes com barras de argamassa produzidas com vidro Pyrex como agregado reativo, o índice álcali do cimento foi aumentado de 1,15\% $\mathrm{Na}_{2} \mathrm{O}$ adicionando $\mathrm{NaOH}$ na mistura da água. Aproximadamente 100 compostos foram investigados, e as quantidades de vários tipos de sais de lítio foram determinadas como os agentes mais efetivos para atenuar a expansão devido ao gel nas barras de argamassa. O mínimo da razão molar de lítio por álcali suficiente para evitar a expansão foi de $0.74([\mathrm{Li}] /[\mathrm{Na}+\mathrm{K}])$. 
A partir destes resultados, outras pesquisas foram feitas com sais de lítio para evitar a expansão, Lawrence e Vivian fizeram testes com LiOH (22) comprovando sua eficácia para controlar a expansão, Sakaguchi (23) usou o vidro Pyrex como agregado reativo nas barras de argamassa e adicionou quantidades de $\mathrm{LiOH} . \mathrm{H}_{2} \mathrm{O}, \mathrm{LiNO}_{2}$, e $\mathrm{Li}_{2} \mathrm{CO}_{3}$ todos os resultados foram satisfatórios, mas Sakaguchi percebeu que a concentração de sais de lítio diminuía na solução com o tempo enquanto que a de sódio e potássio ficava constante, e em testes sem sal de lítio, as concentrações de sódio e potássio diminuem com o tempo. Stark $(24,25)$ concluiu que a quantidade insuficiente de sais de lítio aumenta a alcalinidade $\left(\mathrm{OH}^{-}\right)$da solução poro, fazendo com que o gel na barra de argamassa se expanda mais com o sal de lítio do que sem o sal. O composto $\mathrm{LiNO}_{3}$ é o único que não tende a aumentar o pH da solução poro (26), o que é vantajoso, pois assim não contribui para a dissolução da sílica. Estes resultados são promissores com relação ao desenvolvimento de tratamentos que impeçam o avanço da RAS ou que diminuam a expansão do gel já presente no concreto. No entanto, não é ainda compreendido se a redução de expansão se deve à inibição da RAS, a modificações causadas sobre o próprio gel, ou até mesmo se tem alguma ligação com a teoria de dupla camada (27).

A exposição do concreto à solução de silano é uma proposta recente de proteger os agregados que ainda não reagiram com as soluções alcalinas. Poucos estudos foram feitos até aqui, mas segundo os testes por métodos acelerados em barras de argamassa com agregados reativos de basalto feitos por Tosun (28) utilizando o iso-butiltrimetoxisilano, o tratamento com silano é capaz de prevenir a RAS.

O objetivo do tratamento é que ocorra a substituição de grupos reativos $\mathrm{OH}$ na superfície da sílica por cadeias poliméricas estáveis, mediante a exposição aos silanos, inibindo assim a ocorrência da RAS. Um possível composto apropriado para tratamentos em grande escala é o metiltrimetoxisilano (MTMS), com estrutura mostrada na figura 2.3, devido a seu baixo peso molecular. A eficiência do processo depende da capacidade de difusão do silano dentro da estrutura porosa da fase reativa, quando a solução é aplicada sobre o sistema heterogêneo de partículas minerais. O peso molecular do silano e a concentração da solução são parâmetros importantes para definir a eficiência, assim como o tipo de agregado mineral que se pretenda neutralizar. 


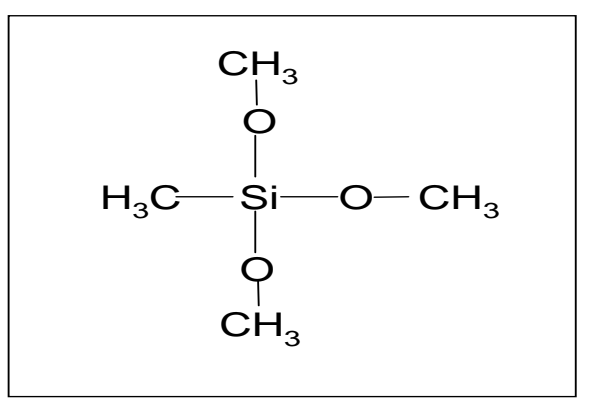

Figura 2.3- Esquema da molécula de metiltrimetoxisilano (MTMS). 


\section{Capítulo 3}

\section{Técnicas Experimentais}

Neste capítulo serão descritas as bases teóricas das técnicas utilizadas para o estudo da reação álcali-sílica.

\subsection{Introdução a RMN}

Ressonância Magnética Nuclear (RMN) é uma ferramenta muito utilizada para identificação de espécies químicas e estruturais em materiais. Os resultados em RMN são obtidos através do acoplamento magnético entre o spin de um núcleo estudado e um campo magnético externo aplicado. A condição para que ocorra o acoplamento é que o spin seja diferente de zero, ou seja, que possua momento magnético. A absorção da radiação eletromagnética ocorre de forma ressonante quando a freqüência coincide com a freqüência de transição entre os possíveis estados de energia magnética.

\subsubsection{Princípios básicos de RMN}

Uma descrição básica do fenômeno da RMN é feita considerando um spin de momento angular diferente de zero colocado num campo magnético externo aplicado. Por simplicidade, será considerado o caso de spin I=1/2. 
Para um spin isolado colocado num campo magnético externo estático e uniforme na direção z $\left(\mathrm{B}_{0}\right)$, sem nenhuma outra interação, a hamiltoniana $(\mathrm{H})$ deste acoplamento é dada por:

$$
\begin{aligned}
& \hat{\mathrm{H}}=-\boldsymbol{\mu} \cdot \mathbf{B}_{0} \\
& \hat{\mathrm{H}}=-\gamma \hbar \hat{\mathrm{I}}_{z} \mathrm{~B}_{0}(3.2)
\end{aligned}
$$

Os autovalores da hamiltoniana apresentada na equação 3.2 são múltiplos de $\gamma \hbar B_{0}$ :

$$
E_{n}=-m \gamma \hbar B_{0}(3.3)
$$

Onde m= I, I-1, I-2,...,-I (29). A hamiltoniana da equação 3.3 é conhecida como Hamiltoniana Zeeman e seus estados são referidos como estados Zeeman. Se para um spin-1/2, tem-se m=+1/2 e $m=-1 / 2$, as energias da Hamiltoniana Zeeman correspondentes são $E_{+1 / 2}=-\gamma \hbar B_{0}$ e $E_{-1 / 2}=+\gamma \hbar B_{0}$, ou seja, há um desdobramento dos níveis de energia. Portanto a diferença de energia $\Delta E$ entre os dois possíveis estados de energia para o spin-1/2 é:

$$
\Delta E=\gamma \hbar B_{0}
$$

Conclui-se, então, que um núcleo de spin-1/2 acoplado com um campo magnético constitui um sistema de dois níveis como mostrados na figura 3.1.

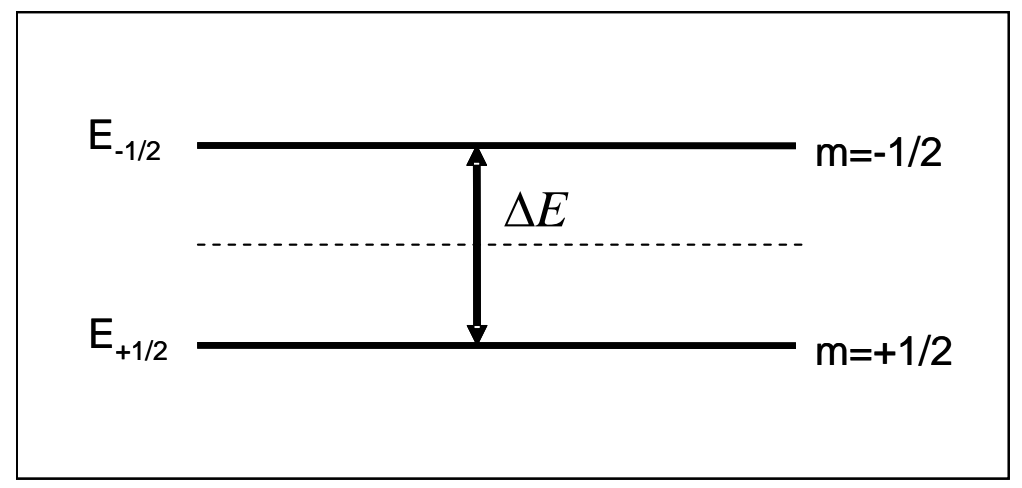

Figura 3.1- Níveis de energia para o núcleo de spin 1⁄2 num campo magnético externo $\mathrm{B}_{0}$. 
Assim é possível induzir transições entre os dois estados de spin através da radiação eletromagnética. Substituindo na equação 3.4 a diferença de energias pela relação de Planck ( $\Delta E=\hbar \omega)$, resulta que a freqüência deve ser:

$$
\omega_{0}=\gamma B_{0} \quad(3.5)
$$

Que é conhecida como freqüência de Larmor e é a condição fundamental de ressonância, para que ocorram transições entre os níveis nucleares de energia (29). A freqüência de Larmor dos núcleos, para os valores de campos normalmente empregados em laboratório, localiza-se na região de radiofreqüência. Para um campo de 9.4T, por exemplo, as freqüências de Larmor dos núcleos de ${ }^{29} \mathrm{Si},{ }^{13} \mathrm{C}$ e ${ }^{1} \mathrm{H}$ são respectivamente da ordem de $79 \mathrm{MHz}, 100 \mathrm{MHz}$ e $400 \mathrm{MHz}$.

No sistema de muitos spins, que são os sistemas físicos reais, há a interação de um número grande de spins com os campos externos aplicado. A soma de todas as contribuições de cada componente do momento magnético na direção z é representada por um vetor de magnetização macroscópico M esquematizado na figura 3.2.

$$
\mathbf{M}=\sum_{n-1}^{n} \boldsymbol{\mu}_{n} \text { (3.6) }
$$

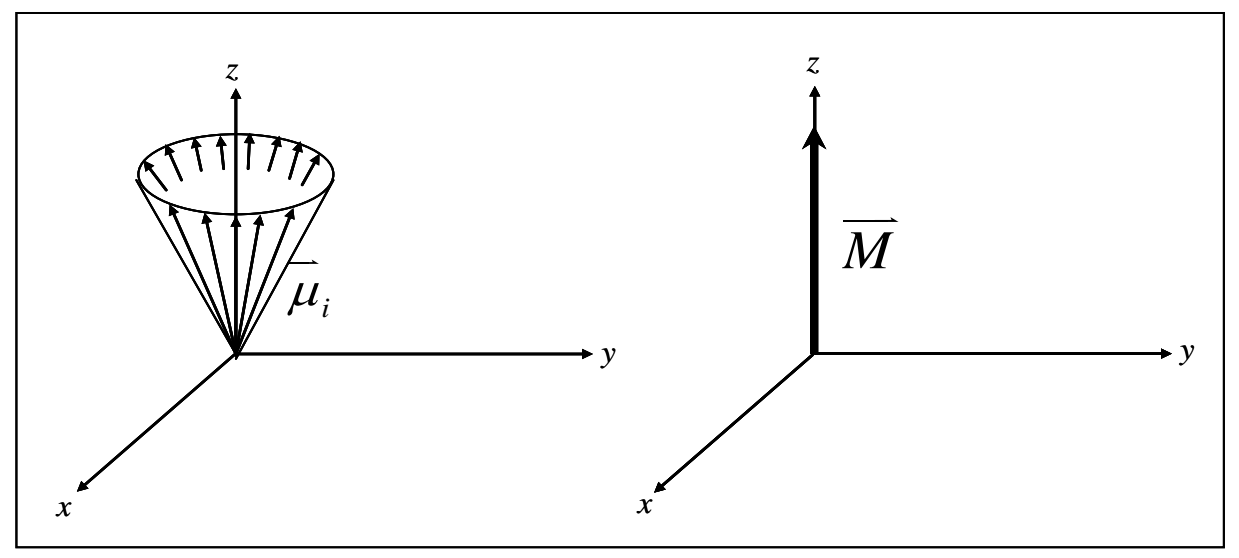

Figura 3.2- Soma vetorial dos momentos magnéticos $\mu_{\mathrm{i}}$ resultando no vetor de magnetização macroscópica M.

É conveniente considerar um sistema de $\mathrm{N}$ spins não interagentes, e definir a diferença de populações existente entre os níveis de energia. Pela estatística de Boltzmann a relação entre 
populações dos estados $E_{+}$e $E_{\text {_ }}$ de um sistema de dois níveis no equilíbrio termodinâmico é dada por:

$$
\frac{N_{-}}{N_{+}}=e^{-\frac{\Delta E}{k_{B} T}}
$$

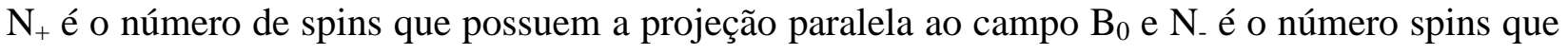
possuem a projeção antiparalela ao campo $\mathrm{B}_{0}$, a variação de energia de um sistema de dois níveis é dada pela equação 3.6 ( $\Delta E=E_{-}-E_{+}=\gamma \hbar H_{0}$ ), T é a temperatura do sistema e $\mathrm{k}_{\mathrm{B}}$ é a constante de Boltzmann (30). Os mecanismos para induzir transições entre $\mathrm{N}_{+}$e $\mathrm{N}_{-}$vêm do acoplamento entre o sistema de spins e algum outro sistema. Denotando a probabilidade por segundo de tais acoplamentos induzirem uma transição de spins de energia para cima, ou seja, de + para -, por $P_{\uparrow}$ e o processo inverso por $P_{\downarrow}$, a taxa de transição de $\mathrm{N}_{+}$é:

$$
\frac{d N_{+}}{d t}=+N_{-} P_{\downarrow}-N_{+} P_{\uparrow}
$$

Onde no estado estacionário resulta em

$$
\frac{N_{-}}{N_{+}}=\frac{P_{\uparrow}}{P_{\downarrow}}
$$

Essas transições são feitas através de pulsos de radiofreqüência (rf) que atuam como perturbações da hamiltoniana Zeeman que serão discutidos na seção 3.1.2. Os pulsos de rf têm função de tirar o sistema do equilíbrio. As ondas eletromagnéticas de rf são aplicadas com um solenóide que gera um campo magnético oscilante. Este é o campo que interage com o núcleo juntamente com o campo magnético estático. O experimento de RMN é baseado na perturbação do equilíbrio da magnetização $\mathrm{M}$ e a observação da evolução de $\mathrm{M}$ retornando ao equilíbrio. O retorno das componentes x e y de $\mathrm{M}$ ao equilíbrio origina o sinal de RMN observado, apresentado na seção 3.1.3. 


\subsubsection{RMN pulsada}

Os experimentos de RMN pulsada envolvem a aplicação de campos magnéticos oscilantes perpendiculares ao campo magnético estático. Esses campos são aplicados para induzir perturbações na população de spins e assim obter a magnetização transversal ao campo magnético. O campo magnético oscilante, gerado por um solenóide perpendicular ao campo $\mathrm{B}_{0}$ tem a forma $B_{x}(t)=B_{x 0}$ cos $\omega t$. Este campo linearmente polarizado pode ser separado em duas componentes, polarizadas circularmente, denotadas por $\mathrm{B}_{\mathrm{R}}$ e $\mathrm{B}_{\mathrm{L}}(30)$, com sentidos de rotação opostos. As duas componentes são diferenciadas apenas por um sinal negativo, ou seja, uma componente irá rotacionar no mesmo sentido como a precessão do momento e outra no sentido oposto. Assim, pode-se assumir que apenas uma componente existe e será representada por $\mathrm{B}_{1}$.

Considerando um campo $\mathrm{B}_{0}$ como sendo aplicado na direção z $\left(\vec{B}_{0}=\hat{k} B_{0}\right)$ e o campo $\mathrm{B}_{1}$ como o campo oscilante aplicado na direção perpendicular a $\mathrm{B}_{0}$, a equação de movimento de um spin incluindo os efeitos dos dois campos, é:

$$
\frac{d \boldsymbol{M}}{d t}=\mu \times \gamma\left(\boldsymbol{B}_{0}+\boldsymbol{B}_{1}(t)\right)
$$

Para eliminar a dependência de $\mathrm{B}_{1}$ com o tempo, utiliza-se um sistema de coordenadas que rotaciona sobre o eixo $\mathrm{z}$ na freqüência $\omega_{\mathrm{z}}$. Este sistema de coordenadas é chamado de sistema rotante. Nesse sistema, $\mathrm{B}_{1}$ será estático e como $\mathrm{B}_{0}$ já está na direção z, ele coincide com o eixo de rotação e também será estático. E assim temos a soma dos dois campos dado por um campo efetivo $\mathrm{B}_{\text {ef }}$ como é mostrado na figura 3.3:

$$
\frac{\partial \boldsymbol{M}}{\partial t}=\boldsymbol{M} \times \boldsymbol{B}_{\text {eff }}
$$

Onde $\mathrm{B}_{\mathrm{ef}}$ é dado por: $B_{e f}=\hat{k}\left(B_{0}-\frac{\omega}{\gamma}\right)+B_{1} \hat{i}$ 


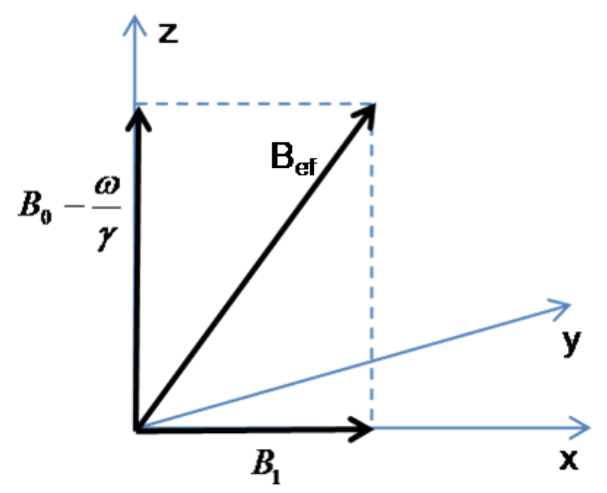

Figura 3.3- Campo magnético efetivo no sistema de campo rotante.

O campo $\mathrm{B}_{\mathrm{ef}}$ é o campo magnético estático onde o momento magnético atua, precessionando em um cone de ângulo fixo na direção de $B_{\text {ef }}$ como na figura 3.4.

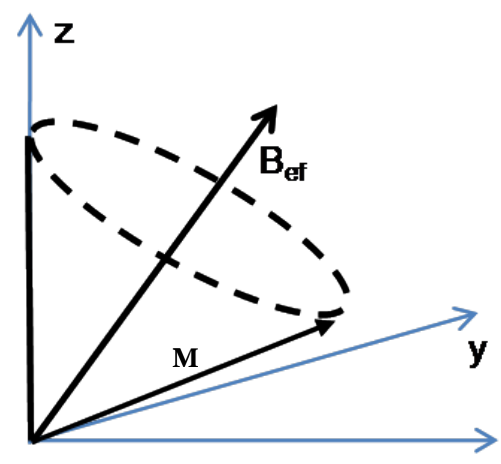

Figura 3.4- Movimento do momento magnético $\mathbf{M}$ em torno do campo magnético efetivo no sistema de coordenadas rotante.

Se o sistema estiver em ressonância, então $\omega=\omega_{0}$ e apenas $B_{1}$ na direção de x será o campo magnético efetivo, pela equação 3.12, com freqüência angular de nutação $\omega_{1}=\gamma B_{1}$ para a magnetização, conhecido como freqüência de nutação.

Quando um pulso de rf é aplicado em ressonância, o vetor de magnetização M precessa em torno do campo resultante $\left(B_{1}\right)$, na freqüência $\omega_{1}$. O ângulo que o campo $B_{1}$, aplicado durante um tempo $\tau_{\mathrm{rf}}$, faz com o eixo x no sistema rotante, é chamado de ângulo de “flip” ( $\left.\theta_{\mathrm{rf}}\right)$.

$$
\theta_{r f}=\omega_{1} \tau_{r f}=\gamma B_{1} \tau_{r f}
$$


Os pulsos cujos ângulos de flip correspondem a $90^{\circ}$ geram máxima magnetização transversal e se aplicados ao longo do eixo x são referidos como "pulsos x" (30). Depois de aplicado um pulso de $90^{\circ}$ em x $\left(90^{\circ}\right.$ x), a magnetização nuclear que inicialmente estava em $\mathrm{z}$, passará para a parte negativa do eixo y como mostra a figura 3.5. Quando o pulso de rf é desligado, a magnetização resultante estará precessionando na freqüência de Larmor no plano xy.

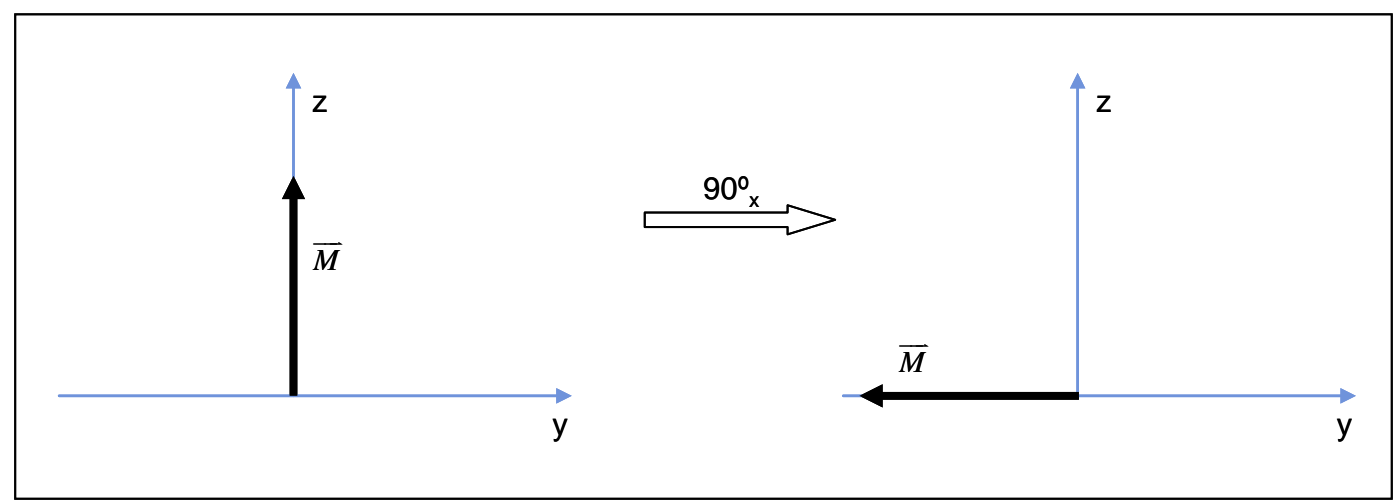

Figura 3.5- Efeito do pulso de $90^{\circ}$ na direção x da magnetização em equilíbrio no sistema de coordenadas rotantes.

Observando a equação 3.12, conclui-se que é possível controlar a duração de aplicação do campo, e assim escolher um valor do ângulo de “flip” favorável.

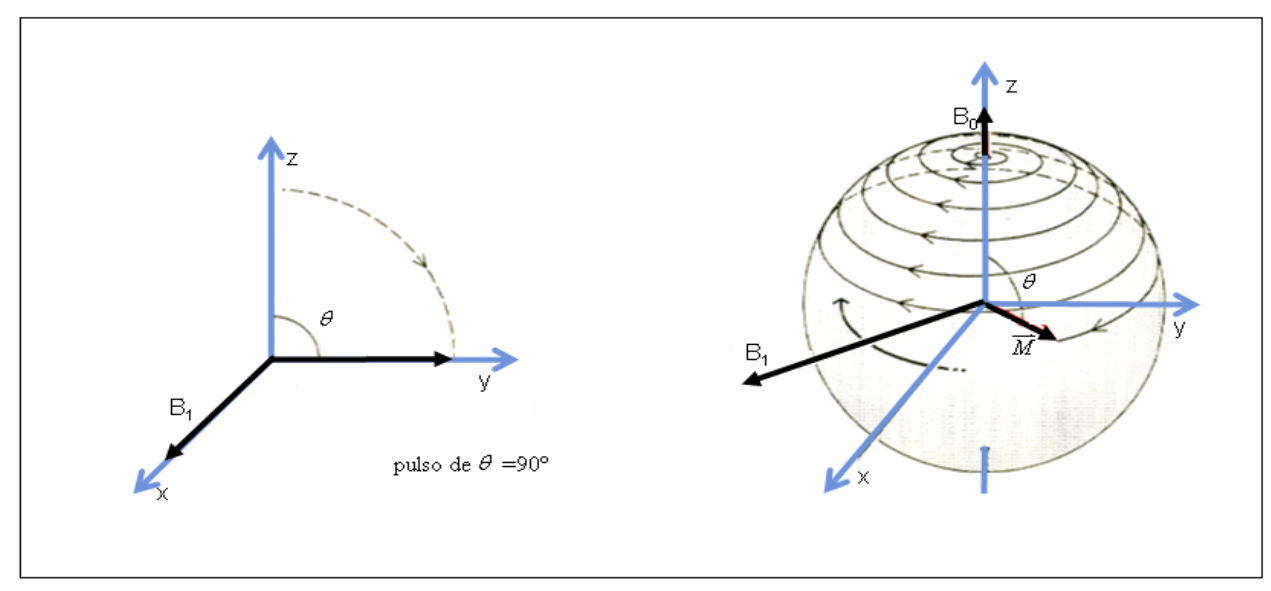

Figura 3.6- Evolução do vetor de magnetização M após um pulso de $90^{\circ}$.

Como mostrado na figura 3.6, a magnetização volta ao seu estado de equilíbrio, quando o campo $\mathrm{B}_{1}$ é desligado. Os tempos característicos para a componente de magnetização atingir o 
equilíbrio são chamados tempo de relaxação. As equações fenomenológicas que descrevem o movimento da magnetização incluindo a relaxação são chamadas de equações de Bloch.

A relaxação transversal é o processo que leva a anular a componente da magnetização no plano perpendicular ao campo estático. O processo resulta da interação entre os spins e o ambiente magnético ao seu. É também conhecida como relaxação spin-spin. As interações dos spins fazem com que cada um interaja com um campo efetivo flutuante diferente e assim tenha uma de precessão diferente, gerando a perda de coerência de fase destes spins no plano transversal em relação ao campo magnético estático (30). A figura 3.7 mostra a aplicação de um pulso de $90^{\circ}$ na direção de x e após a magnetização se encontrar no plano xy, as interações diretas entre os spins geram uma defasagem entre eles provocando uma diminuição na magnetização. Esta defasagem é provocada pelas interações entre os spins e os ambientes químicos ao seu redor, e que fazem com que cada um dos spins tenha freqüência de precessão diferente, gerando a perda de coerência de fase destes spins no plano transversal em relação ao campo magnético estático. A relaxação transversal ocorre num tempo característico $\mathrm{T}_{2}$, tempo de relaxação spin-spin.

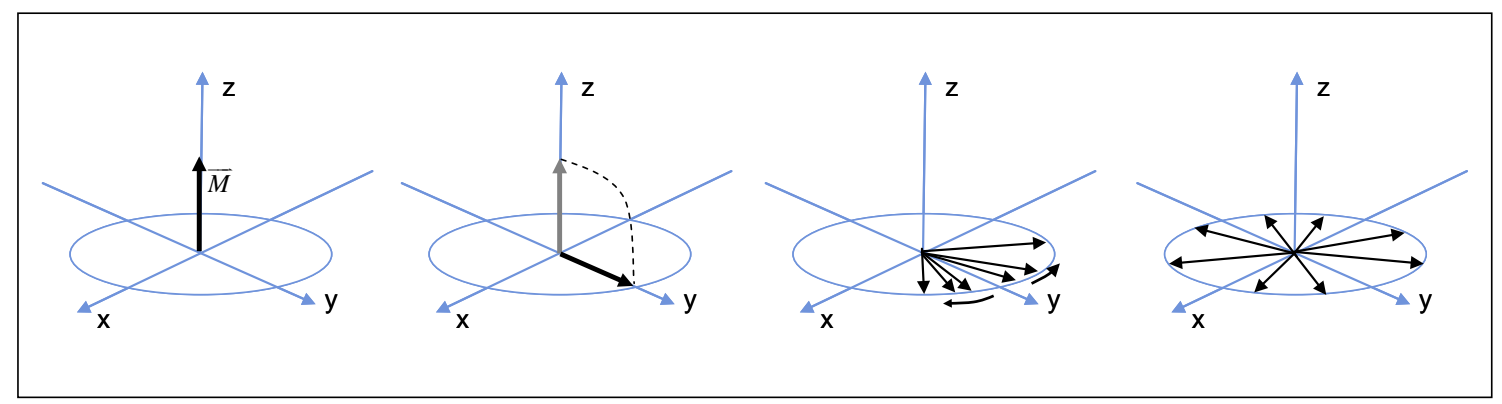

Figura 3.7- Relaxação transversal: evolução da magnetização no eixo xy mediante um pulso de $90^{\circ}$ aplicado.

A relaxação longitudinal é o processo que leva à recuperação da componente da magnetização paralela ao campo estático, até o valor de equilíbrio térmico. Esta relaxação ocorre quando os spins perdem energia para a rede em que estão acoplados, ocasionando a recuperação do equilíbrio no eixo z, não é uma relaxação espontânea, depende dos campos magnéticos flutuantes locais originados dos movimentos moleculares aleatórios presentes na amostra (30). A figura 3.8 ilustra a recuperação da magnetização longitudinal de um sistema de spins após um pulso de $90^{\circ}$ até a magnetização total $\mathbf{M}$ atingir o seu estado de equilíbrio. A relaxação longitudinal ocorre num tempo característico $\mathrm{T}_{1}$, o tempo de relaxação spin-rede. 


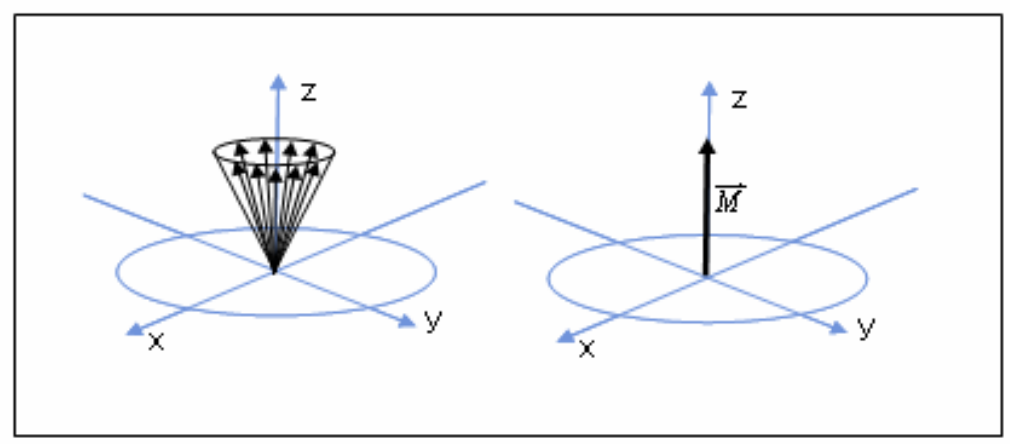

Figura 3.8- Relaxação Longitudinal: Evolução da magnetização no eixo z mediante um pulso de $90^{\circ}$ aplicado.

Em sólidos a relaxação transversal ocorre mais rapidamente que a relaxação longitudinal $\left(\mathrm{T}_{2}<\mathrm{T}_{1}\right)$.

As descrições segundo a mecânica quântica ou a mecânica clássica, descrevem o movimento não interagentes dos spins como tendo em comum um movimento periódico da magnetização no sistema rotante. Para descrever a relaxação longitudinal e transversal de um sistema de spins em um campo magnético Bloch propôs uma equação simples de primeira ordem

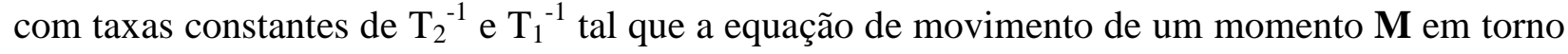
do campo pode ser descrita por:

$$
\frac{d \mathbf{M}}{d t}=\mathbf{M} \times \gamma \mathbf{B}-\frac{M_{x}}{T_{2}} \boldsymbol{i}-\frac{M_{y}}{T_{2}} \boldsymbol{j}-\frac{M_{0}-M_{z}}{T_{1}} \boldsymbol{k}
$$

O retorno da magnetização em z em torno da sua posição de equilíbrio é:

$$
\frac{d M_{z}}{d t}=\frac{M_{0}-M_{z}}{T_{1}}+\gamma(\vec{M} \times \vec{B})_{z}
$$

Onde $\mathrm{M}_{0}$ é a magnetização no equilíbrio térmico. No plano xy ocorre um decaimento da magnetização dada por:

$$
\begin{aligned}
& \frac{d M_{x}}{d t}=\gamma(\vec{M} \times \vec{B})_{x}-\frac{M_{x}}{T_{2}} \\
& \frac{d M_{y}}{d t}=\gamma(\vec{M} \times \vec{B})_{y}-\frac{M_{y}}{T_{2}}
\end{aligned}
$$


As equações de Bloch permitem interpretar qualitativamente os resultados dos experimentos de RMN pulsada. As equações são válidas para líquidos, pois possuem sistemas de spins com forte acoplamento spi-spin, acoplamentos fracos com a rede e as flutuações dos campos locais são rápidas, mas para sólidos elas não são estritamente válidas.

\subsubsection{Obtendo o sinal de RMN}

Nesta seção será descrita a origem do sinal de RMN medido experimentalmente, lembrando dos pontos já mencionados na seção anterior.

Uma amostra num campo $\mathrm{B}_{0}$ recebe um pulso de radiofreqüência através de uma bobina, que gera um campo $\mathrm{B}_{1}$ perpendicular ao campo $\mathrm{B}_{0}$. $\mathrm{O}$ campo magnético $\mathrm{B}_{1}$ desloca a magnetização $\mathrm{M}$ da amostra fazendo um ângulo $\theta$ com a coordenada $\mathrm{x}$ do sistema rotante. Quando o campo $\mathrm{B}_{1}$ é desligado a magnetização $\mathrm{M}$ tende a voltar ao seu equilíbrio sob os processos simultâneos de precessão e relaxação.

A componente $M_{x}$ da magnetização induz uma força eletromotriz na bobina. Essa força eletromotriz não será constante, ela vai decaindo exponencialmente devido ao retorno da magnetização do sistema ao equilíbrio termodinâmico. O decaimento da força eletromotriz é o sinal observado em RMN e recebe o nome de Free Induction Decay (FID). À medida que a força eletromotriz vai diminuindo conforme a coerência de fases dos spins no plano xy, o sinal de FID vai ficando menor até chegar ocorrer a coerência total onde não há mais sinal de FID. Este decaimento ocorre exponencialmente. 


\subsubsection{Interações Nucleares}

Até aqui foi considerado apenas a interação Zeeman entre o spin nuclear e o campo magnético estático externo $\mathrm{B}_{0}$ e de rf. No entanto, na matéria também existem interações entre o spin nuclear e campos magnéticos internos (campo local) que afetam o sinal em RMN e a forma da linha espectral.

Geralmente o campo magnético externo $\mathrm{B}_{0}$ aplicado é muito maior do que o campo local, assim, muitos desses campos locais são tratados como perturbações dos auto estados de spin da hamiltoniana Zeeman. As componentes desses campos que causam efeitos significativos nos estados de spin são aquelas paralelas e antiparalelas ao campo $\mathrm{B}_{0}$ desses campos locais e as componentes que precessionam no plano xy do campo $B_{0}$ na freqüência próxima a freqüência de Larmor.

Nas próximas seções serão descritas as Hamiltonianas das interações mais importantes e existentes nas amostras deste trabalho como: Interação Zeeman, interação dipolo-dipolo, interação de desvio químico e interação de Quadrupolo elétrico.

\subsubsection{Interação Zeeman}

A interação Zeeman, já mencionada na seção 3.1.1, é a interação do sistema de spins nucleares com o campo magnético externo aplicado, $\mathrm{B}_{0}$. É a interação dominante do sistema, descrita pela hamiltonaia $\mathrm{H}_{0}$, sendo que as outras interações, causadas por campos locais, podem ser consideradas como perturbações da hamiltoniana $\mathrm{H}_{0}$ (31). Os desdobramentos dos níveis de energia Zeeman foram ilustrados na figura 3.1 da seção 3.1.1 para I=1/2. A hamiltoniana total do sistema de spins nucleares pode ser dada por:

$$
\hat{H}=\hat{H}_{0}+\hat{H}_{1}
$$


Sendo que $\mathrm{H}_{1}$, que é a perturbação do sistema, pode ser dada por qualquer tipo de interações que serão tratadas nas próximas seções e cujos níveis de energia podem ser extraídos utilizando as equações de teoria da perturbação, essencialmente de primeira ordem (31). Por este motivo, as hamiltonianas apresentadas nas próximas seções correspondem apenas às componentes seculares, que comutam com $\mathrm{H}_{0}$.

\subsubsection{Interação de Desvio Químico.}

Os elétrons ao redor do núcleo não são indiferentes ao campo magnético usado nos experimentos de RMN, eles contribuem para o campo total produzindo um campo magnético secundário que é sentido pelo núcleo, mudando a freqüência de ressonância do mesmo. Essa interação do campo secundário produzido pelos elétrons cria uma blindagem ao redor do núcleo e o desvio de freqüência que essa interação causa no espectro de RMN é chamado de desvio químico (32).

A blindagem pode ser considerada como a resultante de duas componentes:

- contribuição diamagnética: é o campo secundário oposto ao campo magnético aplicado. O campo secundário é produzido através do movimento de todos os elétrons ao redor do campo magnético aplicado. Essa contribuição orbital varia com $1 / \mathrm{r}^{3}$ da distancia de cada elétron ao núcleo (32).

- contribuição paramagnética: é o campo secundário criado pela mistura dos estados eletrônicos excitados que possuem propriedades paramagnéticas com o estado fundamental, criando uma pequena quantidade de paramagnetismo no estado fundamental da molécula enquanto está no campo magnético aplicado (32).

A hamiltoniana de desvio químico atuando em um spin I é dada por:

$$
\hat{H}_{D Q}=-\gamma \hbar \boldsymbol{I} \cdot \boldsymbol{\sigma}^{L A B} \cdot \boldsymbol{B}_{0}
$$


O termo $\sigma^{\mathrm{LAB}}$ é o tensor de blindagem e descreve como a blindagem varia com a orientação dos núcleos em relação ao campo magnético externo aplicado, pois, de maneira geral, a distribuição eletrônica ao redor do núcleo não possui simetria esférica. O tensor de blindagem é representado por uma matriz 3x3:

$$
\boldsymbol{\sigma}=\left(\begin{array}{lll}
\sigma_{x x} & \sigma_{x y} & \sigma_{x z} \\
\sigma_{y x} & \sigma_{y y} & \sigma_{y z} \\
\sigma_{z x} & \sigma_{z y} & \sigma_{z z}
\end{array}\right)
$$

E o campo magnético local $\mathrm{B}_{\text {loc }}$ de um núcleo com fator de blindagem é:

$$
\boldsymbol{B}_{l o c}=\boldsymbol{\sigma}^{l a b} \cdot \boldsymbol{B}_{0}
$$

É possível encontrar um sistema de coordenadas que faça com que o tensor de blindagem seja uma matriz diagonal. Este sistema é chamado de sistema de eixos principais (SEP). Os valores ao longo da diagonal principal $\sigma^{\mathrm{SEP}}$ são os valores principais do tensor de blindagem. A orientação do sistema de coordenadas principais é determinada pela estrutura eletrônica da molécula que contem o núcleo em questão e é fixado com relação à molécula. Graficamente, representa-se o tensor de blindagem por um elipsóide fixo à molécula e centrado no núcleo (32), como mostra a figura 3.9. Os eixos principais do elipsóide coincidem com o SEP do tensor de blindagem e o comprimento de cada eixo principal de elipse é proporcional ao valor principal do tensor de blindagem associado com o eixo principal. Se a orientação da molécula no sistema do laboratório muda, em seguida o mesmo acontece com a orientação do tensor de blindagem.

Considerando os três valores principais do tensor de blindagem, $\sigma_{x x}^{S E P}, \sigma_{y y}^{S E P}, \sigma_{z z}^{S E P}$, pode-se definir o valor isotrópico $\sigma_{\text {iso, }}$ a anisotropia $\Delta$ e o parâmetro de assimetria $\eta$ (32):

$$
\begin{aligned}
& \sigma_{i s o}=\frac{1}{3}\left(\sigma_{x x}^{S E P}+\sigma_{y y}^{S E P}+\sigma_{z z}^{S E P}\right) \\
& \Delta=\sigma_{z z}^{S E P}-\sigma_{i s o} \\
& \eta=\frac{\left(\sigma_{x x}^{S E P}-\sigma_{y y}^{S E P}\right)}{\sigma_{z z}^{S E P}}
\end{aligned}
$$


Passando as coordenadas do referencial do laboratório para o sistema de eixos principais, considerando os ângulos $\theta$ e $\phi$ como os ângulos de Euler entre o sistema de laboratório e o SEP, como mostra a figura 3.9, a hamiltoniana 3.16 fica:

$$
\hat{H}_{D Q}=I_{z} \omega_{D Q}
$$

Onde $\omega_{\mathrm{DQ}}$ é a correção da freqüência Zeeman (32).

$$
\omega_{D Q}=-\omega_{0} \sigma_{\text {iso }}-\omega_{0} \frac{\Delta}{2}\left(3 \cos ^{2} \theta-1+\eta \sin ^{2} \theta \cos 2 \phi\right)
$$

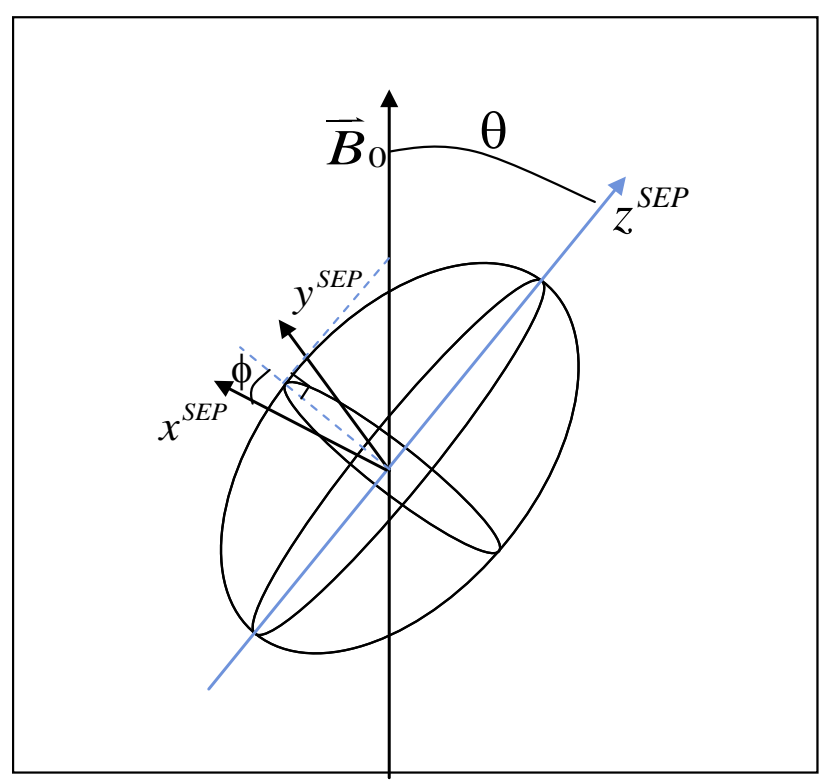

Figura 3.9- Definição dos ângulos polares $\theta$ e $\phi$ definidos pelo campo magnético $B_{0}$ com o SEP do tensor de blindagem.

Para uma amostra no estado policristalino todas as orientações da molécula com relação ao campo $\mathrm{B}_{0}$ estão presentes. Como o SEP é fixo na molécula, na amostra com padrão de pó todos os valores de $\theta$ e $\phi$ são possíveis. Portanto, no padrão de pó de acordo com a equação 3.21 haverá diferentes desvios químicos para cada orientação e a linha de RMN resultará alargada de maneira não-homogênea, devido à superposição das ressonâncias correspondentes a orientações diferentes. A figura 3.10 mostra o padrão resultante para um caso particular: ambiente químico axialmente simétrico $(\eta=0)$. 


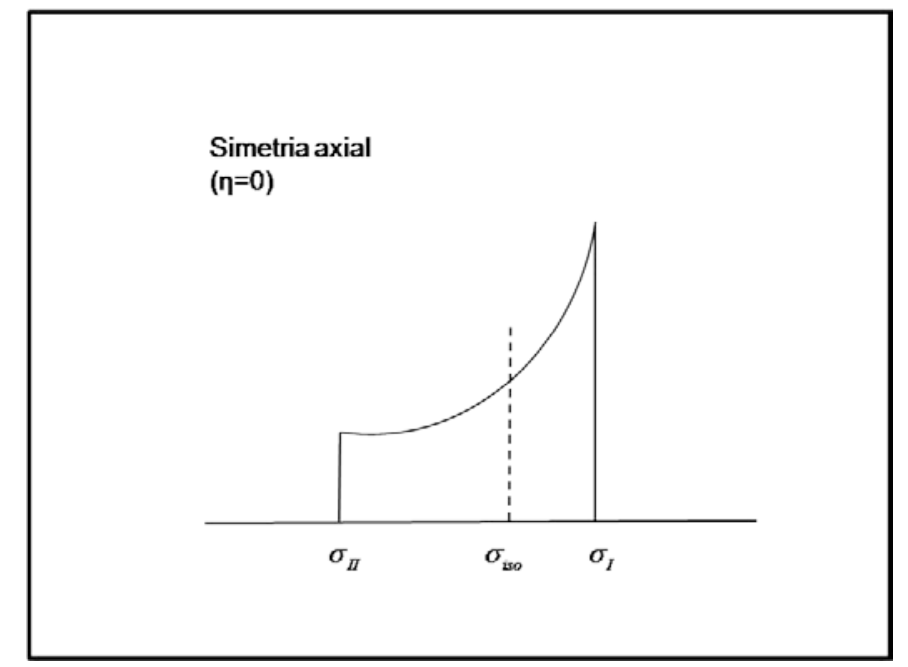

Figura 3.10- Espectro correspondente a um tensor de desvio químico de simetria axial.

Nos experimentos de RMN as freqüências são representadas de maneira relativa à ressonância de uma amostra de referencia $v_{\text {ref. }}$ O desvio químico $\delta_{\text {iso }}$ é definido como:

$$
\delta=\frac{v-v_{r e f}}{v_{r e f}}
$$

Onde vé a freqüência espectral do sinal para o spin de interesse e ref é a freqüência de ressonância do mesmo spin na amostra padrão.

\subsubsection{Interação dipolo-dipolo}

A interação dipolo-dipolo é resultado do acoplamento do momento magnético que cada spin nuclear possui. A energia de interação entre dois dipolos $\mu_{\mathrm{I}}$ e $\mu_{\mathrm{S}}$ separados por uma distancia r, parte da expressão clássica e varia com $1 / r^{3}$.

A partir da equação clássica e do campo local $B_{\text {Dip }}$ gerado pelos campos vizinhos tem-se a hamiltoniana de interação para o acoplamento dipolar entre dois spins I e S:

$$
\hat{H}_{d d}=-\left(\frac{\mu_{0}}{4 \pi}\right) \gamma_{1} \gamma_{2}\left(\frac{\boldsymbol{I} \cdot \boldsymbol{S}}{r^{3}}-3 \frac{(\boldsymbol{I} \cdot \boldsymbol{r})(\boldsymbol{S} \cdot \boldsymbol{r})}{r^{5}}\right)
$$


Dois casos de acoplamento dipolar podem ser considerados: acoplamento dipolar homonuclear onde os spins I e S são da mesma espécie e acoplamento dipolar heteronuclear onde os spins I e S são de diferentes espécies. As hamiltonianas dessas duas espécies de acoplamento são escritas em termos dos ângulos de Euler $\theta$ e $\phi$ do vetor internuclear. A figura 3.11 ilustra a orientação dos spins I e $\mathrm{S}$, mediante um campo magnético aplicado $\mathrm{B}_{0}$, através dos ângulos polares $\theta$ e $\phi$ no referencial do laboratório.

$$
\begin{gathered}
\hat{H}_{d d}^{\text {homo }}=-\left(\frac{\mu_{o}}{4 \pi}\right) \frac{\gamma_{I} \gamma_{S} \hbar}{r^{3}}\left(3 \cos ^{2} \theta-1\right)\left[I_{z} S_{z}-\frac{1}{2}\left(I_{x} S_{x}+I_{y} S_{y}\right)\right] \text { (hamiltoniana dipolar } \\
\text { homonuclear) }(3.24) \\
\hat{H}_{d d}^{\text {hetero }}=-\left(\frac{\mu_{o}}{4 \pi}\right) \frac{\gamma_{I} \gamma_{S} \hbar}{r^{3}}\left(3 \cos ^{2} \theta-1\right) I_{z} S_{z} \quad \text { (hamiltoniana dipolar heteronuclear) (3.25) }
\end{gathered}
$$

Com freqüência de acoplamento dipolar:

$$
\omega_{I S}=\frac{\gamma_{I} \gamma_{S}}{r_{I S}^{3}}\left(1-3 \cos ^{2} \theta\right)
$$

Nas equações 3.24 e 3.25 já foram considerados apenas os termos que comutam com $\hat{H}_{0}$ (32). No acoplamento dipolar heteronuclear o alargamento é heterogêneo, semelhante ao caso do desvio químico, resultando da distribuição de campos magnéticos locais diferentes na direção z. No caso homonuclear com muitos spins o alargamento é homogêneo: os estados de spin estão acoplados e a função de onda já não é um produto direto: há mistura de estados.

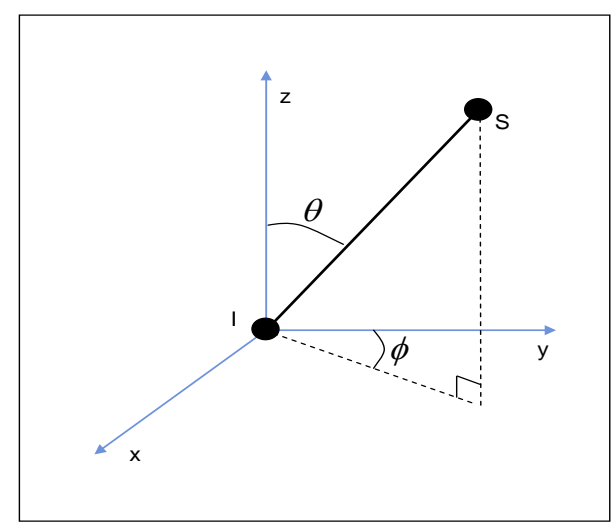

Figura 3.11- Orientação de I e S pelos ângulos polares $\theta$ e $\phi$ em relação ao campo $\mathrm{B}_{0}$ ao longo do eixo z no sistema do laboratório. 


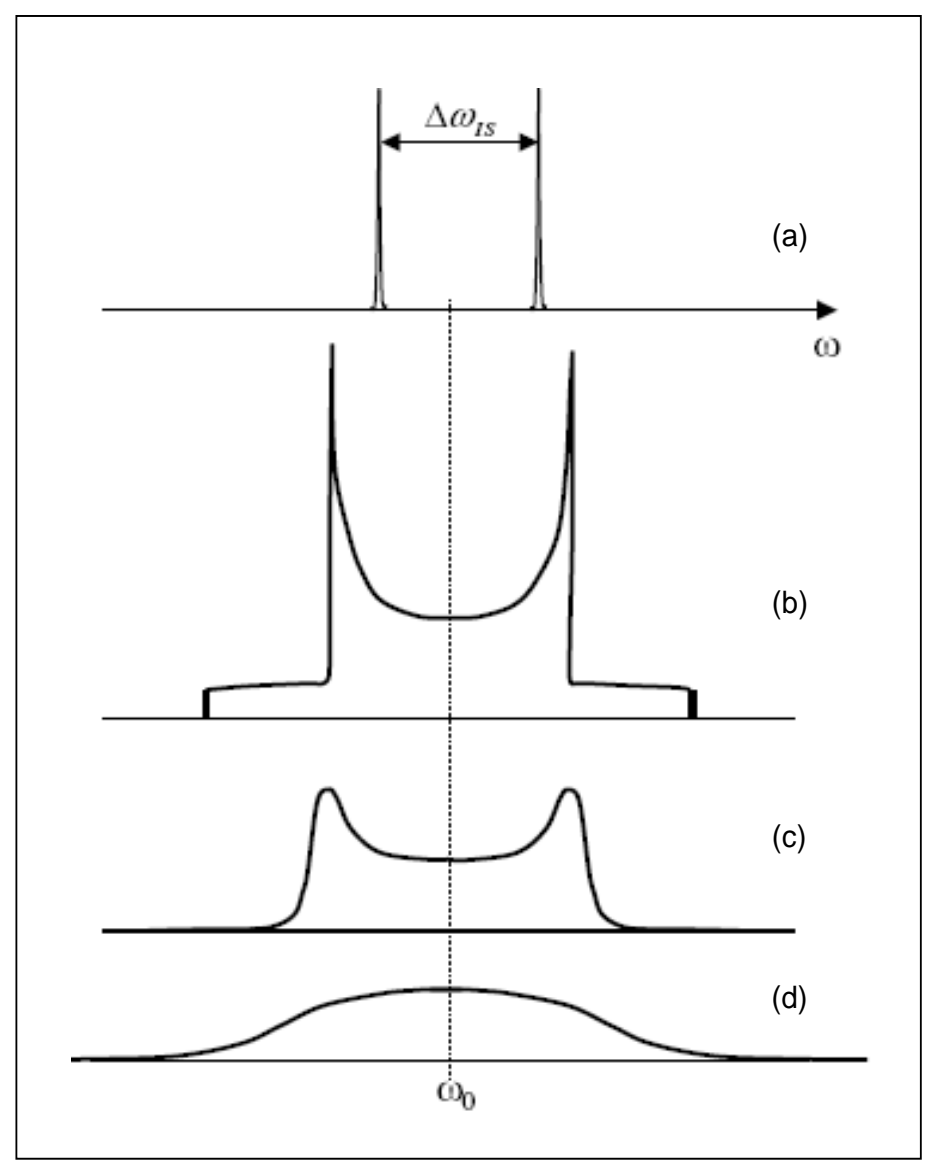

Figura 3.12- Espectro teórico de acoplamento dipolar. (a) um par de spins com orientação única. (b) um par de spins num policristal. (c) par de spins num policristal com outras interações de spin. (d) muitos spins com múltiplas interações.

A figura 3.12 mostra os espectros teóricos do acoplamento dipolar. Num sistema com um par de spin com uma única orientação, aparecem duas linhas estreitas como mostra a figura 3.12a. Para um par de spin num policristal, isto é, com orientações aleatórias, figura 3.12b e com outras interações de spin, figura 3.12c, a linha se alarga devido a dependência do desdobramento com as variáveis espaciais $\theta$ e r. No caso de muitos spins com múltiplas interações entre spins a linha é bastante larga com a ausência de desdobramentos. A distância entre o desdobramento, $\Delta \omega_{\text {IS }}$ na figura 3.12a, fornece a constante de acoplamento dipolar, que não foi utilizada neste trabalho devido à dificuldade por não se tratar de sistemas de dois spins como descrito acima. 


\subsubsection{Interação de Quadrupolo}

Todo núcleo com spin I maior que 1/2 possui momento de quadrupolo elétrico (eQ), pois a densidade de carga elétrica não é esfericamente simétrica (32). Um núcleo com spin maior do que meio não interage apenas com o campo magnético aplicado e com os campos magnéticos locais, mas também com qualquer gradiente de campo elétrico presente na posição do núcleo.

A interação ocorre pelo fato do núcleo não possuir simetria esférica, como ocorre no caso de núcleos com spin-1/2. A figura 3.13 mostra a geometria dos núcleos em função do spin I.

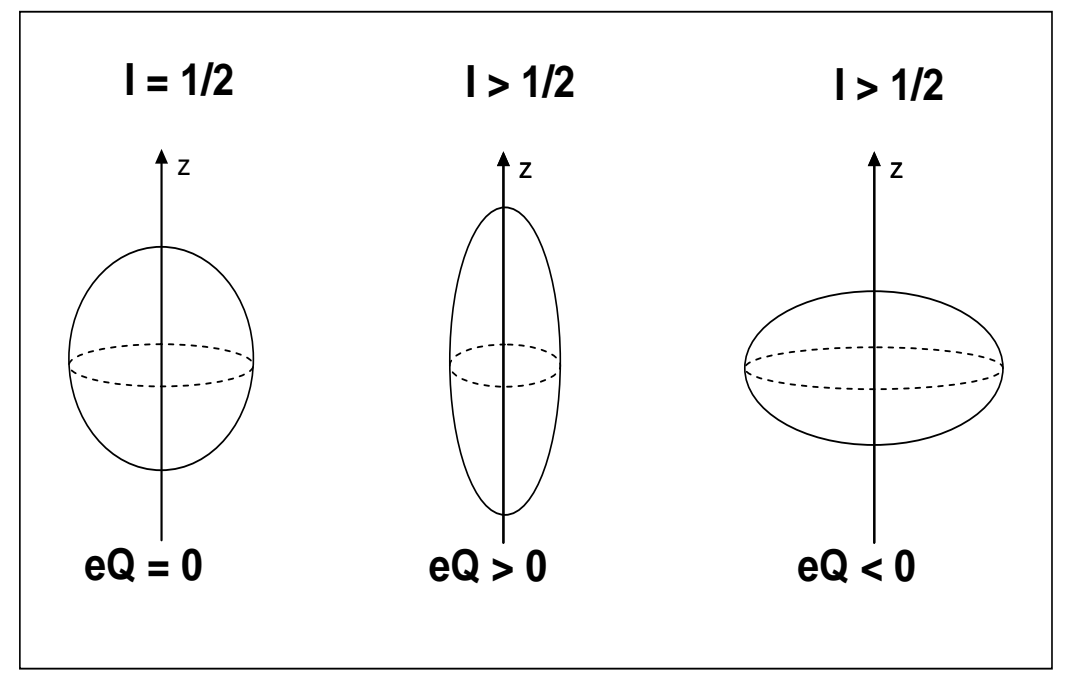

Figura 3.13- Representação geométrica da distribuição volumétrica das cargas elétricas dos núcleos de spin=1/2, spin $>1 / 2$ e $\operatorname{spin}<1 / 2$.

A intensidade de interação depende da magnitude do momento de quadrupolo e do gradiente de campo elétrico (gce). A hamiltoniana de interação de quadrupolo para um spin I é dada em função do momento de quadrupolo, $e Q$ (32):

$$
H_{Q}=\frac{e Q}{6 I(2 I-1) \hbar} \vec{I} \cdot e \vec{q} \cdot \vec{I}
$$


Assim como na interação de desvio químico, a hamiltoniana pode ser escrita em termos do SEP escolhendo os eixos para que resulte $V_{x x} \geq V_{y y} \geq V_{z z}$. Definem-se dois parâmetros: a constante de acoplamento de quadrupolo $\chi$ e o parâmetro de assimetria $\eta_{\mathrm{Q}}$, que são expressos em termos dos valores principais do tensor de gradiente de campo elétrico no SEP.

$$
\begin{gathered}
\eta_{Q}=\frac{V_{x x}^{S E P}-V_{y y}^{S E P}}{V_{z z}^{S E P}} \\
\chi=\frac{e^{2} q Q}{\hbar} \\
\hat{H}_{Q}=\frac{e Q}{6 I(2 I-1)} \sum_{i}\left(3 I_{i}^{2}-I^{2}\right) V_{i, i}^{S E P} \\
=\omega_{Q} \times\left[\frac{3 I_{z}^{2}-I^{2}+e^{-1} \eta\left(I_{x}^{2}-I_{y}^{2}\right)}{4 I(2 I-1)}\right]
\end{gathered}
$$

Onde $\omega_{\mathrm{Q}}$ é a freqüência de transição do núcleo quadrupolar. A interação de quadrupolo é uma perturbação dos níveis de energia da hamiltoniana Zeeman. Apenas os termos que comutam com $\mathrm{H}_{0}$ contribuem para a correção de primeira ordem dos níveis de energia (31):

$$
E_{m}^{(1)}=\frac{\chi\left[3 \cos ^{2} \theta-1+\eta_{Q} \operatorname{sen}^{2} \theta \cos 2 \varphi\right]\left(3 m^{2}-I(I+1)\right)}{8 I(2 I-1)}
$$

Os desdobramentos dos níveis de energia são mostrados na figura 3.14, que ilustra o caso de um spin $\mathrm{I}=-3 / 2$ e com simetria axial $\eta_{\mathrm{Q}}=0(47,48)$. No caso das transições de $\mathrm{m}=1 / 2$ para $\mathrm{m}=-$ $1 / 2$, não sofre deslocamento em primeira ordem pela interação de quadrupolo, mas as outras transições de $3 / 2$ para $1 / 2$ e de $-1 / 2$ para $-3 / 2$ sofrem deslocamento. O resultado dos deslocamentos nessas ultimas transições são linhas simétricas em torno da linha central, chamadas de linhas satélites. Na figura 3.14 as três linhas observadas são referentes às seguintes transições: $1 / 2$ para -1/2, que é a linha central, $-1 / 2$ para -3/2 e 3/2 para 1/2, que são as linhas satélites. 
As freqüências de ressonância são:

$$
\begin{gathered}
\omega_{0}=\omega_{ \pm 1 / 2}=\frac{\gamma B_{0}}{2 \pi} \\
\omega_{ \pm 3 / 2}=\frac{\gamma B_{0}}{2 \pi} \mp 2 \Delta \\
\Delta=\frac{e^{2} q Q}{8 \hbar}\left(3 \cos ^{2} \theta-1\right)
\end{gathered}
$$
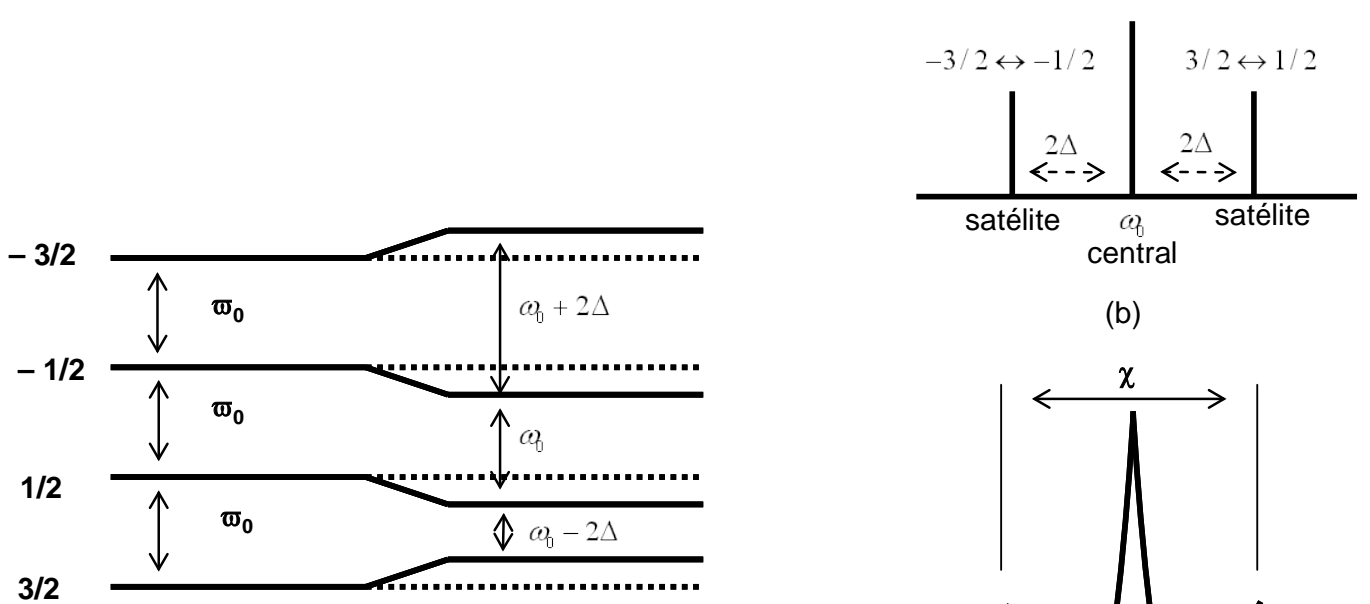

(a)

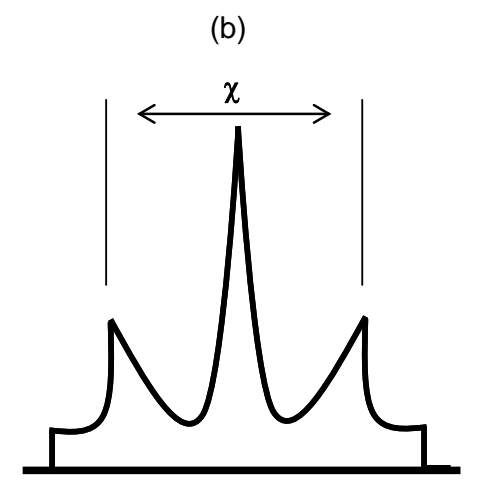

(c)

Figura 3.14- (a) Esquema de níveis de energia de um núcleo de spin-3/2 para uma orientação arbitrária do tensor gce, $\eta_{\mathrm{Q}}=0$ (b) Espectro de um monocristal. (c) Espectro de policristal.

A correção na freqüência de transição para a linha central, utilizando a teoria de perturbação de segunda ordem é (31): 


$$
\omega_{Q}^{(2)}=\frac{\chi^{2} \hbar}{48 I^{2}(2 I-1)^{2} \omega_{0}}\left\{\begin{array}{l}
\frac{3}{2} \operatorname{sen}^{2} \theta\left[\left(\frac{27}{8}-\frac{9}{2} I(I+1) \cos ^{2} \theta\right)+\frac{3}{8}-\frac{I(I+1)}{2}\right]+ \\
+\frac{\eta_{Q}^{2}}{6}\left[\begin{array}{c}
3-4 I(I+1)-\left(\frac{3}{2}-2 i(I+1) \cos ^{2} \theta\right)- \\
+\left(\frac{27}{8}-\frac{9}{2} I(I+1)\right)\left(\cos ^{2} 2 \phi\left(\cos ^{2} \theta-1\right)^{2}\right)
\end{array}\right]
\end{array}\right\}
$$

Tanto a linha central quanto as linhas satélites apresentam dependência angular com os ângulos de Euler do sistema de eixos principais do tensor gce e por isso são interações anisotrópicas, e por conseqüência o espectro de um acoplamento de quadrupolo de uma amostra com padrão de pó é alargado como na figura 3.15. Para obter o desvio químico isotrópico nos estudos de ${ }^{23} \mathrm{Na}$ deste trabalho foi necessário utilizar a técnica de 3Q-MAS que será explicada na seção 3.3.4.

A posição das linhas satélites permite calcular o acoplamento de quadrupolo elétrico que é um parâmetro útil para identificar a simetria ou tipo de ligação química ao redor do núcleo da espécie estudada, como o núcleo de ${ }^{23} \mathrm{Na}$ ( $\left.\mathrm{I}=3 / 2\right)$ analisado neste trabalho.

\subsection{Técnica de RMN de baixa resolução: Spin-eco de Hahn}

A técnica de spin-eco foi utilizada com o objetivo de calcular a constante de acoplamento de quadrupolo e assim analisar o ambiente químico ao redor do núcleo de ${ }^{7} \mathrm{Li} \mathrm{e}{ }^{23} \mathrm{Na}$. As linhas de ressonância desses núcleos são largas, logo o FID é curto e considerando que no espectrômetro de RMN há um tempo perdido antes do sinal (tempo morto) foi necessário utilizar a técnica de spin-eco. A técnica consiste numa sequência de dois pulsos de $90^{\circ}-180^{\circ}$, separados por um tempo $\tau(30)$.

Quando um pulso de $90^{\circ}$ é aplicado num sistema em equilíbrio, o vetor da magnetização passa para o eixo -y como nas figuras 3.5 e 3.6, e o sistema começa a evoluir livremente num tempo que aqui é chamado de $\tau$. Se todos os spins sentissem o mesmo campo magnético, isto é, 
se houvesse homogeneidade, não haveria o decaimento exponencial da magnetização transversal de acordo com a equação de Bloch, pois os spins precessionariam com a mesma freqüência $\omega$, e a magnetização continuaria na direção y por tempo indeterminado no sistema rotante. É a não homogeneidade do campo que causa a diferença de freqüências e a defasagem dos spins.

Hahn (31) fez uma descoberta notória: aplicando um segundo pulso de $90^{\circ}$ depois de um tempo $\tau$ do primeiro pulso, aparece outro FID depois de um tempo $2 \tau$ do primeiro pulso. Para ilustrar, considera-se um elemento de magnetizaçãoM relativoà magnetizaç ão total de um conjunto de spins como mostrado na figura 3.15.

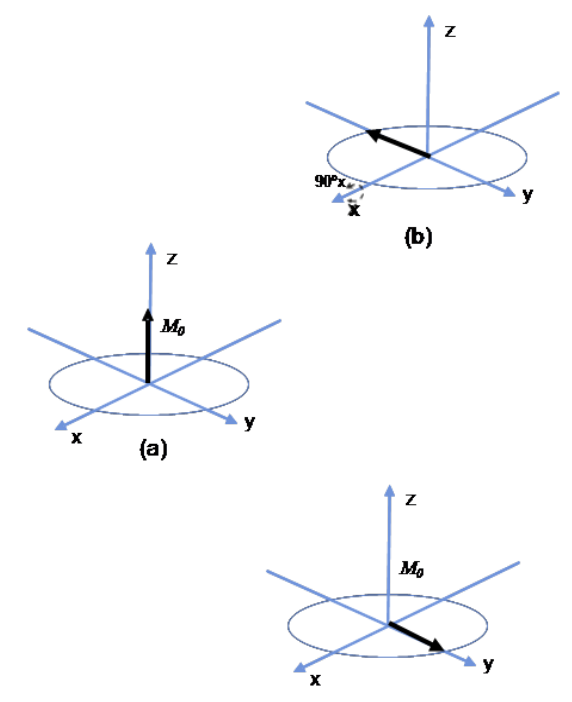

(f)

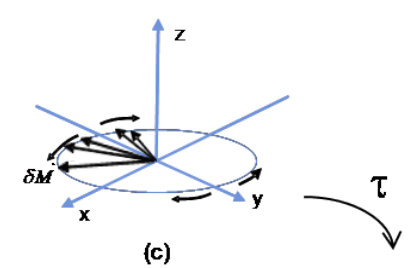

(c)

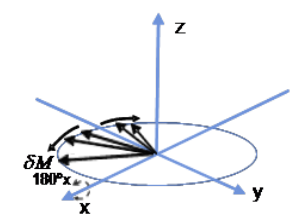

(d)

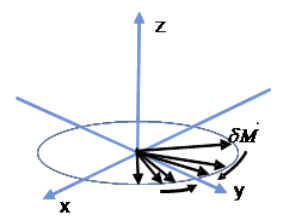

(e)

Figura 3.15- Evolução da magnetização $M$ utilizando técnica de spin-eco. (a) Magnetização no tempo $t=0$, antes da aplicação do primeiro pulso. (b) Magnetização no eixo -y, logo após a aplicação do pulso de $90^{\circ}$. (c) Evolução da magnetizaçãoßM durante um tempo $\tau$. (d) Aplicação do pulso de $180^{\circ}$. (e) Inversão e evolução da magnetizaçãøM aṕs o pulso de $180^{\circ}$. (f) RefocalizaçãळMo recupera̧ão da magnetização.

Depois de aplicado um pulso de $90^{\circ}$, o vetor $\delta \mathrm{M}$ se encontra na dirȩão -y e precessiona no plano xy com a mesma freqüência comum a todos os spins do sistema. É esperado um tempo $\tau$ e então é aplicado um novo pulso de $180^{\circ}$, gerando uma rotação de $180^{\circ}$ sobø̇e colocando -o na direção +y. O mesmo pode ser dito dos outros elementos de magnetização e assim num tempo igual ao dobro do tempo de espera do primeiro pulso $(\mathrm{t}=2 \delta)$, todos os vetores de magneţĩ̃̊ 
estarão no eixo positivo de y. Nesse instante a magnetização é totalmente refocalizada voltando ao seu valor inicial após o primeiro pulso.

A sequência de pulsos de spin-eco de Hahn compensa a evolução coerente da magnetização transversal associadas às interações proporcionais ao operador $I_{z}$ tais como a interação de desvio químico e não homogeneidade do campo magnético externo $\mathrm{B}_{\mathrm{o}}$. No entanto, a defasagem durante o período de evolução ¿ causada pelo acoplamento dipolar homonuclear rão é afetada pelo pulso de refocalização e, portanto, o sinal de spin eco apresenta uma intensidade menor comparado ao sinal logo após o primeiro pulso.

\subsection{Técnicas de Ressonância Magnética Nuclear de Alta Resolução}

As amostras utilizadas em RMN de sólidos são policristalinas e os espectros resultantes são alargados inomogêneamente pela anisotropia das interações dos spins em estado sólido (padrão de pó). A aplicação de técnicas que eliminem o efeito da anisotropia permite obter espectros ditos de alta resolução: unicamente as componentes isotrópicas das interações contribuirão ao deslocamento das linhas de ressonâncias, que resultarão consideravelmente mais estreitas. Em RMN de estado sólido a identificação de diferentes ambientes químicos ou estruturais da espécie ressonante é possível somente através da resolução destes deslocamentos isotrópicos das linhas espectrais, determinados pelos desvios químicos isotrópicos e, em espécies com I $>1 / 2$, pelos valores do acoplamento de quadrupolo elétrico. Nas próximas seções serão descritas as técnicas de RMN de alta resolução que foram utilizadas neste trabalho. Para espécies com I=1/2 foram aplicadas a técnica de rotação em torno do ângulo mágico (Magic Angle Spinning, MAS) e desacoplamento heteronuclear de ${ }^{1} \mathrm{H}$, para eliminar respectivamente a anisotropia de desvio químico e o acoplamento dipolar com ${ }^{1} \mathrm{H}$. Estas técnicas são aplicadas simultaneamente para o experimento de RMN realizados em polarização direta da espécie ressonante ou em polarização cruzada desde ${ }^{1} \mathrm{H}$. Para spins com $\mathrm{I}>1 / 2$ foi aplicada a técnica de Triplo Quantum (3Q-MAS). Será descrita também a técnica de correlação heteronuclear (HETCOR). 


\subsubsection{Rotação em Torno do Ângulo Mágico (MAS)}

A técnica de Rotação em Torno do Ângulo Mágico (MAS) é usada na maioria dos experimentos de RMN de estado sólido sendo possível remover os efeitos do desvio químico anisotrópico e auxiliar na diminuição do acoplamento dipolar heteronuclear.

A técnica de MAS consiste em girar a amostra sobre um eixo com um ângulo de inclinação $\theta_{R}$ com relação ao campo magnético aplicado $B_{0}$ como na figura 3.16. $O$ ângulo $\theta$ que descreve a orientação do tensor de interação fixado na molécula dentro da amostra varia com o tempo devido à rotação. De acordo com a equação 3.21, a anisotropia de interação de desvio químico tem uma dependência angular dada por $\left(3 \cos ^{2} \theta-1+\eta \cos 2 \phi \operatorname{sen}^{2} \theta\right)$. Calculando a média temporal de $\left(3 \cos ^{2} \theta-1\right)$ sobre um período de rotação resulta (32):

$$
\left\langle 3 \cos ^{2} \theta-1\right\rangle=\frac{1}{2}\left(3 \cos ^{2} \theta_{R}-1\right)\left(3 \cos ^{2} \beta-1\right)
$$

Onde $\beta$ é o ângulo entre o tensor de interação e o eixo de rotação. Para uma amostra policristalina, $\beta$ assume todos os valores possíveis entre 0 e. Oângulo $\theta_{\mathrm{R}}$ é definido pela montagem experimental. Para eliminar o termo anisotrópico 3.33, pode-se adotar o $\theta_{R}=54.74^{\circ}$, dito de "ângulo mágico", fazendo com que o termo $\left(3 \cos ^{2} \theta-1\right)$ seja nulo. Desta forma a única contribuição da interação de desvio químico à freqüência de ressonância é o termo isotrópico. A técnica de MAS é efetiva para toda interação anisotrópica com dependência angular do tipo da equação 3.21. 


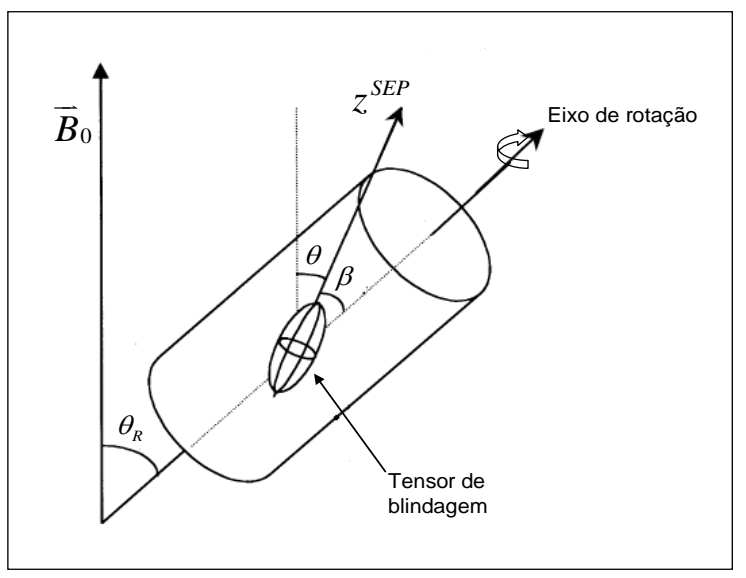

Figura 3.16-Experimento de ângulo mágico MAS. Rotação macroscópica da amostra segundo um ângulo $\beta=54.74^{\circ}$ com relação ao campo magnético aplicado.

Para ter anulação completa da anisotropia, a freqüência de rotação tem que ser maior que a largura da linha do espectro estático. Quando o alargamento da linha de ressonância é inomogêneo, resultante de interações anisotrópicas, ainda é possível obter linhas isotrópicas com freqüência de rotação menores que a largura da linha em condições estáticas. Nesse caso são observadas bandas laterais de rotação, réplicas do espectro isotrópico separadas por múltiplos da freqüência de rotação (32). Para o caso de alargamentos espectrais homogêneos, causado por acoplamento dipolar homonuclear intenso, MAS com rotações e a velocidades menores que a largura da linha não produz estreitamentos significativos.

\subsubsection{Polarização Direta}

A técnica de RMN pulsada de polarização direta consiste em aplicar um pulso de rf sobre a espécie ressonante que se deseja medir. O pulso de $90^{\circ}$ fornece o máximo sinal e espera-se um tempo cinco vezes maior que o maior $\mathrm{T}_{1}$ característico da amostra para garantir que todos os sinais do espectro vão retornar ao equilíbrio. Desta forma a intensidade das linhas poderá ser usada para quantificar a fração de spins que contribui para cada uma delas. 
Em grande parte deste trabalho foi necessário aplicar durante a medida do FID as técnicas de rotação da amostra em torno do ânulo mágico (MAS) para obter espectros de amostras policristalinas de alta resolução, eliminando a anisotropia de desvio químico.

\subsubsection{Polarização Cruzada}

Esta é uma técnica de dupla ressonância baseada na existência de acoplamento dipolar entre duas espécies de spin I e S. A espécie I é irradiada diretamente enquanto que a detecção é feita na freqüência da espécie S. Caso exista acoplamento dipolar entre elas, será observado um sinal de RMN (32). O experimento é feito com a sequência de pulsos esquematizada na figura 3.17 .

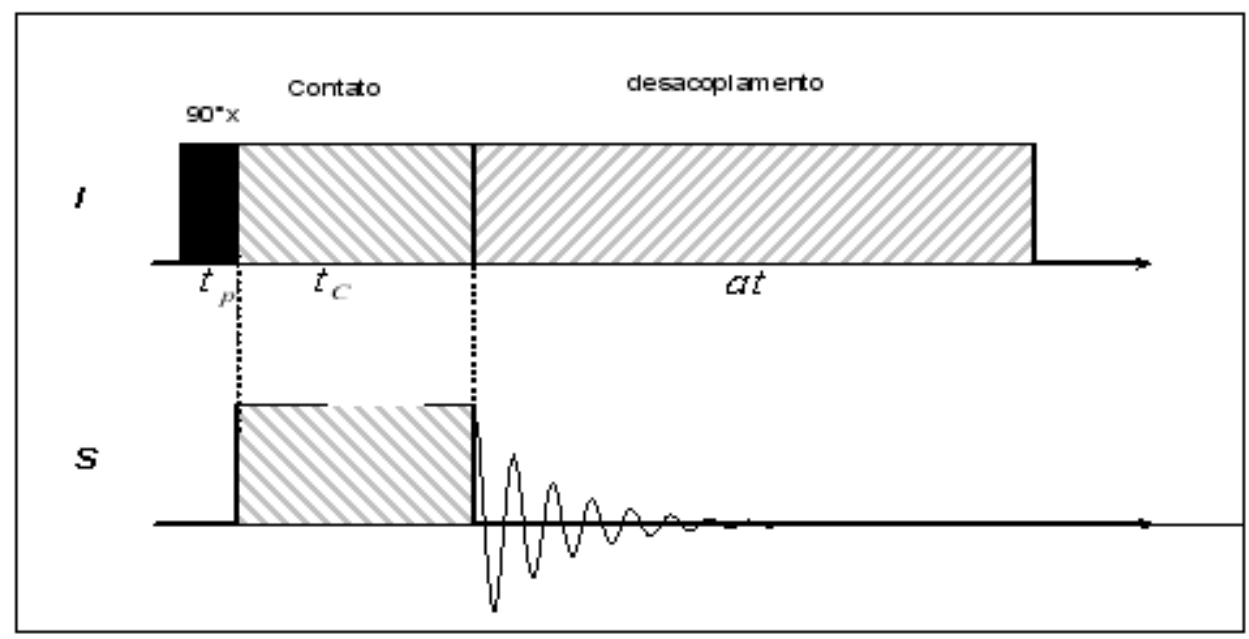

Figura 3.17- Sequência de pulsos do experimento de Polarização Cruzada entre as espécies I e $S$. tp é o tempo de aplicação do pulso, $t_{C}$ é o tempo de contato e até o tempo de aquisição do FID da espécie S.

Aplica-se um pulso de $90^{\circ}$ ao sistema de spins I, criando uma magnetização em -y no sistema rotante. Na ressonância, em -y, o pulso de contato do sistema I é então aplicado. O campo devido a esse pulso, ao longo de -y, é conhecido como campo de spin-lock, que é um campo aplicado na mesma direção de $\mathrm{M}$, fixando $\mathrm{M}$ na direção $-\mathrm{y}$, e é rotulado por $\mathrm{B}_{1}(\mathrm{I})$. Se não houver o spin-lock depois do pulso de $90^{\circ}$, haverá simplesmente o tempo de relaxação $\mathrm{T}_{2}$. $\mathrm{B}_{1}(\mathrm{I})$ é apenas o campo atuando nos spins da espécie I no eixo rotante da espécie I. Os estados de spin no 
eixo rotante durante o pulso de contato (ao longo de $-\mathrm{y}$ ) são $\alpha_{\mathrm{I}}$, que corresponde a componente paralela a $\mathrm{B}_{1}(\mathrm{I})$, e $\beta_{\mathrm{I}}$, que corresponde a componente antiparalela a $\mathrm{B}_{1}(\mathrm{I})$, como está ilustrado na figura 3.19. Simultaneamente os spins $\mathrm{S}$ ficam sujeitos a um pulso de contato, com campo de spin-lock $B_{1}(S)$ no eixo rotante com estados de spin $\alpha_{\mathrm{S}}$ e $\beta_{\mathrm{S}}$, correspondentes a componente paralela e antiparalela a $\mathrm{B}_{1}(\mathrm{~S})$, como mostra a figura 3.18. Os dois pulsos de contato têm que estar na condição de Hartmann-Hahn para que a transição ocorra.

Na condição de Hartmann-Hahn, uma transição no sistema I pode induzir uma transição em sentido oposto sobre o sistema S. Para atingir esta condição é necessário irradiar ambas as espécies simultaneamente com campos de radiofreqüência fazendo com que o conjunto de gaps de energia entre os estados de spin I e $\mathrm{S}$ sejam iguais. $\mathrm{O}$ acoplamento dipolar entre as duas espécies I e S, observando a equação 3.25, não afeta a energia do sistema de spin no eixo rotante, pois I e S são quantizados na direção perpendicular a z.

Para alcançar esta igualdade, a amplitude do pulso de uma das espécies é fixada e a amplitude do outro pulso é variada até que seja atingido um sinal parecido com o da primeira espécie. As amplitudes são ajustadas no sinal máximo e devem ser a condição de HartmannHahn. Quando a condição de Hartmann-Hahn é encontrada, os gaps de energia entre as espécies I e S dos sistemas de spins são iguais, então para uma transição exigida por uma espécie I, pode ser compensada por uma transição de energia liberada na espécie S, ilustrado na figura 3.18.

$$
\gamma_{I} B_{1}(I)=\gamma_{S} B_{1}(S) \text { (3.34) }
$$

Assim toda transição de um spin I é compensada por uma transição oposta do spin S, assim a rede de magnetização total do sistema é também preservada. Nessas circunstâncias, o acoplamento dipolar entre I e S pode permitir uma redistribuição de energia entre essas espécies enquanto mantêm a energia total do sistema constante.

Os experimentos de polarização cruzada podem também fornecer informações sobre o acoplamento dipolar e a relaxação da espécie I nos sistemas rotantes quando realizados com tempo de contato variável. 


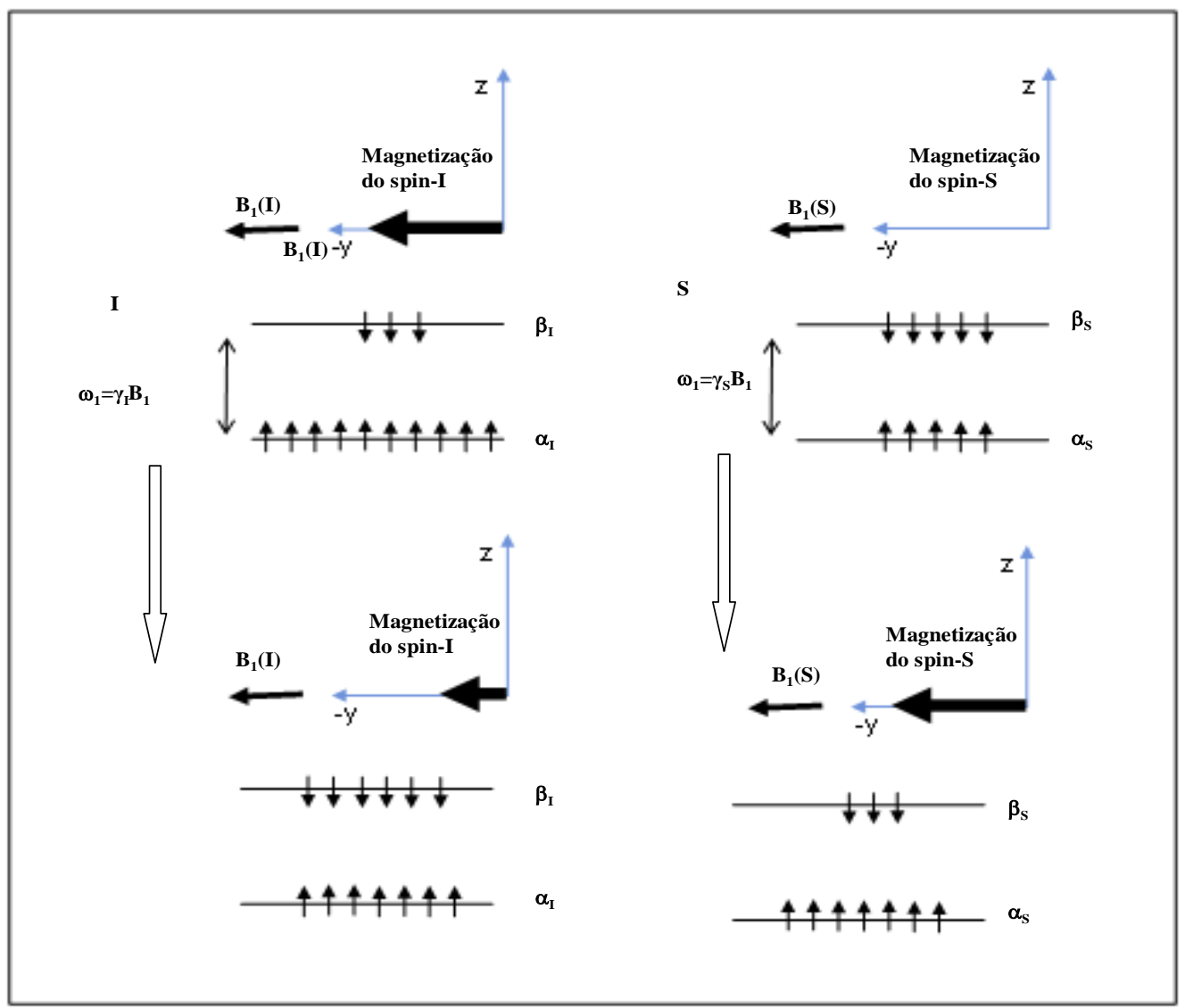

Figura 3.18- População de spins no experimento de Polarização Cruzada $\alpha$ e $\beta$ ão os estados de spin no sistema rotante relativo a cada espécie I e S.

É possível obter os valores dos tempos de contato do ajuste da curva experimental com relação à equação abaixo (34):

$$
M(t)=\frac{A}{a_{+}-a_{-}}\left(e^{-\frac{t}{T_{H S}} a_{-}}-e^{-\frac{t}{T_{H S}} a_{+}}\right)
$$

Onde

$$
a_{ \pm}=a_{0}\left(1 \pm \sqrt{1-2 \frac{T_{H S}}{a_{0} T_{1 \rho}^{(H)}}}\right)
$$

E $\alpha$ é a fração $\mathrm{N}_{\mathrm{S}} / \mathrm{N}_{\mathrm{I}}$ de núcleos interagentes da espécie observada (S) por núcleos da espécie polarizada diretamente (I) (34). Os experimentos de polarização cruzada com tempo de contato variável foram feitos entre as espécies ${ }^{1} \mathrm{H}$ e ${ }^{29} \mathrm{Si}$.

A figura 3.19 é um modelo da forma da curva de evolução da magnetização da espécie S com o tempo de contato. 


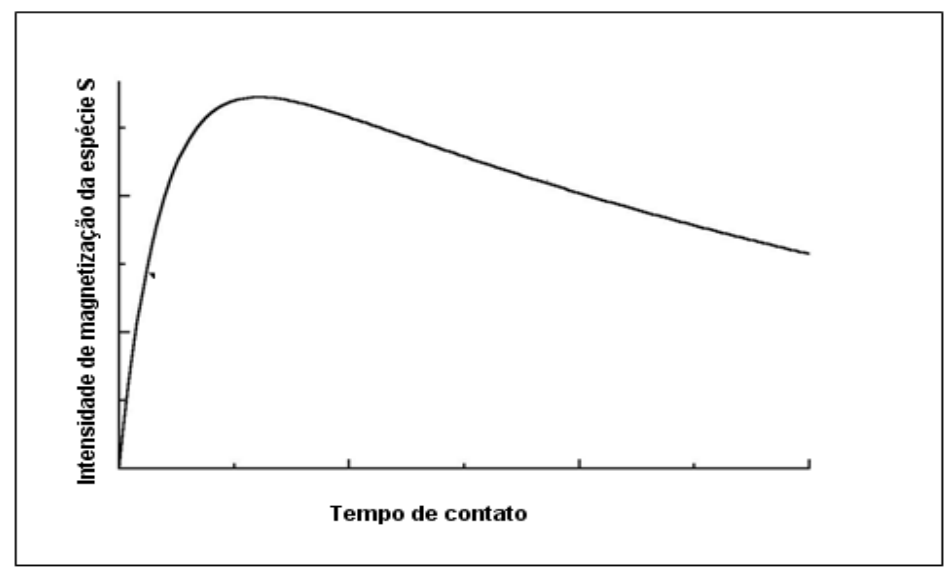

Figura 3.19- Intensidade da magnetização da espécie $\mathrm{S}$ em função do tempo de contato no experimento de polarização cruzada $\{I\}$-S.

Esta curva é caracterizada por dois parâmetros:

(i) $\mathrm{T}_{\text {IS }}$, o tempo característico de contato dipolar entre I e $\mathrm{S}$, que governa o comportamento inicial crescente da magnetização da espécie I.

(ii) $T_{1 \rho}$, tempo de relaxação spin-rede no sistema rotante da espécie I que é relacionado à transferência de energia desde o sistema de spins I para a rede, que governa o decréscimo de intensidade de polarização cruzada para tempos de contatos longos.

O tempo $\mathrm{T}_{\mathrm{IS}}$ é diretamente proporcional à intensidade da interação dipolar em média temporal. Assim resulta proporcional a $1 / r_{I S}^{3}$, sendo $\mathrm{r}_{\text {IS }}$ a distância internuclear e ao número de núcleos I acoplados. O tempo de relaxação $\mathrm{T}_{1}{ }^{\rho}$ esta relacionado de maneira inversa à flutuação do acoplamento com a rede, na escala de tempos de $1 / \omega_{1}(30,34)$.

\subsubsection{Triplo Quantum- MAS (3Q-MAS)}

Em espécies com spin maior do que 1/2 e acoplamento quadrupolar elétrico intenso, como ${ }^{23} \mathrm{Na}$, as vezes se faz necessário utilizar a técnica de Triple Quantum MAS (3Q-MAS). Essa técnica permite eliminar das linhas de ressonância os alargamentos anisotrópicos devido aos 
termos de segunda ordem da interação de quadrupolo elétrica que a técnica de MAS convencional não consegue suprimir (34).

A diferença de MAS, baseada numa rotação física da amostra, no experimento de Triplo Quantum MAS (3Q-MAS) a eliminação da anisotropia é obtida através de uma manipulação no espaço de spin (35).

A seqüência de pulsos básica para MQ-MAS é mostrada na figura 3.21. O primeiro pulso serve para excitar coerências de spin simétricas $\left(\mathrm{m}_{\mathrm{I}},-\mathrm{m}_{\mathrm{I}}\right)$ de ordem $\left|\mathrm{p}=2 \mathrm{~m}_{\mathrm{I}}\right|>1$ (32), que evoluem durante $o$ intervalo $t_{1}$ em presença das interações quadrupolares e de deslocamento químico. Neste trabalho foi aplicada a técnica para analisar a evolução de coerências de ordem p=3. O segundo pulso converte estas coerências $\mathrm{p}=3$ em coerências de um quantum (-1), que são detectadas durante o período $t_{2}$. Existem valores de largura destes pulsos que optimizam a excitação e reconversão das coerências em função do spin I (36). A evolução das coerências de 3Q durante $t_{1}$ está codificada na fase inicial $\phi_{1}$ das coerências de ordem 1 no começo da evolução após o segundo pulso. É possível demonstrar que em presença de MAS a fase $\phi_{1}$ acumulada ao tempo $t_{1}$ por uma coerência simétrica de ordem 3 para um cristalito de orientação $(\theta, \varphi)$ é (35):

$$
\phi_{1}=\omega_{I S O}^{C S} 2 m t_{1}+\omega_{I S O}^{Q} C_{0}^{(I)}(m) t_{1}+\omega_{4}^{Q}(\theta, \varphi) C_{4}^{(I)}(m) P_{4}\left(\cos \beta_{M}\right) t_{1}
$$

Onde $\omega_{\text {ISO }}^{\text {CS }}$ é o deslocamento químico isotrópico, $\omega_{\text {ISO }}^{\mathrm{Q}}$ é o deslocamento quadrupolar isotrópico

$$
\omega_{I S O}^{Q}=-\frac{C_{q}^{2}\left(3+\eta_{q}{ }^{2}\right)}{10 \omega_{0}[2 I(2 I-1)]^{2}}
$$

$\mathrm{P}_{4}\left(\cos \beta_{\mathrm{M}}\right)$ é o polinômio de Legendre de ordem 4 e os $\mathrm{C}_{\mathrm{i}}^{(\mathrm{I})}(\mathrm{m})$ são coeficientes dependentes do spin I e da ordem da transição $m_{I}$ e $\beta_{m}$ é o ângulo mágico. A função angular $\omega_{4}{ }^{\mathrm{Q}}(\theta, \varphi)$ representa a componente anisotrópica de ordem i da interação quadrupolar. É possível observar em 3.36 que a coerência evolui devido a três termos fisicamente diferentes: o deslocamento químico isotrópico, a interação quadrupolar isotrópica e a componente quadrupolar anisotrópica. Este último termo está modulado pelo fator $\mathrm{P}_{4}$, que não é nulo para o angul] mo pois qual como foi relatado na 
seção 3.3.1, o valor $\beta_{\mathrm{m}}$ foi escolhido para anular o polinômio $\mathrm{P}_{2}$ e eliminar assim a anisotropia do desvio químico. Este é o motivo pelo qual a técnica de MAS não remove completamente a anisotropia do acoplamento de quadrupolo elétrico.

A fase acumulada até um tempo $t_{2}$ após o segundo pulso, que converte a coerência $-\mathrm{m}_{1} \rightarrow$ $\mathrm{m}_{1}$ na coerência observável $-1 / 2 \rightarrow 1 / 2$, pode ser avaliada de forma análoga a $\phi_{1}$ resultando:

$$
\phi_{2}=\omega_{I S O}^{C S} t_{2}+\omega_{I S O}^{Q} C_{0}^{(I)}(1 / 2) t_{2}+\omega_{4}^{Q}(\theta, \varphi) C_{4}^{(I)}(1 / 2) P_{4}\left(\cos \beta_{M}\right) t_{2}
$$

É interessante observar que dado um valor de $\mathrm{t}_{1}$, é possível encontrar um instante $\mathrm{t}_{2}$ (e um sinal de $\phi_{1}$ ) adequado para cancelar mutuamente os termos anisotrópicos em 3.36 e 3.37. Portanto, no instante $t_{2}^{(E)}=\left|C_{4}^{(I)}(m)\right| / C_{4}^{(I)}(1 / 2) t_{1}$ a evolução do sistema está determinada somente pelos termos isotrópicos:

$$
\pm \phi_{1}+\phi_{2}= \pm\left(\omega_{I S O}^{C S} 2 m+\omega_{I S O}^{Q} C_{0}^{(I)}(m)\right) t_{1}+\left(\omega_{I S O}^{C S}+\omega_{I S O}^{Q} C_{0}^{(I)}(1 / 2)\right) t_{2}
$$

(a)

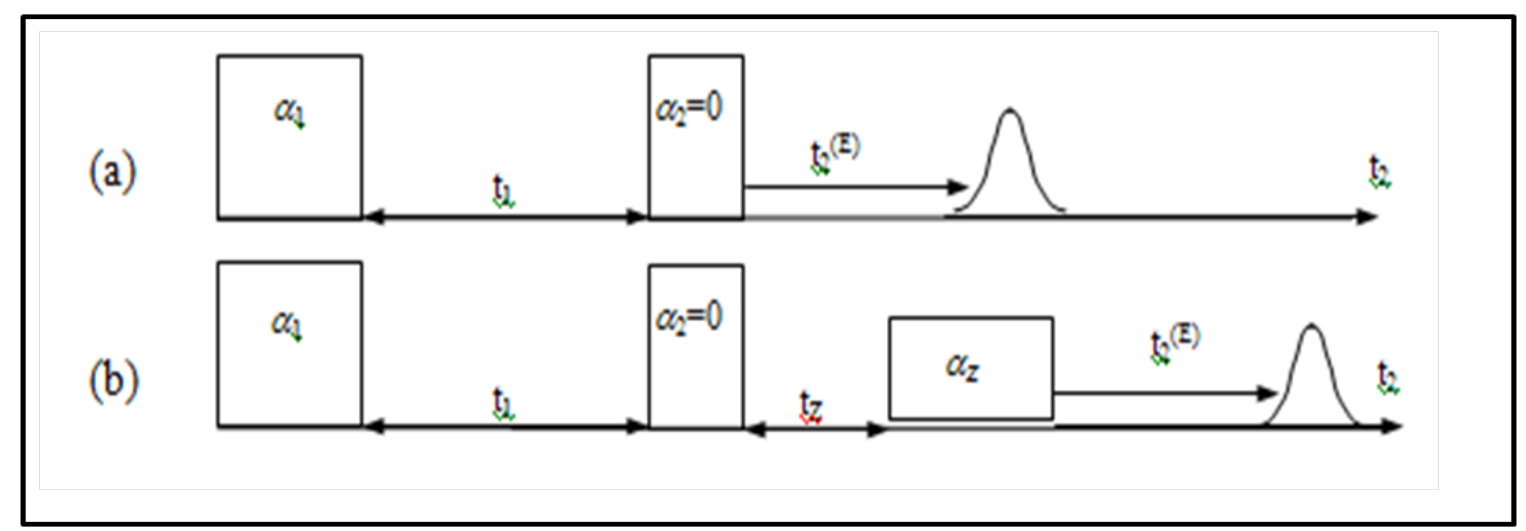

Figura 3.20- (a) Seqüência básica de 3Q-MAS excitação-reconversão $(0, \pm p,-1)$. $t_{2}$ : intervalo de aquisição, $t_{1}$ intervalo de evolução das coerências $|\mathrm{p}|>1 . \mathrm{t}_{2}{ }^{(\mathrm{E})}$ : tempo ao eco de spin isotrópico. (b) 3Q-MAS com filtro Z, para simetrização da transferência de coerência: $(0, \pm p, 0,-1)$.

Fisicamente, isto significa que durante o segundo período de evolução, a contribuição quadrupolar anisotrópica faz evoluir o sistema de maneira inversa a respeito do primeiro período. No instante $\mathrm{t}_{2}{ }^{(\mathrm{E})}$, o efeito da anisotropia sobre a fase durante a primeira etapa é cancelado. Isto 
significa que para uma amostra policristalina existirá um sinal de eco de spin isotrópico para $t_{2}=$ $\mathrm{t}_{2}^{(\mathrm{E})}$.

O experimento é realizado na forma bidimensional: o sinal é adquirido durante o intervalo de tempo $t_{2}$ após o segundo pulso variando sistematicamente o tempo $t_{1}$ de evolução das coerências $p= \pm 3$. A transformada de Fourier 2-D deste conjunto de FID permite obter um espectro de correlação com dimensões anisotrópica (dimensão MAS ou direta) $v_{2}$ e dimensão isotrópica (indireta) $v_{1}$. Assim, as projeções deste espectro de 2D são espectros de linhas estreitas em $v_{1}$, tantas como valores diferentes de parâmetros isotrópicos existam no sistema, e linhas alargadas anisotropicamente em $v_{2}$. Na figura 3.20b é mostrada uma variante da seqüência de pulsos onde os trajetos das coerências $\pm p$ até o terceiro pulso são simétricos $(0, \pm p$, 0), incorporando um pulso adicional seletivo da transição central para transferir coerência $0 \rightarrow 1$ (37). Esta seqüência é a mais utilizada, pois elimina de maneira eficiente artefatos no espectro de absorção.

Para obter o conjunto de parâmetros de acoplamento $\mathrm{C}_{\mathrm{q}}, \eta_{\mathrm{q}}$ e $\delta^{\mathrm{CS}}$ ISO para cada sítio, é preciso medir as posições das linhas isotrópicas observadas na projeção $v_{1}$ e os valores dos centros gravidade $v_{\mathrm{CG}}$ dos picos correlacionados na dimensão $v_{2}$. Neste trabalho, as medidas de 3Q-MAS foram utilizadas no núcleo de ${ }^{23} \mathrm{Na}$ ( de gravidade da linha central em presença desvio químico isotrópico tem-se $(35,37)$ :

$$
\begin{array}{r}
v_{C G}=v_{0}+v_{I S O}-v_{Q} \\
v_{Q}=\frac{\left[C_{q}\left(1+\frac{\eta_{q}^{2}}{3}\right)\right]^{2}}{40 v_{0}} \equiv \frac{P_{q}^{2}}{40 v_{0}}
\end{array}
$$

E a relação entre o desvio isotrópico $\delta_{\text {ISO }}$ e o desvio $\delta_{1}$ da linha experimentalmente medida na dimensão indireta $v_{1}$ é:

$$
\delta_{I S O}=\frac{8}{27}\left(\delta_{1}+\frac{5}{4} \delta_{C G}\right)
$$


Colocando nestas expressões os valores de $v_{\mathrm{CG}}\left(\right.$ ou $\left.\delta_{\mathrm{CG}}\right)$ e $\delta_{1}$ medidos no espectro 3Q-MAS é possível obter $\mathrm{P}_{\mathrm{q}}$ e $\delta_{\text {ISO }}$.

\subsubsection{Experimentos de Correlação Heteronuclear (HETCOR)}

Neste experimento de dupla ressonância é utilizado o acoplamento dipolar heteronuclear para estabelecer correlações entre as ressonâncias das duas espécies I e S, no caso deste trabalho elas correspondem à ${ }^{1} \mathrm{H}$ e ${ }^{29} \mathrm{Si}$, respectivamente. O princípio do experimento é o mesmo do caso de polarização cruzada desde a espécie mais abundante $\left({ }^{1} \mathrm{H}\right)$. A figura 3.21 mostra a seqüência de pulsos básica do experimento, realizado de maneira bidimensional.

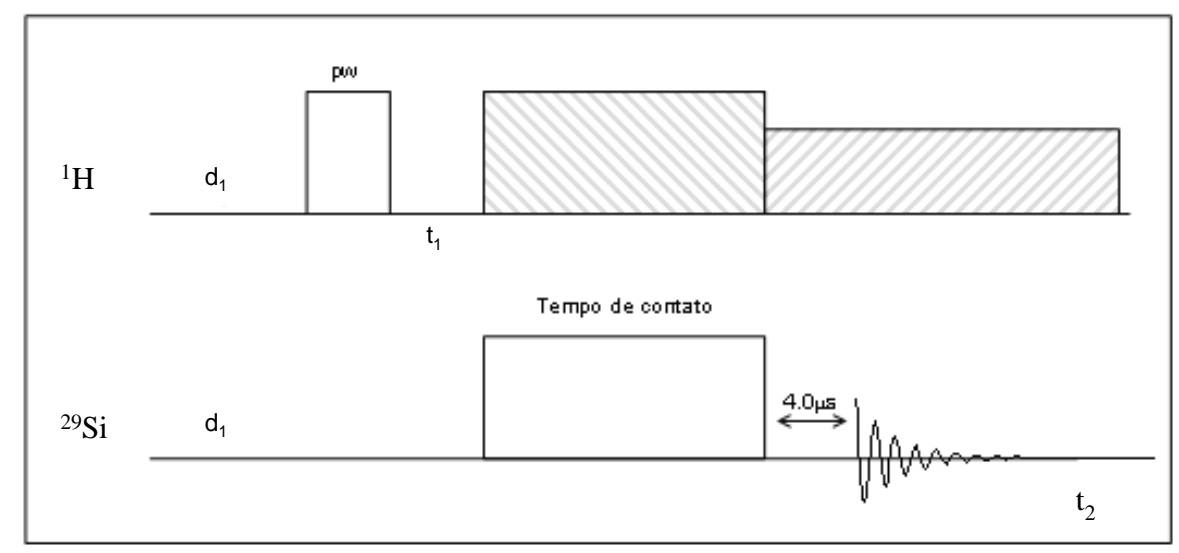

Figura 3.21- Seqüência de pulsos no experimento de HETCOR $\left\{{ }^{1} \mathrm{H}\right\}-{ }^{29} \mathrm{Si}$, $\mathrm{d}_{1}$ : tempo de espera. pw: duração do pulso de $90^{\circ}$ de ${ }^{1} \mathrm{H}$. $\mathrm{X}={ }^{13} \mathrm{C}$ ou ${ }^{29} \mathrm{Si}$. Tempo de contato: tempo em que as duas espécies são colocadas em contato da condição de Hartmann-Hahn.

Um pulso de $90^{\circ}$ é aplicado sobre o sistema de ${ }^{1} \mathrm{H}$, gerando assim magnetização transversal. Durante o intervalo $t_{1}$, a dimensão indireta, o sistema de ${ }^{1} \mathrm{H}$ evolui livremente, sob o efeito das interações de desvio químico e dipolar até a aplicação dos pulsos de contato na condição de Hartmann-Hahn. Após o contato, a evolução da magnetização de ${ }^{29}$ Si é registrada durante o intervalo $t_{2}$, a dimensão direta, sob MAS e desacoplamento heteronuclear (32). 
A transformada de Fourier em $t_{1}$ e $t_{2}$ fornece o espectro bidimensional de ${ }^{1} \mathrm{H}$ e ${ }^{29} \mathrm{Si}$ ao longo de $\omega_{1}$ e $\omega_{2}$ respectivamente. Os picos de correlação entre as ressonâncias indicam a existência de transferência de polarização desde cada ${ }^{1} \mathrm{H}$. Para certa freqüência $\omega_{2}$ correspondente a um sítio de ${ }^{29} \mathrm{Si}$, as seções ao long® de ${ }_{1}$ fornecem espectros de ${ }^{1} \mathrm{H}$ alargados fundamentalmente pela interação dipolar homonuclear, que podem auxiliar na identificação do ambiente de ${ }^{1} \mathrm{H}$ polarizado esse tipo de ${ }^{29} \mathrm{Si}$. A seletividade do experimento pode ser incrementada, de maneira de obter picos de correlação para pares ${ }^{1} \mathrm{H}^{29}{ }^{29} \mathrm{Si}$ próximos, diminuindo o tempo de contato $\tau$. Este experimento é de interesse para identificar a presença de ligações Si$\mathrm{OH}, \mathrm{Si}-\mathrm{CH}_{3}$ ou Si-H dentro do gel.

\subsection{Grupos silicatos}

A maioria dos estudos de ${ }^{29}$ Si em RMN são feitos analisando a distribuição de silicatos tetraédricos $\left(\mathrm{SiO}_{4}\right)$. O desvio químico de grupo silicato está determinado pelo número de pontes Si-O-Si e Si-O-Al, além de perturbações mais fracas produzidas por cátions coordenando os restantes $\mathrm{O}$. As espécies de tetraedros são identificadas com a nomenclatura $\mathrm{Q}_{\mathrm{m}}^{\mathrm{n}} \mathrm{Al}$, onde $\mathrm{n}$ é o numero das oxigênios em pontes $\mathrm{Si}-\mathrm{O}-\mathrm{Si}(\mathrm{n}=0,1,2,3$ ou 4) e m o número de oxigênios em pontes Si-O-Al, como ilustrado na figura 3.22. Cada sítio $\mathrm{Q}^{\mathrm{n}}$ apresenta uma distribuição de desvios químicos isotrópicos causados pela desordem estrutural de cada um dos ambientes de ${ }^{29} \mathrm{Si}$, o que origina formas de linha de tipo gaussianas. Cada ponte Si-O-Si produz um deslocamento do desvio isotrópico de aproximadamente -10ppm. Nos grupos $\mathrm{Q}^{4}$, que formam a estrutura da sílica, o desvio químico apresenta valores em torno de -110ppm (38). As faixas de desvios químicos típicas para sítios $\mathrm{Q}^{\mathrm{n}}$ são mostrados na figura 3.23 (38). Quando existem pontes Si-O-Al, cada uma contribui com um deslocamento da ressonância de ${ }^{29} \mathrm{Si}$ em aproximadamente $+5 \mathrm{ppm}$ (38).

O número médio de oxigênios que não fazem ligação com silício (oxigenios-nãoponte, ou NBO) é calculado através da média entre as áreas $\left(\mathrm{A}_{\mathrm{Q}}{ }^{\mathrm{n}}\right)$ das curvas gaussianas correspondentes a cada espécie $\mathrm{Q}^{\mathrm{n}}$ de acordo com a equação 


$$
\overline{N B O}=\frac{\sum_{n=0}^{4}\left(A_{Q^{n}}(4-n)\right)}{100}
$$

onde as áreas estão expressadas em percentuais da área total espectral.

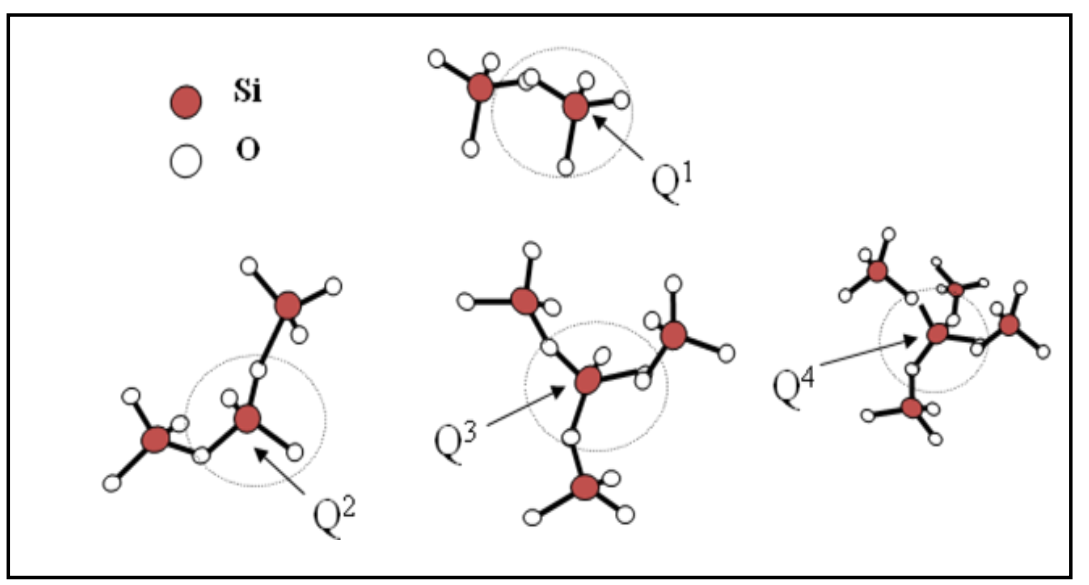

Figura 3.22- Grupos silicatos $Q^{n}$ (n=0,1,2,3,4). Classificação quanto a quantidade de ligacões entre O-Si-O.

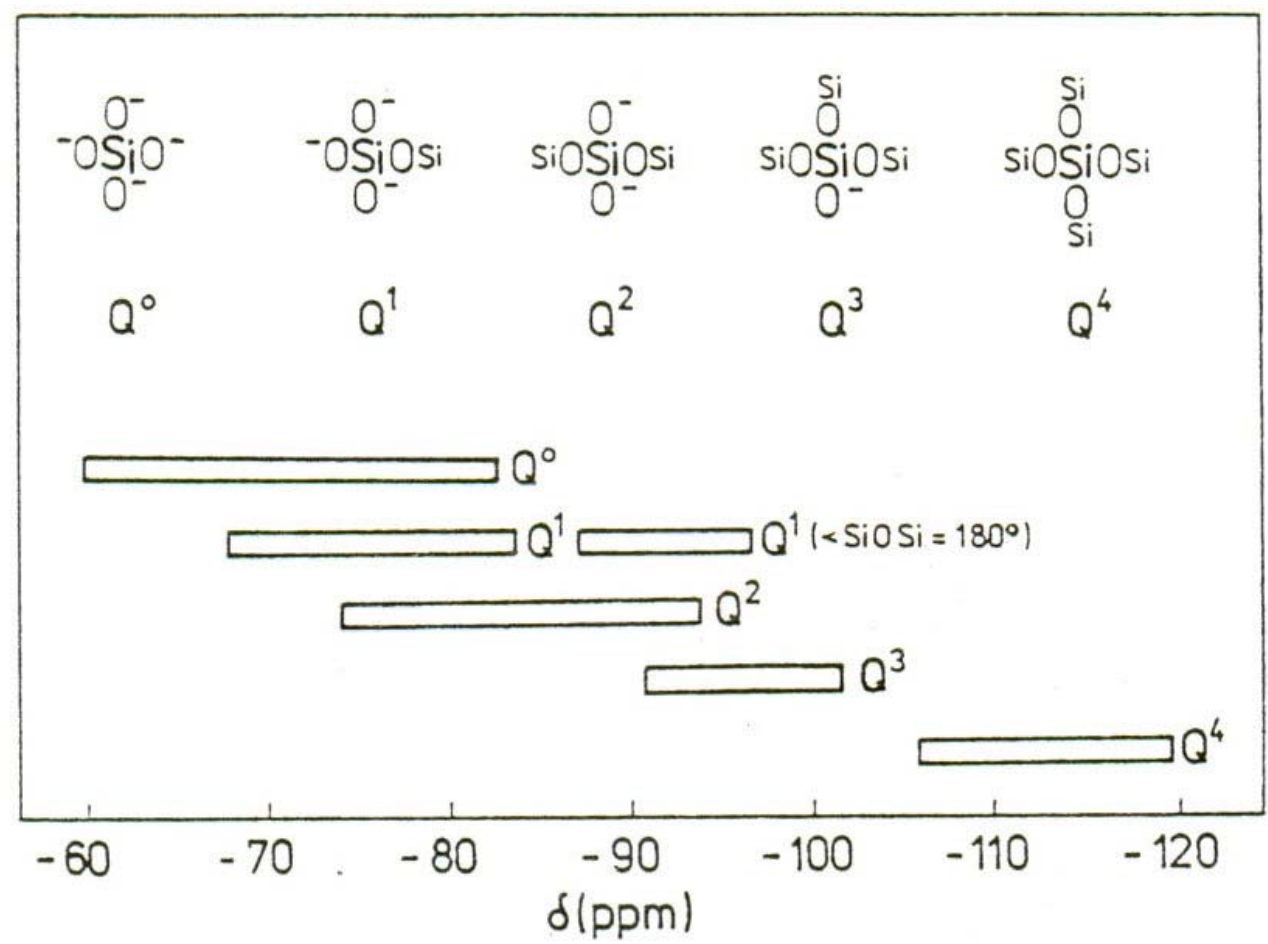

Figura 3.23- Intervalo de desvios químicos das unidades de silicatos $\mathrm{Q}^{\mathrm{n}}$ (38). 
Se os sítios de silicatos possuem ligações Si-O-C, os desvios químicos tendem a ficar mais negativos que os desvios químicos das ligações $\mathrm{Q}^{\mathrm{n}}$. Quando os grupos silicatos possuem uma ligação $\mathrm{Si}$ com $\mathrm{CH}_{3}$, os desvios químicos ficam por volta de -57ppm, esses silicatos são classificados como T. Se além da ligação com $\mathrm{CH}_{3}$ há uma ligação com um grupo $\mathrm{OH}$, os desvios químicos ficam por volta de -67ppm e estes silicatos são classificados como D. No caso de três ligações com $\mathrm{CH}_{3}$ os desvios químicos são por volta de -48ppm e trata-se dos silicatos classificados como M. Os três casos, mostrados na figura 3.24, estão presentes nos espectros das amostras contendo MTMS mostrados na seção 6.2.1.1.1.

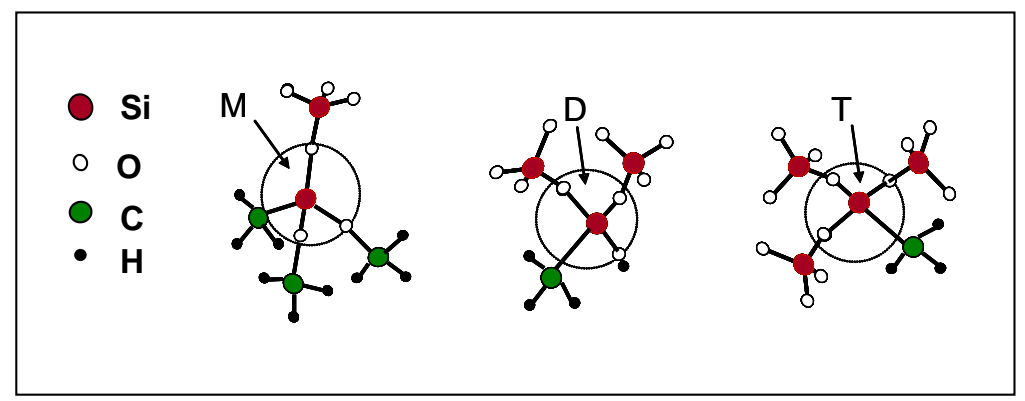

Figura 3.24- Grupos silicatos $\mathrm{D}^{\mathrm{OH}}$ (ligações Si-O, $\mathrm{CH}_{3}$ e $\mathrm{OH}$ ) e T ( ligações Si-O e $\mathrm{CH}_{3}$ ). 


\section{Capítulo 4}

\section{Montagem Experimental}

\subsection{Espectrômetro de RMN}

As medidas de RMN foram realizadas no Grupo de Ressonância Magnética do Instituto de Física de São Carlos (IFSC-USP) utilizando um espectrômetro Varian Unity Inova 400 com campo magnético estático 9,4 T. A figura 4.1 apresenta um diagrama de blocos desse espectrômetro.

O campo magnético externo é produzido por um magneto supercondutor Oxford de intensidade de 9,4 T de 89mm de diâmetro. A geração do sinal de rf é feita por um sintetizador de onda contínua PTS modelo D500 que opera em duas bandas de freqüência: a de alta freqüência entre $370 \mathrm{MHz}$ e 500MHz e a banda de baixa freqüência, utilizada para a excitação de núcleos entre $1 \mathrm{MHz}$ e $220 \mathrm{MHz}$. A potência do sinal sintetizado é da ordem de mW.

O sinal de rf gerado pelo sintetizador segue para um divisor de potência que divide o sinal em dois sem ganho de potência. No transmissor 1 (desacoplamento) o sinal de alta freqüência é modulado na forma de pulso retangular. Parte do sinal de baixa freqüência é recebida no transmissor 2 (observação) que irradia o núcleo de interesse transformando em um pulso de duração pw. Os sinais que saem dos transmissores 1 e 2 vão para os amplificadores de potência, com valores máximos de 100W para o canal de desacoplamento e 300W para o canal de observação.

Os pulsos passam por um filtro de diodos cruzados para cortar ruídos de pequena amplitude, seguindo então para a sonda onde excitam a amostra. O sinal de FID retorna por um cabo de $\lambda / 4(40,41)$. A finalidade deste cabé a proteção do pré -amplificador contra sinais da aplicação das altas potencias de irradiação (41). Após a passagem pelo pré-amplificador o sinal 
de FID é encaminhado ao sistema de detecção em fase de quadratura, posteriormente sendo conduzidos ate filtros passa baixa (P.B.), que permitirão somente a passagem dos sinais de baixa freqüência da ordem de KHz. Estes sinais são conduzidos para conversores analógicos digitais (A/D) com máxima freqüência de digitalização de $1 \mathrm{MHz}$ e finalmente para um computador onde são medidos e processados.

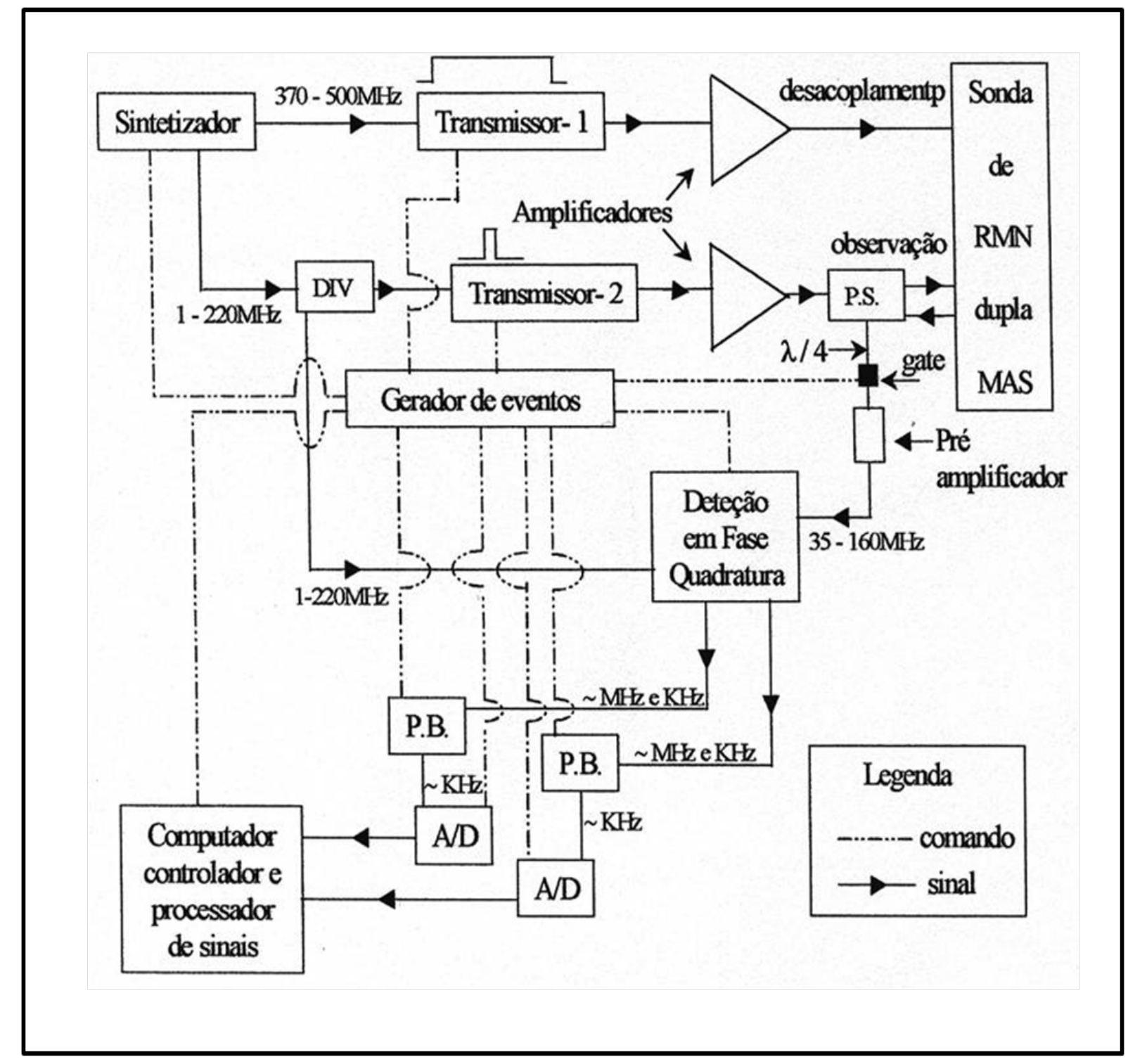

Figura 4.1- Diagrama de blocos do espectrômetro de RMN de dupla ressonância Varian UNITY Inova. 


\subsubsection{Sondas de RMN}

A sonda contém a bobina de rf e o circuito ressonante adequado para a transmissão de potência, e recepção do sinal de FID do sistema de spins excitado. As sondas de dupla ressonância utilizadas para as medidas de RMN de alta resolução foram a sonda de $7 \mathrm{~mm}$ CP/MAS da Varian, que possibilita irradiações em freqüências entre $35 \mathrm{MHz}$ e $160 \mathrm{MHz}$ e a sonda de 5mm CP/MAS TLT da Jakobsen, que possibilita irradiações em freqüências entre $49 \mathrm{MHz}$ e $162 \mathrm{MHz}$. Ambas permitem rotação da amostra até $7 \mathrm{KHz}$ na $7 \mathrm{~mm}$ e $12 \mathrm{KHz}$ na de

$5 \mathrm{~mm}$. Nesta última sonda foram medidos espectros de ${ }^{29} \mathrm{Si}$ para algumas amostras, nesses casos a resolução do espectro foi baixa comparada a resolução do espectro da sonda de $7 \mathrm{~mm}$, devido ao menor volume do rotor.

Nos experimentos de baixa resolução de ${ }^{7} \mathrm{Li}$ e ${ }^{23} \mathrm{Na}$, em condições estáticas, foi utilizada uma sonda Doty Scientific com bobina de $7 \mathrm{~mm}$ que possibilita irradiação em freqüências entre $35 \mathrm{MHz}$ e $160 \mathrm{MHz}$.

Os rotores com diâmetro de $7 \mathrm{~mm}$ eram de nitreto de silício e apresentavam sinais de fundo em RMN do núcleo de ${ }^{29} \mathrm{Si}$ em -48ppm e foram devidamente extraídos dos espectros de ${ }^{29} \mathrm{Si}$ das amostras, e os rotores com diâmetro de $5 \mathrm{~mm}$ eram de zircônia.

\subsubsection{Parâmetros utilizados nos experimentos de RMN}

Nesta seção serão descritos os parâmetros das sequências de pulsos utilizadas em cada experimento. Os valores de tempo de espera $d_{1}$ apropriados para quantificação dos espectros foram estimados através da análise da evolução da intensidade dos sinais em função de $d_{1}$. Os valores de pw para a condição de $\pi$ ou $\pi / 2$ foram ajustados experimentalmente realizando varreduras da duração do pulso em todas as amostras. O tempo morto nos experimentos foi estimado entre 6 e $10 \mu \mathrm{s}$. 
Em todas as amostras foram realizados experimentos de polarização direta de ${ }^{29} \mathrm{Si}$ com a sequência de um pulso simples de excitação, em condições de MAS, ilustrada na figura 4.2.

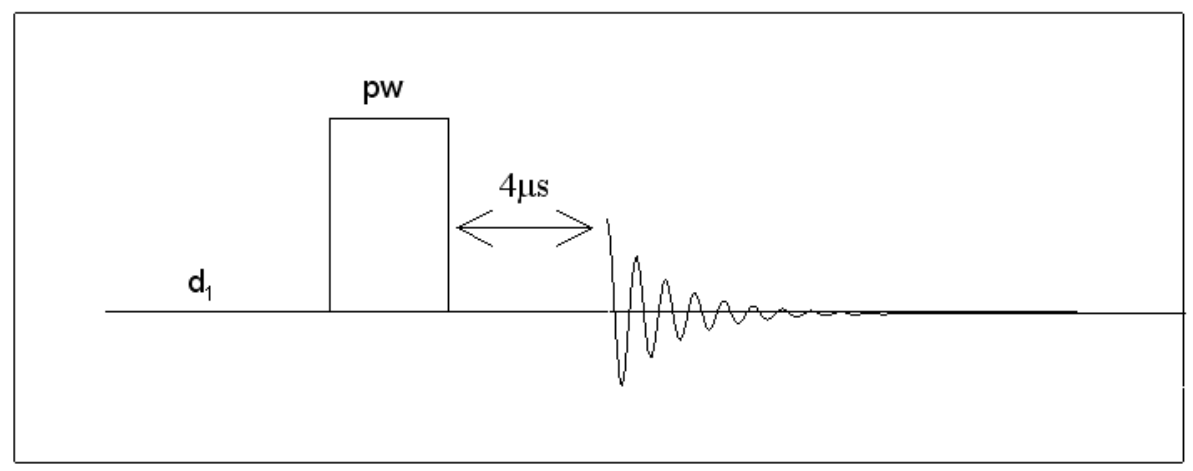

Figura 4.2- Esquema da sequência de pulsos simples para o experimento de polarização direta. $d_{1}$ : tempo e espera. pw: duração do pulso de rf correspondente ao pulso de $90^{\circ}$ para espécies com I=1/2.

As amostras de gel original, gel $+\mathrm{LiNO}_{3}-\mathrm{NaOH}$, gel + MTMS, gel $+\mathrm{KOH}+\mathrm{MTMS}$ e gel $+\mathrm{NaOH}+\mathrm{MTMS}$ foram medidas com valores de $\mathrm{d}_{1}$ igual a 3600s, 100s, 350s, 200s e 250s respectivamente. Os valores de pulso $\pi / 2$ para os experimentos nessas amostras foram entre 3,5 $\mu$ s e 4,0 4 s e todas as medidas possuem por volta de 400 médias para a aquisição do espectro. Os experimentos nas amostras de rochas quartzito, quartzito $+\mathrm{KOH}$, quartzito $+\mathrm{LiNO}_{3}-\mathrm{KOH}$, basalto, basalto $+\mathrm{KOH}$, basalto $+\mathrm{LiNO}_{3}-\mathrm{KOH}$, granito, granito $+\mathrm{KOH}$ e granito $+\mathrm{LiNO}_{3} \mathrm{KOH}$ foram feitos com d1 de 100s, pw de 4,0 $\mu$ s e o número de transientes dependente do tipo de sonda utilizada, sendo por volta de 700 para os espectros feitos na sonda de $7 \mathrm{~mm}$ e por volta de 2000 para os espectros feitos na sonda de $5 \mathrm{~mm}$. Foram também realizados experimentos de polarização direta do ${ }^{13} \mathrm{C}$ nas amostras de gel + MTMS e gel + KOH + MTMS com d1 de 20,0s, número de transientes de 1500 e pw de 3,5 $\mu$ s. Na amostra de gel $+\mathrm{LiNO}_{3}-\mathrm{NaOH}$ foram realizados experimentos de polarização direta de ${ }^{7} \mathrm{Li}$ com $\mathrm{d}_{1}$ de 5,0s, número de transientes de 900 e pw de $0,5 \mu$ s e de ${ }^{23} \mathrm{Na}$ com $\mathrm{d}_{1}$ de 5,0s, número de transientes de 2000 e pw de 1,0 $\mu$ s.

Foram realizados experimentos de Polarização Cruzada $\left\{{ }^{1} \mathrm{H}\right\}-{ }^{29} \mathrm{Si}$, com a sequência mostrada na figura 4.3. Os tempos de contato foram de $2,0 \mathrm{~ms}$ com $\mathrm{d}_{1}$ de $5 \mathrm{~s}$, pw de ${ }^{1} \mathrm{H}$ entre $3,5 \mu \mathrm{s}$ e 4,0 4 s e número de médias em torno de 1500. Nos experimentos de polarização cruzada com tempo de contato variável foram utilizados $\mathrm{d}_{1}$ de $15 \mathrm{~s}$, número de médias por volta de 1500 e tempos de contatos entre $0,4 \mathrm{~ms}$ até $30,0 \mathrm{~ms}$. 


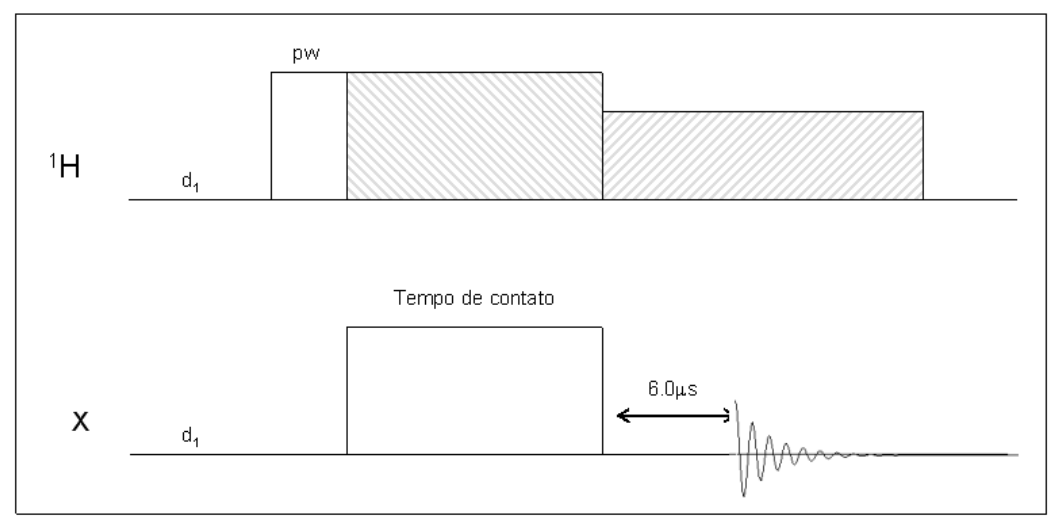

Figura 4.3- Esquema do experimento de polarização cruzada $\left\{{ }^{1} \mathrm{H}\right\}$-X. $\mathrm{d}_{1}$ : tempo de espera. pw: duração do pulso de $90^{\circ}$ de ${ }^{1} \mathrm{H}$. $\mathrm{X}={ }^{13} \mathrm{C}$ ou ${ }^{29} \mathrm{Si}$. Tempo de contato: tempo em que as duas espécies são colocadas em contato da condição de Hartmann-Hahn.

Foram realizados experimentos de polarização cruzada $\left\{{ }^{1} \mathrm{H}\right\}-{ }^{13} \mathrm{C}$ com $\mathrm{d}_{1}$ da ordem de $2 \mathrm{~s}$, número de transientes em torno de 3000 e tempo de contato de 2,0ms.

A condição de Hartmann-Hahn foi ajustada observando o máximo sinal de ${ }^{29}$ Si sobre o espectro em função da potência aplicada sobre esta espécie. Fixado este valor o mesmo é feito para a potência do ${ }^{1} \mathrm{H}$.

$\mathrm{Na}$ amostra de gel $+\mathrm{LiNO}_{3}-\mathrm{NaOH}$ foi realizado o experimento de 3Q-MAS, com d1 de

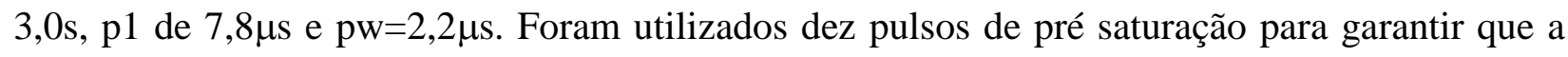
amostra estará sempre relaxada antes da aplicação do próximo pulso.

Nas amostras de gel original, gel $+\mathrm{LiNO}_{3}-\mathrm{NaOH}$ e gel + MTMS foram realizados experimentos de HETCOR $\left\{{ }^{1} \mathrm{H}\right\}{ }^{29} \mathrm{Si}$, como mostrado na figura 3.21 , com valores de d1 da ordem de 1 s com pulsos de $90^{\circ}$ de ${ }^{1} \mathrm{H}$ entre 3,5 $\mu$ s e 5,0 $\mu$ s e tempos de contato da ordem de 2,0ms.

\subsubsection{Substâncias de referência das linhas dos espectros.}

- Referência ${ }^{29}$ Si-RMN: Foi utilizado como referência o espectro de polarização direta de uma amostra de caulim com linha central referenciada em $-91.5 p p m$ com relação ao tetrametilsilano (TMS). 
- Referência ${ }^{13} \mathrm{C}$-RMN: Foi utilizado como referência o espectro de polarização direta de uma amostra de adamantano $\left(\mathrm{C}_{10} \mathrm{H}_{16}\right)$ com linha central referenciada em 38,6ppm para a ressonância do $\mathrm{CH}$, com relação ao TMS.

- Referência ${ }^{1}$ H-RMN: Foi utilizado como referência o espectro de polarização direta de uma amostra de etanol $\left(\mathrm{C}_{2} \mathrm{H}_{5} \mathrm{OH}\right)$ com a linha mais intensa referenciada 1.1ppm.

- Referência ${ }^{23} \mathrm{Na}-\mathrm{RMN}$ : Foi utilizado como referência o espectro de polarização direta de uma solução de $1 \mathrm{M}$ de $\mathrm{NaCl}$ com linha central referenciada em 0ppm.

- Referência ${ }^{7} \mathrm{Li}-\mathrm{RMN}$ : Foi utilizado como referência o espectro de polarização direta de uma solução de $1 \mathrm{M}$ de $\mathrm{LiCl}$ com linha central referenciada em 0ppm. 


\section{Capítulo 5}

\section{Amostras e Tratamentos}

\subsection{Amostras de gel da RAS}

As amostras de concreto atacado pela RAS extraídas de estruturas consistem de uma mistura complexa em escala microscópica de agregado mineral, silicato de cálcio hidratado e o gel resultante da RAS. As amostras de gel utilizadas neste trabalho extraídas da barragem de Furnas (Minas Gerais) foram blocos de gel quase em estado puro, com dimensões características da ordem de centímetros, provenientes das paredes das galerias de drenagem. Os géis exsudados, mostrados na figura 2.2, foram coletados manualmente na superfície da barragem utilizando-se uma pequena talhadeira e fazendo-se golpes delicados através de um martelo na sua base de forma que o gel se desprendesse da superfície do concreto por inteiro, sem se quebrar.

As amostras de gel utilizadas neste trabalho são particularmente interessantes por terem sido exsudadas naturalmente das paredes da galeria das barragens sendo praticamente livres dos agregados do concreto. A aparência da amostra é translúcida e foram classificadas qualitativamente em quatro grupos de acordo com sua coloração: branca transparente, amarelo claro, branco e marrom (3), como é mostrado na figura 5.1.

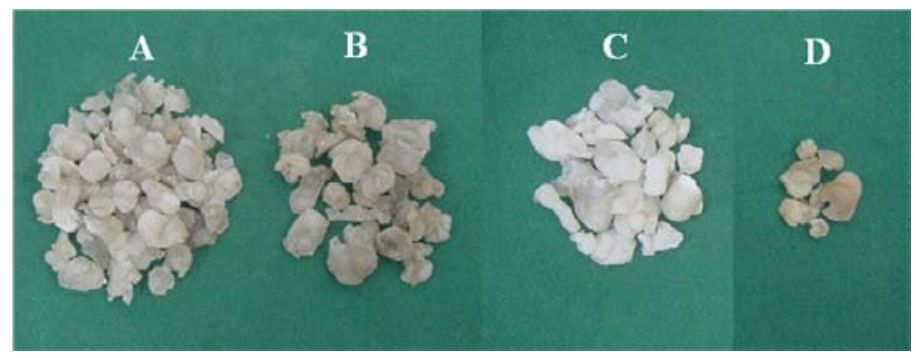

Figura 5.1- Aspecto dos quatro tipos de amostras de gel extraídas da barragem de Furnas (Minas Gerais). (A) Branca transparente. (B) Amarelo claro. (C) Branco. (D) Marrom. 
A composição química das amostras está listada na tabela 5.1 e foi obtida da análise por titulação complexométrica para óxidos e também por espectrofotometria de absorção atômica para elementos álcalis, realizados no Laboratório de Concreto DCT.T em Furnas. Os principais compostos encontrados no gel são referentes ao silício, potássio e sódio, resultados estes que vão de acordo com a literatura (1). Não se observam grandes diferenças na composição química dos quatro tipos de gel. O potássio é o álcali de maior concentração presente em todas as amostras de gel.

Tabela 5.1- Composição química dos quatro tipos de gel em \% Mol.

\begin{tabular}{cccccccc}
\hline Amostra & $\mathbf{S i O}_{2}$ & $\mathbf{K}_{\mathbf{2}} \mathbf{O}$ & $\mathbf{N a}_{\mathbf{2}} \mathbf{O}$ & $\mathbf{C a O}$ & $\mathbf{A l}_{2} \mathbf{O}_{3}$ & $\mathbf{F e}_{2} \mathbf{O}_{3}$ & $\mathbf{M g O}$ \\
\hline $\mathrm{A}$ & 80.8 & 14.3 & 3.2 & 1.0 & 0.13 & 0.02 & 0.05 \\
$\mathrm{~B}$ & 80.1 & 14.4 & 3.2 & 1.5 & 0.30 & 0.05 & 0.05 \\
$\mathrm{C}$ & 77.2 & 17.3 & 5.2 & 1.3 & 0.08 & 0.09 & 0.02 \\
$\mathrm{D}$ & 80.2 & 13.1 & 6.1 & 0.38 & 0.22 & 0.08 & 0.02 \\
\hline
\end{tabular}

Das amostras apresentadas na figura 5.1, a amostra A foi escolhida para ser estudada por ser a mais abundante na barragem de Furnas. Portanto, todos os ataques e tratamentos foram feitos neste tipo de amostra, a qual aqui será referida simplesmente como gel.

\subsection{Amostras de rochas reativas}

Para os estudos de reatividade em rochas, foram analisadas amostras de quartzito, basalto e granito por possuírem maior potencial álcali-reativo.

\subsubsection{Basalto}

O basalto é uma rocha ígnea de granulação fina constituído de 35\% de plagioclásio $\left(\mathrm{NaAlSi}_{3} \mathrm{O}_{8}\right.$ ), 30\% piroxênio (( $\left.\mathrm{Na}, \mathrm{Mg}, \mathrm{Fe}\right) \mathrm{Si}_{2} \mathrm{O}_{6}$ ), 10\% Ti-magnetita ( $\left.\mathrm{Ti}-\mathrm{Fe}_{3} \mathrm{O}_{4}\right), 13 \%$ mesóstase 
(material intersticial, micro cristalino que se encontra como uma massa entre os grãos do basalto), 8\% de argilominerais e podem aparecer traços de apatita e hematita (42). A mesóstase se apresenta sob forma variada, podendo ser constituída por material de baixa cristalinidade, por argilominerais (especialmente do tipo esmectita) e, ainda conter pequenos grãos de quartzo. $\mathrm{O}$ piroxênio aparece em grãos subédricos, ou seja, grãos que não possuem faces perfeitamente formadas e ocorrem principalmente na forma de aglomerados de pequenos grãos. O plagioclásio tem formas tabulares e ripiformes (morfologia de fibras). Os dados químicos da rocha são apresentados na tabela 5.2 e a procedência das amostras da rocha utilizadas nestes experimentos é da jazida da região de Ponta Grossa (PR). Através dos espectros de RMN de ${ }^{29} \mathrm{Si}$, as espécies $\mathrm{Q}^{\mathrm{n}}$ esperadas a serem identificadas são $\mathrm{Q}^{4}$ e $\mathrm{Q}^{2}$ referentes ao plagioclásio e piroxênio respectivamente.

\subsubsection{Granito Gnaisse}

O granito é uma rocha ígnea constituída por quartzo (estrutura cristalina trigonal composta por tetraedros de $\mathrm{SiO}_{2}$ ), feldspato plagioclásio $\left(\mathrm{NaAlSi}_{3} \mathrm{O}_{8}\right)$ e mica (biotita, $\mathrm{K}(\mathrm{Mg}$, $\mathrm{Fe})_{3}(\mathrm{OH}, \mathrm{F})_{2}(\mathrm{Al}, \mathrm{Fe}) \mathrm{Si}_{3} \mathrm{O}_{10}$, e muscovita, $\left.\mathrm{KAl}_{2}\left(\mathrm{Si}_{3} \mathrm{Al}\right) \mathrm{O}_{10}(\mathrm{OH}, \mathrm{F})_{2}\right)$ (41). Secundariamente podese observar a presença de magnetita $\left(\mathrm{Fe}_{3} \mathrm{O}_{4}\right)$. Através dos espectros de $\mathrm{RMN}$ de ${ }^{29} \mathrm{Si}$, as espécies $\mathrm{Q}^{\mathrm{n}}$ esperadas a serem identificadas são $\mathrm{Q}^{4}$, no caso dos quartzos e feldspatos plagioclásios e $\mathrm{Q}^{3}$ referentes à muscovita e mica. A composição química da rocha está na tabela 5.2 e a amostra de granito analisada aqui é proveniente de jazida da região de Recife (PE).

\subsubsection{Quartzito}

O quartzito é uma rocha metamórfica composta quase que inteiramente de quartzo $\left(\mathrm{SiO}_{2}\right)$. O quartzito possui minerais granulares de estrutura fina sem orientação (granoblástica) e nítida foliação metamórfica. Apresenta 90\% de quartzo nanométrico que ocorrem em forma de cristais 
com dimensões reduzidas $(0,10 \mathrm{~mm})$ e $10 \%$ de muscovita $\left(\mathrm{KAl}_{2}\left(\mathrm{Si}_{3} \mathrm{Al}\right) \mathrm{O}_{10}(\mathrm{OH}, \mathrm{F})_{2}\right)$ que ocorre sob a forma de pequenas palhetas orientadas entre os cristais de quartzo (13). O quartzito utilizado neste trabalho foi coletado na região da Usina Hidrelétrica de Furnas (MG) e sua composição química está apresentada na tabela 5.2. As espécies $\mathrm{Q}^{\mathrm{n}}$ esperadas nos espectros de $\mathrm{RMN}$ de ${ }^{29} \mathrm{Si}$ são $\mathrm{Q}^{4}$ e $\mathrm{Q}^{3}$ referentes ao quartzo e muscovita respectivamente.

Tabela 5.2- Análise química das rochas de granito, quartzito e basalto (\% em fração molar)

\begin{tabular}{|c|c|c|c|}
\hline Componentes (\%) $(*)$ & Basalto & Granito & Quartzito \\
\hline Perda ao Fogo $(* *)$ & 0,70 & 0,60 & 0,35 \\
\hline Óxido de magnésio (MgO) & 4,79 & 0,33 & 0,18 \\
\hline Dióxido de silício $\left(\mathrm{SiO}_{2}\right)$ & 53,93 & 67,31 & 92,06 \\
\hline Óxido de ferro $\left(\mathrm{Fe}_{2} \mathrm{O}_{3}\right)$ & 10,32 & 2,82 & 1,19 \\
\hline Óxido de alumínio $\left(\mathrm{Al}_{2} \mathrm{O}_{3}\right)$ & 16,67 & 14,53 & 1,15 \\
\hline Óxido de cálcio (CaO) & 9,20 & 1,42 & 0,14 \\
\hline Óxido de sódio $\left(\mathrm{Na}_{2} \mathrm{O}\right)$ & 1,73 & 3,16 & 0,18 \\
\hline Óxido de potássio $\left(\mathrm{K}_{2} \mathrm{O}\right)$ & 1,39 & 5,31 & 0,54 \\
\hline Dióxido de Titânio $\left(\mathrm{TiO}_{2}\right)$ & 0,94 & & \\
\hline Óxido de Manganês (MnO) & 0,18 & & \\
\hline Pentóxido de fósforo $\left(\mathrm{P}_{2} \mathrm{O}_{5}\right)$ & 0,14 & & \\
\hline Total & 100,00 & 95,48 & 95,79 \\
\hline $\begin{array}{l}\text { Elementos identificados, porém não } \\
\text { possíveis de serem quantificados }\end{array}$ & & $\begin{array}{l}\text { Ti; P; Mn; } \\
\text { Rb; Zr; Sr }\end{array}$ & $\mathrm{Ti} ; \mathrm{Mn} ; \mathrm{Zr}$ \\
\hline
\end{tabular}

\subsection{Ataques e tratamentos das amostras}

O tratamento sobre o gel foi feito utilizando solução de Li, pois as pesquisas com sais de lítio mostram que é possível diminuir a expansividade dos concretos afetados pela RAS (capítulo 2). A exposição à solução de MTMS foi feita na tentativa de prevenir a RAS, neutralizando os sítios $\mathrm{OH}$ reativos dos agregados. Já os ataques contendo soluções de $\mathrm{KOH}$ nas rochas, tiveram o 
objetivo de simular a RAS em condições aceleradas em cada uma das rochas estudadas (basalto, granito e quartzito).

Os ataques e tratamentos foram feitos no DCT.T. FURNAS Centrais Elétricas S.A supervisionado pela Engenheira Dra. Nicole Hasparyk. Os frascos utilizados nos ataques e tratamentos das amostras (gel e rochas) foram os recipientes plásticos de armazenamentos de filmes. Não é possível realizar os ataques em vidraria convencional, pois a alta alcalinidade das soluções utilizadas é corrosiva para silicatos (troca iônica entre os íons alcalinos do vidro e íons hidroxila da solução). Estes frascos foram previamente lavados com água e sabão e depois de enxaguados foram lavados com solução de limpeza de ácido clorídrico (concentração ácido:água = 1:3), enxaguados com água deionizada em abundância e finalmente colocados em estufa de secagem.

\subsubsection{Tratamentos nas amostras de gel}

Para os tratamentos, as amostras de gel original foram moídas com o auxílio de um moinho de discos até passar pela peneira de $5 \mu \mathrm{m}$. Na tabela 5.3 estão apresentados as nomenclaturas das amostras utilizadas neste trabalho, os tipos de ataques, o tempo de exposição e secagem a estes.

No período de ataque as amostras ficaram armazenadas dentro de um dissecador com sílica gel para absorver a umidade. Foi realizado vácuo no interior do mesmo e os frascos ficaram tampados. Além disso, dentro do dissecador, colocou-se uma pequena quantidade de cal sodada

(mistura de óxido de cálcio e hidróxido de sódio), que é fortemente reativa com dióxido de carbono atmosférico, funcionando assim como agente absorvedor deste componente e evitando a carbonatação nas amostras (1).

Uma importante observação a ser feita sobre os tratamentos do gel é que nas amostras atacadas com soluções de $\mathrm{KOH}$ e $\mathrm{NaOH}$, foi observada a dissolução completa e imediata do gel original antes de ser tratado com MTMS. O mesmo não ocorreu nas amostras que foram 
previamente expostas ao MTMS e em seguida atacadas com as soluções citadas. A proteção do silicato, neste caso o gel, frente à ação da solução alcalina é qualitativamente consistente com o efeito esperado pela interação do silano com o silicato.

Tabela 5.3- Procedimento utilizado no tratamento das amostras de gel

\begin{tabular}{|c|c|c|c|c|}
\hline Amostra & $1^{\circ}$ tratamento/ataque/exposição & Secagem $(*)$ & $2^{\circ}$ exposição/ataque & Secagem $(*)$ \\
\hline $\begin{array}{l}\mathrm{Gel}+ \\
\mathrm{LiNO}_{3^{-}} \\
\mathrm{NaOH}\end{array}$ & $\begin{array}{c}\text { Solução: } \\
\mathrm{LiNO}_{3} \mathrm{NaOH}, \quad \text { fração molar de } 0,74\end{array}$ & $\begin{array}{c}\mathrm{T}_{\mathrm{A}} \\
\text { Tempo: } 48 \mathrm{~h}\end{array}$ & & \\
\hline & Solução: & & & \\
\hline $\begin{array}{c}\text { Gel + } \\
\text { MTMS }\end{array}$ & $\begin{array}{l}\text { metiltrimetoxisilano (MTMS), } \\
\text { concentração de 3\% em massa de } \\
\text { MTMS em 97\% de água. }\end{array}$ & $\begin{array}{c}45^{\circ} \mathrm{C} \\
\text { Tempo:26h }\end{array}$ & & \\
\hline $\begin{array}{l}\mathrm{Gel}+ \\
\mathrm{KOH}+ \\
\mathrm{MTMS}\end{array}$ & $\begin{array}{c}\text { Solução: } \\
\text { KOH, concentração de 1M }\end{array}$ & $\begin{array}{c}45^{\circ} \mathrm{C} \\
\text { Tempo: } 26 \mathrm{~h}\end{array}$ & $\begin{array}{l}\text { Solução: metiltrimetoxisilano } \\
\text { (MTMS) concentração de 3\% } \\
\text { em massa de MTMS em } 97 \% \\
\text { de água. }\end{array}$ & $\begin{array}{c}45^{\circ} \mathrm{C} \\
\text { Tempo: } 28 \mathrm{~h}\end{array}$ \\
\hline $\begin{array}{l}\text { Gel + } \\
\mathrm{NaOH}+ \\
\mathrm{MTMS}\end{array}$ & $\begin{array}{c}\text { Solução: } \\
\text { NaOH, concentração de } 1 \mathrm{M}\end{array}$ & $\begin{array}{c}45^{\circ} \mathrm{C} \\
\text { Tempo: } 26 \mathrm{~h}\end{array}$ & $\begin{array}{l}\text { Solução: metiltrimetoxisilano } \\
\text { (MTMS) concentração de } 3 \% \\
\text { em massa de MTMS em } 97 \% \\
\text { de água. }\end{array}$ & $\begin{array}{c}45^{\circ} \mathrm{C} \\
\text { Tempo: } 28 \mathrm{~h}\end{array}$ \\
\hline $\begin{array}{c}\text { Gel + } \\
\text { MTMS+ } \\
\text { KOH }\end{array}$ & $\begin{array}{l}\text { Solução: metiltrimetoxisilano } \\
\text { (MTMS), concentração de 3\% em } \\
\text { massa de MTMS em } 97 \% \text { de água. }\end{array}$ & $\begin{array}{c}45^{\circ} \mathrm{C} \\
\text { Tempo: } 28 \mathrm{~h}\end{array}$ & $\begin{array}{c}\text { Solução: } \\
\text { KOH, concentração de } 1 \mathrm{M}\end{array}$ & $\begin{array}{c}45^{\circ} \mathrm{C} \\
\text { Tempo: } 72 \mathrm{~h}\end{array}$ \\
\hline $\begin{array}{c}\mathrm{Gel}+ \\
\mathrm{MTMS}+ \\
\mathrm{NaOH}\end{array}$ & $\begin{array}{l}\text { Solução: metiltrimetoxisilano } \\
\text { (MTMS), concentração de 3\% em } \\
\text { massa de MTMS em } 97 \% \text { de água. }\end{array}$ & $\begin{array}{c}45^{\circ} \mathrm{C} \\
\text { Tempo: } 28 \mathrm{~h}\end{array}$ & $\begin{array}{c}\text { Solução: } \\
\mathrm{NaOH} \text {, concentração de } 1 \mathrm{M}\end{array}$ & $\begin{array}{c}45^{\circ} \mathrm{C} \\
\text { Tempo: } 72 \mathrm{~h}\end{array}$ \\
\hline
\end{tabular}

(*) O tempo de secagem se refere ao tempo aproximado observado em que houve a secagem completa da amostra.

$\mathrm{T}_{\mathrm{A}}=$ temperatura ambiente 


\subsubsection{Ataques nas amostras das rochas}

A tabela 5.4 apresenta a nomenclatura utilizada para as amostras, os tipos de ataques realizados e as condições de secagem. Depois de preparadas e secas em estufas as amostras foram moídas, utilizando-se almofariz de ágata, de forma a se apresentarem sobre forma de pó não sendo necessário nenhum procedimento de peneiramento para realizar o empacotamento no rotor para medidas de RMN.

Tabela 5.4- Procedimento de ataque das amostras de basalto, granito e quartzito.

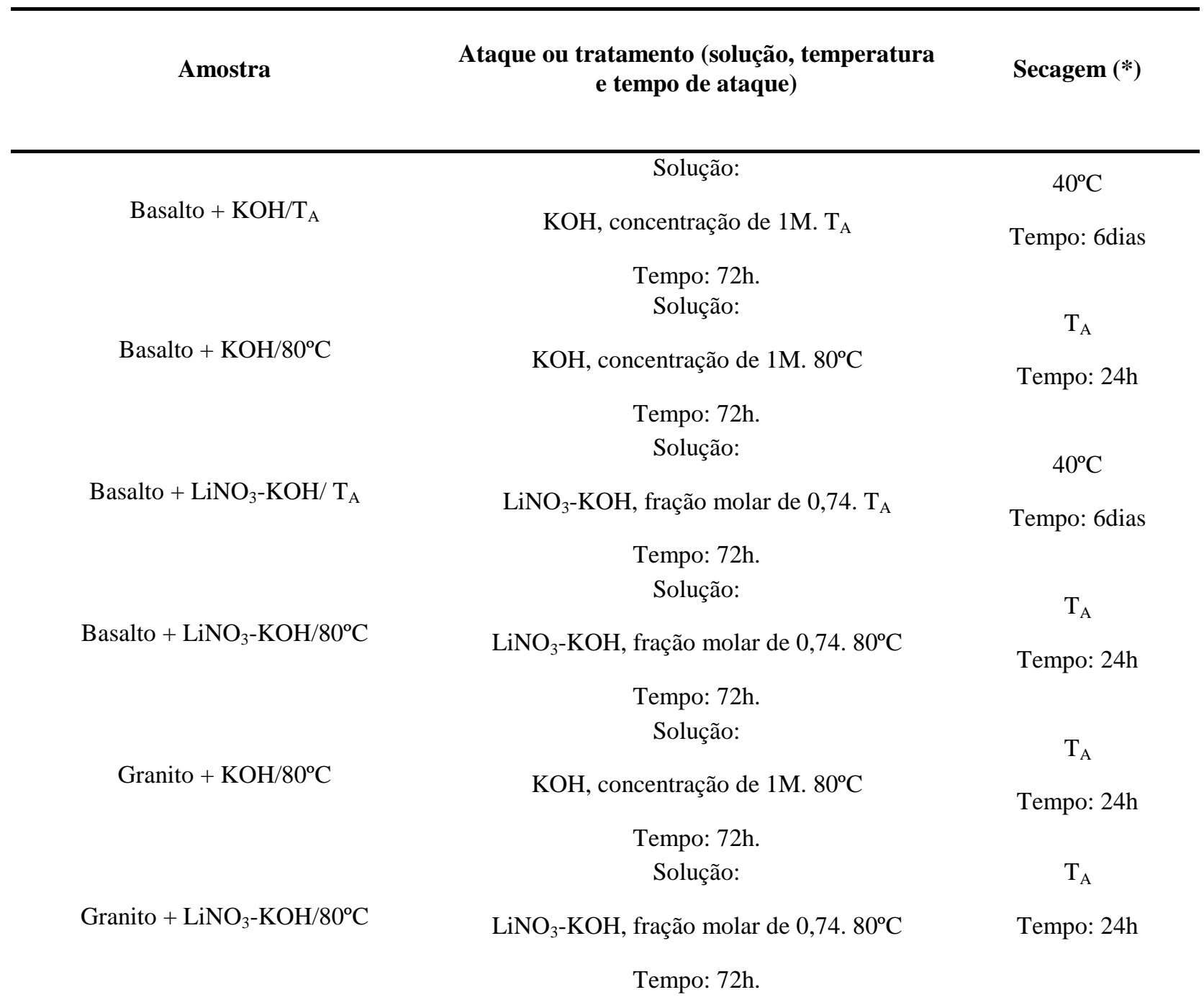


continuação

\begin{tabular}{|c|c|c|}
\hline Quartzito $+\mathrm{KOH} / \mathrm{T}_{\mathrm{A}}$ & Solução: & $40^{\circ} \mathrm{C}$ \\
\hline & $\mathrm{KOH}$, concentração de $1 \mathrm{M} . \mathrm{T}_{\mathrm{A}}$ & Tempo: 6dias \\
\hline & Tempo: 72h. & \\
\hline & Solução: & $40^{\circ} \mathrm{C}$ \\
\hline Quartzito $+\mathrm{KOH} / 45^{\circ} \mathrm{C}$ & $\mathrm{KOH}$, concentração de $1 \mathrm{M} . \mathrm{T}_{\mathrm{A}}$ & Tempo: 6dias \\
\hline & Tempo: 72h. & \\
\hline & Solução: & $\mathrm{T}_{\mathrm{A}}$ \\
\hline Quartzito + KOH $/ 80^{\circ} \mathrm{C}$ & $\mathrm{KOH}$, concentração de $1 \mathrm{M} .80^{\circ} \mathrm{C}$ & Tempo: 24h \\
\hline & $\begin{array}{l}\text { Tempo: } 72 \mathrm{~h} . \\
\left(1^{\circ}\right) \text { Solução: }\end{array}$ & \\
\hline & $\mathrm{KOH}$, concentração de $1 \mathrm{M} .80^{\circ} \mathrm{C}$ & $\left.1^{\circ}\right) \mathrm{T}_{\mathrm{A}}$ \\
\hline & Tempo: 72h. & Tempo: 24h \\
\hline Quartzito + KOH + MTMS $/ 80^{\circ} \mathrm{C}$ & $2^{\circ}$ ) Solução: & $\left.2^{\circ}\right) \mathrm{T}_{\mathrm{A}}$ \\
\hline & $\begin{array}{l}\text { metiltrimetoxisilano (MTMS), concentração de } \\
3 \% \text { em massa de MTMS em } 97 \% \text { de água. } 80^{\circ} \mathrm{C}\end{array}$ & Tempo: 24h \\
\hline & Tempo: 72h & \\
\hline & Solução: & $40^{\circ} \mathrm{C}$ \\
\hline Quartzito $+\mathrm{LiNO}_{3}-\mathrm{KOH} / \mathrm{T}_{\mathrm{A}}$ & $\mathrm{LiNO}_{3}-\mathrm{KOH}$, fração molar de $0,74 . \mathrm{T}_{\mathrm{A}}$ & Tempo: 6dias \\
\hline & Tempo: 72h. & \\
\hline & Solução: & $40^{\circ} \mathrm{C}$ \\
\hline Quartzito + $\mathrm{LiNO}_{3}-\mathrm{KOH} / 45^{\circ} \mathrm{C}$ & $\mathrm{LiNO}_{3}-\mathrm{KOH}$, fração molar de $0,74.45^{\circ} \mathrm{C}$ & Tempo: 6dias \\
\hline & $\begin{array}{l}\text { Tempo: 24h. } \\
\text { Solução: }\end{array}$ & $\mathrm{T}_{\mathrm{A}}$ \\
\hline Quartzito + $\mathrm{LiNO}_{3}-\mathrm{KOH} / 80^{\circ} \mathrm{C}$ & $\mathrm{LiNO}_{3}-\mathrm{KOH}$, fração molar de $0,74.80^{\circ} \mathrm{C}$ & Tempo: 24h \\
\hline & Tempo: 72h. & \\
\hline
\end{tabular}

$\left({ }^{*}\right)$ O tempo de secagem se refere ao tempo aproximado observado em que houve a secagem completa da amostra. 


\subsubsection{Preparo das soluções}

Todas as soluções utilizadas nos ataques do gel e das rochas foram preparadas pelo laboratório de química do Departamento de Apoio e Controle Técnico - DCT.T. - FURNAS Centrais Elétricas S.A. Toda a água utilizada no preparo das soluções foi deionizada e o pH da água foi medido apresentando um valor de 5,87. Os métodos de preparo das soluções de $\mathrm{KOH}$, $\mathrm{NaOH}$ e MTMS foram os seguintes:

- Solução de $\mathrm{KOH}(1 \mathrm{M})$ : Foi colocado uma quantidade de 5,6090 g de KOH (massa molar $=56,09 \mathrm{~g}$ ) em um balão volumétrico de $100 \mathrm{ml}$ e completado o volume com água deionizada até o menisco do balão.

- Solução de $\mathrm{NaOH}(1 \mathrm{M})$ : Foi colocado uma quantidade de 4 g de $\mathrm{NaOH}$ (massa molar $=40,00$ g) em um balão volumétrico de $100 \mathrm{ml}$ e completado o volume com água deionizada até o menisco.

- Solução de MTMS: Para preparar uma quantidade de solução de 3\% de MTMS em água, uma quantidade de 3 g de MTMS foi pesada e dissolvida com $97 \mathrm{~g}$ de água deionizada. Para a dissolução completa foi necessário agitar manualmente a solução, resultando uma solução homogênea com pH de 4,92.

As reações entre o $\mathrm{KOH}$ e água e entre o $\mathrm{NaOH}$ e água, que ocorrem nas soluções de $\mathrm{KOH}(1 \mathrm{M})$ e $\mathrm{NaOH}(1 \mathrm{M})$ respectivamente, são reações exotérmicas, ou seja, sua temperatura se eleva, por isso foi tomado o cuidado de esperar a solução retornar à temperatura ambiente para completar seu volume até o menisco. 


\section{Capítulo 6}

\section{Resultados}

\section{$6.1 \mathrm{Gel}$}

Os resultados experimentais nas amostras de gel foram obtidos das técnicas de: difração de raios-X, polarização direta de ${ }^{29}$ Si, polarização cruzada $\left\{{ }^{1} \mathrm{H}\right\}-{ }^{29}$ Si e HETCOR $\left\{{ }^{1} \mathrm{H}\right\}-{ }^{29}$ Si.

\subsubsection{Difração de raios-X}

No difratograma da amostra de gel, mostrado na figura 6.1, é possível observar uma difração larga centrada aproximadamente em $26^{\circ}$, posição típica de sílicas amorfas com difrações na região entre $24^{\circ}$ e $31^{\circ}(43,44)$. Por volta de $6^{\circ}$ aparecem picos de difração que correspondem a espaçamentos de 14.7Å. Esta reflexão é similar ao que foi observado por Hou nos difratogramas das amostras de gel sintético (15). Hou analisou amostras de gel sintético hidratadas e não hidratadas e os resultados apresentaram espaçamentos entre camadas por volta de $8 \AA$ nas amostras não hidratadas e por volta de $12 \AA$ nas amostras hidratadas. O espaçamento de $14.7 \AA$ encontrado na amostra de gel pode então estar associado ao estado de hidratação da amostra. No difratograma da figura 6.1 há também reflexões estreitas indicando a presença de algumas fases cristalinas que foram atribuídas ao $\mathrm{Na}_{2} \mathrm{CO}_{3} \cdot \mathrm{NaHCO}_{3} \cdot 2 \mathrm{H}_{2} \mathrm{O}$ (trona) (3). Apesar de o gel ser constituído de $14.3 \% \mathrm{~K}_{2} \mathrm{O}$, não há identificação de fases cristalinas com esse elemento, indicando que o potássio está na parte amorfa do gel. 


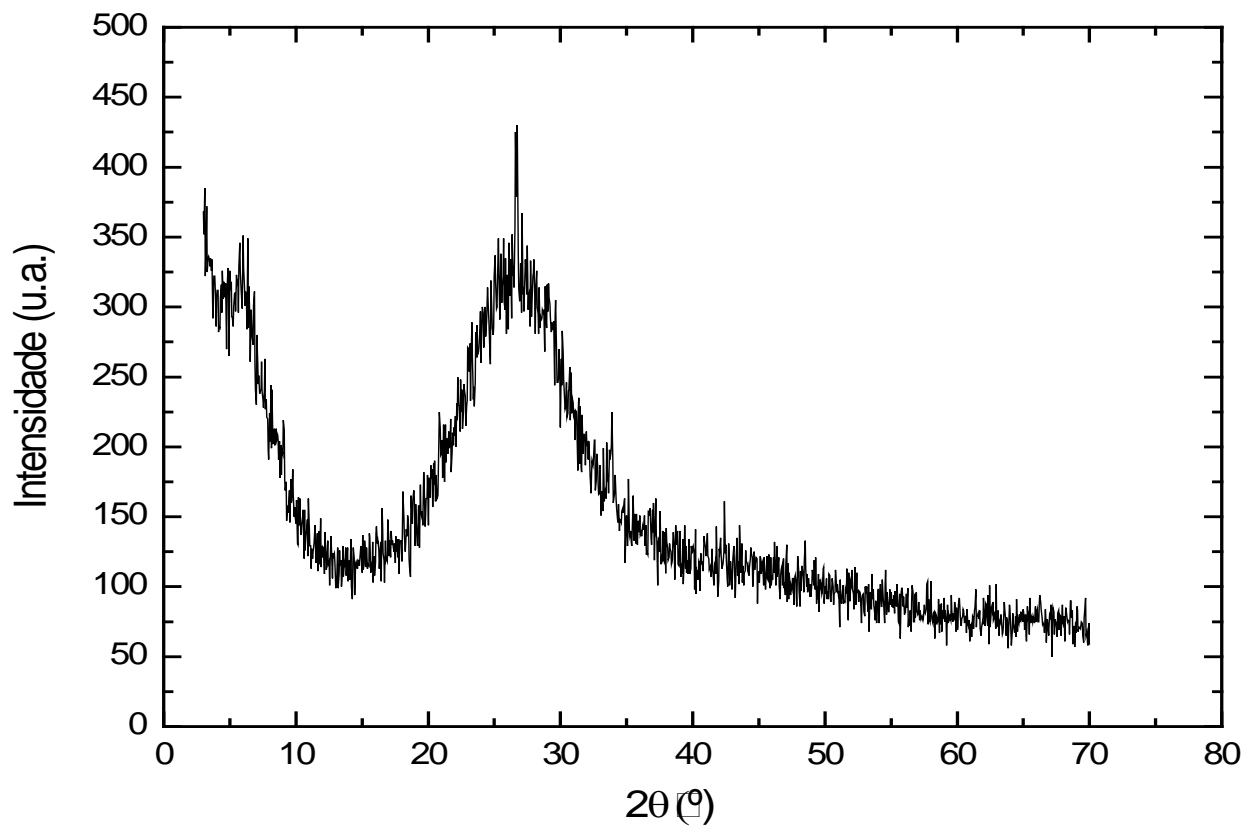

Figura 6.1- Difratograma de Raio X de pó para a amostra de gel.

\subsection{2 ${ }^{29} \mathrm{Si}-\mathrm{RMN}$}

$\mathrm{Na}$ amostra de gel foram realizados experimentos de polarização direta de ${ }^{29} \mathrm{Si}$ para determinar a distribuição de grupos silicatos $\mathrm{Q}^{\mathrm{n}}$. No espectro do gel na figura 6.2a, foi possível identificar as espécies $\mathrm{Q}^{1}, \mathrm{Q}^{2}, \mathrm{Q}^{3}$ e $\mathrm{Q}^{4}$. Os desvios químicos $($ ) e asáreas (A $\mathrm{PD}$ ) de cada linha, obtidas pelos ajustes de funções gaussianas de cada espécie, estão listados na tabela 6.1. Na tabela 6.1, observa-se o sítio $\mathrm{Q}^{3}$ como o mais abundante na amostra de gel, responsável por aproximadamente 56\% da parte amorfa da estrutura de silicatos. E o número médio de oxigênios não ponte (NBO), calculado pela equação 3.42, resulta 1,0 o que é equivalente a um ambiente de silicatos médio de tipo $\mathrm{Q}^{3}$. Portanto a rede amorfa de silicatos pode ser descrita em média como lamelar, consistente principalmente de planos de silicatos $\mathrm{Q}^{3}$. 


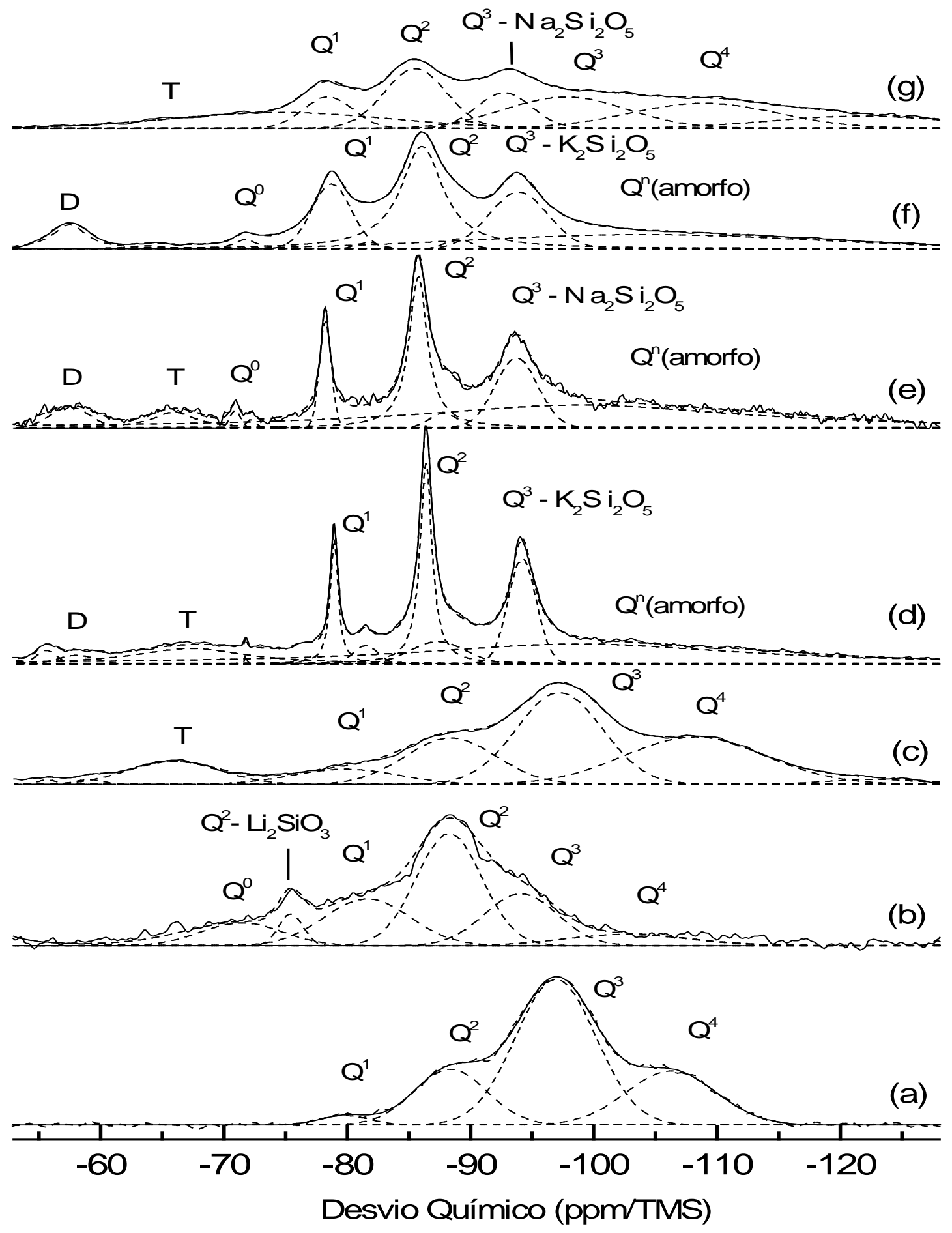

Figura 6.2- Espectros de Polarização Direta de ${ }^{29} \mathrm{Si}$. (a) gel. (b) gel $+\mathrm{LiNO}_{3}-\mathrm{NaOH}$. (c) gel + MTMS. (d) gel $+\mathrm{KOH}$ + MTMS. (e) gel + NaOH + MTMS. (f) gel + MTMS + KOH. (g) gel + MTMS + NaOH. 
Na amostra de gel foram realizados também experimentos de polarização cruzada $\left\{{ }^{1} \mathrm{H}\right\}$ -

${ }^{29} \mathrm{Si}$, apresentados na figura 6.3a, para identificar os sítios silicatos com maior acoplamento dipolar com ${ }^{1} \mathrm{H}$.

No espectro de gel na figura 6.3a, podem ser identificadas as linhas referentes aos sítios $\mathrm{Q}^{1}, \mathrm{Q}^{2}, \mathrm{Q}^{3}$ e $\mathrm{Q}^{4}$. Na tabela 6.1, estão os desvios químico§)(e asáreas (A) de cada sítio Q ${ }^{\mathrm{n}}$ ajustados através de funções gaussianas. As intensidades $A_{P C}$ das linhas observadas em polarização cruzada foram calculadas apenas para realizar comparações qualitativas dos fatores de atenuação $A_{P C} / A_{P D}$ entre sítios silicatos diferentes no conjunto de amostras. Pelas áreas da tabela 6.1 observa-se que para as espécies $\mathrm{Q}^{2}$ e $\mathrm{Q}^{1}$ são observados fatores acima de 1 , devido à presença de mais prótons próximos em grupos $\mathrm{OH}$. Para o sítio $\mathrm{Q}^{4}$ o fator é menor que 1 , pois os sítios $\mathrm{Q}^{4}$ não possuem ligações $\mathrm{Si}-\mathrm{OH}$ e necessariamente são polarizados por ${ }^{1} \mathrm{H}$ mais remotos. No entanto a observação do sinal $\mathrm{Q}^{4}$ em polarização cruzada indica que estas espécies não estão segregadas em domínios do tipo sílica, mas sim que estão formando pontes Si-O-Si com silicatos de menor conectividade, com ligações $\mathrm{OH}$.

Tabela 6.1-Desvio químico $\delta$ (ppm, módulo do valor negativo) e área relativa A (\%) das gaussianas dos espectros de ${ }^{29}$ Si-RMN de polarização direta e de polarização cruzada $\left\{{ }^{1} \mathrm{H}\right\}-{ }^{29}$ Si para os sítios $\mathrm{Q}^{\mathrm{n}}$, T e D no gel, gel + $\mathrm{LiNO}_{3}-\mathrm{NaOH}$ e gel + MTMS. NBO = número médio de oxigênios não ponte. $\mathrm{PD}=$ Polarização Direta. $\mathrm{PC}=$ Polarização Cruzada. $\mathrm{A}_{\mathrm{PC}} / \mathrm{A}_{\mathrm{PD}}=$ razão entre as áreas de polarização cruzada e polarização direta.

\begin{tabular}{|c|c|c|c|c|c|c|c|c|c|c|}
\hline & & \multicolumn{3}{|c|}{ Gel } & \multicolumn{3}{|c|}{$\mathrm{Gel+}+\mathrm{LiNO}_{3} \mathrm{NaOH}(*)$} & \multicolumn{3}{|c|}{ Gel+MTMS } \\
\hline & & PD & PC & $\begin{array}{l}\mathbf{A}_{\mathbf{P C}} / \\
\mathbf{A}_{\mathbf{P D}}\end{array}$ & PD & PC & $\begin{array}{l}\mathbf{A}_{\mathbf{P C}} / \\
\mathbf{A}_{\mathbf{P D}}\end{array}$ & PD & PC & $\begin{array}{l}\mathbf{A}_{\mathbf{P C}} / \\
\mathbf{A}_{\mathbf{P D}}\end{array}$ \\
\hline \multirow[t]{2}{*}{$\mathrm{D}$} & $\delta$ & & & & & & & 58,7 & 58,7 & 12 \\
\hline & $\mathrm{A}$ & & & & & & & 1 & 12 & 12 \\
\hline \multirow[t]{2}{*}{$\mathrm{T}$} & $\delta$ & & & & & & & 66,1 & 66,2 & 2,3 \\
\hline & A & & & & & & & 8 & 17 & \\
\hline \multirow[t]{2}{*}{$\mathrm{Q}^{0}$} & $\delta$ & & & & 71,0 & 71,5 & 0,2 & & & \\
\hline & A & & & & 15 & 3 &, 2 & & & \\
\hline \multirow[t]{2}{*}{$\mathrm{Q}^{1}$} & $\delta$ & 79,8 & 79,0 & 2 & 82,1 & 80,2 & 13 & 79,2 & 79,1 & 005 \\
\hline & A & 2 & 4 & & 23 & 30 & & 7 & 1 & \\
\hline \multirow[t]{2}{*}{$\mathrm{Q}^{2}$} & $\delta$ & 88,4 & 88,0 & 1.5 & 88,0 & 88,7 & 1.6 & 88,4 & 88,7 & 0,9 \\
\hline & A & 19 & 29 & & 26 & 38 & & 19 & 16 & \\
\hline \multirow[t]{2}{*}{$\mathrm{Q}^{3}$} & $\delta$ & 96,9 & 96,8 & 1.0 & 92,9 & 94,0 & 1,1 & 97,3 & 98,1 & 1,1 \\
\hline & A & 56 & 55 & 1,0 & 23 & 29 & 1,1 & 36 & 37 & 1,1 \\
\hline \multirow[t]{2}{*}{$\mathrm{Q}^{4}$} & $\delta$ & 106,3 & 106,4 & 0.5 & 104,4 & & & 108,3 & 110,3 & 0.6 \\
\hline & A & 23 & 12 & & 10 & & & 29 & 17 & \\
\hline NBO & & 1,0 & & & 2,0 & & & 1,0 & & \\
\hline
\end{tabular}

$(*) \mathrm{O}$ total da área de PD da amostra de gel+LiNO $3-\mathrm{NaOH}$ não fecha em $100 \%$ pois ainda há 3\% de área do $\mathrm{Li}_{2} \mathrm{SiO}_{3}$. 


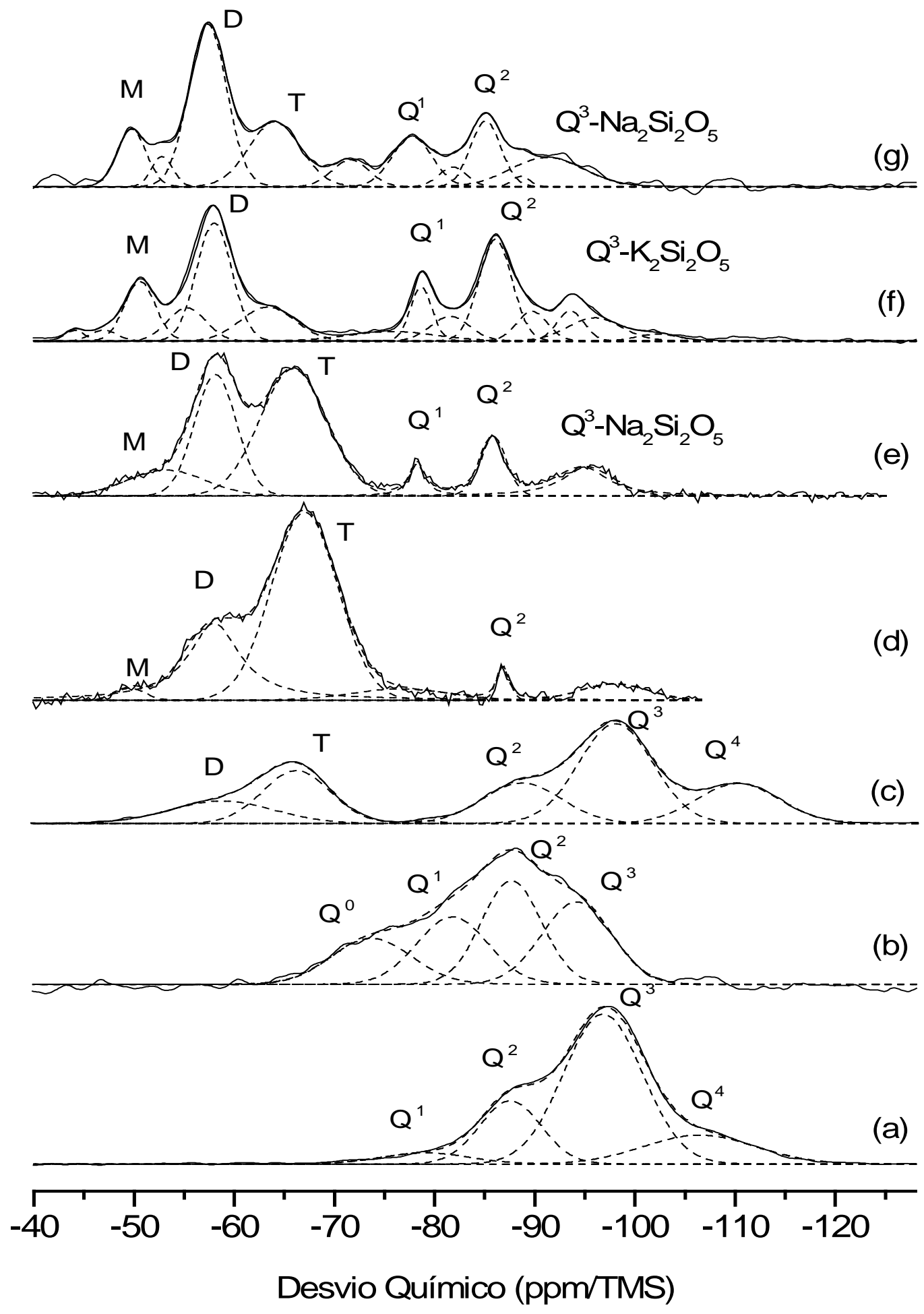

Figura 6.3- Espectros de polarização cruzada $\left\{{ }^{1} \mathrm{H}\right\}-{ }^{29} \mathrm{Si}$. (a) gel. (b) gel $+\mathrm{LiNO}_{3}-\mathrm{NaOH}$. (c) gel + MTMS. (d) gel + $\mathrm{KOH}+$ MTMS. (e) gel + NaOH + MTMS. (f) gel + MTMS + KOH. (g) gel + MTMS + NaOH. 


\subsubsection{Polarização cruzada $\left\{{ }^{1} \mathrm{H}\right\}-{ }^{29}$ Si com tempo de contato variável}

Nas amostras de gel e gel $+\mathrm{LiNO}_{3}-\mathrm{NaOH}$ foram realizados experimentos de polarização cruzada $\left\{{ }^{1} \mathrm{H}\right\}-{ }^{29} \mathrm{Si}$ com tempo de contato variável. Os resultados para a amostra de gel, apresentados nos gráficos da figura 6.4a e 6.4c, mostram a evolução da intensidade dos sinais de $\mathrm{Q}^{2}$ e $\mathrm{Q}^{3}$ em função do tempo de contato. As curvas contínuas na figura 6.4 correspondem a ajustes pelo método de mínimos quadrados utilizando a equação 3.35, para determinar os valores do tempo de contato entre os núcleos ( $\left.\mathrm{T}_{\mathrm{H}-\mathrm{Si}}\right)$ e o tempo de relaxação da magnetização do ${ }^{1} \mathrm{H}$ para a rede nos sistema rotatório $\left(T_{1 \rho}\right)(4)$, cujos valores são apresentados na tabela 6.2.
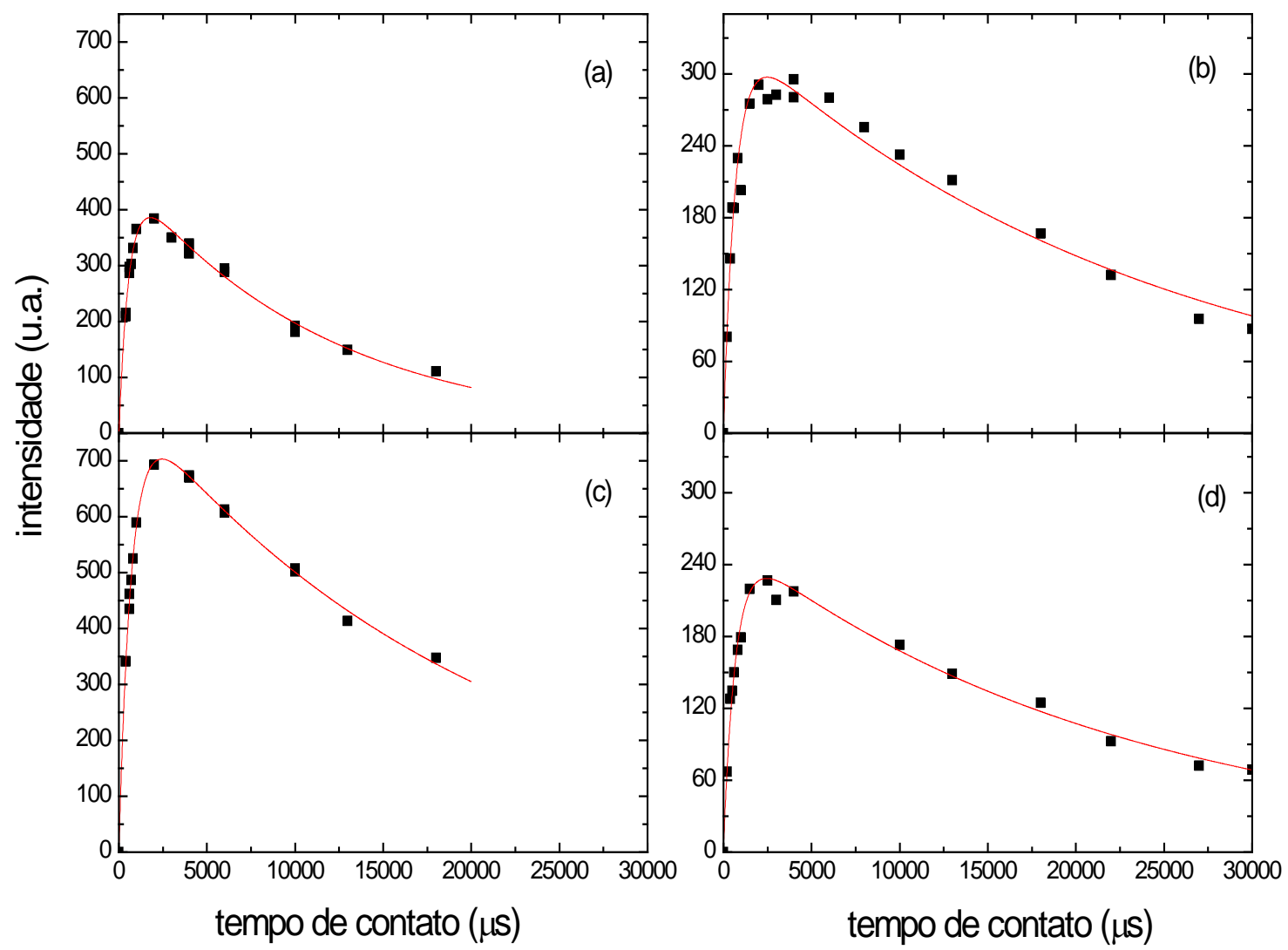

Figura 6.4- Curvas de magnetização de ${ }^{29} \mathrm{Si}$ em função do tempo de contato com ${ }^{1} \mathrm{H}$, em experimentos de polarização cruzada, para as espécies de silicato mais abundantes $Q^{2}$ e $Q^{3}$. (a) $Q^{2}$ no gel. (b) $Q^{2}$ no gel $+\mathrm{LiNO}_{3}-\mathrm{NaOH}$. (c) $\mathrm{Q}^{3}$ no gel. (d) $\mathrm{Q}^{3}$ no gel $+\mathrm{LiNO}_{3}-\mathrm{NaOH}$. 
Na tabela 6.2, a diferença entre os valores de $T_{H-S i}$ e $T_{1 \rho}$ correspondente a $Q^{2}$ e $Q^{3}$ no gel está indicando configurações locais de ${ }^{1} \mathrm{H}$ diferenciadas ao redor desses silícios. Os sítios $\mathrm{Q}^{2}$ apresentam tempo de contato menor que o sítio $\mathrm{Q}^{3}$ indicando uma quantidade maior de $\mathrm{H}$ próximos aos Si que vai de acordo com o fato dos sítios $\mathrm{Q}^{2}$ apresentarem dois oxigênios livres para as ligações Si-OH ou maior quantidade de moléculas de água próximas a estes sítios.

Tabela 6.2-Tempos de contato $\mathrm{T}_{\mathrm{H}-\mathrm{Si}} \mathrm{e}$ relaxação spin-rede $\mathrm{T}_{1 \rho}$ das espécies de silicatos mais abundantes em cada gel $\left(\mathrm{Q}^{2}\right.$ e $\left.\mathrm{Q}^{3}\right)$, obtidos dos experimentos de polarização cruzada $\left\{{ }^{1} \mathrm{H}\right\}{ }^{29} \mathrm{Si}$ das amostras de gel e gel $+\mathrm{LiNO}_{3^{-}}$ $\mathrm{NaOH}$.

\begin{tabular}{cccc}
\hline Amostra & $\mathbf{Q}^{\mathbf{n}}$ & $\mathbf{T}_{\mathbf{H S i}}(\boldsymbol{\mu s})$ & $\mathbf{T}_{\mathbf{1} \mathbf{p}}(\boldsymbol{\mu s})$ \\
\hline \multirow{2}{*}{$\mathrm{Gel}$} & $\mathrm{Q}^{2}$ & $560 \pm 30$ & $11400 \pm 500$ \\
& $\mathrm{Q}^{3}$ & $700 \pm 10$ & $20200 \pm 400$ \\
& $\mathrm{Q}^{2}$ & $670 \pm 50$ & $24000 \pm 1500$ \\
Gel + $\mathrm{LiNO}_{3}-\mathrm{NaOH}$ & $\mathrm{Q}^{3}$ & $680 \pm 40$ & $22000 \pm 1000$ \\
\hline
\end{tabular}

\subsubsection{HETCOR $\left\{{ }^{1} \mathrm{H}\right\}-{ }^{29} \mathrm{Si}$}

$\mathrm{Na}$ amostra de gel foi realizado o experimento de HETCOR $\left\{{ }^{1} \mathrm{H}\right\}-{ }^{29} \mathrm{Si}$ mostrado na figura 6.5. No eixo vertical está representada a projeção integral correspondente ao espectro de polarização cruzada de ${ }^{29} \mathrm{Si}$ e no eixo horizontal está representada a projeção integral sobre a freqüência de ${ }^{1} \mathrm{H}$ correspondendo ao espectro dos ${ }^{1} \mathrm{H}$ que estão polarizando os ${ }^{29} \mathrm{Si}$. As seções do espectro bidimensional (subespectros), ao longo da freqüência de ${ }^{1} \mathrm{H}$, são referentes aos prótons próximos aos sítios de $\mathrm{Q}^{1}, \mathrm{Q}^{2}, \mathrm{Q}^{3}$ e $\mathrm{Q}^{4}$ e são alargados pelo acoplamento dipolar homonuclear entre ${ }^{1} \mathrm{H}$. Como comparação, no traço superior está mostrado também o espectro de polarização direta do ${ }^{1} \mathrm{H}$ com posição central em 6.5ppm. Os desvios químicos dos espectros de ${ }^{1} \mathrm{H}$ com relação aos desvios químicos do ${ }^{29} \mathrm{Si}$ estão na tabela 6.3.

As linhas centrais dos subespectros apresentam larguras por volta de $10 \mathrm{KHz}$ e posição central de -5,9ppm. A grandeza destes alargamentos indica que a rotação da amostra por volta de $6.6 \mathrm{KHz}$ mostra-se insuficiente para eliminar completamente a anisotropia do acoplamento homonuclear. A baixa intensidade de bandas laterais é relacionada com acoplamento dipolar 
homonuclear moderado entre os prótons (45), o que leva a conclusão que os núcleos de Si dos grupos de silicatos são polarizados pelos prótons provenientes de grupos hidroxilas das ligações Si-OH dos grupos $Q^{n}$. Já no espectro de polarização direta do ${ }^{1} \mathrm{H}$, a maioria dos prótons observados são referentes à água contida na amostra, e não estão polarizando os ${ }^{29} \mathrm{Si}$, isso explica o fato dos desvios químicos das linhas centrais serem diferentes entre os subespectros e o espectro do traço superior.

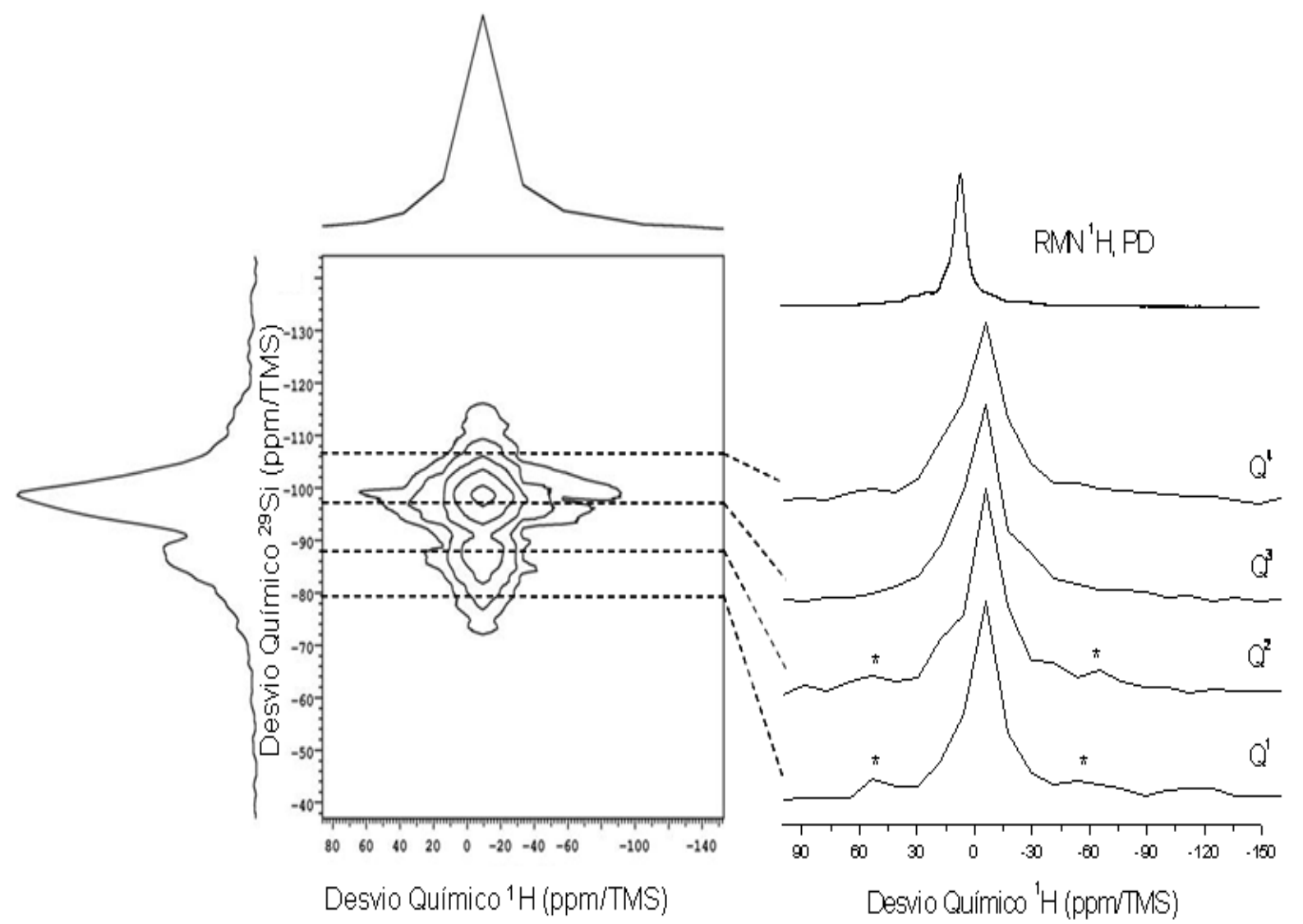

Figura 6.5- Espectro bidimensional de HETCOR $\left\{{ }^{1} \mathrm{H}\right\}-{ }^{29} \mathrm{Si}$ do gel. Eixo vertical: desvio químico e espectro projetado de ${ }^{29}$ Si. Eixo horizontal: desvio químico e espectro projetado do ${ }^{1} \mathrm{H}$. Subespectros mostrados do lado direito: seções do espectro bidimensional, correspondentes às posições dos sítios $Q^{1}, Q^{2}, Q^{3}, Q^{4}$. Espectro superior: espectro de ${ }^{1} \mathrm{H}$ em 1D. Asteriscos (*): bandas laterais de rotação da amostra. 
Tabela 6.3- Desvio químico $\left({ }^{1} \mathrm{H}\right)$ das linhas centrais do subespectro com relação ao desvio quínđi(co $\left.{ }^{29} \mathrm{Si}\right)$ do espectro de ${ }^{29} \mathrm{Si}$ dos experimentos de HETCOR $\left\{{ }^{1} \mathrm{H}\right\}-{ }^{29} \mathrm{Si}$.

\begin{tabular}{cccc}
\hline Amostra & $\mathbf{Q}^{\mathbf{n}}$ & $\boldsymbol{\delta}\left({ }^{29} \mathbf{S i}\right)(\mathbf{p p m})$ & $\left.\boldsymbol{\delta}\left({ }^{\mathbf{1}} \mathbf{H}\right) \mathbf{( p p m}\right)$ \\
\hline \multirow{4}{*}{ gel original } & $\mathrm{Q}^{1}$ & $-79,0$ & $-5,9$ \\
& $\mathrm{Q}^{2}$ & $-88,1$ & $-5,9$ \\
& $\mathrm{Q}^{3}$ & $-96,8$ & $-5,9$ \\
& $\mathrm{Q}^{4}$ & $-106,4$ & $-5,9$ \\
& $\mathrm{Q}^{0}$ & $-71,5$ & $-2,6$ \\
gel + LiNO ${ }_{3}-\mathrm{NaOH}$ & $\mathrm{Q}^{1}$ & $-80,2$ & $-2,6$ \\
& $\mathrm{Q}^{2}$ & $-88,7$ & $-2,6$ \\
& $\mathrm{Q}^{3}$ & $-94,0$ & $-2,6$ \\
& $\mathrm{D}$ & $-58,7$ & $-2,7$ \\
& $\mathrm{~T}$ & $-66,2$ & $-5,2$ \\
& $\mathrm{Q}^{2}$ & $-88,7$ & 0,63 \\
& & & $0,63(\mathrm{~B})$ \\
& $\mathrm{Q}^{3}$ & $-98,1$ & $12,2(\mathrm{~A})$ \\
& & & $-2,3$ \\
\hline & $\mathrm{Q}^{4}$ & $-110,3$ &
\end{tabular}

\subsection{Tratamentos}

Nesta seção serão apresentados os resultados do gel tratado com solução de Li e gel tratado com solução de MTMS.

\subsubsection{Tratamento com solução de $\mathrm{Li}\left(\right.$ gel $\left.+\mathrm{LiNO}_{3}-\mathrm{NaOH}\right)$}

A amostra de gel tratado com solução de Li foi analisada através das técnicas de: difração de raios-X, polarização direta de ${ }^{7} \mathrm{Li},{ }^{29} \mathrm{Si}$ e ${ }^{23} \mathrm{Na}$, polarização cruzada $\left\{{ }^{1} \mathrm{H}\right\}-{ }^{29} \mathrm{Si}$, HETCOR $\left\{{ }^{1} \mathrm{H}\right\}$ - 
${ }^{29} \mathrm{Si}$, polarização direta de ${ }^{7} \mathrm{Li}$ e ${ }^{23} \mathrm{Na}$ e 3Q-MAS de ${ }^{23} \mathrm{Na}$, complementando um estudo preliminar realizado em nosso laboratório (3).

\subsubsection{Difração de raios-x}

O difratograma de Raios-X da amostra de gel $+\mathrm{LiNO}_{3}-\mathrm{NaOH}$ está mostrado na figura 6.6. Observa-se o aparecimento de novas fases cristalinas. Os picos mais intensos indicados por símbolos foram identificados como silicato de lítio $\left(\mathrm{Li}_{2} \mathrm{SiO}_{3}\right)$ (46), nitrato de potássio $\left(\mathrm{KNO}_{3}\right)$ (47), nitrato de sódio $\left(\mathrm{NaNO}_{3}\right)$ (48), carbonato de potássio $\left(\mathrm{K}_{2} \mathrm{CO}_{3}\right)(49)$ e carbonatos sódio-lítio $\left(\mathrm{LiNaCO}_{3}\right)(50)$. A presença de duas fases cristalinas contendo potássio indica que o gel perdeu parte do potássio da sua estrutura para a parte cristalina quando foi tratado com solução de Li.

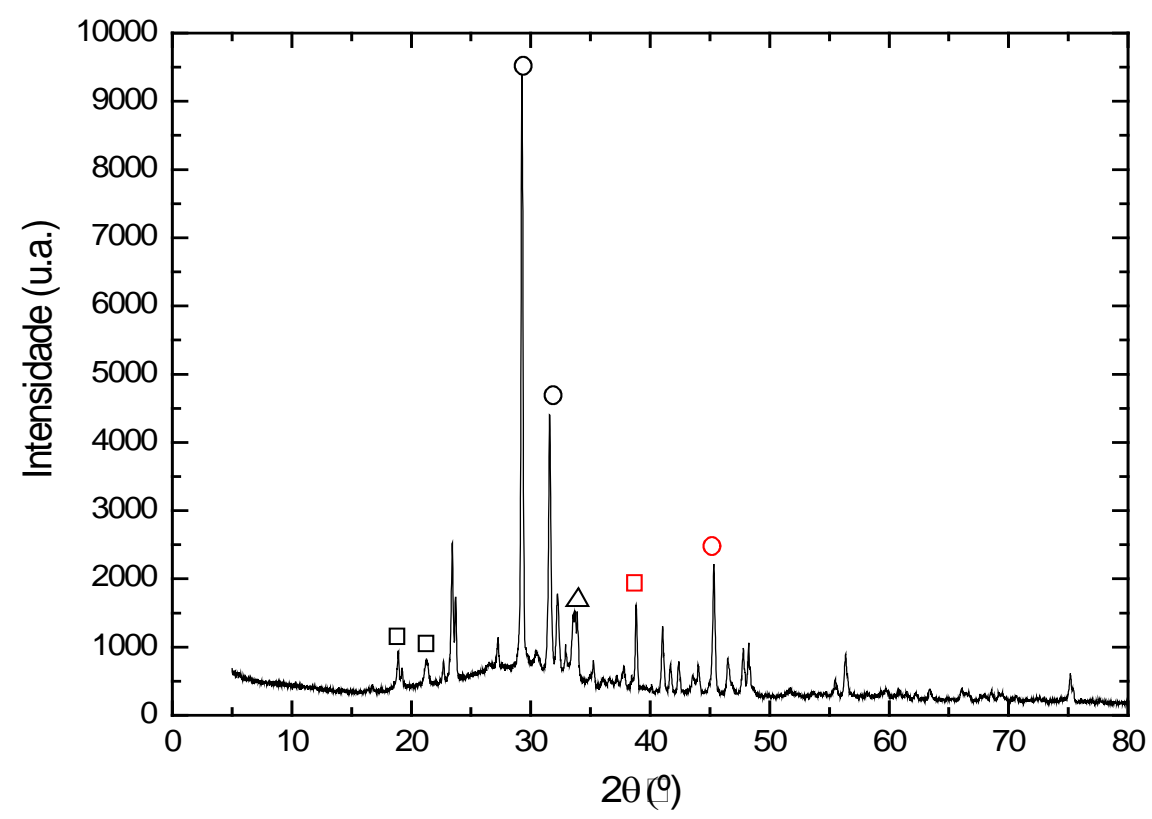

Figura 6.6- Difratograma de Raio X de pó para o material resultante do ataque do gel $+\mathrm{LiNO}_{3}-\mathrm{NaOH} \square \mathrm{LiNaCO}_{3}$. $\mathrm{O} \mathrm{K}_{2} \mathrm{CO}_{3} . \Delta \mathrm{Li}_{2} \mathrm{SiO}_{3} . \square \mathrm{KNO}_{3} . \mathrm{O} \mathrm{NaNO}_{3}$. 


\subsubsection{2 ${ }^{29} \mathrm{Si}-\mathrm{RMN}$}

$\mathrm{Na}$ amostra de gel $+\mathrm{LiNO}_{3}-\mathrm{NaOH}$, o espectro de polarização direta de ${ }^{29} \mathrm{Si}$ da figura $6.2 \mathrm{~b}$ permite identificar uma estrutura amorfa formada por grupos silicatos $Q^{0}, Q^{1}, Q^{2}, Q^{3}$ e $Q^{4}$ e uma linha mais estreita, correspondente a um ambiente estruturalmente mais organizado, em 75,2ppm. Os desvios químicos isotrópicoso) de cada grupo de silicato $\mathrm{Q}^{\mathrm{n}}$ estão listados na tabela 6.1 .

As áreas de cada sítio $\mathrm{Q}^{\mathrm{n}}$ apresentadas na tabela 6.1, indicam uma abundância de sítios $\mathrm{Q}^{2}, 26 \%$ da área da parte amorfa, e um aumento significativo da área de do sítio $\mathrm{Q}^{1}, 23 \%$, se comparado à quantidade deste último na amostra de gel (2\%). Estas informações aliadas com o valor do NBO resultante igual a 2,0 (valor que coincide com o NBO dos grupos $\mathrm{Q}^{2}$ ) e comparadas com a amostra de gel indicam uma despolimerização, em média da rede de silicatos, passando de uma estrutura com grupos silicatos mais abundantes $Q^{3}$ para outra com $Q^{2}(9)$.

A linha de RMN observada em -75,2ppm é ajustada por uma curva lorentziana, forma que é característica de sítios cristalinos, e pode ser atribuído a uma espécie de silicato em ambiente mais ordenado. De acordo com o desvio químico observado, a linha poderia ser atribuída ao metasilicato de lítio $\mathrm{Li}_{2} \mathrm{SiO}_{3}$ (51). A largura dessa linha no espectro não é tão estreita a ponto de ser comparado a um cristal, o que indica uma certa concentração de defeitos nesses domínios $\mathrm{Li}_{2} \mathrm{SiO}_{3}$.

No espectro de polarização cruzada $\left\{{ }^{1} \mathrm{H}\right\}-{ }^{29} \mathrm{Si}$ da amostra de gel $+\mathrm{LiNO}_{3}-\mathrm{NaOH}$, apresentado na figura 6.3b, é possível observar os sítios $\mathrm{Q}^{0}, \mathrm{Q}^{1}, \mathrm{Q}^{2}$ e $\mathrm{Q}^{3}$ (valores de desvios químicos na tabela 6.1). Neste espectro não é possível observar a linha dos sítios $\mathrm{Q}^{4}$, indicando que eles não estão próximos aos prótons que polarizam os outros sítios observados. Esta observação indica que os $\mathrm{Q}^{4}$ se encontram segregados em domínios essencialmente desconexo do resto das espécies $\mathrm{Q}^{\mathrm{n}}$. As ligações de $\mathrm{Si}-\mathrm{OH}$ dos sitos $\mathrm{Q}^{0}, \mathrm{Q}^{1}, \mathrm{Q}^{2}$ e $\mathrm{Q}^{3}$ não estão próximas ao $\mathrm{Q}^{4}$, indicando ligações de ${ }^{29} \mathrm{Si}$ com $\mathrm{Li}^{+}$ou $\mathrm{Na}^{+}$. Conjuntamente, na razão $\mathrm{A}_{\mathrm{PC}} / \mathrm{A}_{\mathrm{PD}}$ da tabela 6.1 observa-se que para as espécies $\mathrm{Q}^{3}, \mathrm{Q}^{2}$ e $\mathrm{Q}^{1}$ são observados fatores acima de 1 devido à presença de mais prótons próximos em grupos $\mathrm{OH}$, resultado muito parecido ao observado no gel. 


\subsubsection{Polarização cruzada $\left\{{ }^{1} \mathrm{H}\right\}-{ }^{29}$ Si com tempo de contato variável}

Os resultados do experimento de polarização cruzada com tempo de contato variável da amostra de gel $+\mathrm{LiNO}_{3}-\mathrm{NaOH}$ estão apresentados nos gráficos da figura $6.4 \mathrm{~b}$ e $6.4 \mathrm{~d}$, que mostram a evolução da intensidade dos sinais de ${ }^{29} \mathrm{Si}$ para $\mathrm{Q}^{2}$ e $\mathrm{Q}^{3}$ em função do tempo de contato.

Da tabela 6.2 observa-se que o valor de $\mathrm{T}_{\mathrm{H}-\mathrm{Si}}$ dos sítios $\mathrm{Q}^{3}$ e $\mathrm{Q}^{2}$ da amostra de gel + $\mathrm{LiNO}_{3}-\mathrm{NaOH}$ são semelhantes. Isso indica que as configurações locais de ${ }^{1} \mathrm{H}$ desses sítios são semelhantes, experimentando o mesmo grau de acoplamento dipolar ${ }^{1} \mathrm{H}-{ }^{29} \mathrm{Si}$. Esta possibilidade é consistente com os valores de $T_{1 \rho}$ que agora são comuns aos prótons polarizando $Q^{2}$ e $Q^{3}$. Comparando com os valores de $\mathrm{T}_{\mathrm{H}-\mathrm{Si}}$ do sítio $\mathrm{Q}^{2}$ do gel, conclui-se que o sítio $\mathrm{Q}^{2}$ no gel, tem o maior acoplamento dipolar ${ }^{1} \mathrm{H}^{29} \mathrm{Si}$ se comparado ao sítio $\mathrm{Q}^{2}$ do gel com lítio, pois tem o menor valor de $\mathrm{T}_{\mathrm{H}-\mathrm{Si}}$ pela tabela 6.2. Este fato indica uma menor mobilidade destes prótons próximos a $\mathrm{Q}^{2}$ no gel ou a proximidade de mais outros prótons dos grupos $\mathrm{Q}^{3}$. O $\mathrm{T}_{\mathrm{H}-\mathrm{Si}}$ essencialmente idêntico para as espécies $\mathrm{Q}^{2}$ e $\mathrm{Q}^{3}$ do gel com $\mathrm{Li}$, sugere também um ambiente de múltiplos prótons comuns em distâncias próximas, provavelmente envolvendo $\mathrm{OH}$ e $\mathrm{H}_{2} \mathrm{O}$.

\subsubsection{HETCOR $\left\{{ }^{1} \mathrm{H}\right\}-{ }^{29} \mathrm{Si}$}

$\mathrm{Na}$ amostra de gel $+\mathrm{LiNO}_{3}-\mathrm{NaOH}$ foi realizado o experimento de HETCOR $\left\{{ }^{1} \mathrm{H}\right\}{ }^{29} \mathrm{Si}$ mostrado na figura 6.7. No eixo vertical está representada a projeção integral correspondente ao espectro de polarização cruzada de ${ }^{29}$ Si e no eixo horizontal está representada a projeção integral sobre a freqüência de ${ }^{1} \mathrm{H}$ correspondendo ao espectro dos ${ }^{1} \mathrm{H}$ que estão polarizando os ${ }^{29} \mathrm{Si}$. Os subespectros, ao longo da freqüência de ${ }^{1} \mathrm{H}$, são referentes aos prótons próximos aos sítios de $\mathrm{Q}^{0}$, $\mathrm{Q}^{1}, \mathrm{Q}^{2}$ e $\mathrm{Q}^{3}$. A linha da espécie $\mathrm{Q}^{4}$ não foi observada, o que já era esperado pelo resultado do espectro de polarização cruzada (figura 6.3b). O traço superior mostra o espectro de polarização 
direta do ${ }^{1} \mathrm{H}$ com posição central em $4.9 \mathrm{ppm}$. Na tabela 6.3 estão os desvios químicos dos espectros de ${ }^{1} \mathrm{H}$ com relação aos desvios químicos do ${ }^{29} \mathrm{Si}$.

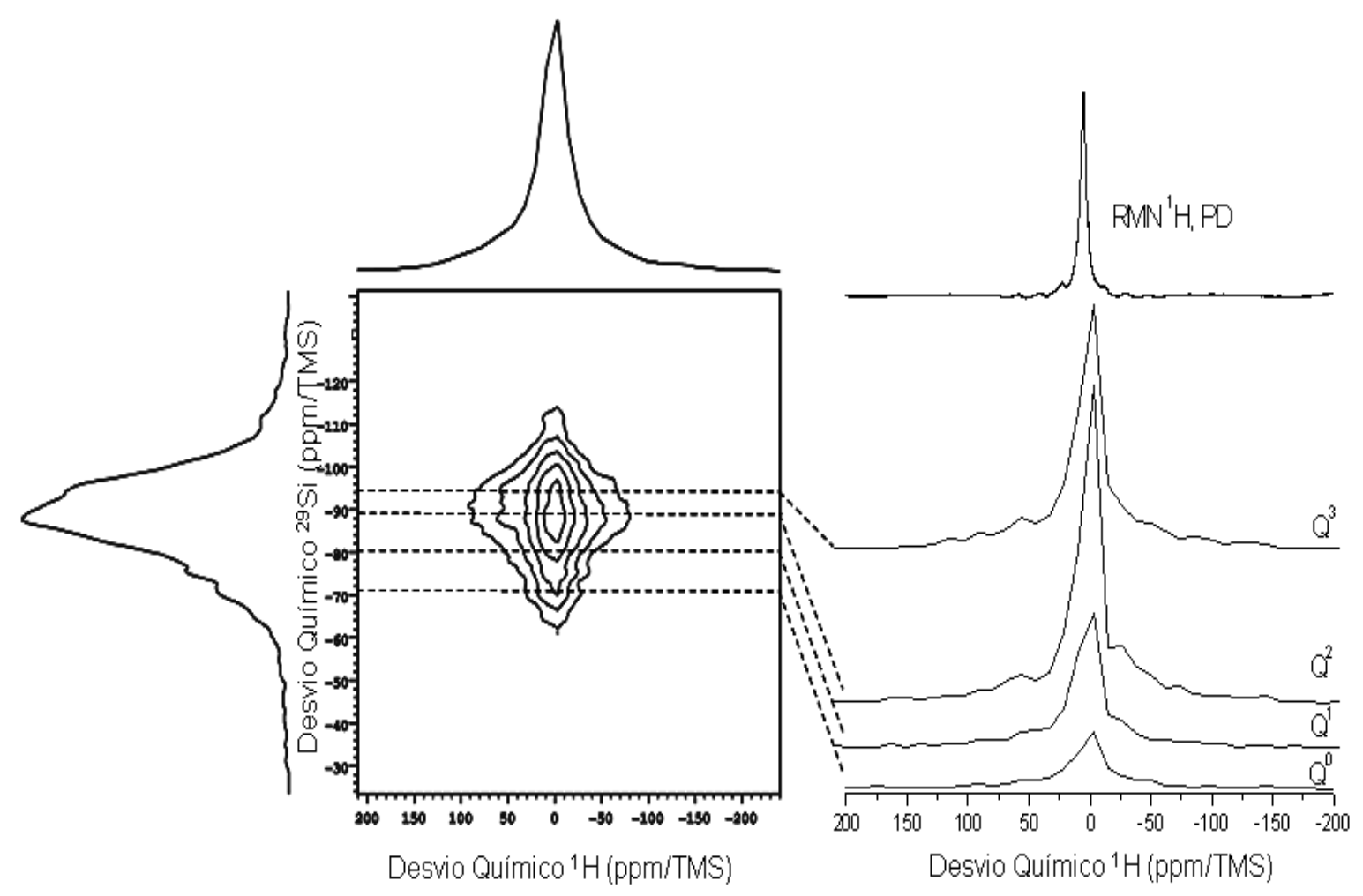

Figura 6.7- Espectro bidimensional de HETCOR $\left\{{ }^{1} \mathrm{H}\right\}-{ }^{29} \mathrm{Si}$ do gel $+\mathrm{LiNO}_{3}-\mathrm{NaOH}$. Eixo vertical: desvio químico e espectro projetado de ${ }^{29} \mathrm{Si}$. Eixo horizontal: desvio químico e espectro projetado do ${ }^{1} \mathrm{H}$. Subespectros mostrados do lado direito: seções do espectro bidimensional, correspondentes às posições dos sítios $\mathbf{Q}^{0}$, $\mathrm{Q}^{1}, \mathrm{Q}^{2}, \mathrm{Q}^{3}$. Espectro superior: espectro de ${ }^{1} \mathrm{H}$ em $1 \mathrm{D}$.

As linhas centrais dos subespectros apresentam larguras por volta de $10 \mathrm{KHz}$, causadas pelo acoplamento dipolar homonuclear entre ${ }^{1} \mathrm{H}$, semelhantes às linhas centrais dos subespectros do gel. Também aqui, a largura dessas linhas dos subespectros indica que a rotação da amostra por volta de $6.6 \mathrm{KHz}$ é insuficiente para eliminar completamente a anisotropia do acoplamento homonuclear. Os subespectros apresentam desvios químicos em -2,6ppm, diferente dos subespectros do gel em -5,9ppm, indicando possíveis efeitos do $\mathrm{Li}^{+}$. As bandas laterais possuem baixa intensidade e estão parcialmente superpostas, fato que indica acoplamento dipolar moderado entre os prótons (45), indicando que os núcleos de Si dos grupos de silicatos são polarizados pelos prótons provenientes de grupos hidroxilas das ligações Si-OH dos grupos $\mathrm{Q}^{\mathrm{n}}$. O espectro de polarização direta de ${ }^{1} \mathrm{H}$ é referente principalmente à água contida na amostra. $\mathrm{O}$ 
valor de desvio químico da linha central deste espectro não condiz com o valor da linha central dos subespectros, indicando que a água não é responsável pela polarização dos grupos de silicatos e sim apenas os grupos hidroxilas.

\subsubsection{5 ${ }^{7} \mathrm{Li}-\mathrm{RMN}$}

$\mathrm{Na}$ amostra de gel $+\mathrm{LiNO}_{3}-\mathrm{NaOH}$ foram realizadas medidas estáticas do núcleo de ${ }^{7} \mathrm{Li}$ utilizando sequência de spin-eco de Hahn, cujo espectro é mostrado na figura 6.8. Essa técnica foi aplicada para tentar medir o acoplamento de quadrupolo elétrico e obter informação sobre a simetria do ambiente ao redor do núcleo. Na figura 6.8 é observada apenas uma linha lorentziana centrada em -0,6ppm, correspondente às ligações Si-O-Li. É descartada a hipótese de essa linha corresponder ao reagente usado no tratamento $\left(\mathrm{LiNO}_{3}\right)$, pois esta tem um desvio químico em MAS de -1,5ppm, além disso os resultados dos experimentos de ${ }^{7} \mathrm{Li}$-MAS, realizados anteriormente, mostram que o $\mathrm{LiNO}_{3}$ reage completamente durante o processo do tratamento do gel (9). O padrão de acoplamento quadrupolar não é visível no espectro, conclui-se então, que o gradiente de campo elétrico em torno do núcleo de Li é baixo, o que representa sítios de alta simetria.

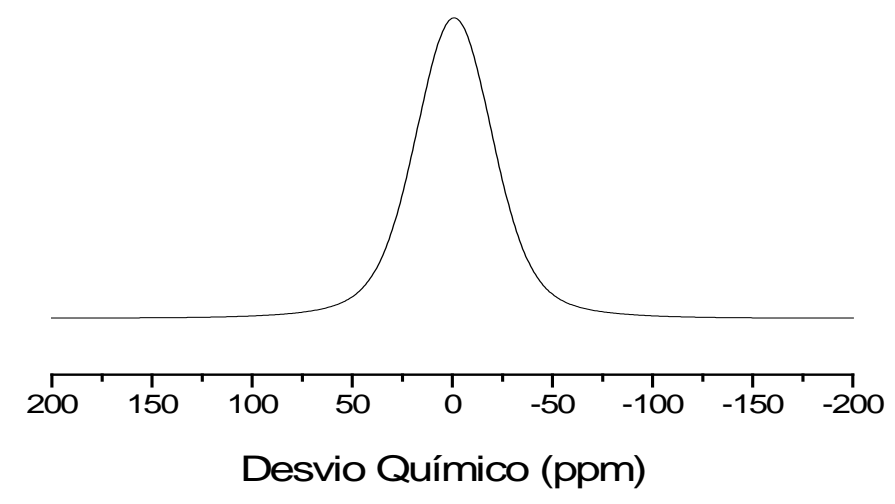

Figura 6.8- Espectro estático de ${ }^{7} \mathrm{Li}$ utilizando sequência de spin eco da amostra de gel $+\mathrm{LiNO}_{3}-\mathrm{NaOH}$. 


\subsubsection{6 ${ }^{23} \mathrm{Na}-\mathrm{RMN}$}

O sódio é o elemento mais abundante na estrutura do gel depois do Si, K e O. Por este motivo foi realizado o experimento de $\mathrm{RMN}$ de ${ }^{23} \mathrm{Na}$, complementando os resultados previamente obtidos em nosso laboratório (9). A figura 6.9 apresenta os espectros de MAS do núcleo de ${ }^{23} \mathrm{Na}$ no gel e gel $+\mathrm{LiNO}_{3}-\mathrm{NaOH}$. As medidas foram feitas com técnicas de ângulo mágico (MAS) para diminuir a anisotropia do espectro e assim ser possível identificar as possíveis fases cristalinas ou componentes amorfos.

Pela figura 6.9a observa-se que o espectro de gel possui uma linha larga. Esse espectro é atribuído ao $\mathrm{Na}_{2} \mathrm{CO}_{3} \cdot \mathrm{NaHCO}_{3} \cdot 2 \mathrm{H}_{2} \mathrm{O}$ (trona) $(3,52)$. Já no espectro do gel tratado com solução de Li (figura 6.9b), observa-se o aparecimento de duas linhas estreitas e uma linha mais larga na base. Estas linhas são identificadas como $\mathrm{NaNO}_{3}$ em -8ppm e a outra linha estreita em 7ppm e a linha de padrão anisotrópico largo entre 0 e 10 ppm correspondem aos dois sítios cristalográficos: $\mathrm{Na}_{2} \mathrm{CO}_{3}$ (sítio I) e $\mathrm{Na}_{2} \mathrm{CO}_{3}$ (sítio II) (9). Através da integração numérica das áreas sob as linhas de ${ }^{23} \mathrm{Na}-\mathrm{RMN}$ foi possível calcular a razão entre estas duas fases cristalinas: $\mathrm{Na}_{2} \mathrm{CO}_{3} / \mathrm{NaNO}_{3}=3 / 2$.

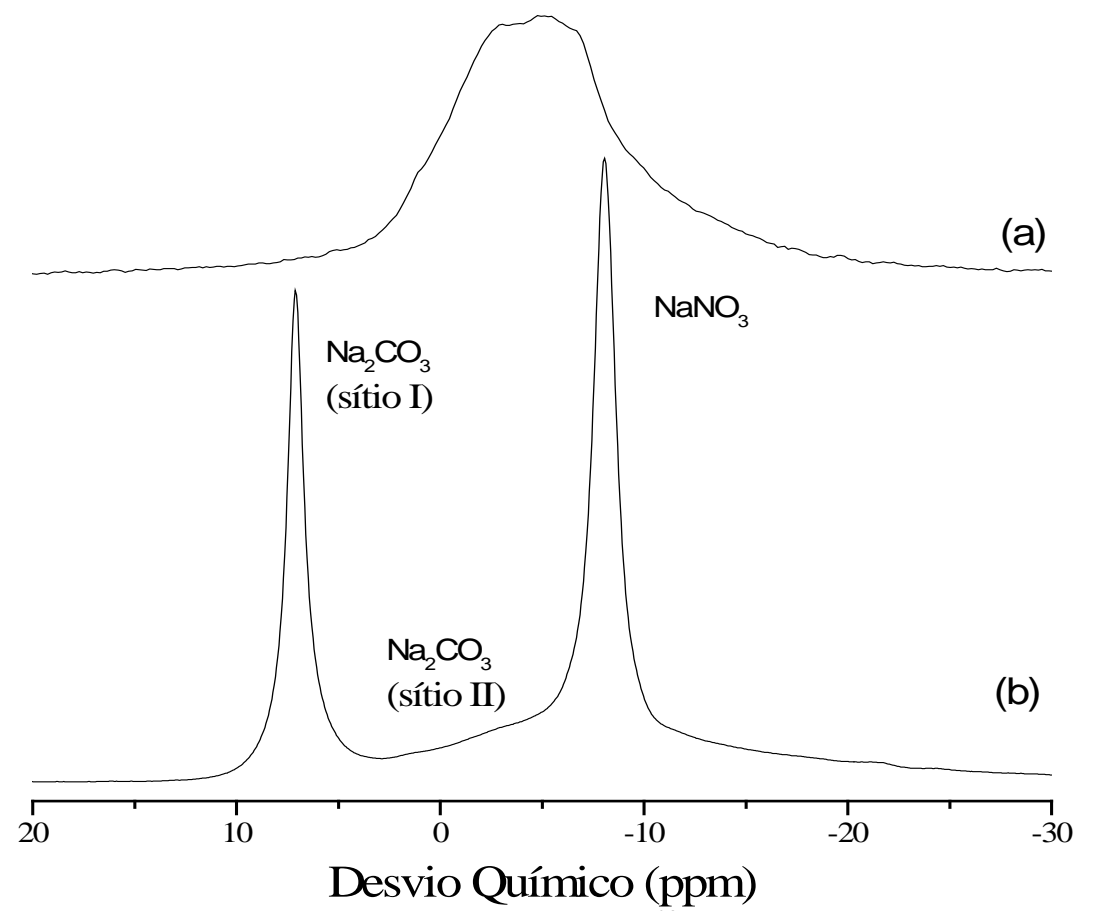

Figura 6.9- Espectro de RMN de alta resolução (MAS) do núcleo de ${ }^{23} \mathrm{Na}$. (a) gel: Trona (1). (b) gel $+\mathrm{LiNO}_{3}$ $\mathrm{NaOH}$. 
Através do experimento de ${ }^{23} \mathrm{Na}-\mathrm{RMN}$ em condições de baixa resolução utilizando a técnica de spin-eco de Hahn foi possível obter o acoplamento quadrupolar elétrico, útil para identificar a simetria ou tipo de ligação química ao redor do núcleo com I=3/2 (31).

Do espectro da figura 6.10 do gel $+\mathrm{LiNO}_{3}-\mathrm{NaOH}$, observa-se uma linha central larga devido ao acoplamento de quadrupolo elétrico e as linhas satélites (indicadas por asteriscos) equidistantes da linha central. Nas linhas satélites há um leve alargamento causado pela superposição entre os padrões de $\mathrm{Na}_{2} \mathrm{CO}_{3}$ (sítio I) e $\mathrm{NaNO}_{3}$. O cálculo da constante de acoplamento quadrupolar aparente é feito através do $\Delta$ da equø̧ão 3.31 que é equivalente à distância em $\mathrm{Hz}$ entre as linhas satélites: $\mathrm{Pq}=\Delta / 2=340 \mathrm{KHz}$.

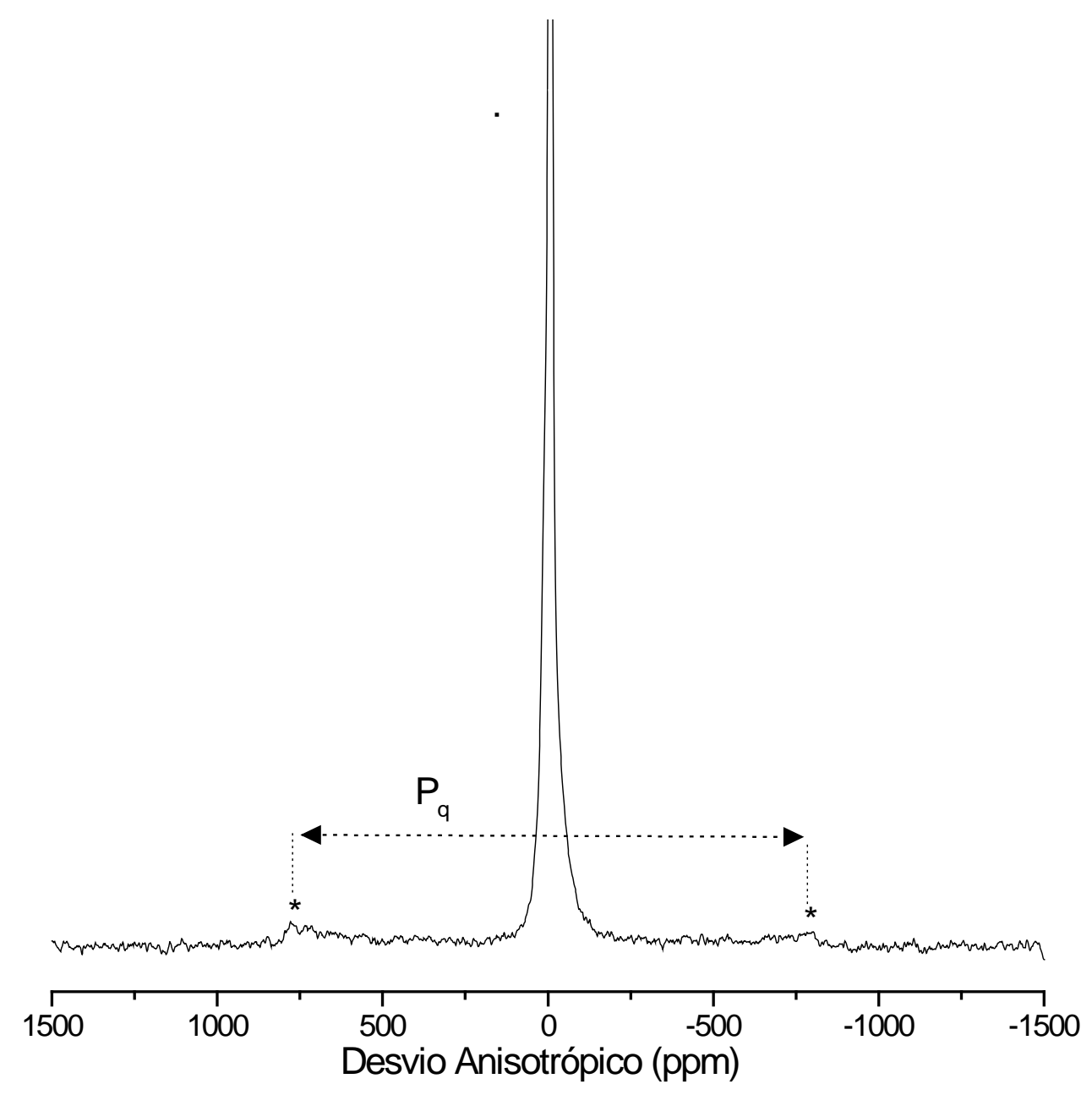

Figura 6.10- Espectro estático de $\mathrm{RMN}$ de ${ }^{23} \mathrm{Na}$ na amostra de gel $+\mathrm{LiNO}_{3}-\mathrm{NaOH}$, sequência de spin-eco. As linhas indicadas por asterisco correspondem aos máximos do padrão de policristal das transições satélites. 
O experimento MAS não é capaz de fornecer a constante de quadrupolo dos múltiplos sítios. Para determinar os parâmetros de acoplamento quadupolar do núcleo de ${ }^{23} \mathrm{Na}$ na amostra de gel $+\mathrm{LiNO}_{3}-\mathrm{NaOH}$, foi aplicada a técnica de 3Q-MAS, resultando o espectro mostrado na figura 6.11. A projeção no eixo vertical corresponde à dimensão anisotrópica e é similar ao espectro da figura 6.9. A perda de intensidade do sinal do sítio I do $\mathrm{Na}_{2} \mathrm{CO}_{3}$, comparado com o espectro MAS, é devido à perda de coerência causada pela relaxação ou pelo baixo acoplamento quadrupolar de segunda ordem. Os parâmetros de acoplamento iso e $\mathrm{P}_{\mathrm{q}}$ (37) estão listados na tabela 6.4. Comparando o valor do acoplamento quadrupolar obtido no experimento de 3Q-MAS com o experimento estático da figura 6.10, observa-se que os que os valores são compatíveis. Os valores de $\mathrm{P}_{\mathrm{q}} \mathrm{e} \delta_{\text {iso }}$ do sítio II do $\mathrm{Na}_{2} \mathrm{CO}_{3}$ são proximos aos atribuidos ao gel (1.1MHz) (3).

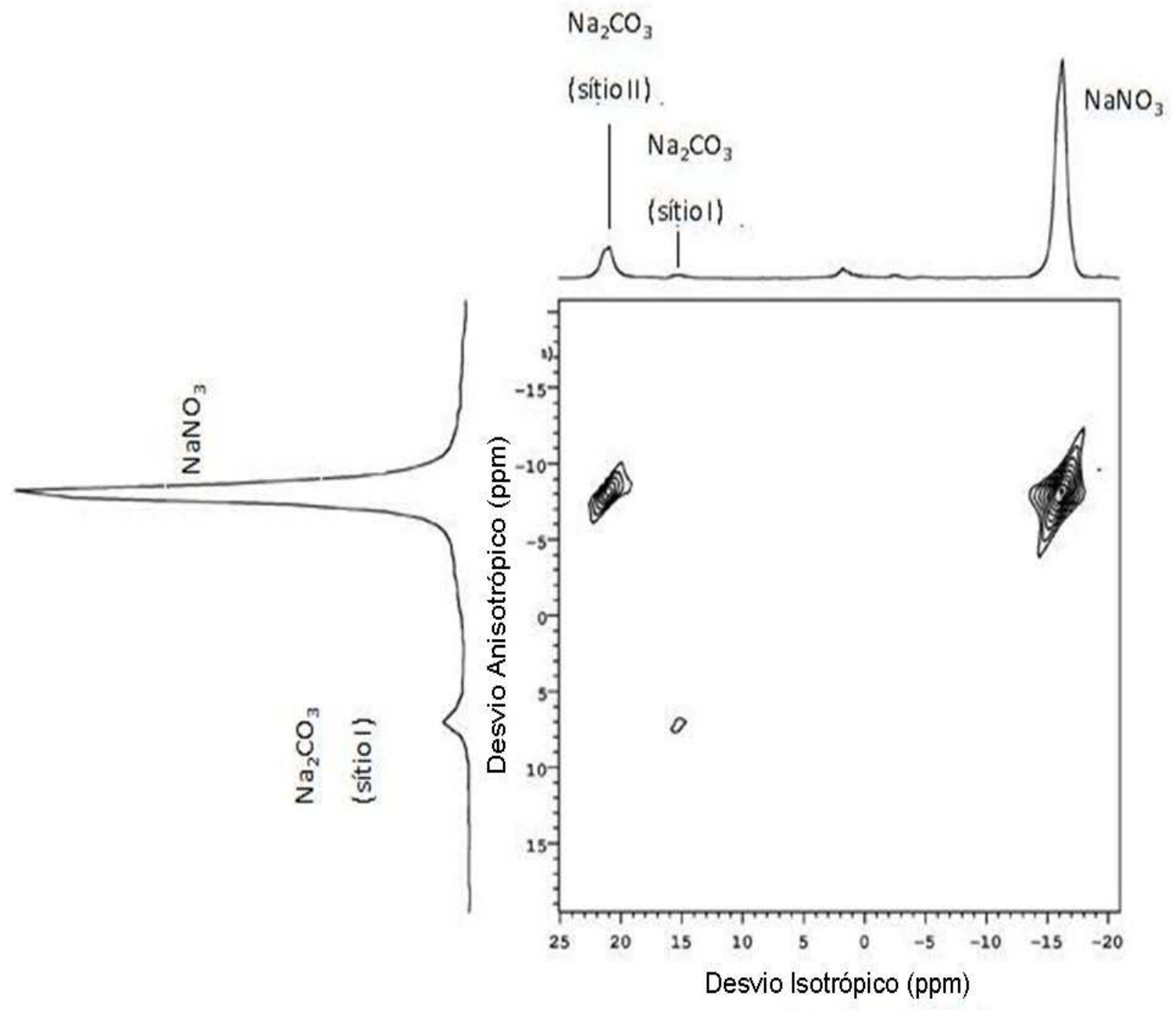

Figura 6.11- Experimento de 3Q-MAS de ${ }^{23} \mathrm{Na}$ na amostra de gel $+\mathrm{LiNO}_{3}-\mathrm{NaOH}$. No eixo vertical está o desvio anisotrópico e no horizontal o desvio isotrópico. 


\begin{tabular}{|c|c|c|}
\hline Sítio & $\delta_{\text {iso }}(\mathrm{ppm})$ & $\mathbf{P}_{\mathbf{Q}}(\mathbf{M H z})$ \\
\hline $\mathrm{NaNO}_{3}$ & $-7,7$ & 0,4 \\
\hline $\mathrm{Na}_{2} \mathrm{CO}_{3}$ (sítio I) & 7,1 & 0,2 \\
\hline $\mathrm{Na}_{2} \mathrm{CO}_{3}$ (sítio II) & $-0,6$ & 0,9 \\
\hline
\end{tabular}

\subsubsection{Tratamento com solução de MTMS (gel + MTMS)}

Três amostras de gel tratadas com solução de MTMS foram medidas: gel + MTMS, gel + $\mathrm{KOH}+\mathrm{MTMS}$, gel + MTMS + KOH, gel + NaOH + MTMS e gel + MTMS + NaOH. Foram obtidos resultados através das técnicas de: difração de raios-X, polarização direta de MAS-RMN dos núcleos de ${ }^{29}$ Si e ${ }^{13} \mathrm{C}$, polarização cruzada $\left\{{ }^{1} \mathrm{H}\right\}-{ }^{29} \mathrm{Si}$ e HETCOR $\left\{{ }^{1} \mathrm{H}\right\}-{ }^{29} \mathrm{Si}$.

\subsubsection{Difração de Raios-X}

As amostras de gel + KOH + MTMS e gel + NaOH + MTMS foram analisadas através de difração de raios-x e os difratogramas obtidos são apresentados nas figuras 6.12 e 6.13 respectivamente.

O difratograma da amostra de gel $+\mathrm{KOH}+$ MTMS, figura 6.12, não mostra picos de difração significativos que possam ser associados a fases cristalinas, apenas uma difração larga por volta de $29^{\circ}$, que usualmente observada em silicatos amorfos.

No difratograma da amostra de gel $+\mathrm{NaOH}+\mathrm{MTMS}$, figura 6.13, há picos não identificados que mostram a presença de fases cristalinas e há difrações correspondentes á fases cristalinas entre $30^{\circ}$ e $40^{\circ}$ que podem ser associados a $\mathrm{K}_{2} \mathrm{Si}_{2} \mathrm{O}_{5}$ (54). 


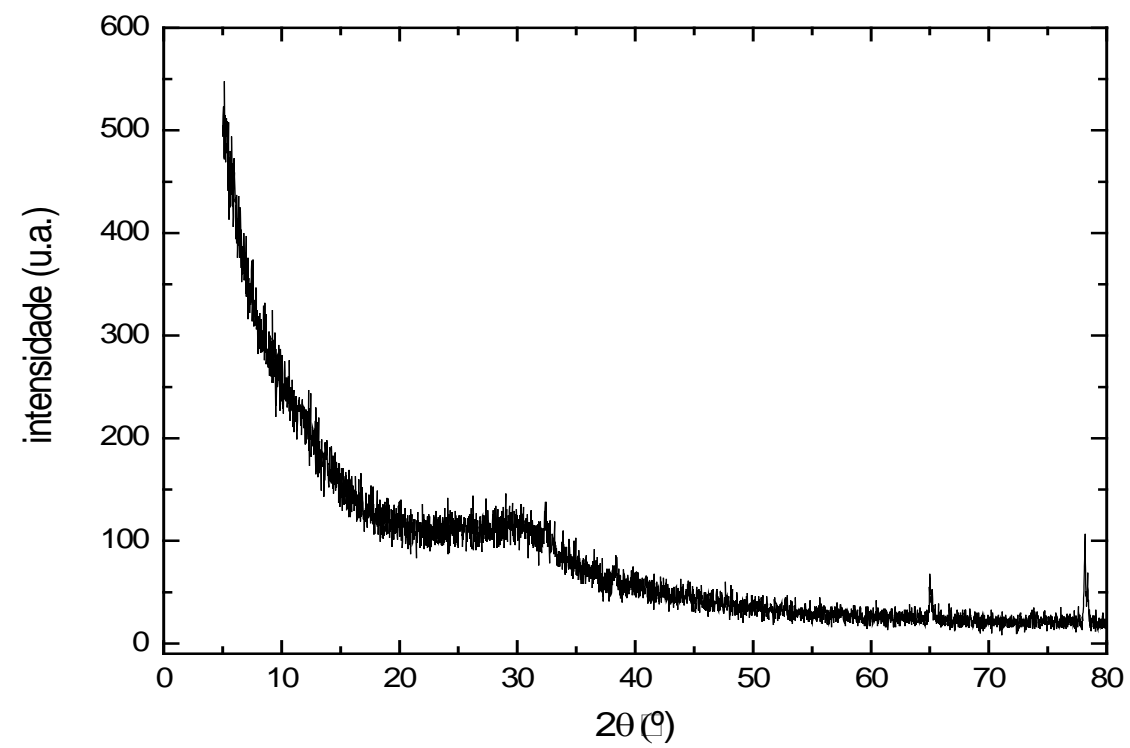

Figura 6.12- Difratograma de Raio X de pó para o material resultante do ataque do gel com solução de $\mathrm{KOH}$ e tratamento com MTMS.

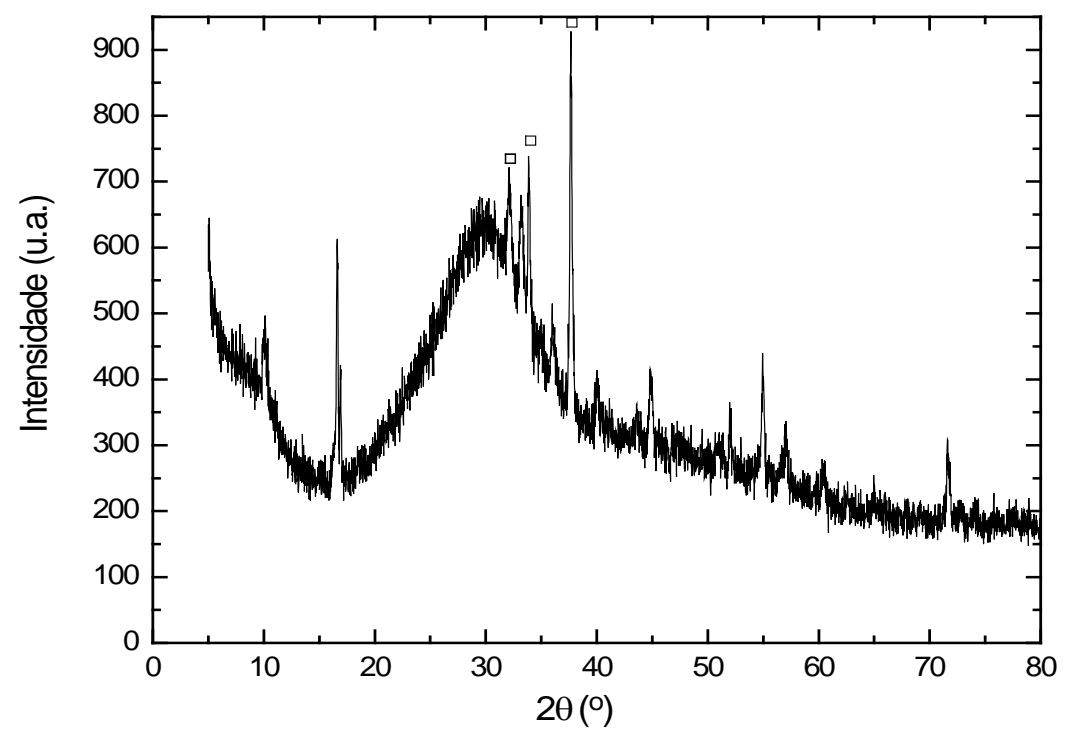

Figura 6.13- Difratograma de Raio X de pó para o material resultante do ataque do gel com solução de $\mathrm{NaOH}$ e tratamento com MTMS. $\square \mathrm{K}_{2} \mathrm{Si}_{2} \mathrm{O}_{5}$. 


\subsubsection{2 ${ }^{29} \mathrm{Si}-\mathrm{RMN}$}

Nas amostras de gel + MTMS, gel + KOH + MTMS, gel + MTMS + KOH, gel + NaOH + MTMS e gel + MTMS + NaOH foram realizados experimentos de polarização direta de ${ }^{29} \mathrm{Si}$ e de polarização cruzada $\left\{{ }^{1} \mathrm{H}\right\}-{ }^{29} \mathrm{Si}$. Os espectros são apresentados na figura 6.2 e 6.3 respectivamente.

\section{(i) gel + MTMS:}

No espectro de polarização direta de ${ }^{29} \mathrm{Si}$ da amostra de gel + MTMS, figura 6.2c, observa-se a presença dos grupos silicatos $\mathrm{Q}^{1}, \mathrm{Q}^{2}, \mathrm{Q}^{3}, \mathrm{Q}^{4}, \mathrm{D}$ e $\mathrm{T}$, com desvios químicos e intensidades indicadas na tabela 6.1. Observa-se que o espectro do gel após exposição ao MTMS é muito semelhante ao espectro do gel, permanecendo o sítio $\mathrm{Q}^{3}$ como o mais abundante e número médio de NBO igual a 1,0. As ligações formadas de Si-C, provenientes das cadeias de carbono do MTMS, originam os sítios D e T.

No espectro de polarização cruzada do gel + MTMS, figura 6.3c, é possível observar as linhas dos sítios $\mathrm{Q}^{2}, \mathrm{Q}^{3}, \mathrm{Q}^{4}$, D e T. Pela tabela 6.1, os aumentos significativos das áreas dos sítios $\mathrm{D}$ e $\mathrm{T}$, onde há ligações Si-C, estão relacionados à $\mathrm{H}$ ligados ao $\mathrm{C}$ que estão muito próximos do ${ }^{29} \mathrm{Si}$.

\section{(ii) gel + KOH + MTMS}

No espectro de polarização direta de ${ }^{29}$ Si do gel + KOH + MTMS, figura 6.2d, é possível identificar linhas correspondentes aos sítios $\mathrm{D}, \mathrm{T}, \mathrm{Q}^{1}$ e $\mathrm{Q}^{2}$. Os sítios $\mathrm{Q}^{1}$ apresentaram sinais em 78.8ppm e -81.4ppm e formas de linhas mais estreitas, foram ajustados por curvas lorentzianas (características de fases cristalinas) e podem estar associado a sítios mais organizados de $\mathrm{Q}^{1}$. O sinal relativo ao sítio $\mathrm{Q}^{2}$ em -86.4ppm, assim como $\mathrm{Q}^{1}$, também corresponde a ambiente de silicatos mais organizados sendo ajustados por funções lorentzianas. A linha em -94.2ppm correspondente a $\mathrm{Q}^{3}$ poderia ser identificada de acordo com sua posição como $\mathrm{K}_{2} \mathrm{Si}_{2} \mathrm{O}_{5}$ (55). Fases cristalinas de $\mathrm{Na}_{2} \mathrm{Si}_{2} \mathrm{O}_{5}$ também apresentam desvios químicos nesta posição (55), o que significa que esta linha poderia ser de uma superposição das duas fases, mas ainda com predominância do $\mathrm{K}_{2} \mathrm{Si}_{2} \mathrm{O}_{5}$, pois o $\mathrm{K}$ apresenta-se em maior quantidade no gel do que o Na. As áreas e desvios químicos correspondente aos ajustes de cada sítio são apresentados na tabela 6.5. 
A diferença entre os espectros das amostras de gel e gel + $\mathrm{KOH}+$ MTMS é compatível com a observação feita na seção 3.2.1 de que o ataque do gel com a solução de KOH resultou numa visível dissolução do gel. A identificação de fases cristalinas por RMN seria aparentemente incompatível com os resultados de difração de Raios-X na amostra de gel + $\mathrm{KOH}+\mathrm{MTMS}$ (figura 6.12), pois no difratograma não são observados picos de difração estreitos e sim apenas fase amorfa de silicatos. No entanto deve ser considerada a diferença de sensibilidade de ambas as técnicas. Para observar difração de Raios-X é necessário que existam domínios cristalinos de tamanho e qualidade suficiente para definir planos de Bragg. No caso de RMN, pelo fato da técnica ser local, domínios cristalinos de pequenos tamanhos, em escala nanométrica, ou perturbados por defeitos podem ainda ser detectados e identificados como localmente ordenados desde que o ambiente ao redor dos tetraedros $\mathrm{SiO}_{4}$ não seja fortemente distorcido. No caso de silicatos de potássio, muitos dos quais são higroscópicos, a absorção de água na estrutura pode perturbar consideravelmente a cristalinidade. Especificamente em silicatos lamelares como o $\mathrm{K}_{2} \mathrm{Si}_{2} \mathrm{O}_{5}$, existe a possibilidade de desordenar os planos definidos pelos tetraedros de silicatos devido à incorporação da molécula de $\mathrm{H}_{2} \mathrm{O}$.

Nos experimentos de polarização cruzada desta amostra, figura 6.3d, apenas as linhas D, $\mathrm{T}, \mathrm{Q}^{2}$ e a parte amorfa do gel são polarizadas pelos ${ }^{1} \mathrm{H}$. O aumento substancial de intensidade das linhas dos sítios D e T se dá pelo fato dos prótons ligados ao C do MTMS estarem muito próximos dos ${ }^{29} \mathrm{Si}$. Por outro lado, nas linhas dos sítios em ambientes cristalinos observa-se intensidade nula $\left(\mathrm{Q}^{1}\right.$ e $\left.\mathrm{Q}^{3}-\mathrm{K}_{2} \mathrm{Si}_{2} \mathrm{O}_{5}\right)$ ou muito baixa $\left(\mathrm{Q}^{2}\right)$, indicando que na estequiometria destes compostos não há $\mathrm{H}$ ou as moléculas de água inseridas se encontram em movimento, reduzindo drasticamente o acoplamento dipolar ${ }^{1} \mathrm{H}-{ }^{29} \mathrm{Si}$.

(iii) gel + NaOH + MTMS:

$\mathrm{O}$ espectro do gel $+\mathrm{NaOH}+\mathrm{MTMS}$, figura 6.2e, é semelhante ao espectro do gel $+\mathrm{KOH}$ + MTMS. É possível identificar as linhas correspondentes aos sítios D, T, Q ${ }^{1}, \mathrm{Q}^{2}$ e $\mathrm{Q}^{3}$. Os sítios D e T são referentes às ligações de Si-C do MTMS. O sinal em -78.1ppm pode estar associado a sítios mais organizados de $\mathrm{Q}^{1}$, o sinal em -85.7ppm é referente ao sítio $\mathrm{Q}^{2}$, ambos ajustados através de funções lorentzianas. A linha em -93.7ppm pode ser identificada pelo valor de desvio como $\mathrm{Na}_{2} \mathrm{Si}_{2} \mathrm{O}_{5}$ (55), correspondendo a um sítio $\mathrm{Q}^{3}$. O difratograma desta amostra indica a presença de fases cristalinas, sendo identificado o $\mathrm{K}_{2} \mathrm{Si}_{2} \mathrm{O}_{5}$. Portanto, a linha observada em - 
93.7ppm poderia corresponder a $\mathrm{K}_{2} \mathrm{Si}_{2} \mathrm{O}_{5}$, tal como é observada na amostra gel + $\mathrm{KOH}+\mathrm{MTMS}$, onde a quantidade de $\mathrm{Na}$ é baixa. A linha larga observada na base no espectro atribuída aos silicatos $\mathrm{Q}^{3}$ e $\mathrm{Q}^{4}$, corresponde a uma estrutura amorfa, possivelmente em estado de gel. Na seção 5.3.1, foi observado que após os ataque com $\mathrm{NaOH}$ houve dissolução do gel, assim como no ataque com $\mathrm{KOH}$, que vai de acordo com os resultados dos espectros que mostram que não houve integridade na estrutura de silicatos após o ataque.

Nos experimentos de polarização cruzada desta amostra, figura 6.3e, as linhas $\mathrm{D}, \mathrm{T}, \mathrm{Q}^{1}$, $\mathrm{Q}^{2}$ e $\mathrm{Q}^{3}-\mathrm{Na}_{2} \mathrm{Si}_{2} \mathrm{O}_{5}$ são polarizadas pelos ${ }^{1} \mathrm{H}$. Assim como no gel + KOH + MTMS, as linhas D e T são polarizadas pelos prótons ligados ao C do MTMS que estão muito próximos do Si e por este motivo apresenta linhas de grande intensidade comparadas ao espectro de polarização direta da amostra. Porém, ao contrário do espectro de polarização cruzada do gel + $\mathrm{KOH}+\mathrm{MTMS}$, observa-se que todos os sítios observados em polarização direta na amostra atacada com $\mathrm{NaOH}$ são polarizados pelos ${ }^{1} \mathrm{H}$, indicando que os produtos precipitados apresentam considerável incorporação de $\mathrm{OH}$.

\section{(iv) gel + MTMS + KOH}

No espectro da amostra de gel + MTMS + KOH apresentado na figura 6.1f observa-se a presença dos sítios $\mathrm{D}, \mathrm{Q}^{1}$ e $\mathrm{Q}^{2}$ e uma linha correspondente ao sítio $\mathrm{Q}^{3}$ em -93.8ppm identificada como $\mathrm{K}_{2} \mathrm{Si}_{2} \mathrm{O}_{5}$ (55). Este espectro é semelhante ao espectro da amostra (ii), porém observa-se que todas as linhas são mais largas, o que indica maior grau de desordem estrutural ao redor destes sítios. Conseqüentemente, foram ajustadas linhas gaussianas, em vez de lorentzianas, para determinar as intensidades e posições centrais indicadas na tabela 6.5.

O espectro de polarização cruzada desta amostra, figura 6.2f, apresenta linhas correspondentes aos sítios $\mathrm{D}, \mathrm{Q}^{1}, \mathrm{Q}^{2}$ e $\mathrm{Q}^{3}$ de $\mathrm{K}_{2} \mathrm{Si}_{2} \mathrm{O}_{5}$ observados em polarização direta, mais sítios $\mathrm{M}$ e $\mathrm{T}$. A intensidade das linhas de $\mathrm{M}, \mathrm{D}$ e $\mathrm{T}$ é substancialmente incrementada em polarização cruzada, devido à proximidade entre o Si e os prótons de grupos $\mathrm{CH}_{3}$, permitindo a detecção destas espécies. 
Tabela 6.5- Desvio químico $\delta$ (ppm, módulo do valor negativo) e área relativa A (\%) das gaussianas dos espectros de ${ }^{29} \mathrm{Si}-\mathrm{RMN}$ de polarização direta e de polarização cruzada $\left\{{ }^{1} \mathrm{H}\right\}{ }^{29} \mathrm{Si}$ para os sítios $\mathrm{Q}^{\mathrm{n}}$, T, D e M no gel+KOH+MTMS, gel+MTMS+KOH, gel+NaOH+MTMS e gel+MTMS+NaOH. $\mathrm{NBO}=$ número médio de oxigênio não ponte. $\mathrm{PD}=$ Polarização Direta. $\mathrm{PC}=$ Polarização Cruzada. $\mathrm{A}_{\mathrm{PC}} / \mathrm{A}_{\mathrm{PD}}=$ razão entre as áreas de polarização cruzada e polarização direta.

\begin{tabular}{|c|c|c|c|c|c|c|c|c|c|c|c|c|c|}
\hline & & \multicolumn{3}{|c|}{ Gel+KOH+silano } & \multicolumn{3}{|c|}{ Gel+silano+KOH } & \multicolumn{3}{|c|}{ Gel+NaOH+silano } & \multicolumn{3}{|c|}{$\mathrm{Gel}+$ silano $+\mathrm{NaOH}$} \\
\hline \multirow{3}{*}{$\mathrm{M}$} & & PD & PC & $\begin{array}{l}\mathbf{A}_{\mathbf{P C}} / \\
\mathbf{A}_{\mathbf{P D}}\end{array}$ & PD & PC & $\begin{array}{l}\mathbf{A}_{\mathbf{P C}} / \\
\mathbf{A}_{\mathbf{P D}}\end{array}$ & PD & PC & $\begin{array}{c}\mathbf{A}_{\mathbf{P C}} / \\
\mathbf{A}_{\mathbf{P D}}\end{array}$ & PD & PC & $\begin{array}{l}\mathbf{A}_{\mathbf{P C}} / \\
\mathbf{A}_{\mathbf{P D}}\end{array}$ \\
\hline & $\delta$ & & 49,9 & & & 50,6 & & & & & & 49,8 & \\
\hline & A & & 3 & & & 10 & & & & & & 8 & \\
\hline \multirow[t]{2}{*}{$\mathrm{D}$} & $\delta$ & 57,1 & 58,1 & & 57,5 & 58,0 & & 57,5 & 58,0 & & & 57,4 & \\
\hline & A & 3 & 27 & 9 & 5 & 22 & 4,4 & 6 & 26 & 4,3 & & 31 & \\
\hline \multirow[t]{2}{*}{$\mathrm{T}$} & $\delta$ & 67,3 & 67,1 & & & 65,1 & & 66,0 & 66,0 & & 69,0 & 64,6 & \\
\hline & A & 10 & 62 & 6,2 & & 10 & & 4 & 42 & 10,5 & 8 & 17 & 2,1 \\
\hline \multirow{2}{*}{$\mathrm{Q}^{0}$} & $\delta$ & & & & 71,2 & 71,2 & 4 & 71,0 & & & & 71,6 & \\
\hline & A & & & & 1 & 4 & 4 & 1 & & & & 5 & \\
\hline \multirow[t]{2}{*}{$\mathrm{Q}^{1}$} & $\delta$ & 78,9 & & & 78,7 & 78,7 & & 78,2 & 78,3 & 0 & 78,1 & 77,8 & \\
\hline & A & 7 & & & 15 & 6 & 0,4 & 8 & 4 & 0,5 & 7 & 10 & 1,4 \\
\hline \multirow[t]{2}{*}{$\mathrm{Q}^{2}$} & $\delta$ & 86,4 & 86,9 & & 86,1 & 86,1 & & 85,8 & 85,7 & & 85,5 & 85,1 & \\
\hline & A & 17 & 3 & 0,2 & 32 & 5 & 0,2 & 20 & 10 & 0,5 & 35 & 10 & 0,3 \\
\hline \multirow[t]{2}{*}{$\mathrm{Q}^{3}$} & $\delta$ & & & & & & & & & & 98,0 & & \\
\hline & A & & & & & & & & & & 12 & & \\
\hline \multirow[t]{2}{*}{$\mathrm{Q}^{4}$} & $\delta$ & & & & & & & & & & 108,1 & & \\
\hline & A & & & & & & & & & & 16 & & \\
\hline $\mathrm{Q}^{\mathrm{n}}$ amorfo & A & 46 & 5 & 0,2 & 27 & 39 & & 43 & 10 & & 13 & 8 & 0,6 \\
\hline \multirow{2}{*}{$\mathrm{K}_{2} \mathrm{Si}_{2} \mathrm{O}_{5}$} & $\delta$ & 94,2 & & & 93,8 & 93,5 & 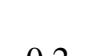 & & & & & & \\
\hline & A & 17 & & & 20 & 4 & 0,2 & & & & & & \\
\hline \multirow{2}{*}{$\mathrm{Na}_{2} \mathrm{Si}_{2} \mathrm{O}_{5}$} & $\delta$ & & & & & & & 93,7 & 94,6 & $0 \Omega$ & 93,0 & 92,0 & 12 \\
\hline & A & & & & & & & 18 & 8 & 0,4 & 9 & 11 & 1,2 \\
\hline
\end{tabular}

Nos espectros de PD e PC do gel + KOH+MTMS, há 46\% e 10\% de sítios que não foram identificados, respectivamente. Nos espectros de PD e PC do gel + MTMS + KOH, há 28\% e 53\% de sítios que não foram identificados, respectivamente. Nos espectros de PD e PC do gel + NaOH+MTMS, há 44\% e 10\% de sítios que não foram identificados, respectivamente. Nos espectros de PD e PC do gel + MTMS + $\mathrm{NaOH}$, há $21 \%$ e $30 \%$ de sítios que não foram identificados, respectivamente.

\section{(v) gel + MTMS + NaOH}

O espectro de polarização direta de ${ }^{29} \mathrm{Si}$ da amostra de gel + MTMS $+\mathrm{NaOH}$ está apresentado na figura 6.1g. O espectro mostra linhas de $\mathrm{Q}^{1}$ e $\mathrm{Q}^{2}$ com posições semelhantes às observadas na amostra atacada com $\mathrm{KOH}$, porem consideravelmente mais largas do que estas, o que indica maior desordem estrutural. Também é observada a linha $\mathrm{Q}^{3}-\mathrm{Na}_{2} \mathrm{Si}_{2} \mathrm{O}_{5}$ em -93.7ppm. São identificadas também linhas largas de sítios $Q^{3}$ e $Q^{4}$, que devem corresponder a uma 
estrutura amorfa. Os desvios químicos e áreas de todas as linhas observadas estão indicados na tabela 6.5 .

No espectro de polarização cruzada, figura 6.2g, é possível observar também linhas das espécies menos abundantes $\mathrm{M}, \mathrm{D}, \mathrm{T}$ e $\mathrm{Q}^{0}$, que apresentam grande acoplamento dipolar com ${ }^{1} \mathrm{H}$. O estado final desta amostra atacada com $\mathrm{NaOH}$ tem semelhanças com a amostra atacada com $\mathrm{KOH}$, com relação ao acoplamento com ${ }^{1} \mathrm{H}$ dos três sítios mais abundantes, $\mathrm{Q}^{1}, \mathrm{Q}^{2}$ e $\mathrm{Q}^{3}$, apresentando porém uma estrutura mais amorfa e complexa.

\subsubsection{HETCOR $\left\{{ }^{1} \mathrm{H}\right\}-{ }^{29} \mathrm{Si}$}

Na amostra de gel + MTMS foi realizado experimento de HETCOR $\left\{{ }^{1} \mathrm{H}\right\}-{ }^{29} \mathrm{Si}$ mostrado na figura 6.14. As seções são referentes aos subespectros dos ${ }^{1} \mathrm{H}$ próximos aos sítios de $\mathrm{D}, \mathrm{T}, \mathrm{Q}^{2}$, $\mathrm{Q}^{3}$ e $\mathrm{Q}^{4}$. O espectro superior corresponde ao espectro ${ }^{1} \mathrm{H}$ medido em polarização direta. Os desvios químicos dos espectros de ${ }^{1} \mathrm{H}$ com relação aos desvios químicos do ${ }^{29} \mathrm{Si}$ estão na tabela 6.3. As linhas dos subespectros apresentam larguras por volta de $8 \mathrm{KHz}$. Assim como na amostra de gel, as linhas centrais são largas com linhas sobrepostas, porem, em todas as seções, são observadas bandas laterais melhor definidas e mais intensas que nas amostras de gel (figura 6.5). Este fato indica acoplamento homonuclear moderado mais intenso que no gel, com a existência de grupos $\mathrm{OH}$ próximos no caso dos ${ }^{1} \mathrm{H}$ referentes aos grupos $\mathrm{Q}^{2}, \mathrm{Q}^{3}$ e $\mathrm{Q}^{4}$.

$\mathrm{Na}$ linha central do subespectro de ${ }^{1} \mathrm{H}$ correspondente ao silicato $\mathrm{Q}^{3}$ observam-se duas linhas, indicadas na figura 6.14 como A e B. As bandas laterais do subespectro de $\mathrm{Q}^{3}$ são mais intensas e estão sobrepostas a linha central indicando um acoplamento homonuclear dipolar moderado. Essas bandas laterais correspondem à linha B e se referem a grupos OH. A linha A é muito complexa e trata-se de uma linha estreita sem bandas laterais e por isso sem acoplamento homonuclear significativo. Este fato junto com a comparação com a posição da linha central do espectro superior de polarização direta de ${ }^{1} \mathrm{H}$, que é a mesma posição da linha $\mathrm{A}$ de $\mathrm{Q}^{3}$, sustenta a afirmação de que a linha A se trata de ${ }^{1} \mathrm{H}$ provenientes de moléculas de $\mathrm{H}_{2} \mathrm{O}$. As linhas dos subespectros de ${ }^{1} \mathrm{H}$ próximo aos sítios $\mathrm{T}$ e $\mathrm{D}$ são mais estreitas com bandas laterais de forte intensidade indicando acoplamento homonuclear mais forte que nos caso dos $\mathrm{Q}^{\mathrm{n}}$. Este 
comportamento é compatível com a presença de vários $\mathrm{H}$ mutuamente próximos, o que é esperado para estes ambientes de Si com ligações Si-C-H.

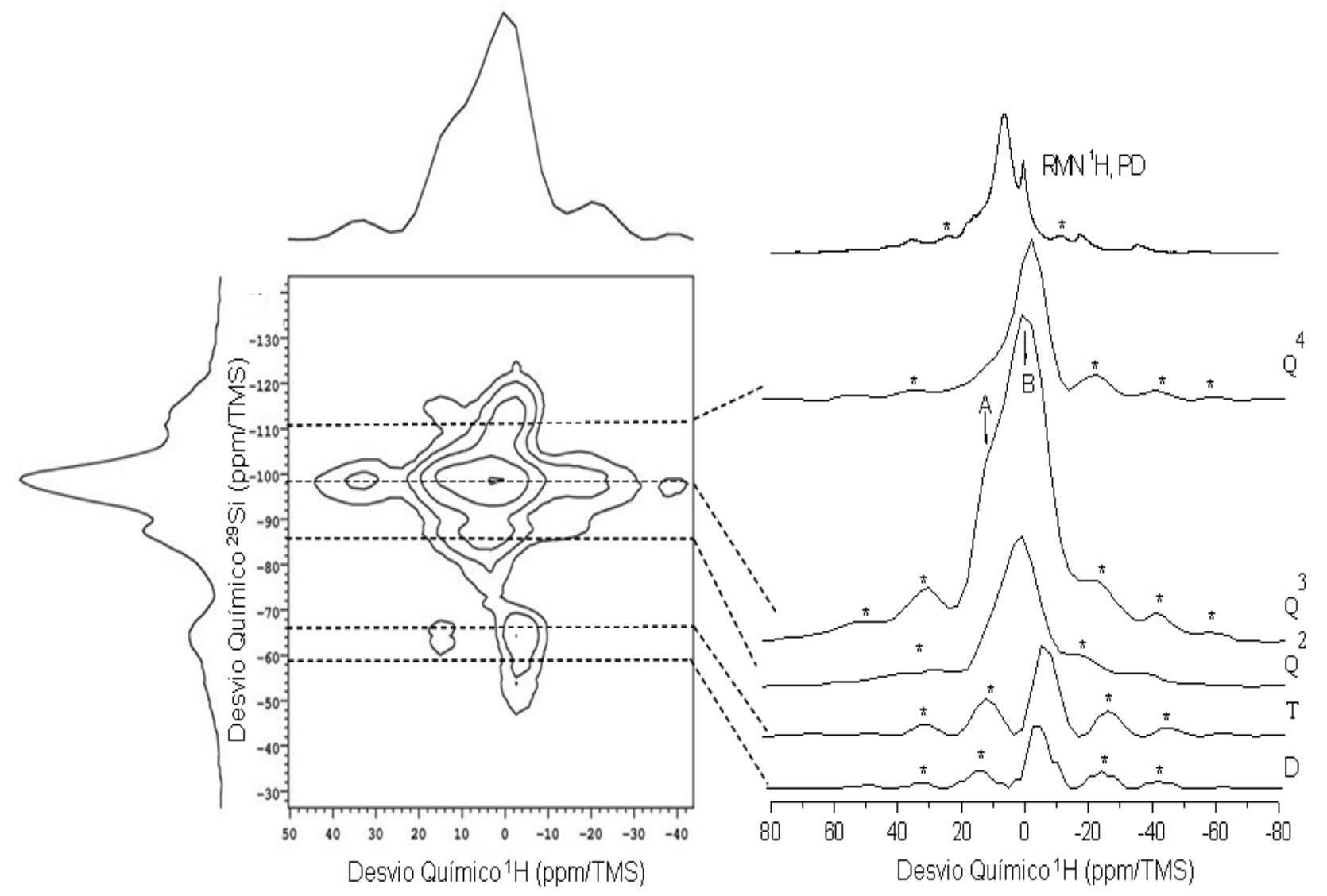

Figura 6.14- Espectro bidimensional de HETCOR $\left\{{ }^{1} \mathrm{H}\right\}-{ }^{29} \mathrm{Si}$ do gel + MTMS. Eixo vertical: desvio químico e espectro projetado de ${ }^{29}$ Si. Eixo horizontal: desvio químico e espectro projetado do ${ }^{1} \mathrm{H}$. Subespectros mostrados do lado direito: seções do espectro bidimensional, correspondentes às posições dos sítios D, $\mathrm{T}, \mathrm{Q}^{2}, \mathrm{Q}^{3}, \mathrm{Q}^{4}$. Traço superior: espectro de ${ }^{1} \mathrm{H}$ em polarização direta. Asteriscos (*): bandas laterais de rotação da amostra.

\subsubsection{4 ${ }^{13} \mathrm{C}-\mathrm{RMN}$ nas amostras de gel + MTMS e gel + KOH + MTMS}

Nas amostras de gel + MTMS e gel + KOH + MTMS, para complementar as medidas de polarização direta e cruzada, foram realizados experimentos de polarização direta de $\mathrm{RMN}$ de ${ }^{13} \mathrm{C}$ e polarização cruzada $\left\{{ }^{1} \mathrm{H}\right\}-{ }^{13} \mathrm{C}$. Os espectros obtidos são mostrados na figura 6.15. 
Os sinais fracos que aparecem marcados com asteriscos, em 133ppm, são originados na tampa do porta-amostra. Nos espectros de ambas as amostras o pico mais intenso encontra-se na região entre 0ppm e -2,5ppm, dependendo da amostra e o tipo de experimento, que corresponde a carbonos em ligações $\mathrm{SiCH}_{3}$. A detecção deste sinal é consistente com a presença dos grupos metila do MTMS. No espectro da figura 6.15d podem ser observados três sinais correspondentes a carbonos em metilas com três ambientes estruturais diferentes (-17ppm, -1,6ppm e 10,7ppm) e provavelmente menor mobilidade para as espécies em -17ppm e 10,7ppm. A tabela 6.6 apresenta os valores de desvios químicos de ${ }^{13} \mathrm{C}$ correspondente a cada amostra.

Existem também sinais de RMN na região das carbonilas, entre 160ppm e 175ppm em todas as amostras, em concentração substancialmente menor aos carbonos em grupos metila. Destes sinais, o mais intenso é observado na amostra de gel $+\mathrm{KOH}+\mathrm{MTMS}$ em polarização direta (figura 6.15c), com desvio em 169,6ppm. Este sinal estreito é típico de estado líquido, atribuição confirmada pelo fato de não ser observado em polarização cruzada (figura 6.15d): em estado líquido o acoplamento dipolar ${ }^{1} \mathrm{H}-{ }^{13} \mathrm{C}$ é desprezível, devido à alta mobilidade molecular. Esta carbonila pode ser identificada com carbonato de potássio $\left(\mathrm{K}_{2} \mathrm{CO}_{3}\right)$, que de acordo com a literatura apresenta desvio em 169,3ppm (56). Nesta mesma amostra, em polarização cruzada, é possível observar um sinal mais fraco e alargado centrado nessa posição, que indica também a presença de carbonato de potássio hidratado em estado sólido. Os espectros da amostra de gel + MTMS também mostram sinais de carbonatos em estado sólido em posições próximas, porém resulta mais difícil determinar qual é a espécie catiônica destes compostos.

Tabela 6.6- Desvio químico $\delta$ (ppm) das linhas observadas nos espectros de ${ }^{13} \mathrm{C}$-RMN de polarização direta e de polarização cruzada $\left\{{ }^{1} \mathrm{H}\right\}-{ }^{13} \mathrm{C}$ nas amostras de gel + MTMS e gel $+\mathrm{KOH}+\mathrm{MTMS}$.

\begin{tabular}{cccc}
\hline & & Gel + MTMS & Gel + KOH + MTMS \\
\hline Polarização Direta & $\mathrm{CH}_{3}$ & 0,3 & 0,7 \\
$\delta\left({ }^{13} \mathrm{C}\right)$ & $\mathrm{CO}_{3}{ }^{2-}$ & 172,9 & 169,6 \\
& $\mathrm{CH}_{3}$ & 2,7 & $-1,6$ \\
Polarização Cruzada & $\mathrm{CH}_{3}$ & 161,9 & $-17,0$ \\
$\delta\left({ }^{13} \mathrm{C}\right)$ & $\mathrm{CH}_{3}$ & & 10,7 \\
$(\mathrm{ppm})$ & $\mathrm{CO}_{3}{ }^{2-}$ & & 169,0 \\
& & & \\
\hline
\end{tabular}




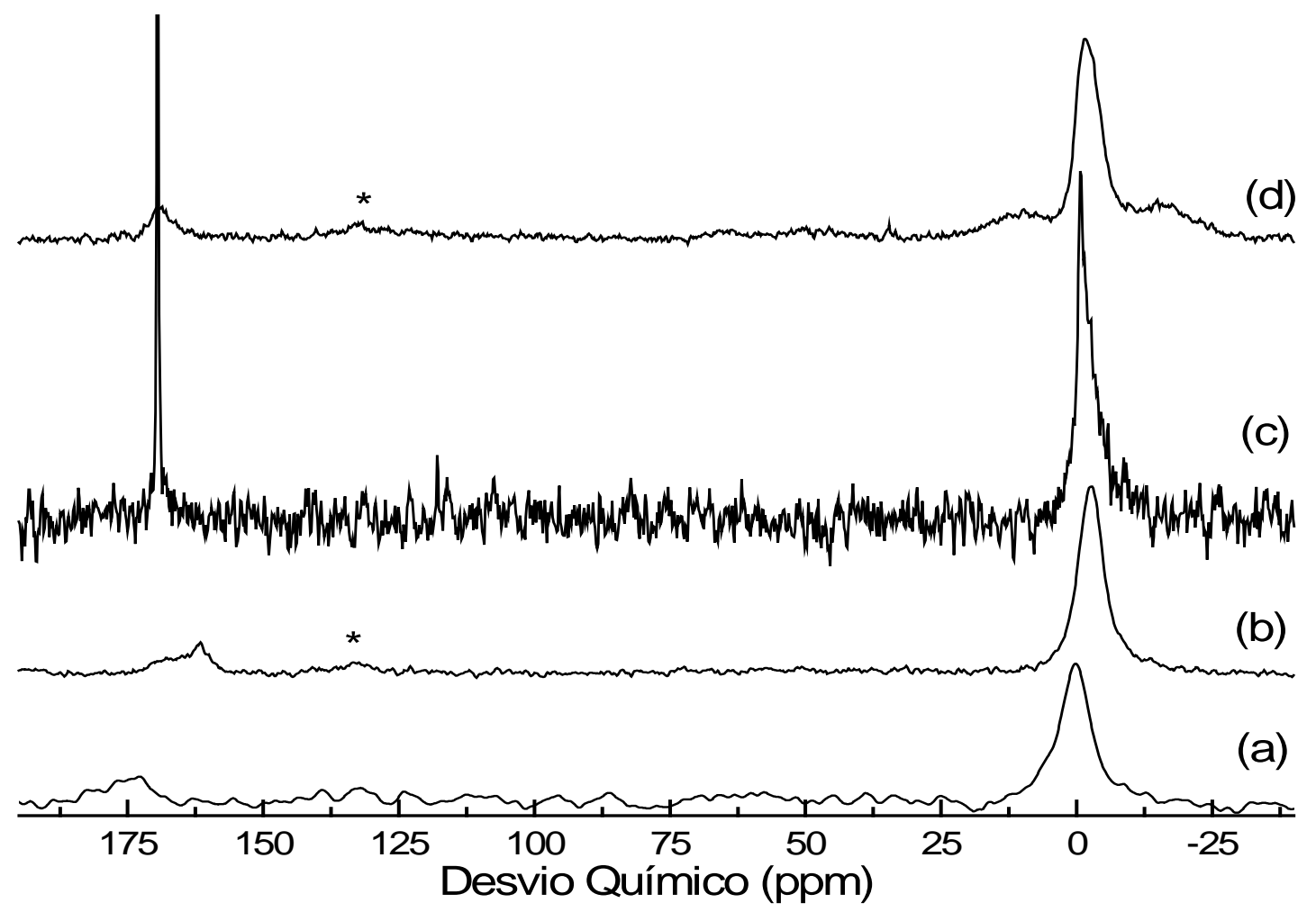

Figura 6.15- Espectros de ${ }^{13} \mathrm{C}$ em polarização direta e em polarização cruzada $\left\{{ }^{1} \mathrm{H}\right\}-{ }^{13} \mathrm{C}$. Amostra de gel + MTMS: (a) polarização direta, (b) polarização cruzada. Amostra de gel + KOH + MTMS: (c) polarização direta, (d) polarização cruzada.

\subsection{Rochas}

Para o estudo da reatividade em rochas foram realizados análises de RMN em polarização direta de ${ }^{29} \mathrm{Si}$ nas amostras de basalto, granito e quartzito. Para simular a RAS estas amostras de rochas foram atacadas com solução de $\mathrm{KOH}$. Em alguns casos foi utilizado o método de ataque acelerado aumentando a temperatura de ataque para $45^{\circ} \mathrm{C}$ e $80^{\circ} \mathrm{C}$ ou aumentando o tempo de exposição da amostra ao ataque por até 30 dias. No quartzito houve ainda uma exposição ao MTMS após ataque com $\mathrm{KOH}$. Ainda nesta rocha, para simular o processo de reação num concreto sendo tratado, foram testados tratamentos com solução combinando $\mathrm{LiNO}_{3}$ e KOH. 


\subsubsection{Basalto}

Na figura 6.16 são mostrados os espectros de polarização direta de ${ }^{29} \mathrm{Si}$ para a amostra de basalto, basalto $+\mathrm{KOH} / \mathrm{T}_{\mathrm{A}}$, basalto $+\mathrm{KOH} / 80^{\circ} \mathrm{C}$, basalto $+\mathrm{LiNO}_{3}-\mathrm{KOH} / \mathrm{T}_{\mathrm{A}}$ e basalto $+\mathrm{LiNO}_{3}-$ $\mathrm{KOH} / 80^{\circ} \mathrm{C}$.

A linha do basalto é larga, formada por sinais de vários tipos de $\mathrm{Q}^{\mathrm{n}} \mathrm{Al}$ e, portanto, é difícil resolver se há mudanças na região central da linha. As mudanças detectáveis correspondem apenas à ambientes com sinais de RMN nos extremos do espectro. Devido à falta de resolução espectral não foram realizadas as atribuições detalhadas do número m de pontes Si$\mathrm{O}-\mathrm{Al}$, indicando-se apenas um numero $\mathrm{n}$ representativo da faixa de desvio químico correspondente.

A tabela 6.7 apresenta a porcentagem de sítios de alta conectividade $\left(Q^{3}\right.$ e $\left.Q^{4}\right)$ e baixa conectividade $\left(\mathrm{Q}^{0}, \mathrm{Q}^{1}\right.$ e $\left.\mathrm{Q}^{2}\right)$ identificados nas amostras de basalto. Tanto na amostra de basalto quanto nas amostras atacadas observa-se pela tabela a predominância dos sítios de alta conectividade, nominalmente $\mathrm{Q}^{3}$ e $\mathrm{Q}^{4}$. No espectro de basalto puro (figura 6.16a) observa-se que a rocha é formada basicamente por grupos silicatos $\mathrm{Q}^{3}$ e $\mathrm{Q}^{4}$. Os sítios $\mathrm{Q}^{4}$ compreendidos entre 91ppm e -120ppm podem ser referentes ao plagioclásio $\left(\mathrm{NaAlSi}_{3} \mathrm{O}_{8}\right)$. A linha do sítio $\mathrm{Q}^{0}$ observada em -67,6ppm é identificada como $\mathrm{Mg}_{2} \mathrm{SiO}_{4}$ (38), consistente com o fato de a amostra ter 4.8\% de MgO (ver tabela 5.2). Nos ataques da rocha com solução de $\mathrm{KOH}$ e tratamentos com $\mathrm{LiNO}_{3}-\mathrm{KOH}$ é possível observar alterações na distribuição de espécies de silicatos. Observa-se um incremento da fração de silicatos de baixa conectividade, nominalmente $\mathrm{Q}^{\mathrm{n}} \operatorname{com} n=0,1,2$. O aumento da população destes silicatos, comum a todas as amostras de basalto atacadas, se dá pela inserção de $\mathrm{K}^{+}$ou $\mathrm{OH}^{-}$, depolimerizando a rede de silicatos e produzindo grupos $\mathrm{Q}^{\mathrm{n}}$ de menor interconectividade, com ligações $\mathrm{Si}^{-} \mathrm{O}^{-} \mathrm{K}^{+}$ou Si-OH.

Os ataques apresentam essencialmente os mesmos efeitos citados com uma diferença menor na amostra de basalto $+\mathrm{KOH} / \mathrm{T}_{\mathrm{A}}$, onde aparece um pequeno pico em -93,7ppm que pela literatura (56) e pela comparação com os espectros do gel tratados com $\mathrm{KOH}$ na figura 6.2 pode ser associado ao $\mathrm{K}_{2} \mathrm{Si}_{2} \mathrm{O}_{5}$. 

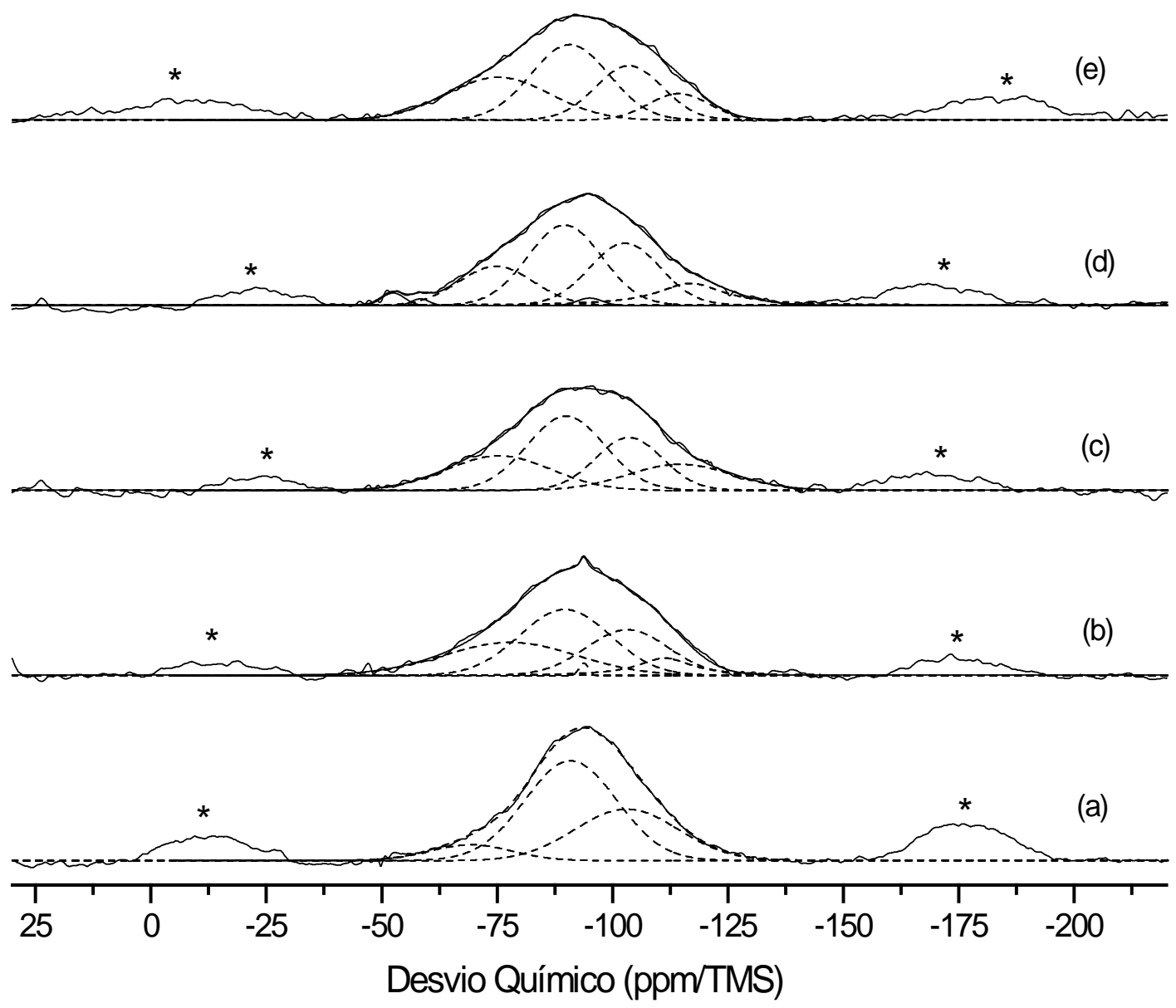

Figura 6.16: Espectros de Polarização Direta de ${ }^{29} \mathrm{Si}$ das amostras de: (a) basalto puro. (b) basalto $+\mathrm{KOH} / \mathrm{T}_{\mathrm{A}}$. (c) basalto $+\mathrm{KOH} / 80^{\circ} \mathrm{C}$. (d) basalto $+\mathrm{LiNO}_{3}-\mathrm{KOH} / \mathrm{T}_{\mathrm{A}}$. (e) basalto $+\mathrm{LiNO}_{3}-\mathrm{KOH} / 80^{\circ} \mathrm{C}$. Asteriscos: bandas laterais.

Tabela 6.7- Quantidade em porcentagem, dos sítios de alta e baixa conectividade, das áreas relativas das curvas de ajuste dos espectros de polarização direta de ${ }^{29} \mathrm{Si}$ de basalto, basalto $+\mathrm{KOH} / 80^{\circ} \mathrm{C}$, basalto $+\mathrm{LiNO}_{3^{-}}$ $\mathrm{KOH} / 80^{\circ} \mathrm{C}$, basalto $+\mathrm{KOH} / \mathrm{T}_{\mathrm{A}}$ e basalto $+\mathrm{LiNO}_{3}-\mathrm{KOH} / \mathrm{T}_{\mathrm{A}}$.

\begin{tabular}{ccc}
\hline Amostra & $\mathbf{Q}^{\mathbf{n}}$ & $\mathbf{Q}^{\mathbf{n}}$ \\
& $\mathbf{n = 0 , \mathbf { 1 , 2 }}$ & $\mathbf{n = 3 , 4}$ \\
\hline Basalto & 8 & 92 \\
Basalto $+\mathrm{KOH} / 80^{\circ} \mathrm{C}$ & 23 & 77 \\
Basalto $+\mathrm{LiNO}_{3}-\mathrm{KOH} / 80^{\circ} \mathrm{C}$ & 29 & 71 \\
\hline
\end{tabular}




\begin{tabular}{ccc}
\hline Basalto $+\mathrm{KOH} / \mathrm{T}_{\mathrm{A}}$ & 29 & 71 \\
Basalto $+\mathrm{LiNO}_{3}-\mathrm{KOH} / \mathrm{T}_{\mathrm{A}}$ & 19 & 81 \\
\hline
\end{tabular}

\subsubsection{Granito}

Na figura 6.17, estão os espectros de polarização direta de ${ }^{29} \mathrm{Si}$ das amostras de granito, granito $+\mathrm{KOH} / 80^{\circ} \mathrm{C}$, granito $+\mathrm{LiNO}_{3}-\mathrm{KOH} / 80^{\circ} \mathrm{C}$. Os espectros das amostras de granito + $\mathrm{KOH} / 80^{\circ} \mathrm{C}$ e granito $+\mathrm{LiNO}_{3}-\mathrm{KOH} / 80^{\circ} \mathrm{C}$ foram realizados na sonda de $5 \mathrm{~mm}$ e por este motivo apresentam a relação sinal/ruído inferior ao espectro de granito puro, que foi realizado na sonda de $7 \mathrm{~mm}$.

Os ajustes dos espectros da figura 6.17 estão apresentados na tabela 6.8. A multiplicidade de linhas e sua superposição impedem fazer atribuições específicas sobre muitos destes sítios, especialmente na região de $-90 \mathrm{ppm}$, atribuída na tabela 6.8 aos sítios de Si com alumínios. A presença dos sítios correspondentes aos aluminosilicatos é coerente com o fato da amostra de granito conter $14 \%$ de oxido de alumínio $\left(\mathrm{Al}_{2} \mathrm{O}_{3}\right)$ (ver tabela 5.2) proveniente dos feldspatos. É possível fazer identificações aproximadas por regiões espectrais.

No espectro de granito, a linha em -75,6ppm pode ter estrutura semelhante à margarite $\left(\mathrm{CaAl}_{2}\left(\mathrm{Al}_{2} \mathrm{Si}_{2} \mathrm{O}_{10}\right)(\mathrm{OH})_{2}\right.$, que pela literatura apresenta desvio químico em -75,5ppm (38). Nos espectros das amostras atacadas, figuras 6.17b e 6.17c, também é observado a linha em 75,6ppm, porém observam-se duas mudanças principais: a linha em -72,3ppm, que aparece como um sinal bem resolvido, podendo pertencer a um mineral estruturalmente semelhante à margarite mas com cátion $\mathrm{K}$ inserido em sua composição deslocando o desvio químico para um valor mais positivo, e o incremento da intensidade na região de $\mathrm{Q}^{\mathrm{n}} \operatorname{com} \mathrm{n}=3,4$ na região de desvios menores que -105ppm. Assim, pode-se afirmar que em todas as amostras há uma predominância de sítios de alta conectividade, $\mathrm{Q}^{3}, \mathrm{Q}^{4}, \mathrm{Q}^{4}{ }_{1} \mathrm{Al}$ (referentes ao quartzo e feldspatos plagioclásios), correspondendo a desvios entre -95ppm e -120ppm, e sítios $\mathrm{Q}^{3}{ }_{1} \mathrm{Al}$ na faixa entre 80 e $89 \mathrm{ppm}$, que não foram possíveis de serem ajustados devido à baixa resolução espectral, e que são referentes à muscovita. 


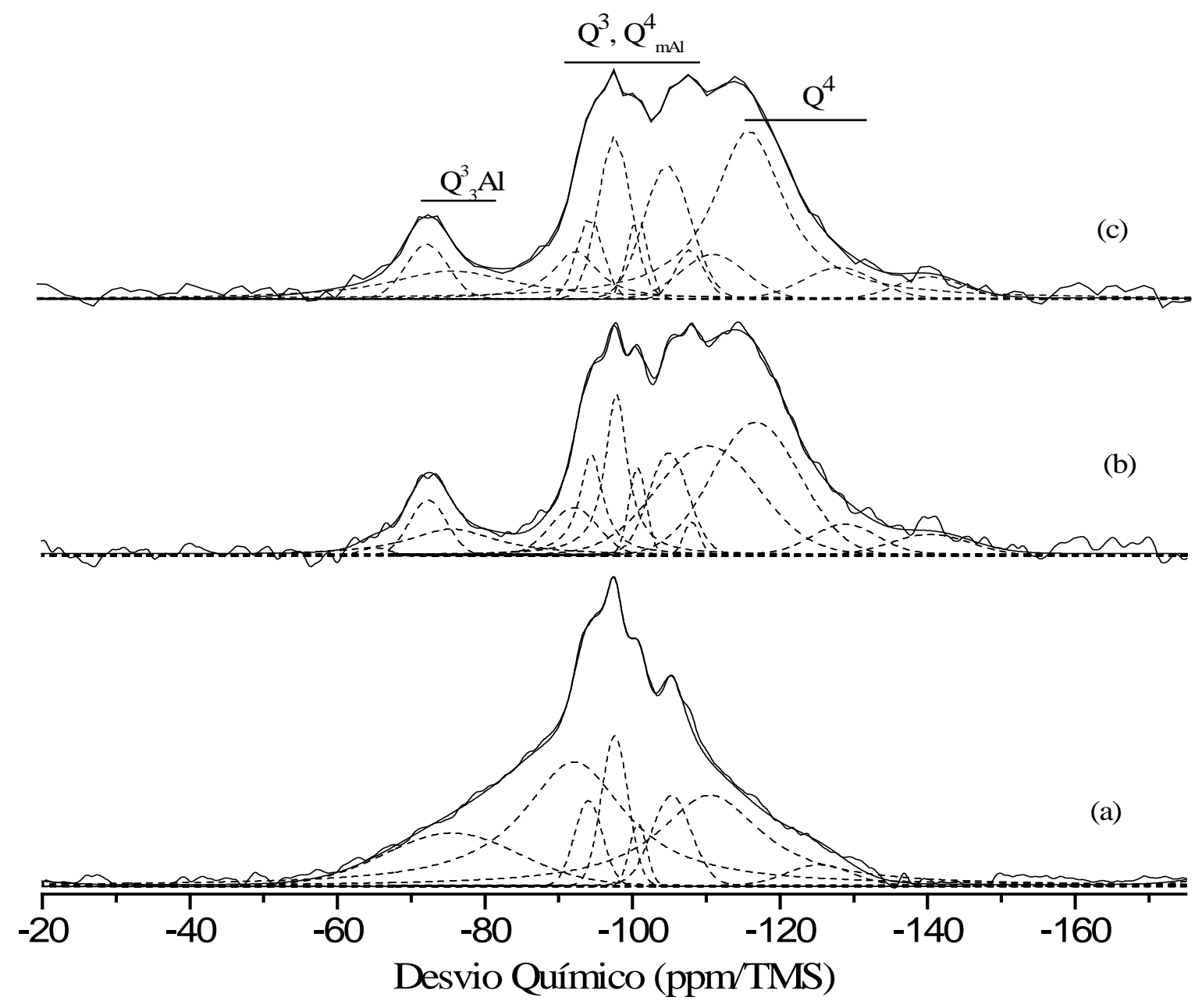

Figura 6.17- Espectros de Polarização Direta de ${ }^{29} \mathrm{Si}$. (a) Granito. (b) Granito $+\mathrm{KOH} / 80^{\circ} \mathrm{C}$. (c) Granito $+\mathrm{LiNO}_{3}$ $\mathrm{KOH} / 80^{\circ}$.

Tabela 6.8- Desvios químicos $\delta$ eáreas relativas das curvas de ajuste dos espectros de polarização direta de ${ }^{29}$ Si$\mathrm{RMN}$ das amostras de granito, granito $+\mathrm{KOH} / 80^{\circ} \mathrm{C}$ e granito $+\mathrm{LiNO}_{3}-\mathrm{KOH} / 80^{\circ} \mathrm{C}$.

\begin{tabular}{cccc}
\hline AMOSTRA & sítio & $\boldsymbol{\delta}$ (ppm) & Área (\%) \\
\hline \multirow{2}{*}{ Granito } & $\mathrm{Q}^{3}{ }_{3} \mathrm{Al}$ & -75.6 & 14 \\
& $\mathrm{Q}^{3}, \mathrm{Q}_{\mathrm{m}}{ }_{\mathrm{m}} \mathrm{Al}$ (feldspatos) & $-92 \mathrm{a}-100$ & 51 \\
& $\mathrm{Q}^{4}$ & $-105 \mathrm{a}-110$ & 35 \\
Granito + $\mathrm{KOH} / 80^{\circ} \mathrm{C}$ & $\mathrm{Q}^{0}$ & -65.7 & 1 \\
& $\mathrm{Q}^{3}{ }_{3} \mathrm{Al}$ & $-72.2 \mathrm{a}-75.5$ & 10 \\
& $\mathrm{Q}^{3}, \mathrm{Q}^{4}{ }_{\mathrm{m}} \mathrm{Al}$ (feldspatos) & $-92 \mathrm{a}-100$ & 23 \\
Granito + $\mathrm{LiNO}_{3}-\mathrm{KOH} / 80^{\circ} \mathrm{C}$ & $\mathrm{Q}^{4}$ & $-105 \mathrm{a}-116$ & 66 \\
& $\mathrm{Q}^{3}, \mathrm{Q}_{\mathrm{m}}^{4} \mathrm{Al}$ (feldspatos) & $-72.2 \mathrm{a}-75,5$ & 17 \\
& $\mathrm{Q}^{1}$ & $-105 \mathrm{a}-100$ & 25 \\
& & & 58 \\
\hline
\end{tabular}




\subsubsection{Quartzito}

Os espectros da figura 6.18 correspondem aos resultados das medidas de polarização direta de ${ }^{29} \mathrm{Si}$, feitas nas amostras de quartzito puro, quartzito $+\mathrm{KOH} / \mathrm{T}_{\mathrm{A}}$., quartzito $+\mathrm{KOH} / 80^{\circ} \mathrm{C}$, quartzito $+\mathrm{KOH}+\mathrm{MTMS} / 80^{\circ} \mathrm{C}$, quartzito $+\mathrm{LiNO}_{3}-\mathrm{KOH} / \mathrm{T}_{\mathrm{A}}$, quartzito $+\mathrm{LiNO}_{3}-\mathrm{KOH} / 45^{\circ} \mathrm{C} \mathrm{e}$ quartzito $+\mathrm{LiNO}_{3}-\mathrm{KOH} / 80^{\circ} \mathrm{C}$. A tabela 6.9 apresenta a porcentagem de sítios de alta conectividade $\left(\mathrm{Q}^{3}\right.$ e $\left.\mathrm{Q}^{4}\right)$ e baixa conectividade $\left(\mathrm{Q}^{0}, \mathrm{Q}^{1}\right.$ e $\left.\mathrm{Q}^{2}\right)$ identificados nestas amostras de quartzito. Em todos esses espectros são observados sinais estreitos em -107,7ppm correspondentes aos silicatos $\mathrm{Q}^{4}$. Este desvio corresponde exatamente ao observado no quartzo (38). No entanto, este sítio não corresponde a domínios perfeitamente cristalinos senão a formas menos estáveis de quartzo, pois, como se discutirá a seguir, os diferentes ataques produzem uma diminuição notória da fração deste tipo de silicatos.

No espectro da amostra de quartzito puro, figura 6.18a, observa-se um sinal largo correspondente a silicatos numa rede amorfa, com uma distribuição das espécies correspondentes aos sítios com alta e baixa conectividade $\left(\mathrm{Q}^{\mathrm{n}}\right.$, $\operatorname{com} \mathrm{n}=3,4$, e $\mathrm{Q}^{\mathrm{n}}$, com $\left.\mathrm{n}=0,1,2\right)$. A partir da deconvolução e integração do espectro é possível estimar as frações de ${ }^{29} \mathrm{Si}$ em domínios amorfos e quase-cristalinos (quartzo) de cada amostra. Na amostra de quartzito puro a fração de silicato em ambientes de tipo quartzo é de $11 \%$, sendo o $89 \%$ restante correspondente à distribuição de $\mathrm{Q}^{\mathrm{n}}$ fortemente desordenada de quartzo nanométrico e muscovita, que apresenta desvio químico por volta de $-85 \mathrm{ppm}$, com incerteza de $\pm 3 \%$. A linha estreita de quartzo citada em $-107 \mathrm{ppm}$ se refere a quartzo semicristalino.

$\mathrm{Na}$ análise dos espectros do quartzito com ataques de solução de $\mathrm{KOH}$, mostrados nas figuras 6.18b até 6.18e, podem ser observados comportamentos diferentes em função da temperatura ou tempo de ataque. $\mathrm{Na}$ amostra de quartzito $+\mathrm{KOH} / \mathrm{T}_{\mathrm{A}}$ atacada durante 30 dias, figura 6.18b, o espectro de RMN de ${ }^{29} \mathrm{Si}$ revela uma estrutura semelhante ao quartzito, com a presença dos sítios $\mathrm{Q}^{\mathrm{n}}$ de alta e baixa conectividade e uma fração menor, 9\% de quartzo semicristalino.

$\mathrm{O}$ espectro da amostra sujeita ao mesmo ataque em temperatura maior $\left(45^{\circ} \mathrm{C}\right)$, figura 6.18c, não apresentou diferença alguma quanto ao espectro de quartzito puro. Nota-se a presença dos mesmos sítios $\mathrm{Q}^{\mathrm{n}}$ de alta e baixa conectividade e a mesma fração de quartzo (11\%), 
indicando que esta temperatura não foi eficiente para a reação de potássio com a rocha. Já no mesmo ataque com temperatura de $80^{\circ} \mathrm{C}$, figura 6.18c, o espectro mostra uma mudança substancial na linha do silicato amorfo, formada agora essencialmente por silicatos de alta conectividade e $13 \%$ de quartzo. Comparando com o ataque similar à temperatura ambiente e à $45^{\circ} \mathrm{C}$, pode se concluir que o ataque acelerado atua sobre os domínios de quartzo mais distorcidos, produzindo após a secagem um produto com estrutura de silicatos altamente conectados. No ataque de quartzito $+\mathrm{KOH}+\mathrm{MTMS} / 80^{\circ} \mathrm{C}$ observa-se uma estrutura de silicatos abrangendo toda a faixa de desvios de $\mathrm{Q}^{\mathrm{n}}$, e uma ressonância resolvida correspondente a sítios $\mathrm{D}$, originados da reação do MTMS. Não é possível identificar claramente sítios T, que nesta amostra estariam sobrepostos com as linhas de $\mathrm{Q}^{\mathrm{n}} \operatorname{com} \mathrm{n}=0,1$. A diferença mais importante com os outros ataques é a grande fração de silicatos na região de conectividades médias $\left(\mathrm{Q}^{2}\right)$. Em principio, o grande efeito de despolimerização dos silicatos comparando com a amostra sem MTMS (figura 6.18.d) resulta difícil de racionalizar considerando apenas a reação do MTMS com os grupos SiOH. Aparece também no espectro desta amostra um pico em -93,9ppm que pela literatura (55), pelos resultados com basalto $+\mathrm{KOH} / \mathrm{T}_{\mathrm{A}}$ e resultados com gel tratados com $\mathrm{KOH}$, pode ser associado ao $\mathrm{K}_{2} \mathrm{Si}_{2} \mathrm{O}_{5}$.

Mudanças substanciais também foram observadas nos espectros de quartzito com ataques com solução de $\mathrm{LiNO}_{3}-\mathrm{KOH}$. No espectro de quartzito $+\mathrm{LiNO}_{3}-\mathrm{KOH} / \mathrm{T}_{\mathrm{A}}$ atacada durante 30 dias, figura 6.18f, aparecem sinais de sítios $\mathrm{Q}^{\mathrm{n}}$ de alta e baixa conectividade. A fração de quartzo semicristalino nesta amostra é de $2 \%$, indicando maior dissolução comparada com o ataque com $\mathrm{KOH}$ nas mesmas condições. Na amostra de quartzito $+\mathrm{LiNO}_{3}-\mathrm{KOH} / 45^{\circ} \mathrm{C}$, figura $6.18 g$, é observada uma estrutura de silicatos bastante semelhante à amostra de quartzito $+\mathrm{KOH} / 80^{\circ} \mathrm{C}$ formada essencialmente por sítios de alta conectividade e 14\% de quartzo semicristalino. Já na amostra com aumento de temperatura do ataque, quartzito $+\mathrm{LiNO}_{3}-\mathrm{KOH} / 80^{\circ} \mathrm{C}$, é observado sítios com conectividade média e baixa em sua estrutura amorfa, porém observa-se também uma diminuição significativa nas áreas de $\mathrm{Q}^{4}$ e na fração de quartzo semicristalino (2\%) e um pico de maior intensidade aparece em -74,9ppm associado ao $\mathrm{Li}_{2} \mathrm{SiO}_{3}$. O silicato $\mathrm{Li}_{2} \mathrm{SiO}_{3}$ foi identificado também no espectro de gel $+\mathrm{LiNO}_{3}-\mathrm{NaOH}$ (figura 6.2b). 


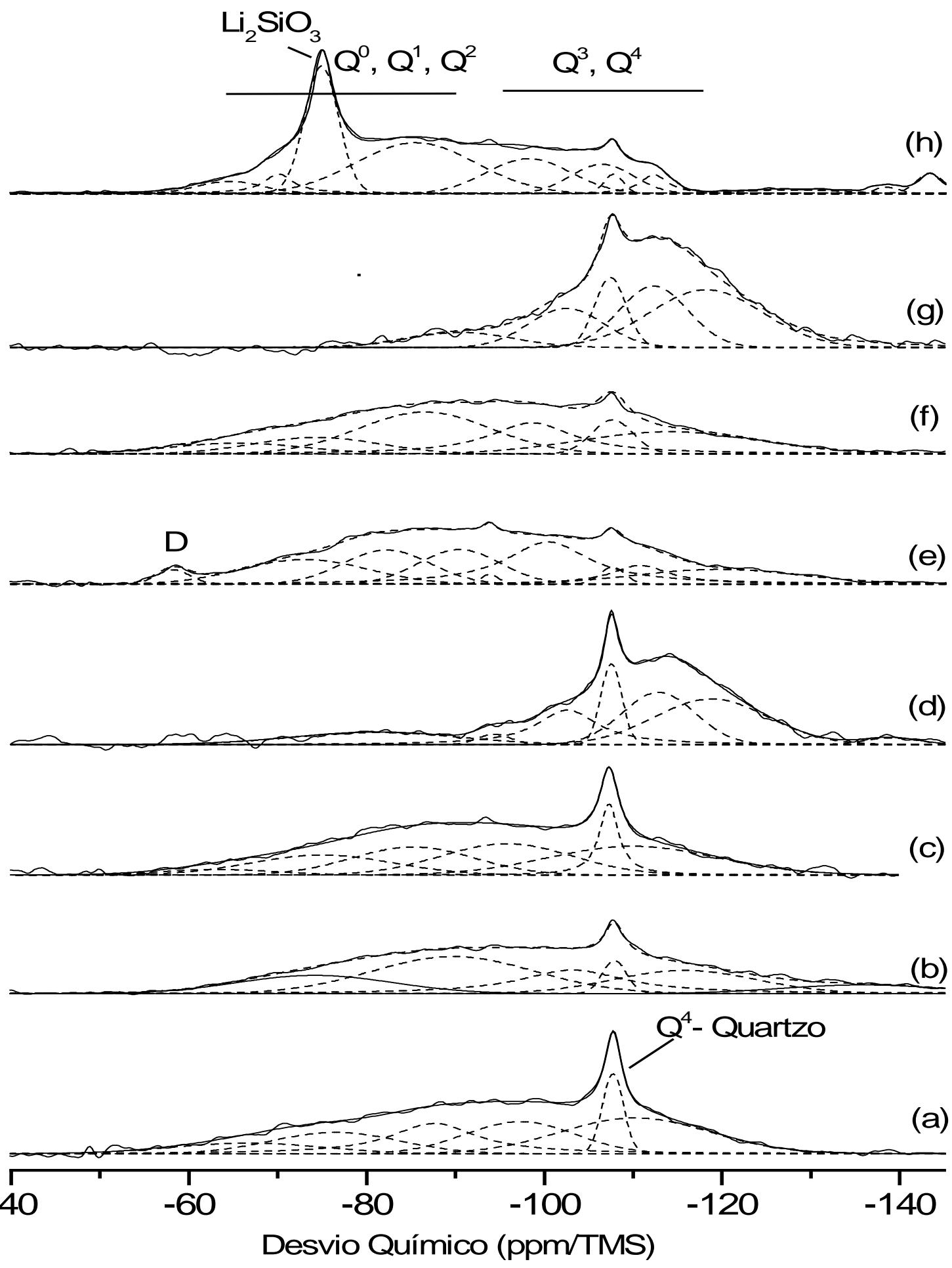

Figura 6.18- Espectros de polarização direta de ${ }^{29} \mathrm{Si}$. (a) Quartzito. (b) Quartzito $+\mathrm{KOH} / \mathrm{T}_{\mathrm{A}}$. (c) Quartzito + $\mathrm{KOH} / 45^{\circ} \mathrm{C}$. (d) Quartzito $+\mathrm{KOH} / 80^{\circ} \mathrm{C}$. (e) Quartzito $+\mathrm{KOH}+\mathrm{MTMS} / 80^{\circ} \mathrm{C}$. (f) Quartzito $+\mathrm{LiNO}_{3}$ $\mathrm{KOH} / \mathrm{T}_{\mathrm{A}}$. (g) Quartzito $+\mathrm{LiNO}_{3}-\mathrm{KOH} / 45^{\circ} \mathrm{C}$. (h) Quartzito $+\mathrm{LiNO}_{3}-\mathrm{KOH} / 80^{\circ} \mathrm{C}$. 
Tabela 6.9- Quantidade em porcentagem, dos sítios de alta e baixa conectividade, das áreas relativas das curvas de ajuste dos espectros de polarização direta de ${ }^{29} \mathrm{Si}$ de quartzito, quartzito $+\mathrm{KOH} / \mathrm{T}_{\mathrm{A}}$, quartzito $+\mathrm{KOH} / 45^{\circ} \mathrm{C}$, quartzito $+\mathrm{KOH}+80^{\circ} \mathrm{C}$, quartzito $+\mathrm{KOH}+\mathrm{MTMS} / 80^{\circ} \mathrm{C}$, quartzito $+\mathrm{LiNO}_{3}-\mathrm{KOH} / \mathrm{T}_{\mathrm{A}}$, quartzito $+\mathrm{LiNO}_{3^{-}}-$ $\mathrm{KOH} / 45^{\circ} \mathrm{C}$ e quartzito $+\mathrm{LiNO}_{3}-\mathrm{KOH} / 80^{\circ} \mathrm{C}$.

\begin{tabular}{cccc}
\hline Amostra & $\mathbf{Q}^{\mathbf{n}}$ & $\mathbf{Q}^{\mathbf{n}}$ & Quartzo \\
& $\mathbf{n = 0 , 1 , 2}$ & $\mathbf{n = 3 , 4}$ & $\mathbf{( \% )}$ \\
& $\mathbf{( \% )}$ & $\mathbf{( \% )}$ & \\
\hline Quartzito & 40 & 49 & 11 \\
Quartzito $+\mathrm{KOH} / \mathrm{T}_{\mathrm{A}}$ & 41 & 51 & 8 \\
Quartzito $+\mathrm{KOH} / 45^{\circ} \mathrm{C}$ & 39 & 50 & 11 \\
Quartzito $+\mathrm{KOH} / 80^{\circ} \mathrm{C}$ & 12 & 75 & 13 \\
Quartzito $+\mathrm{KOH}+\mathrm{MTMS} / 80^{\circ} \mathrm{C}$ & 52 & 41 & 7 \\
Quartzito $+\mathrm{LiNO}_{3}-\mathrm{KOH} / \mathrm{T}_{\mathrm{A}}$ & 39 & 59 & 2 \\
Quartzito $+\mathrm{LiNO}_{3}-\mathrm{KOH} / 45^{\circ} \mathrm{C}$ & 9 & 77 & 14 \\
Quartzito $+\mathrm{LiNO}_{3}-\mathrm{KOH} / 80^{\circ} \mathrm{C}$ & 69 & 29 & 2 \\
\hline
\end{tabular}




\section{Capítulo7}

\section{Discussão}

Neste capítulo serão discutidos os resultados experimentais apresentados no capítulo anterior. Primeiramente será discutida a estrutura do gel seguido da discussão sobre os tratamentos do gel com soluções de Li e MTMS e por último os resultados dos ataques às rochas potencialmente reativas.

\subsection{Estrutura do gel}

Os espectros de ${ }^{29} \mathrm{Si}-\mathrm{RMN}$ mostraram que o gel possui uma estrutura de silicatos desordenada e amorfa com silicatos tetraédricos com diferentes graus de conectividade e estruturas distorcidas. Este resultado concorda com os resultados obtidos dos difratogramas de Raios-X, que apresenta uma difração larga em $26^{\circ}$ típica de sílicas amorfas e que não apresentou nenhuma fase cristalina referente ao potássio e silício. Este fato indica que estes dois elementos se encontram associados à fase amorfa do gel.

Pela tabela 6.1, observa-se que o gel apresenta uma porcentagem em área de 56\% de sítios $\mathrm{Q}^{3}$ em -96,9ppm. Além disso, o número médio de NBO por silicato tetraédrico pode ser usado como uma medida quantitativa de despolimerização da rede de silicatos e de acordo com a tabela 6.1, o gel apresenta NBO igual a 1,0 que corresponde a um ambiente médio de tipo $\mathrm{Q}^{3}$. Destas informações conclui-se que o gel é formado em média por estrutura lamelar. Na absorção de água pelo gel, os espaços interlamelares são capazes de reter maior quantidade de água e causar a expansão do gel. 
Fazendo uma análise comparativa entre o grau de desordem do gel e de um vidro silicato, podemos utilizar os resultados obtidos por Maekawa (57) para vidros de silicato de potássio. Os vidros com concentração de $\mathrm{K}_{2} \mathrm{O}$ próximas a do gel (por volta de 14\%), apresentam número médio de NBO de 0,51, o que representa uma estrutura mais conexa que no caso do gel, com maior concentração de grupos $\mathrm{Q}^{4}$. Esta diferença topológica entre ambos silicatos se deve à presença de ligações Si-O-H no gel.

Com relação à distribuição de $\mathrm{K}$ na estrutura do gel, aqui também resulta interessante comparar os resultados com o caso de vidros silicatos de potássio. Os desvios químicos dos grupos silicatos estão determinados pela presença de $\mathrm{K}^{+}$coordenando os NBO. A figura 7.1 mostra a dependência dos desvios para cada $\mathrm{Q}^{\mathrm{n}}$ em função da concentração de $\mathrm{K}$, obtidos por Maekawa (57). O comportamento linear observado mostra que não existe segregação de $\mathrm{K}^{+}$na estrutura do vidro. Na figura 7.1 são mostrados também os desvios químicos dos $\mathrm{Q}^{\mathrm{n}}$ observados no gel, colocados na concentração de K medida, junto com as extrapolações dos comportamentos lineares observados no vidro. Observa-se uma excelente correlação entre estes dados, fato que indica que a distribuição de $\mathrm{K}^{+}$dentro da rede de silicatos não apresenta heterogeneidades, nem ocorre preferencialmente para alguns dos $\mathrm{Q}^{\mathrm{n}}$. Ainda para o caso $\mathrm{Q}^{4}$, se observa uma variação do desvio com o decréscimo da concentração de $K$, fato que indica que no gel estes grupos não se encontram segregados, senão próximo de outros $\mathrm{Q}^{\mathrm{n}}$ de menor ordem interagindo com $\mathrm{K}^{+}$. 


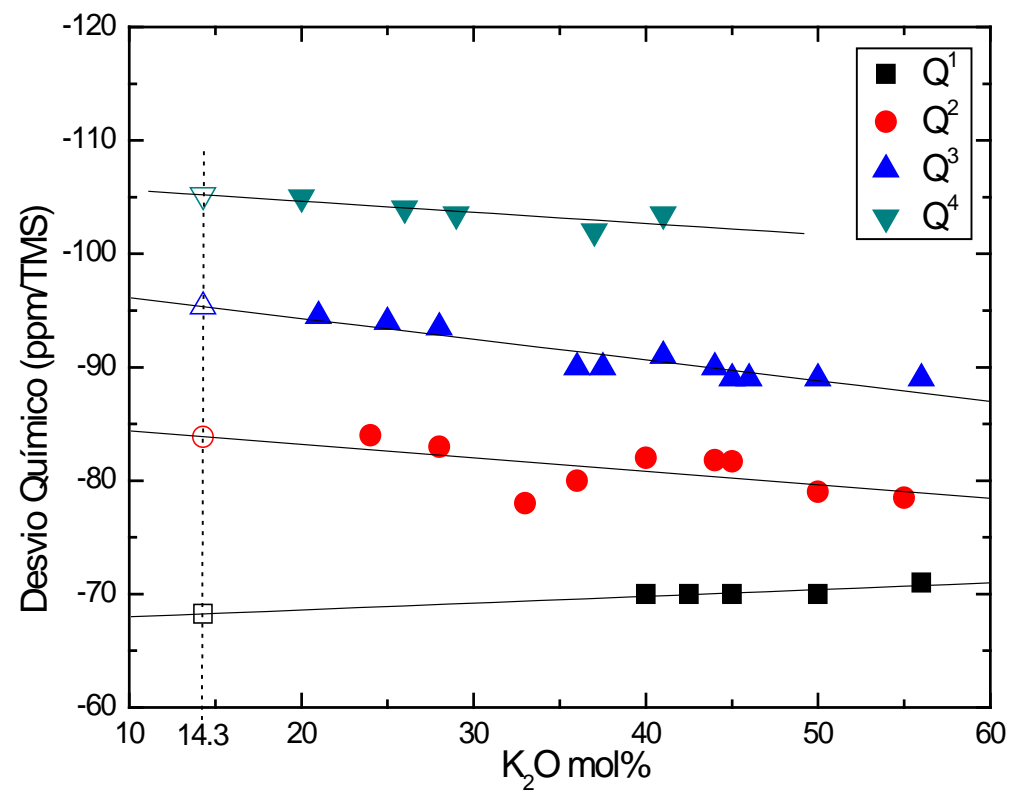

Figura 7.1- Curva de Maekawa (57): desvio químico das espécies $\mathrm{Q}^{\mathrm{n}}$ em função da concentração em mol de $\mathrm{K}_{2} \mathrm{O}$. Linha pontilhada: valores de concentração de $\mathrm{K}_{2} \mathrm{O}$ no gel.

Nos experimentos de polarização cruzada com tempo de contato variável, pela tabela 6.2, observa-se que os sítios $\mathrm{Q}^{2}$ e $\mathrm{Q}^{3}$ apresentam valores diferentes de $\mathrm{T}_{\mathrm{H}-\mathrm{Si}}$, indicando graus de acoplamento dipolar $\left\{{ }^{1} \mathrm{H}\right\}-{ }^{29} \mathrm{Si}$ diferentes, ou seja, estes dois sítios de Si estão em ambientes químicos diferentes. Os valores de $T_{1 \rho}$ são diferentes, sendo igual a 11,4ms e 20,2ms para os sítios $\mathrm{Q}^{2}$ e $\mathrm{Q}^{3}$ respectivamente. Este fato indica que há separação entre os sítios $\mathrm{Q}^{2}$ e $\mathrm{Q}^{3}$ pelo menos entre a maioria dos $Q^{3}$, implicando em domínios $Q^{3}$ bem definidos (planos) ao invés de pontos de ramificação em cadeias de $\mathrm{Q}^{2}$. O espectro de polarização direta do ${ }^{1} \mathrm{H}$ indica a presença abundante de água no gel, mas o experimento de HETCOR mostra que esta água não polariza os núcleos de $\mathrm{Si}$, que interagem com os $\mathrm{H}$ dos grupos hidroxilas.

Os espectros de RMN de ${ }^{23} \mathrm{Na}$ indicam dois sítios estruturais com blindagens semelhantes, mas com acoplamento quadrupolar diferente. Através de difração de Raios-X observou-se que estes dois sítios correspondem a dois sítios de sódio cristalográficos da trona. A diferença na simetria no sítio de sódio causa forte influência no acoplamento quadrupolar. Os 
valores de acoplamento quadrupolar dos dois sítios obtidos através dos experimentos de 3Q-MAS são da ordem de $1,9 \mathrm{MHz}$ indicando baixa simetria $(3,58)$.

Em resumo, a imagem estrutural obtida para a rede de silicatos do gel se corresponde com uma rede de silicatos $Q^{3}$ extensa com ligações $\mathrm{OH}$ e defeitos $\left(\mathrm{Q}^{\mathrm{n}}\right.$ de maior e menor ordem), e cátions $\mathrm{K}^{+}$uniformemente distribuídos para compensar a carga dos NBO. Existe abundância de água na estrutura, mas se encontra em estado móvel.

\subsection{Tratamento do gel $\mathrm{com} \mathrm{Li}$}

Os resultados das medidas de difração de Raios-X da amostra de gel $+\mathrm{LiNO}_{3}-\mathrm{NaOH}$ mostraram um difratograma completamente diferente das amostras de gel. A difração larga em $26^{\circ}$ foi alterada, apresentando várias fases cristalinas (52). Essas novas fases cristalinas são referentes ao metasilicato de lítio $\left(\mathrm{Li}_{2} \mathrm{SiO}_{3}\right)$, nitrato de potássio $\left(\mathrm{KNO}_{3}\right)$, nitrato de sódio $\left(\mathrm{NaNO}_{3}\right)$, carbonato de potássio $\left(\mathrm{K}_{2} \mathrm{CO}_{3}\right)$ e carbonatos sódio-litio $\left(\mathrm{LiNaCO}_{3}\right)$. A presença de dois compostos contendo potássio sugere que o gel perdeu potássio da sua estrutura quando foi tratado com lítio.

O gel tratado com solução de Li mostra um espectro de ${ }^{23} \mathrm{Na}-\mathrm{RMN}$ completamente diferente da amostra de gel, indicando que houve a precipitação de três novas fases: $\mathrm{NaNO}_{3} \mathrm{e}$ dois sítios de $\mathrm{Na}_{2} \mathrm{CO}_{3}$ em ambientes químicos diferentes. $\mathrm{O}$ sítio $\mathrm{Na}_{2} \mathrm{CO}_{3}$ apresenta duas linhas em $7 \mathrm{ppm}$ e uma linha mais larga entre 0 e 10ppm. A diferença entre as larguras das linhas é causada pela diferença de acoplamento quadrupolar elétrico entre os dois sítios (9), como mostra o experimento de 3Q-MAS, que é consistente com o fato do espectro estático apresentar um padrão de quadrupolo com linhas satélites mais alargadas, provavelmente pela sobreposição das linhas dos dois sítios $\mathrm{Na}_{2} \mathrm{CO}_{3}$ associados ainda ao sítio de $\mathrm{NaNO}_{3}$. Os valores da constante de acoplamento quadrupolar são baixos, 0,4; 0,2; e 0,9 para $\mathrm{NaNO}_{3}, \mathrm{Na}_{2} \mathrm{CO}_{3}$ (sítio I) e $\mathrm{Na}_{2} \mathrm{CO}_{3}$ (sítio II), respectivamente, indicando ambientes químicos bastante simétricos. 
Os resultados de RMN de ${ }^{29} \mathrm{Si}$ do gel tratado com Li mostraram uma maior abundância de sítios $\mathrm{Q}^{2}$ diferentemente da amostra de gel. Da distribuição de $\mathrm{Q}^{\mathrm{n}}$ observada foi obtido um número médio de $\mathrm{NBO}$ de 2,0, fato que revela uma estrutura média de tipo linear. Esta propriedade da rede é de importância fundamental para garantir que o produto do tratamento com Li não sofrerá expansão, pois estruturas mais abertas que a lamelar são menos susceptíveis à expansão pela absorção de água. Comparando as primeiras medidas feitas por Schneider e Hasparyk (9) na amostra de gel com tratamento de Li e a medida apresentada neste trabalho, realizada na mesma amostra dois anos depois, observa-se uma mudança na linha central do espectro de ${ }^{29}$ Si. Foi observado um estreitamento das linhas de ${ }^{29} \mathrm{Si}$. Portanto, houve uma evolução estrutural devido à relaxação estrutural da rede ou variação na água da hidratação da amostra. Porém não houve mudança na topologia média $(\mathrm{NBO}=2,0)$, permanecendo o sítio $\mathrm{Q}^{2}$ como o mais abundante na estrutura de silicatos. Este fato prova que mesmo com a evolução do tratamento com o tempo, a estrutura de silicatos é mantida linear, mostrando a eficácia do tratamento.

Os experimentos de polarização cruzada $\left\{{ }^{1} \mathrm{H}\right\}-{ }^{29} \mathrm{Si}$ mostraram que as espécies mais abundantes $\mathrm{Q}^{2}$ e $\mathrm{Q}^{3}$ possuem após o tratamento, tempos de contato e $\mathrm{T}_{1 \rho}$ iguais. Isso indica acoplamento em um conjunto comum de prótons para ambas as espécies. Não há então, uma separação espacial considerável entre $\mathrm{Q}^{2}$ e $\mathrm{Q}^{3}$, fato que indica a dissolução de domínios lamelares extensos. No entanto as espécies $\mathrm{Q}^{4}$ não apresentam sinal de polarização cruzada, fato que indica separação espacial do conjunto de prótons e, portanto, uma segregação em domínios tipo sílica.

O espectro de ${ }^{7} \mathrm{Li}$-RMN apresenta uma linha lorentziana em -0,6ppm, o que não pode corresponder ao $\mathrm{LiNO}_{3}$ que possui um desvio químico em -1,5ppm, ou seja, o $\mathrm{LiNO}_{3}$ reage completamente durante o processo do tratamento do gel. Estes resultados mostram que o Li é realmente incorporado na estrutura do gel após o tratamento. Mas mesmo com as evidencias de que o Li é incorporado ao gel, os espectros do experimento de HETCOR apresentam linhas de subespectros quase sem bandas laterais indicando acoplamento homonuclear moderado com a proximidade dos grupos $\mathrm{OH}$, muito semelhante à amostra de gel, isso significa que mesmo com a inserção de Li ainda existe a presença de grupos $\mathrm{OH}$ em frações significativas de ambientes $\mathrm{Q}^{\mathrm{n}}$. 
Em resumo os resultados mostram que os silicatos produto do ataque com sais de Li é uma estrutura heterogênea de tipo linear, sem regiões lamelares extensas, com segregação de domínios tipo sílica, abundancia de grupos do tipo Si-OH e incorporação de Li.

\subsection{Exposição do gel ao MTMS}

A estrutura de silicatos $Q^{\mathrm{n}}$ do gel exposto a solução de MTMS é topologicamente semelhante ao gel original apresentando numero médio de NBO igual a 1,0 característica de estruturas de silicatos de sítios $\mathrm{Q}^{3}$. $\mathrm{O}$ aparecimento dos sítios $\mathrm{D}$ e $\mathrm{T}$ foi uma característica encontrada em todas as amostras expostas ao MTMS neste trabalho. Existe variação na distribuição das espécies $Q^{\mathrm{n}}$ : há um decréscimo de intensidade em $\mathrm{Q}^{2}$ e $\mathrm{Q}^{3}$ e um aumento na intensidade de $\mathrm{Q}^{4}$. Isto poderia indicar a interação dos grupos siloxanos, introduzidos pelo MTMS, com os silicatos do gel. Cada substituição de um Si-OH por Si-O-SiCH $\mathrm{H}_{3}$ transforma um sítio $\mathrm{Q}^{\mathrm{n}}$ em um sítio $\mathrm{Q}^{\mathrm{n}+1}$, produzindo uma variação na distribuição de espécies tal como a observada no espectro de ${ }^{29} \mathrm{Si}$. No entanto as variações observadas também poderiam corresponder a autocondensação do silano, gerando uma estrutura de silicatos independente do gel e com linhas de silicatos de ressonância de $Q^{\mathrm{n}}$ superpostas.

O experimento de HETCOR pode auxiliar a esclarecer esta questão. Os espectros mostram que os sítios $\mathrm{D}$ e T são polarizados por $\mathrm{H}$ de espécies diferentes com relação às espécies $\mathrm{Q}^{\mathrm{n}}$. Os $\mathrm{Q}^{\mathrm{n}}$ são polarizados por grupos $\mathrm{OH}$ e $\mathrm{H}_{2} \mathrm{O}$, não havendo evidencias da influência dos $\mathrm{H}$ provenientes dos grupos $\mathrm{CH}_{3}$, levando a conclusão de que não há contato próximo, em escala molecular, entre os grupos $\mathrm{D}$ e $\mathrm{T}$ com os grupos $\mathrm{Q}^{\mathrm{n}}$. Os sítios $\mathrm{D}$ e $\mathrm{T}$, que apresentam forte acoplamento homonuclear, são polarizados pelo $\mathrm{H}$ do $\mathrm{CH}_{3}$. A integridade do $\mathrm{SiCH}_{3}$ pode ser observada pelo espectro de polarização direta do ${ }^{13} \mathrm{C}$. Estes fatos levam a crer que em grande parte o silano poderia estar reagindo rapidamente e se autocondensando, sem estabelecer um numero significativo de ligações covalentes com o gel.

Os experimentos de difração de Raios-X nas amostras de gel + $\mathrm{KOH}+$ MTMS e gel + $\mathrm{NaOH}+\mathrm{MTMS}$ apresentaram uma linha de difração larga em torno de $26^{\circ}$ característica do gel. 
Mas em contradição com o experimento de Raios-X, os experimentos de polarização direta e cruzada de ${ }^{29} \mathrm{Si}$ destas amostras não apresentaram as mesmas características do gel. Em ambas amostras há o aparecimento de ambientes de silicatos mais organizados, característicos de fases cristalinas. No gel $+\mathrm{KOH}+$ MTMS há o aparecimento do $\mathrm{K}_{2} \mathrm{Si}_{2} \mathrm{O}_{5}$ e $\mathrm{Na}_{2} \mathrm{Si}_{2} \mathrm{O}_{5}$ na amostra de gel $+\mathrm{NaOH}+\mathrm{MTMS}$. Nos espectros de ${ }^{13} \mathrm{C}$ das amostras de gel $+\mathrm{MTMS}$ e gel $+\mathrm{KOH}+$ MTMS foi observada ainda a integridade dos grupos $\mathrm{SiCH}_{3}$, com diferenças de ambientes estruturais ao redor dos carbonos em ambas. Foi detectada, nos dois casos, a presença de uma pequena fração de carbonatos, particularmente $\mathrm{K}_{2} \mathrm{CO}_{3}$ na amostra atacada com $\mathrm{KOH}$ detectada. Nos ataques com solução de $\mathrm{KOH}$ e $\mathrm{NaOH}$, os espectros de RMN de ${ }^{29} \mathrm{Si}$ mostram uma fração mínima de material amorfo o que é consistente com a observação da dissolução do gel durante a preparação destas amostras.

Nas amostras previamente expostas ao MTMS (gel + MTMS + KOH e gel + MTMS + $\mathrm{NaOH}$ ) as linhas mais alargadas dos sítios de silicatos correspondentes a estruturas menos organizadas sugerem que a presença do MTMS impede a organização de uma estrutura ordenada, ao contrário do que ocorre quando o gel é pós exposto ao MTMS. Na amostra gel $+\mathrm{KOH}+$ MTMS, a ausência de sinal de polarização cruzada para os silicatos $Q^{1}, Q^{2}$ e $Q^{3}-K_{2} S_{2} \mathrm{O}_{5}$, na figura 6.2d, indica que neste caso os produtos precipitados são silicatos com pouca incorporação de $\mathrm{OH}$ ou $\mathrm{H}_{2} \mathrm{O}$, o que é consistente com a presença de silicatos com estequiometria próxima a fases cristalinas anidridas. Na amostra previamente exposta ao MTMS, gel + MTMS + KOH, o espectro correspondente (figura 6.2f) mostra sinais destas mesmas espécies com intensidade apreciável, indicando proximidade entre Si e H. Portanto, a desordem poderia ser parcialmente atribuída à presença de grupos protonados $\left(\mathrm{OH}\right.$, moléculas de água e eventualmente $\mathrm{CH}_{3}$, provenientes de grupos $\mathrm{D}$ e T) integrados à estrutura deste silicato. É interessante observar que o MTMS nesta amostra gera principalmente grupos D, enquanto que na amostra de gel $+\mathrm{KOH}+$ MTMS há uma concentração maior de grupos $\mathrm{T}$, o que seria consistente neste último caso com uma estrutura de silicatos mais interconectada. Resultados semelhantes são observados na comparação entre os espetros das amostras pré e pós expostas ao MTMS (gel + NaOH + MTMS e gel + $\mathrm{NaOH}+\mathrm{MTMS}$ ): a exposição ao MTMS antes do ataque mantém o estado amorfo da estrutura de silicatos evitando a precipitação de silicatos cristalinos. 


\subsection{Efeitos dos ataques e tratamentos nas rochas}

Os espectros de RMN de ${ }^{29} \mathrm{Si}$ das amostras atacadas de basalto apresentaram um alargamento dos espectros com incremento na fração dos sítios nas bordas dos espectros correspondente a sítios de conectividade alta e baixa, referentes ao plagioclásio e piroxênio respectivamente.

Os espectros de ${ }^{29} \mathrm{Si}$ das amostras de granito, apresentaram uma estrutura de silicatos desorganizada composta essencialmente de sítios $\mathrm{Q}^{4}$ e $\mathrm{Q}^{3}(1 \mathrm{Al})$, referentes ao quartzo e muscovita. Os ataques com soluções de $\mathrm{KOH}$ e $\mathrm{LiNO}_{3}-\mathrm{KOH}$ aumentaram a porcentagem de sítios menos e mais conectados $\left(\mathrm{Q}^{1}\right.$ e $\left.\mathrm{Q}^{4}\right)$, semelhante ao efeito na amostra de basalto. Porém nas amostras tanto de granito quanto de basalto não foi possível observar diferenças causadas pelas soluções de ataque ou em função das temperaturas e tempo de exposição à solução. Este fato pode estar indicando que o íon $\mathrm{K}^{+}$das soluções é o principal modificador destas estruturas.

$\mathrm{O}$ resultado no ataque de quartzito $+\mathrm{KOH} / 80^{\circ} \mathrm{C}$ mostra uma mudança substancial na linha do silicato amorfo, formada agora essencialmente por silicatos $Q^{4}$ e $Q^{3}$, e $13 \%$ de quartzo semi cristalino. Comparando com o ataque similar a temperatura ambiente, pode se concluir que o produto do ataque acelerado evolui para uma estrutura altamente conectada. O resultado do quartzito com ataque de $\mathrm{KOH}$ e posteriormente MTMS (quartzito $+\mathrm{KOH}+\mathrm{MTMS} / 80^{\circ} \mathrm{C}$ ) apresenta uma grande quantidade de sítios $\mathrm{Q}^{\mathrm{n}}$ de menor conectividade ao contrario do ataque com $\mathrm{KOH}$ a $80^{\circ} \mathrm{C}$. Para gerar a quantidade de $\mathrm{Q}^{\mathrm{n}} \operatorname{com} \mathrm{n}<3$ observados na figura 6.18e é necessário considerar reações mais complexas envolvendo água e $\mathrm{K}$ remanescente do ataque, potenciadas pelo fato de realizar este segundo processo a $80^{\circ} \mathrm{C}$.

Os resultados dos ataques de solução de Li-K no quartzito foram mais significativos se comparados as soluções de $\mathrm{K}$. A temperatura de $45^{\circ} \mathrm{C}$ foi suficiente para causar alterações no espectro de quartzito, porém o resultado foi muito semelhante à amostra com $\mathrm{KOH}$ a $80^{\circ} \mathrm{C}$ : reação aparente apenas dos silicatos amorfos. Já o resultado do ataque com solução de Li-K a $80^{\circ} \mathrm{C}$ (figura 6.18g) se observa um forte decréscimo na fração de tetraedros $\mathrm{Q}^{4}$, e a forte dissolução do quartzo (2\%). Estes fatos indicam que o Li influencia decisivamente no tipo de silicato formado, um comportamento que é completamente diferente ao observado em basalto e 
granito. Comparando com o tratamento com $\mathrm{KOH}$ a $80^{\circ} \mathrm{C}$, pode-se concluir que a cinética da dissolução do quartzo é potenciada pela presença do Li. O ambiente de silicato mais abundante na estrutura amorfa do quartzito $+\mathrm{LiNO}_{3}-\mathrm{KOH} / 80^{\circ} \mathrm{C}$ é de tipo $\mathrm{Q}^{2}$. Observa-se também uma linha intensa em -74,9ppm correspondente a sítios $\mathrm{Q}^{2}$ em ambientes do tipo existente no $\mathrm{Li}_{2} \mathrm{SiO}_{3}$. A linha relativamente estreita indica que se trata de um estado quase-cristalino. A formação deste composto foi observada também no tratamento do gel com esta solução o que significa que o tratamento da rocha com esta solução se mostra desfavorável à expansão pela absorção de água como no gel.

Em todos os ataques do quartzito é interessante notar que o quartzo semicristalino não reagiu nos ataques com $\mathrm{K}$ e com $\mathrm{Li}$ e $\mathrm{K}$ realizados a altas temperaturas em 3 dias, mas houve uma dissolução considerável quando o ataque se estendeu para 30 dias a temperatura ambiente. Exatamente o contrário ocorre com o silicato amorfo, frações de quartzo nanométrico e muscovita: a reação é potenciada pela temperatura. Estes comportamentos demonstram uma diferença fundamental na cinética de reação de ambos silicatos. Na temperatura ambiente a difusão dos íons $\mathrm{K}^{+}$dentro da estrutura de silicatos desordenados é baixa e, portanto, o grau de reação é baixo. Nesta situação, os cristais de quartzo de maior tamanho ficam expostos a uma solução rica em K e são dissolvidos. Inversamente, para temperaturas maiores, a difusão do $\mathrm{K}^{+}$ dentro da estrutura amorfa é potenciada, ocorrendo a reação sobre estes silicatos. Os cristais de quartzo ficam neste caso exposto a uma solução menos concentrada de $\mathrm{K}^{+}$, não havendo agora uma dissolução significativa. 


\section{Capítulo8}

\section{Conclusões}

Os resultados obtidos permitiram verificar a estrutura do gel, a eficácia do tratamento com solução de Li sobre a diminuição da expansão do gel, os estudos ainda iniciais da prevenção da formação do gel através da exposição ao metiltrimetoxisilano e a reatividade em rochas através de ataques com soluções de $\mathrm{KOH}$ e tratamentos com soluções de Li.

A partir do conjunto de dados de RMN, pode-se concluir que a estrutura do gel é uma rede desordenada do tipo lamelar, formada por domínios extensos de tetraedros $\mathrm{Q}^{3}$ com ligações $\mathrm{OH}$ e conectadas com sítios $\mathrm{Q}^{\mathrm{n}}$ com $\mathrm{n}=1$, 2 e 4. Os cátions $\mathrm{K}^{+}$estão uniformemente distribuídos sobre as diferentes espécies $\mathrm{Q}^{\mathrm{n}}$ compensando as cargas dos NBO. Existe abundância de água na estrutura em estado de alta mobilidade.

Com relação ao tratamento do gel com solução de $\mathrm{LiNO}_{3}-\mathrm{NaOH}$, há efeitos intensos do lítio sobre o gel, alterando a estrutura de silicato de lamelar para linear, com unidades $\mathrm{Q}^{2}$ e $\mathrm{Q}^{3}$ uniformemente misturadas. Os carbonatos de Na (trona) originalmente detectados no gel são dissolvidos e há precipitação de duas fases cristalinas contendo $\mathrm{Na}\left(\mathrm{Na}_{2} \mathrm{CO}_{3}\right.$ e $\left.\mathrm{NaNO}_{3}\right)$. Ainda que exista evolução estrutural no produto do ataque, o caráter linear da rede de silicatos é mantido. Esta propriedade é de importância fundamental para garantir que o produto do tratamento com Li não sofrerá expansão em longos períodos, pois estruturas mais abertas são menos susceptíveis à expansão pela absorção de água, comparada à estrutura lamelar do gel.

Com relação ao tratamento de silicatos com silano, nesta etapa do estudo foi avaliado unicamente a interação entre o MTMS e o gel da RAS. Foi observado que o MTMS não modifica topologicamente a estrutura de silicatos do gel, mantendo uma grande fração de sítios $\mathrm{Q}^{3}$ após a exposição. Os resultados indicam que é pouco provável que nestas amostras tenha ocorrido reação entre o MTMS e os grupos $\mathrm{OH}$ do gel. No entanto a aplicação do silano teve influência nas características dos silicatos produzidos pelo ataque com a solução alcalina. Nas amostras de 
gel pré-tratadas com MTMS os silicatos produto do ataque apresentavam uma estrutura mais desorganizada e com significativo grau de hidratação. Estas primeiras observações da interação do MTMS com um silicato, o gel da RAS, sugerem que o eventual efeito de proteção dos agregados à ação das soluções alcalinas não seria por ligação química direta, senão estabelecendo um bloqueio físico através da precipitação de partículas de silano autocondensado. O próximo passo neste estudo consistiria em aplicar o tratamento com silano sobre amostras de quartzito, para serem posteriormente atacadas com soluções alcalinas e verificar se existe um efeito de proteção significativo.

Com relação ao estudo dos minerais reativos, o método de ataque acelerado, mediante o aumento da temperatura de ataque permitiu observar o desenvolvimento da reação em soluções alcalinas para o basalto, o granito e o quartzito. No basalto e no granito à composição da solução (K ou Li-K) ou à aceleração do processo através da temperatura não produziram diferenças apreciáveis na reatividade ou na estrutura do silicato formado. No ataque do quartzito, a estrutura e concentração do produto de reação são dependentes da temperatura e do tempo do processo. A aceleração por temperatura tem o efeito de dissolver os silicatos amorfos de conectividade baixa e média $\left(Q^{0}, Q^{1}\right.$ e $\left.Q^{2}\right)$ e produzir um silicato altamente conexo formado por espécies $Q^{3}$ e $Q^{4}$, sem causar efeito sobre o quartzo. Para reação a temperatura ambiente durante 30 dias, a componente amorfa do quartzito não experimenta transformações apreciáveis, entanto que o quartzo é dissolvido. Quando a reação é acelerada por temperatura $\left(80^{\circ} \mathrm{C}\right)$ a presença do $\mathrm{Li}$ tem um efeito intenso na estrutura do produto da reação, resultando um silicato de conectividade baixa $\left(\mathrm{Q}^{2}\right)$ misturado com $\mathrm{Li}_{2} \mathrm{SiO}_{3}$. Como este produto é potencialmente menos susceptível à expansão, a adição de Li na solução aquosa seria útil para interferir na estrutura do produto do ataque em escalas de tempos longas. 


\section{Referências}

1 TAYLOR, H. F. W. Cement chemistry. 2. ed. London: Thomaz Telford, 1997.

2 METHA, P. K.; MONTEIRO, P. J. M. Concrete: microstructure, properties and materials. 3. ed. New York: McGraw Hill, 2006.

3 TAMBELLI, C. E.; SCHNEIDER, J.F; HASPARYK, N. P.; MONTEIRO, P.J. M. Study of the structure of alkali-silica reaction gel by high-resolution NMR spectroscopy. Journal of Non-Crystalline Solids, v. 352, n. 32-35, p. 3429-3436, 2006.

4 CONG, X. D.; KIRKPATRICK, R. J. The structure and stoichiometry of C-S-H. Cement Concrete Research, v. 34, p. 1521-1528, 2004.

5 GABORIAUD, F.; NONAT, A.; CHAUMONT, D.; CRAIEVICH, A.; HANQUET, B. Si-29 NMR and small-angle X-ray scattering studies of the effect of alkaline ions $\left(\mathrm{Li}^{+}, \mathrm{Na}^{+}\right.$, and $\mathrm{K}^{+}$) in silico-alkaline sols. Journal of Physical Chemistry B, v. 103, n.12, p. 2091-2099, 1999.

6 FENG, C. X.; THOMAS, M. D. A.; BREMNER, T. W.; BALCOM, B. J.; FOLLIARD, K. J. Cement and Concrete Research, v. 35, n. 9, p. 1789-1796, 2005.

7 YIN Qi; WEN, ZY. Effects of lithium hydroxide on alkali-silica reaction gels created with opal. Construction and Building Materials, v. 21, n. 8, p. 1656-1660, 2007.

8 QINGHAN, B.; NISHIBAYASHI, S.; XUEQUAN, W.; YOSHINO, A.; HONG, Z.; TIECHENG, W.; MINGSHU.T. Preliminary study of effect of $\mathrm{LiNO}_{2}$ on expansion of mortars subjected to alkali-silica reaction. Cement and Concrete Research, v. 25, n. 8, p. 1647-54, 1995.

9 SCHNEIDER, J. F.; HASPARYK, N. P.; SILVA, D. A.; MONTEIRO, P. J. M. Effect of Lithium Nitrate on the Alkali-Silica Reaction Gel. Journal of the American Ceramic Society, v. 91, n. 10, p. 3370-3374, 2008. 
10 PAULON, V. A. Reações álcali-agregado em concreto. 1981. 114p. Dissertação (Mestrado) - Escola Politécnica, Universidade de São Paulo, São Paulo, 1981.

11 CARMAN, P. C. Constitution of colloidal silica. Transactions of the Faraday Society, v. 36, p. 964-972, 1940.

12 HUDEC, P. P.; BANAHENE, N. K. Chemical Treatments and Additives for Controlling Alkali Reactivity. Cement and Concrete Composites, v. 15, n. 1-2, p. 21-26, 1993.

13 HASPARYK, N. P. Investigação de concretos afetados pela reação álcali-agregado e caracterização avançada do gel exsudado. 2005. 42p. Tese (Doutorado) - Escola de Engenharia, Universidade Federal do Rio Grande do Sul, Porto Alegre, 2005.

14 WIEKER, W. Alkali-silica reaction - a problem of the insufficient fundamental, knowledge of its chemical base. In: Materials Science of Concrete: the sidney diamond symposium. [s.l]: John Wiley \& Sons, 1998. ISBN: 1574980726

15 HOU, X.; STRUBLE, L.; KIRKPATRICK, R. J., Formation f ASR gel and the roles of CS-H and portlandite, Journal of the American Ceramic Society, v. 34, n. 9, p. 1683-1696, 2004.

16 HELMUTH, R.; STARK, D. Alkali-Silica Reactivity Mechanisms, Journal Materials Science of Concrete III, v. 3, p. 131-208, 1992.

17 CONG, X. D.; KIRKPATRICK, R. J.; DIAMOND, S. Si-29 MAS NMR spectroscopic investigation of alkali-silica reactions product gels. Cemente Concrete Research, v. 23, n. 4, p. 811-823, 1993.

18 PREZZI, M.; MONTEIRO, P. J. M.; SPOSITO, G. The alkali-silica reaction .1. Use of the double-layer theory to explain the behavior of reaction-product gels. ACI Materials Journal, v. 94, n. 1, p. 10-17, 1997.

19 HOBBS, D. W. Alkali-silica reaction in concrete. London: Thomas Telford, 1988. p. 183 
20 PREZZI, M.; MONTEIRO, P.J.M.; SPOSITO, G. Alkali-silica reaction - Part 2: The effect of chemical admixtures. ACI Materials Journal, v. 95, n.1, p. 3-10, 1998.

21 MCCOY, E. J.; CALDWELL, A. G. New approach to inhibiting alkaliaggregate expansion. Journal American Concrete Institute, v. 22, n. 9, p. 693, 1951.

22 LAWRENCE, M.; VIVIAN, H. H. The reactions of various alkalis with silica. Australian. Journal Applied Science, v. 12, n.1, p. 96, 1961.

23 SAKAGUCHI, T. The inhibitive effect of lithium compounds on alkali-silica reaction. In: INTERNATIONAL CONFERENCE ON ALKALI-AGGREGATE REACTION, 8, 1989, Kyoto. Resumos... Kyoto: Elsevier Applied Science, 1989. p. 229.

24 STARK, D. C. 9th International Conference on Alkali-Aggregate Reaction, 2000, Concrete Society of U.K, London. Lithium salt admixtures-an alternative method to prevent expansive alkali-silica reactivity. London, 2000, p. 1017.

25 STARK, D. C.; MORGAN, B.; OKAMOTO, P.; AND DIAMOND, S. SHRP-C-343: eliminating or minimizing alkali-silica reactivity. Washington, DC: National Research Council, 1993.

26 FOLLIARD, K.; THOMAS, K.M.; KURTIS, K. E. Research, development and technology: Guidelines for the use of lithium to mitigate or prevent alkali-silica reation (ASR), FHWQ-RD-03-047, 2003.

27 GLASSER, L. S.; KATAOKA, N. The chemistry of 'alkali-aggregate' reaction. Cement and Concrete Research, v. 11, n. 1, p.1-9, 1981.

28 TOSUN, K.; FELEKOGLU, B.; BARADAN, B. Effectiveness of alkyl alkoxy silane treatment in mitigating alkali silica reaction. ACI Materials Journal, v. 105, n.1, p.20-25, 2008.

29 ABRAGAM, A. The principles of nuclear magnetism. Oxford: University Press, 1961.

30 SLICHTER, C. P. Principles of magnetic resonance. Berlin: Springer-Verlag, 1990. 
31 GERSTEIN, B. C.; DYBOWSKI, C. R. Transient techniques in NMR of solids, New York: Academic Press, 1985.

32 DUER, M. J. Solid-state NMR spectroscopy. Oxford: Blackwell Science, 2002.

33 HAHN, E. L. Spin Echoes. Physical Review, v. 80, n.4, p. 580-594, 1950.

34 MEHRING, M. Principles of high resolution NMR in solids. Berlin: Springer-Verlag, c1983.

35 MEDEK, A.; HARWOOD, J.; FRYDMAN, L. Multiple-quantum magic-angle spinning NMR: a new method for the study of quadrupolar nuclei in solids. Journal of the American Chemical Society, v. 117, n.51, p. 12779-12787, 1995.

36 AMOREAUX, J. P.; FERNÁNDEZ, C.; FRYDMAN, L. Optimized multiple-quantum magic-angle spinning NMR experiments on half-integer quadrupoles. Chemical Physics Letters, v. 259, n.3-4, p. 347-355, 1996.

37 MASSIOT, D.; TOUZO, B.; TRUMEAUS, D.; COUTURES, J. P.; VIRLET, J.; FLORIAN, P.; GRANDINETTI, P. J. Two-dimensional magic-angle spinning isotropic reconstruction sequences for quadrupolar nuclei. Solid State NMR, v. 6, n. 1, p. 73-83, 1996.

38 ENGELHARDT, G.; MICHEL, D. High resolution solid-state NMR of silicates and zeolites. Chichester: John Wiley, c1987.

39 NUFFIELD, E. W. X-Ray diffraction methods. Toronto: John Wiley \& Sons Inc 1967.

40 TSUSHIDA, J. E. Estrutura de vidros fosfatos ternarios no sistema Pb-Al metafosfato. 2007. Dissertação (mestrado)-Universidade Federal de São Carlos, São Carlos, 2007.

41 TAMBELLI, C. E. Estudo por ressonância magnética nuclear do condutor protônico $\mathbf{H P b}_{2} \mathbf{N b}_{3} \mathbf{O}_{10} \cdot \mathbf{N H}_{\mathbf{2}} \mathbf{O}$. 1998. 110p. Dissertação (mestrado)-Universidade de São Paulo, Instituto de Física de São Carlos, São Carlos, 1998. 
42 TIECHER, F. Influência do grau de cristalinidade e deformação da sílica dos agregados no desencadeamento da reação álcali-agregado. 2008. Exame de Qualificação de Tese do Programa de Pós-Graduação em Engenharia Civil - Universidade Federal do Rio Grande do Sul, Porto Alegre, 2008.

43 IMAOKA, M.; HASEGAWA, H.; YASUI, I. X-ray-diffraction study of the structure of silicate glasses.2. Alkali disilicate glasses. Physics and Chemistry of Glasses, v. 24, n. 3, p.72-78, 1983.

44 AOKI, N.; HASEGAWA, H.; YASUI, I., X-ray-diffraction studies and molecular dynamics calculations of the structure os alkali disilicates glasses, Yogyo Kyokaishi, v. 94, p. 539, 1986.

45 ECKERT, H.; YESINOWSKI, J. P. Characterization of hydrous species in minerals by high-speed ${ }^{1}$ H MAS-NMR. Journal of the American Chemical Society, v. 110, n.5, p. 13671375, 1988.

46 AUSTIN, A. E. X-ray-diffraction data for compounds in systems $\mathrm{Li} 2 \mathrm{O}-\mathrm{SiO} 2$ and $\mathrm{BaO}-$ SiO2. Journal of the American Chemical Society, v. 30, n.7, p. 218-220, 1947.

47 International Center Diffraction Data, Powder diffraction files 72-0026. 1 CD

48 CHERIN, P.; HAMILTON, W. C.; POST, B. Position and thermal parameters of oxygen atoms in sodium nitrate. Acta Crystallographica, v. 23, p. 455, 1967.

49 International Center Diffraction Data, Powder diffraction files 16-0820.

50 CHRISTMANN, M; SADEGHI, N; PAPIN, G. Crystallographic characterization of double carbonates LINACO3 AND LIKCO3. Revue de Chimie Minerale, v. 15, p. 312317, 1978.

51 MAGI, M; LIPPMAA, E; SAMOSON, A. Solid-state high-resolution Si-29 chemicalshifts in silicates. Journal of Physical Chemistry, v. 88, n.8, p. 1518-1522, 1984. 
52 BROWN, C. J.; PEISER, H. S.; TUNNER-JONES. The crystal structure of sodium sesquicarbonate. Acta Crystallographica, v. 2, n. 3, p.167-174, 1949.

53 GLASSER, L. S. Osmotic pressure and the swelling of gels. Cement and Concrete Research, v. 9, p.515-517, 1979.

54 SCHWEINSBERG, H.; LIEBAU, F. Darstellung und kristallographische Daten von K2Si2O5, KHSi2O5-I und K2Si4O9. Zeitschrift fur Anorganische und Allgemeine Chemie, v.387, n.2, p.241-251, 1972.

55 STEBBINS, J. F. Nuclear magnetic resonance spectroscopy of silicates and oxides in geochemistry and geophysics. In: Mineral Physics and Crystallography. A Handbooks Physics Constants. [s.l]: American Geophysical Union, 1995.

56 STUEBER, D.; ORENDT, A. M.; FACELLI, J. C. Carbonates, thiocarbonates, and the corresponding monoalkyl derivatives: III. The C-13 chemical shift tensors in potassium carbonate, bicarbonate and related monomethyl derivatives. Solid State Nuclear Magnetic Resonance, v. 22, n.1, p. 29-49, 2002.

57 MAEKAWA, H.; MAEKAWA, T.; KAWAMURA, K.; YOKOKAWA, T. The structural groups of alkali silicate glasses determined from ${ }^{29} \mathrm{Si}-\mathrm{MAS}$ NMR. Journal of NonCrystalline Solids, v. 127, n.1, p. 53-64, 1991.

58 KOLlER, H.; ENGELHARDT, G.; KENTGENS, A. P. M.; SAUER, J. NA-23 nmr spectroscopy of solids - interpretation of quadrupole interaction parameters and chemical shifts. Journal of Physical Chemistry, v. 98, n. 6, p. 1544-1551, 1994. 